\title{
The costs and benefits of emotional memory formation
}

Citation for published version (APA):

Hurlemann, R. (2007). The costs and benefits of emotional memory formation. [Doctoral Thesis, Maastricht University]. Shaker Verlag. https://doi.org/10.26481/dis.20071025rh

Document status and date:

Published: 01/01/2007

DOI:

10.26481/dis.20071025rh

Document Version:

Publisher's PDF, also known as Version of record

\section{Please check the document version of this publication:}

- A submitted manuscript is the version of the article upon submission and before peer-review. There can be important differences between the submitted version and the official published version of record.

People interested in the research are advised to contact the author for the final version of the publication, or visit the DOI to the publisher's website.

- The final author version and the galley proof are versions of the publication after peer review.

- The final published version features the final layout of the paper including the volume, issue and page numbers.

Link to publication

\footnotetext{
General rights rights.

- You may freely distribute the URL identifying the publication in the public portal. please follow below link for the End User Agreement:

www.umlib.nl/taverne-license

Take down policy

If you believe that this document breaches copyright please contact us at:

repository@maastrichtuniversity.nl

providing details and we will investigate your claim.
}

Copyright and moral rights for the publications made accessible in the public portal are retained by the authors and/or other copyright owners and it is a condition of accessing publications that users recognise and abide by the legal requirements associated with these

- Users may download and print one copy of any publication from the public portal for the purpose of private study or research.

- You may not further distribute the material or use it for any profit-making activity or commercial gain

If the publication is distributed under the terms of Article $25 \mathrm{fa}$ of the Dutch Copyright Act, indicated by the "Taverne" license above, 
Berichte aus der Medizin

\section{René Hurlemann}

The Costs and Benefits

of Emotional Memory Formation

Shaker Verlag

Aachen 2007 
Bibliographic information published by the Deutsche Nationalbibliothek The Deutsche Nationalbibliothek lists this publication in the Deutsche Nationalbibliografie; detailed bibliographic data are available in the Internet at http://dnb.d-nb.de.

Zugl.: Maastricht University, Diss., 2007

Copyright Shaker Verlag 2007

All rights reserved. No part of this publication may be reproduced, stored in a retrieval system, or transmitted, in any form orby any means, electronic, mechanical, photocopying, recording or otherwise, without the priorpermission of the publishers.

Printed in Germany.

ISBN 978-3-8322-6635-6

ISSN 0945-0890

Shaker Verlag GmbH • P.O. BOX 101818 - D-52018 Aachen

Phone: 0049/2407/9596-0 - Telefax: 0049/2407/9596-9

Internet:www.shaker.de • e-mail:info@shaker.de 
The Costs and Benefits of

\title{
Emotional Memory Formation
}

\author{
DISSERTATION \\ to obtain the degree of \\ Doctor at the Maastricht University, \\ on the authority of the Rector Magnificus, Prof. dr. G.P.M.F. Mols, \\ in accordance with the decision of the Board of Deans, \\ to be defended in public \\ on Thursday, the $25^{\text {th }}$ of October 2007, at 16 hours
}

by

René Hurlemann 
Supervisor:

Prof. dr. E.J.L. Griez

Assessment Committee:

Prof. dr. W. Riedel (Chairman)

Prof. dr. K. Kendrick (The Babraham Institute, Cambridge, United Kingdom) Dr. K. Schruers

Prof. Dr. F. Verhey 
Dedicated to my parents

Dieter and Renate Hurlemann 
An impression may be so exciting emotionally as almost to leave a scar upon the cerebral tissues

William James

(The Principles of Psychology, 1890) 
1 Introduction I: Modulatory influences of emotion on perception and memory

Introduction II: An emotion-induced amnesia in humans is amygdala- and $\beta$-adrenergic-dependent

3 Noradrenergic modulation of emotion-induced forgetting and remembering

4 Noradrenergic control of emotion-induced amnesia and Hypermnesia: A review

$5 \quad$ Amygdala control of emotion-induced forgetting and remembering: Evidence from Urbach-Wiethe disease

6 A methodological digression: Analysis of neuroreceptor PET data based on cytoarchitectonic maximum probability maps

$7 \quad$ Enhanced emotion-induced amnesia in borderline personality disorder

8 Emotion-induced retrograde amnesia varies as a function of noradrenergic-glucocorticoid activity

9 The costs and benefits of emotional memory formation

Synopsis

Samenvatting

ix

Acknowledgment

Curriculum Vitae 


\begin{tabular}{|c|c|}
\hline $\mathrm{aHC}$ & Anterior hippocampus \\
\hline AMY & Amygdala \\
\hline ANOVA & Analysis of variance \\
\hline BLA & Basolateral amygdala \\
\hline BP & Blood pressure \\
\hline Cplasma & Plasma concentration \\
\hline CORT & Cortisol \\
\hline Di & Diastolic \\
\hline dis & Distraction task \\
\hline $\mathrm{Dm}$ & Difference due to memory \\
\hline DSM-IV & Diagnostic and statistical manual of mental disorders \\
\hline enc & Episodic memory encoding \\
\hline$E_{\text {neg }} P$ & Emotionally negative perceptual oddball \\
\hline $\mathrm{E}_{\text {pos }} \mathrm{P}$ & Emotionally positive perceptual oddball \\
\hline $\mathrm{E}_{\mathrm{x}} \mathrm{P}$ & Emotional and perceptual oddball \\
\hline $\mathrm{E}_{\mathrm{x}}$ & Isolated emotional oddball component \\
\hline$E_{\text {neg }} \pm 1$ & Item preceding / following negative emotion contact \\
\hline$E_{p o s} \pm 1$ & Item preceding / following positive emotion contact \\
\hline $\mathrm{E}_{\mathrm{x}} \pm 1$ & Item preceding / following any emotion contact \\
\hline ERP & Event-related potential \\
\hline (F)MRI & (Functional) magnetic resonance imaging \\
\hline $\mathrm{HC}$ & Hippocampus \\
\hline HCR & Hydrocortisone \\
\hline HPLC & High-performance liquid chromatography \\
\hline IAPS & International affective picture system \\
\hline LC & Locus coeruleus \\
\hline MEG & Magnetoencephalography \\
\hline $\mathrm{NE}$ & Norepinephrine (noradrenaline) \\
\hline neg & Emotionally negative \\
\hline neu & Emotionally neutral \\
\hline OMIM & 'Online mendelian inheritance in man' database \\
\hline OS & Oddball stimulus \\
\hline $\mathrm{P}$ & Perceptual oddball (component) \\
\hline PET & Positron emission tomography \\
\hline PFC & Prefrontal cortex \\
\hline Plac & Placebo \\
\hline pos & Emotionally positive \\
\hline Pro & Propranolol \\
\hline $\mathrm{Rbx}$ & Reboxetine \\
\hline rec & Free recall \\
\hline SI & Sequence index \\
\hline Sy & Systolic \\
\hline UV & Ultraviolet \\
\hline
\end{tabular}




\title{
CHAPTER 1
}

\section{Introduction I: Modulatory influences of emotion on perception and memory}

\author{
EMOTION AND PERCEPTION
}

From an evolutionary perspective, emotion, whether of an appetitive or aversive nature, signals an event that is likely to have both immediate and future relevance to survival and reproductive success. Therefore, emotion should be susceptible to preferential perceptual processing. One means of achieving this is by emotion enhancing attention, leading to increased detection of emotional stimuli (Dolan, 2002). An emotional capture of attention has been demonstrated in classic visual search (Ohman et al., 2001) and spatial orienting tasks (Mogg et al., 1997; Armony and Dolan, 2002). However, the attraction of attention is not the only means by which emotion can influence perception. For instance, in visual backward masking paradigms, a briefly presented (ms) target is rendered invisible if immediately followed by a second masking stimulus. In situations, where the hidden target is emotional (e.g., a fearful face), preserved processing can be indexed by differential skin conductance responses (SCRs) (Esteves et al., 1994) and anygdala responses (Morris et al., 1998; Whalen et al., 1998), though subjects were not aware of the target. Similar findings are evident using the attentional blink paradigm, where detection of a target in a rapid visual stimulus stream leads to impaired awareness, or inattentional blindness, for a successive second target. This inattentional blindness is reduced if the second target is emotional and engages the amygdala (Anderson and Phelps, 2001). Together, these findings suggest an amygdala-dependent early discrimination between emotional and nonemotional stimuli that takes place under conditions of limited attention or even preattentively, i.e. before the operation of attention.

Supportive evidence for the above hypothesis comes from electrophysiological studies. Event-related potentials (ERPs) to emotional faces already arise $120 \mathrm{~ms}$ post-onset, before sensory processing of faces is completed in visual cortex (170-200 ms), and before any attentional modulation of these cortical responses occurs (170-300 ms) (Vuilleunier, 2005). Moreover, as exemplified in Fig. 1, increasing evidence indicates that even the expectation of emotion can induce a preattentive modulation of the temporal dynamics of sensory processing (Dolan et al., 2006). One suggestion is that coarse emotional cues (e.g., wide-open eyes in masked fearful faces) (Whalen et al., 2004) instantly activate the amygdala via subcortical routes. The amygdala, in turn, feeds back to sensory regions to enhance processing of emotional stimuli in these regions (Vuilleumier, 2005).

\section{EMOTION AND MEMORY}

Privileged perception of emotion provides a means of not only indexing events of immediate and future relevance to survival and reproductive success, but also facilitating their availability to the cognitive domains. The cognitive domain where the influence of emotion is 
most thoroughly characterized is memory. The best example is classical conditioning (a form of implicit or nondeclarative memory), which describes a situation where a neutral stimulus, through pairing in temporal contiguity with an emotional stimulus (e.g., an aversive noise), acquires an ability to predict future presentations of the emotional stimulus (Dolan, 2002). Studies demonstrate that the human amygdala is critical for fear conditioning. Patients with Urbach-Wiethe disease (OMIM 247100) and selective bilateral amygdala calcification lesion fail to acquire conditioned fear responses despite retaining explicit knowledge regarding the conditioned (CS) and unconditioned stimulus (UCS) associations. In contrast, patients with selective bilateral hippocampal damage due to ischemia-anoxia show preserved fear conditioning despite being unable to demonstrate explicit knowledge regarding CS-UCS contingencies (Bechara et al., 1995). Although there is an emphasis on the role of the amygdala in human fear conditioning studies, substantial evidence implicates the amygdala in other forms of associative learning, including reward and appetitive learning (Phelps, 2006).

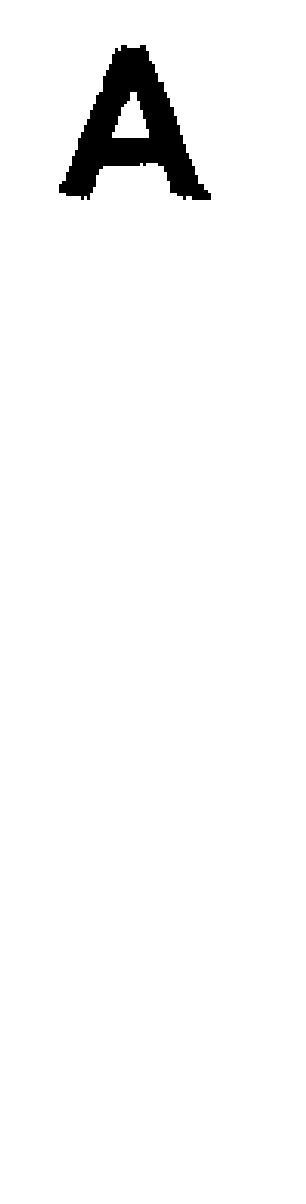

B

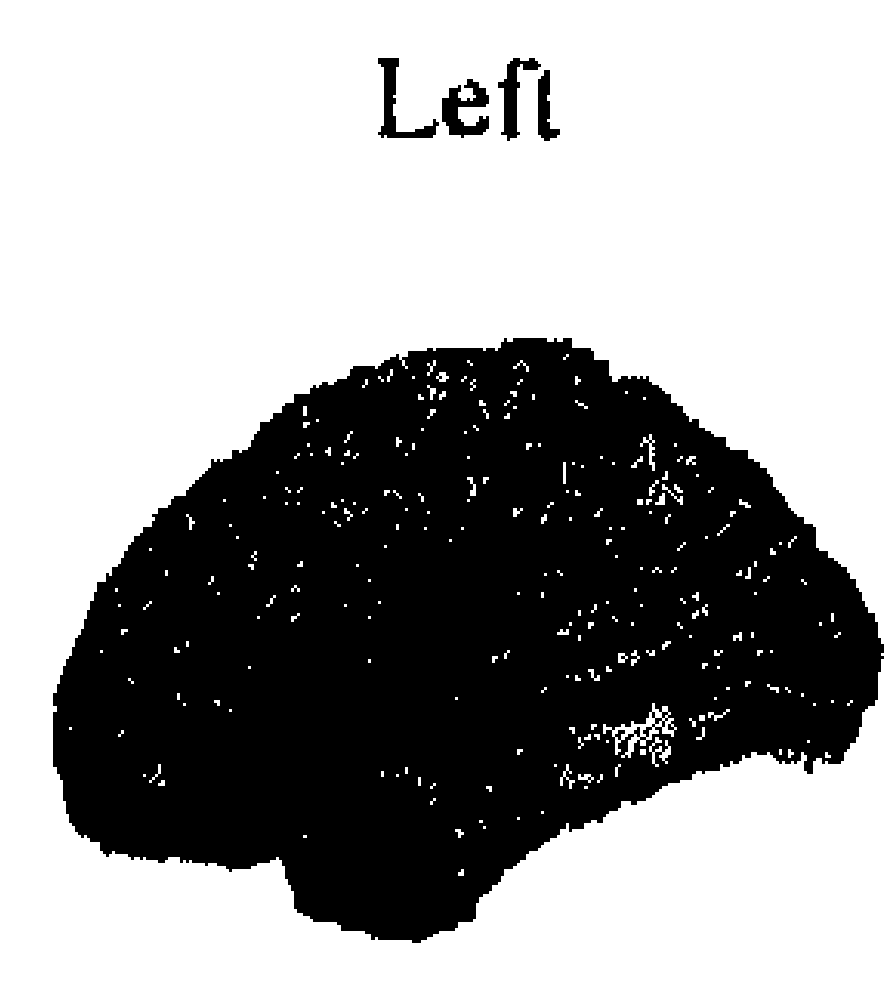

Left

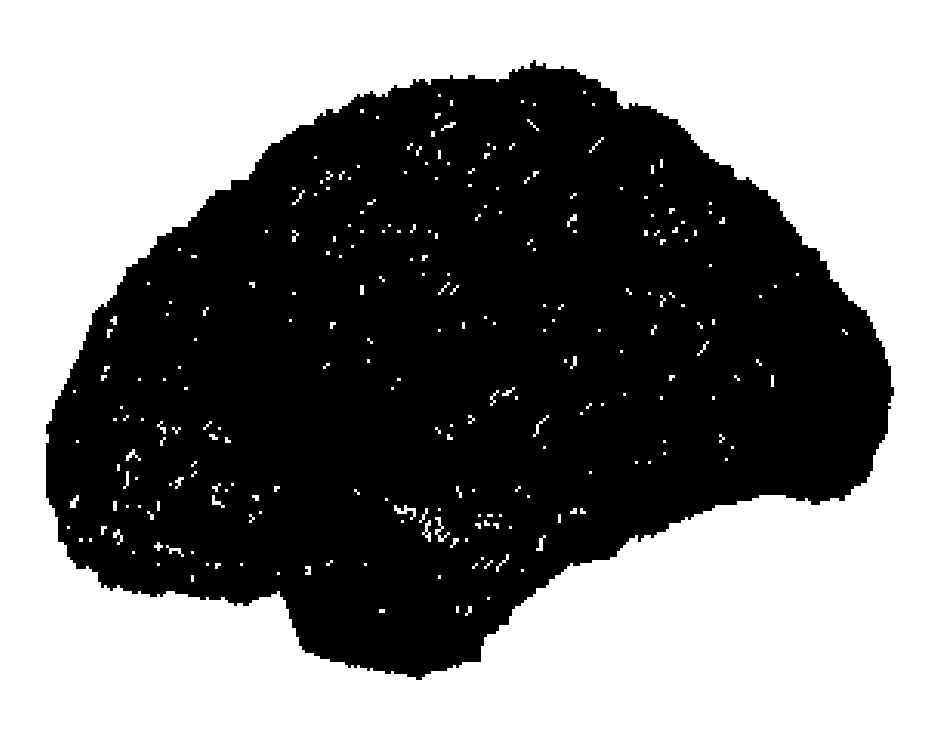

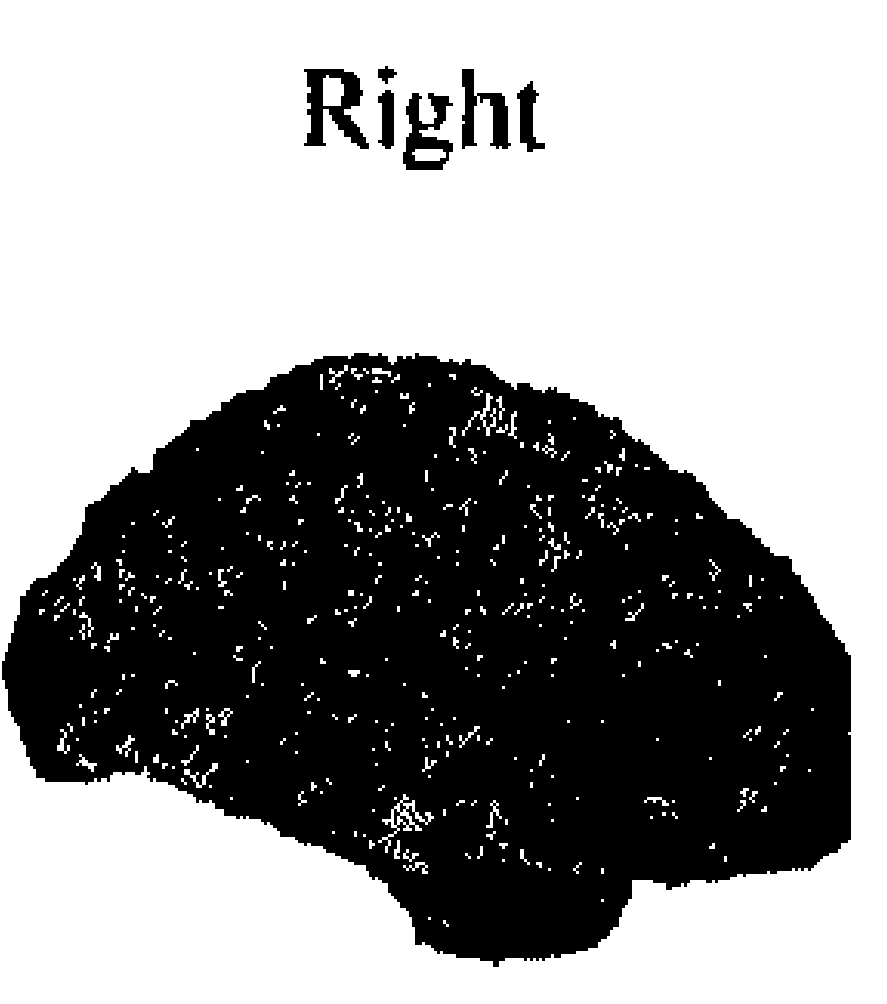

Right

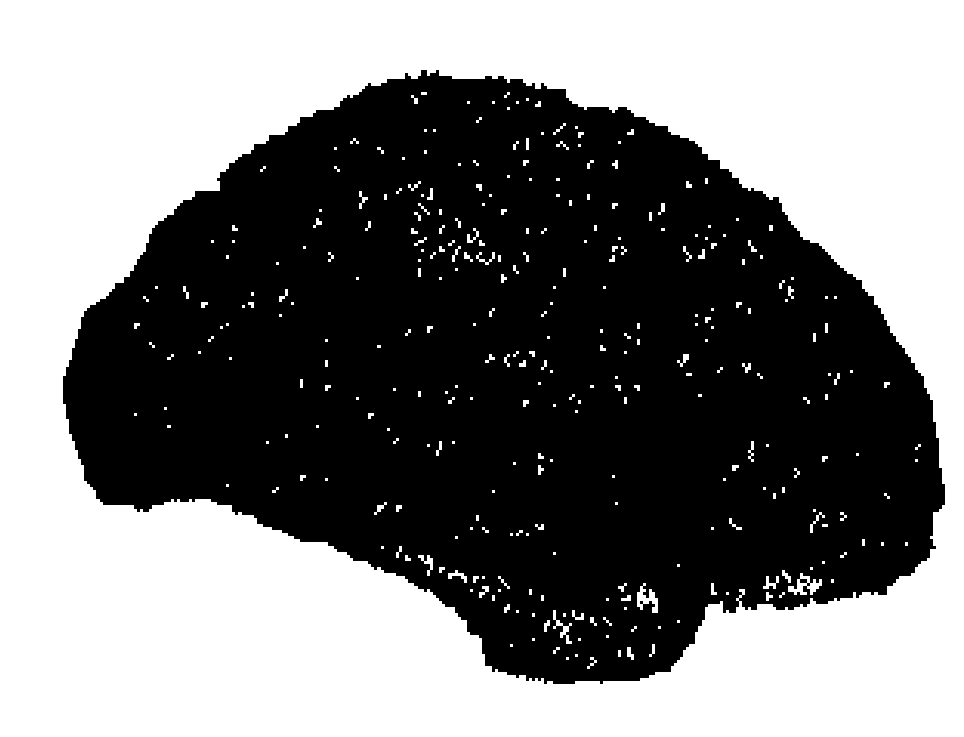

Ventral

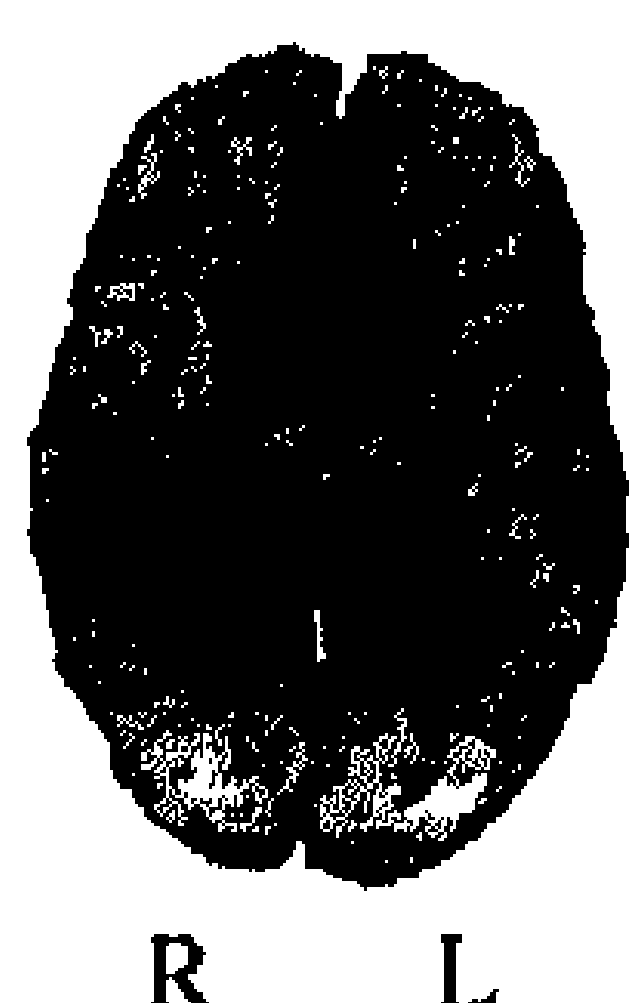

Ventral

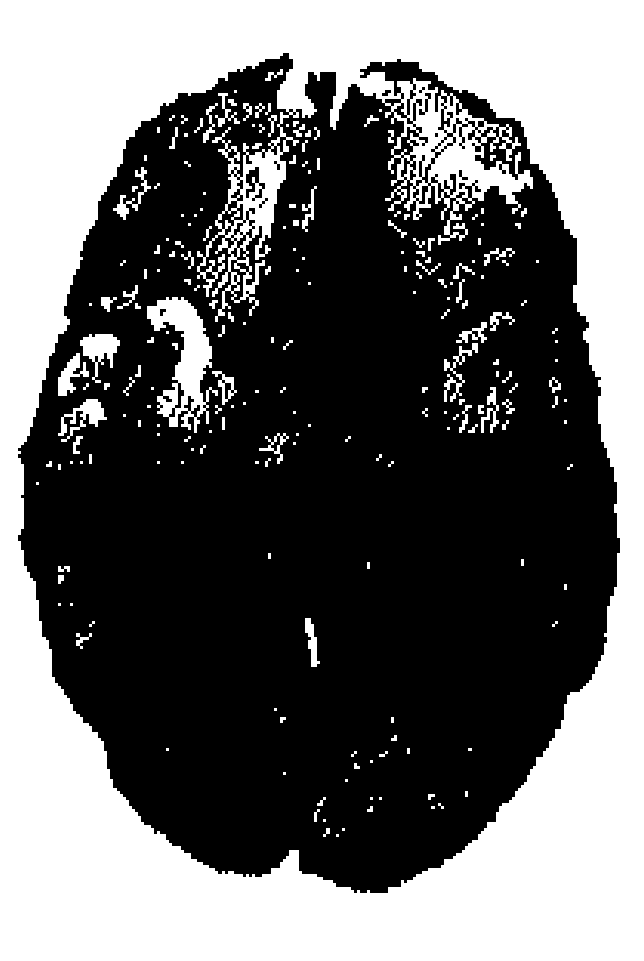

R L

Fig. 1. Using magnetoencephalography (MEG), Dolan et al. (2006) determined the time course of sensoryevoked modulations during differential aversive conditioning to faces, with an aversive noise event (UCS). (A) Conditioning was associated with the development of a differential event-related waveform peaking at approximately $150 \mathrm{~ms}$. Source analysis indicated the localization of this modulation to ventral occipital regions. (B) In the auditory domain, a modulation of auditory-evoked responses to a probe sound was evident in a late component emerging at approximately $180 \mathrm{~ms}$ over sensors in fronto-temporal regions. These findings indicate that the time course in processing sensory stimuli can be altered on the basis of their acquired value.

Enhanced episodic (autobiographical) memory (a form of explicit or declarative memory) for emotional events is well documented in naturalistic studies of flashbulb memories (Brown and Kulik, 1977) for shocking events such as the assassination of President Kennedy or the terrorist attacks on $9 / 11$. The benefit of emotion on episodic memory is confirmed in numerous laboratory studies showing mnemonic enhancement for material that encompasses personal autobiographical, picture-, and word-based items, an effect most pronounced in free-recall tasks. A striking feature of the biology of emotional memory is a dependence on the amygdala that transcends the implicit-explicit distinction (Dolan, 2002). Urbach-Wiethe patients typically lack an advantage in subsequent recall of emotional items (Adolphs et al., 1997). The critical role of the amygdala is also evidenced by studies using 
R. Hurlemann - The Costs and Benefits of Emotional Memory Formation

positron emission tomography (PET) and functional magnetic resonance imaging (fMRI), where amygdala responses during encoding of emotional stimuli predict later recall of these stimuli (the emotional $D m$ effect, see below) (LaBar and Cabeza, 2006). Importantly, amygdala responses to both positive and negative stimuli are predictive of later memory (Hamann et al., 1999).

\section{H.}

Episodic memories become stabilized through a time-dependent consolidation process (Müller and Pilzecker, 1900). During this time, episodic memories are fragile and susceptible to disruption by a number of interfering amnesiogenic agents, including the encoding of new lists of items (an effect called retroactive inhibition) (Müller and Pilzecker, 1900), cerebral trauma (McDougall, 1901; Burnham, 1903), electroconvulsive shock (ECS) (Duncan, 1949, Gerard, 1949) or administration of protein synthesis inhibitors (Davis and Squire, 1984). Human lesion studies indicate that consolidation depends on the hippocampus, although, with time, stored information likely becomes reorganized in a way that makes retrieval gradually less dependent on the hippocampus (so-called system-level consolidation) (Scoville and Milner, 1957; Teng and Squire, 1999; Eichenbaum, 2000). Since the seminal findings of Kleinsmith and Kaplan (1963), behavioral studies in humans have accumulated evidence that retention advantages for emotional items relative to neutral items are greater when episodic memory is tested after long (e.g., $1 \mathrm{~h}$ to 1 day) rather than short (immediate) delays (LaBar and Cabeza, 2006). Findings that Urbach-Wiethe patients are impaired in delayed recall or recognition tests of emotional words, pictures and stories (Markowitsch et al., 1994; Cahill et al., 1995; Adolphs et al., 1997), have been interpreted in support of the memory-modulation hypothesis, which states that emotion engages the amygdala to facilitate hippocampal function during consolidation.

The underlying neural and neurochemical substrates have been extensively studied in lesion and pharmacological experiments in rodents that provide evidence of an endogenous modulation of amygdala function by adrenal stress hormones. Adrenaline (epinephrine) does not freely pass the blood-brain barrier and appears to modulate consolidation by activating $\beta$ adrenergic receptors located peripherally on vagal afferents projecting to the nucleus of the solitary tract in the brainstem. Noradrenergic (norepinephrine, NE) projections from this region influence neuronal activity in other brain regions, including the basolateral amygdala (BLA). In contrast, glucocorticoids readily enter the brain and promote gene expression by activating corticosteroid receptors. BLA activation is critical for mediating the influences of epinephrine and glucocorticoids, because pharmacological manipulations and lesions in this subregion of the amygdala eliminate the modulatory effects of epinephrine and glucocorticoids on consolidation (McGaugh, 2000). In humans, an emotion-induced enhancement of consolidation can be blocked by administration of the $\beta$-adrenoreceptor antagonist propranolol before study (Cahill et al., 1994). This blockade is centrally mediated (van Stegeren et al., 1998) and equivalent to that seen in Urbach-Wiethe patients (Cahill et al., 1995), thus providing indirect evidence that the amygdala is a critical locus for propranolol's effects.

The neural mechanisms underlying the beneficial effect of emotion on consolidation in humans have been examined in PET and fMRI studies, which provide evidence of amygdalahippocampal interactions (LaBar and Cabeza, 2006). Specifically, the evidence suggests a functional coupling of amygdala and hippocampus during emotional memory encoding 
(Richardson et al., 2004). However, these studies do not confirm that the amygdala's role in emotion-induced memory enhancements stems from its influence on consolidation rather than encoding. Moreover, the memory-modulation hypothesis cannot account for all the data obtained from emotional memory studies in humans. The exact time course of consolidation is subject to considerable debate, with estimates ranging from hours to months and years. Even if the shorter estimates of consolidation time are correct, it is evident that episodic memories can be robustly enhanced by emotion even at immediate delays. Thus, there must be modulatory mechanisms operating during encoding that can enhance episodic memory prior to the onset of consolidation (Hamann, 1999).

A widely-accepted psychological framework holds that emotional experiences are best characterized in a two-dimensional space, with one axis describing emotional quality (valence, ranging from unpleasant to pleasant) and the other axis describing emotional intensity (arousal, ranging from calm to excited) (Russel, 1980; Lang, 1995). Within the perceptual domains, there is convincing evidence that valence and arousal exert dissociable effects on the neural processes engaged during sensory processing. To distinguish the contributions of arousal and valence, Anderson et al. (2003) independently manipulated valence and intensity of odors. Amygdala activation was related to odor intensity irrespective of valence, whereas activity in the orbitofrontal cortex reflected odor valence regardless of intensity. Small et al. (2003) found a similar dissociation in the gustatory modality: the amygdala was responsive to taste intensity regardless of valence, whereas the orbitofrontal cortex was responsive to taste valence but not intensity. The impact of valence and arousal on memory, including the explicit and implicit domain, has been investigated in studies using the International Affective Picture system (IAPS) (Lang et al., 1997), a set of colored pictures rated along the arousal and valence dimensions. In (immediate) free recall tests of episodic memory, high-arousing IAPS stimuli were better remembered than low-arousing stimuli, while pleasant IAPS stimuli were better remembered than unpleasant stimuli (Bradley et al., 1992). Using fMRI, Kensinger and Corkin (2004) found that distinct neural processes contribute to enhanced episodic memory for arousing information versus valenced, nonarousing information. The former depended on an amygdalar-hippocampal network, whereas the latter was supported by a PFC-hippocampal network. Thus, although medial temporal lobe (MTL) structures have been emphasized in support of the memory-modulation hypothesis, the PFC also contributes to emotion-induced enhancements of episodic memory, with a regionally specific modulation by both arousal and valence (Kensinger and Corkin, 2004; Dolcos et al., 2004).

W

The observation that humans typically remember the exceptional over the mundane has been the subject of extensive psychological and electrophysiological research using oddball paradigms: Isolating a novel heterogeneous stimulus, i.e. the oddball, against a series of homogeneous standard stimuli, facilitates learning of the oddball. This phenomenon is called the von Restorff (VR) effect (von Restorff, 1933). The VR effect can be created by manipulating the perceptual, semantic, or emotional features of a sensory stimulus. Research using scalp-recorded ERPs has revealed that oddballs elicit an increased positive waveform 
between 250 and $400 \mathrm{~ms}$ (Simons et al., 2001). This ERP component is regarded as a member of the P300 family and labeled novelty P3 or P3a (Polich et al., 1995; Ranganath and Rainer, 2003). The $\mathrm{P} 3 \mathrm{a}$ is not specific to any particular modality and can be elicited even when a stimulus is not task-relevant or ignored (Ranganath and Rainer, 2003). Current hypotheses of the behavioral significance of the P3a state that it reflects context updating (Donchin and Coles, 1998), thus enabling rapid adaptive responses to environmental stimulus changes. Neuroimaging evidence suggests that oddball detection engages a generic novelty detection system including right inferior PFC and posterior fusiform cortex rather than mechanisms sensitive to specific attributes of perceptual, semantic or emotional stimulus deviance (Strange et al., 2000). Moreover, novel stimuli elicit activation in anterior hippocampus, which links novelty detection to MTL structures directly involved in generating memory. In contrast, retrieval of familiar stimuli engages posterior hippocampal regions. This response gradient implicates a weighting of functional hippocampal architecture related to novelty and familiarity processing (Fig. 2) (Strange et al., 2005). Strikingly, ERPs also allow to predict memory performance in list learning tasks. A consisting finding is a greater positive ERP deflection during encoding of items that are subsequently remembered compared to those that are subsequently forgotten. This effect has been labeled 'difference due to subsequent memory' or $D m$ effect (Paller et al., 1987). The $D m$ effect has been replicated in various experimental settings and engages MTL regions as well as right inferior PFC (LaBar and Cabeza, 2006). The same network is also activated during novelty detection (Kirchhoff et al., 2000). As novelty detection requires continuous comparison of sensory input with familiar content stored in memory, it likely recruits regions that are also critical for memory formation (Lisman and Grace, 2005).

\section{A}
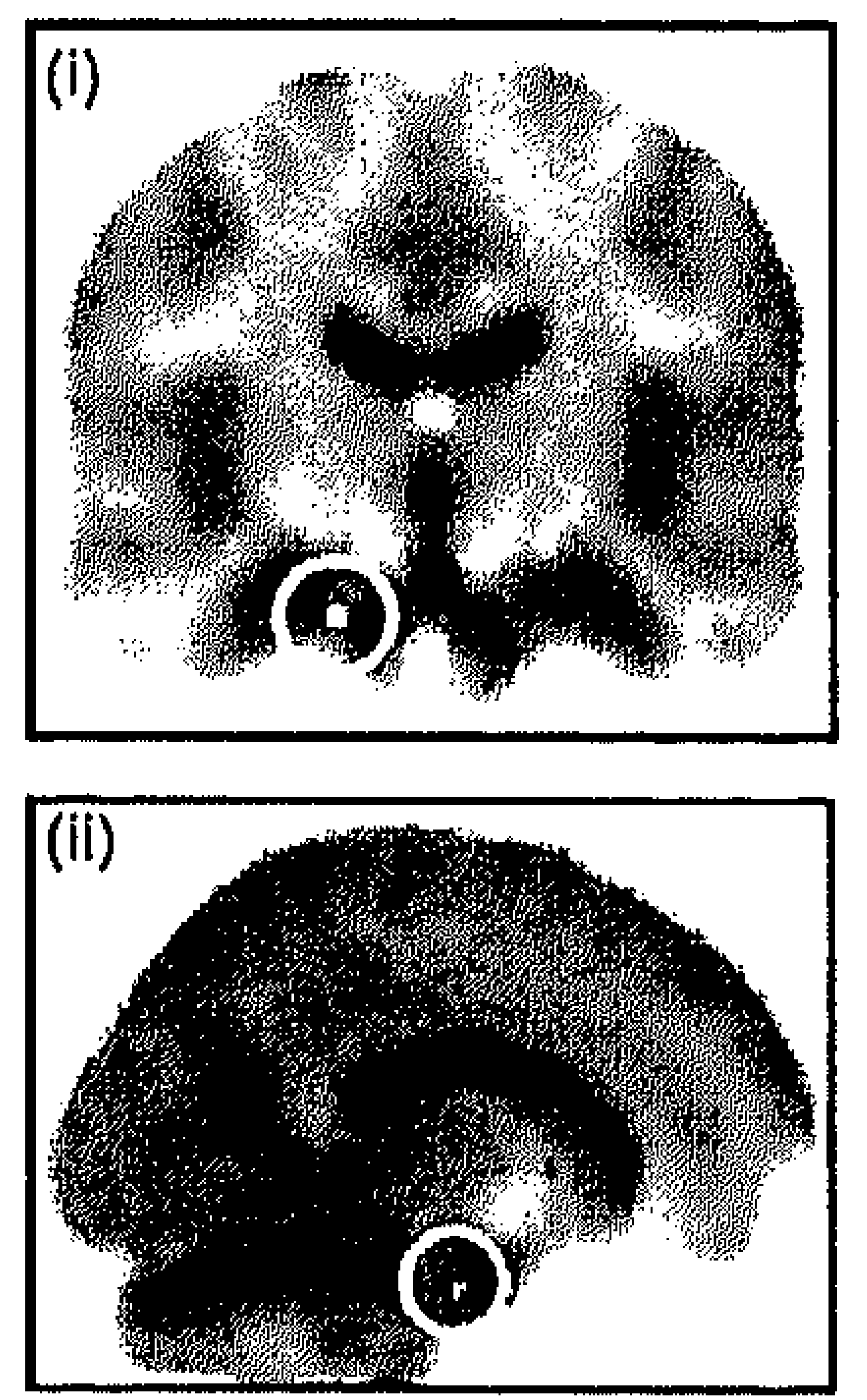

B
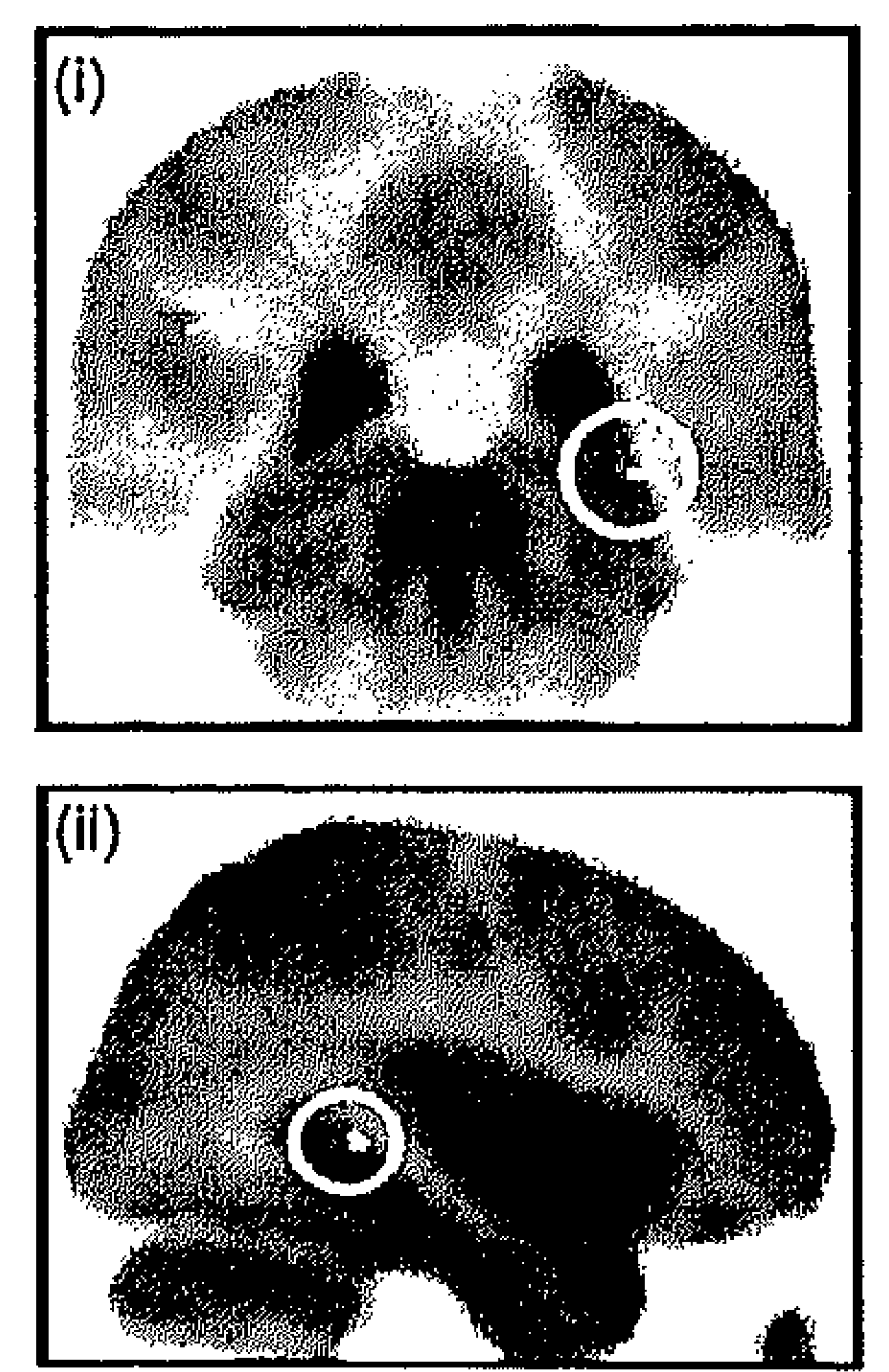

Fig. 2. The establishment of a role for medial temporal lobe (MTL) structures in episodic memory has led to an investigative focus on the specific contributions and interactions between constituent MTL regions, including the hippocampus and surrounding medial temporal cortices. By dissociating an intentional stimulus-category learning condition from a passive viewing condition, Strange et al. (2005) demonstrated, using fMRI, that novelty- and familiarity-driven responses in human anterior and posterior hippocampus, respectively, only occur during intentional learning. With increasing familiarity of stimulus-category associations, there is a shift in neuronal responses from anterior to posterior hippocampal regions. This anterior/posterior response gradient may reflect a weighting of functional hippocampal architecture related to encoding of novel and retrieval of familiar information. (A) SPM showing adaptation of left anterior hippocampal/entorhinal response to novel stimuli only during intentional leaming $(-16,-14,-28, P<0.0001)$. (B) SPM showing linear increase in activation of the right posterior hippocampus in response to increasing familiarity only during intentional learning $(36,-36,00, \mathrm{P}$ $<0.0001$ ). 
However, substantial evidence indicates that the influence of novelty on memory formation is associated with two contradictory effects in the form of memory increments and decrements. In a landmark study, Tulving (1969) described a behavioral effect of retrograde amnesia in a single-trial free-recall task of word lists including 15 items, produced by inserting semantic oddballs (names of famous people such as Columbus, Freud, Aristotle) having priority in recall. This retrograde amnesia in free recall was interpreted by Tulving as a premature termination of episodic encoding and triggered a burst of studies of experimental amnesia, which showed that amnesic effects obtained at short retention intervals are most pronounced for emotional oddballs (Angelini et al., 1994). Several studies simulating experimentally amnesia by emotional trauma (Detterman and Ellis, 1972; Loftus and Burns, 1982; Christianson, 1984) demonstrated robust retrograde and anterograde amnesic effects for items temporally contiguous to emotional oddballs. The experimental strategy typically used in these studies is that subjects were exposed to a sequence of neutral slides (e.g. landscapes), in which were inserted slides of traumatic content (e.g., a mutilation).

\section{QUESTIONS AND HYPOTHESES}

An emotion-induced enhancement of episodic memory formation seems to have costs and benefits (Tulving, 1969; Loftus and Burns, 1982; Angelini et al., 1994). Multiple lines of evidence implicate the anygdala and $\beta$-adrenergic mechanisms in emotion-induced memory enhancements at long retention intervals (McGaugh, 2000). Therefore, one might predict that similar mechanisms are also involved in emotion-induced memory enhancements - and impairments - at short retention intervals. Chapter 2 introduces to a series of psychological, neuropsychological and pharmacological experiments that test this prediction and involve a retrograde amnesic effect in response to emotional oddballs. The role of anygdala- and $\beta-$ adrenergic-dependent mechanisms in emotion-induced retrograde amnesia is probed by testing a rare amygdala-lesioned patient with Urbach-Wiethe disease and by conducting a pharnacological challenge using the $\beta$-adrenergic receptor antagonist propranolol. In Chapter 3, the experimental focus is widened to retrograde and anterograde episodic memory changes in response to emotional oddballs. Emerging evidence indicates dissociable contributions of arousal and valence to emotion-induced memory enhancements (Kensinger and Corkin, 2004). This raises the question whether a similar dissociation might underlie the design that the brain uses to organize forgetting and remembering by emotion. To prove this question, emotional valence and arousal are manipulated by testing positive and negative oddballs relative to neutral oddballs under experimental conditions of low arousal (established by $\beta$-adrenergic blockade with propranolol) versus high arousal (established by NE re-uptake inhibition with reboxetine).

In Chapter 4, based on the data accumulated in the previous chapters, a neurocircuitry model of emotion-induced forgetting and remembering as a function of PFC-hippocampal and amygdala-hippocampal interactions during emotional memory encoding is developed. If emotion-induced forgetting and remembering both require integrity of the BLA, it should be abolished in Urbach-Wiethe patients with a disease emphasis on this subregion as confirmed with cytoarchitectonic maximum probability maps of the amygdala. In Chapter $\mathbf{5}$, this hypothesis is tested in a study of two monozygotic female twins with Urbach-Wiethe disease. Cytoarchitectonic maximum probability maps not only allow to accurately identify structural brain abnormalities, but may also be useful as an atlas for the accurate anatomical analysis of functional imaging data (Toga et al., 2006). The technical feasibility of this approach is tested 
R. Hurlemann - The Costs and Benefits of Emotional Memory Formation

in Chapter 6, which presents a quantitative analysis of in vivo neuroreceptor positron emission tomography (PET) data based on such maps.

In the following two chapters, the focus shifts to the potential significance of emotioninduced amnesia in pathological conditions such as borderline personality disorder (BPD) and post-traumatic stress disorder (PTSD). Current theories of BPD emphasize the disruptive potential of dysregulated negative emotion on cognitive functioning (Fertuck et al., 2005). These disruptive effects could result from amygdala hyper-responsiveness to negative emotion. Therefore, Chapter 7 presents a study of sixteen female BPD patients tested on the behavioral indices of emotion-induced forgetting and remembering established in matched controls. Preliminary evidence from human fMRI studies suggests synergistic effects of NE and cortisol (CORT) in amplifying amygdala responses during emotional encoding (van Stegeren et al., 2007). NE-CORT interactions could thus determine the magnitude of emotioninduced amnesia, which - when expressed in extreme forms - constitutes a powerful predictive risk factor for PTSD (Ozer et al., 2003; Briere et al., 2005; Gil et al., 2005). In an attempt to experimentally model the neurochemical mechanism precipitating amnesia by emotional trauma, Chapter 8 presents a pharmacological study, where the emotion-induced amnesic potential of elevated CORT levels is tested in the presence or absence of elevated NE levels. Finally, the results of the previous chapters are integrated in the concluding Chapter 9.

Adolphs R, Cahill L, Schul R, Babinsky R (1997) Impaired declarative memory for emotional material following bilateral amygdala damage in humans. Learn Mem 4:291-300.

Anderson AK, Phelps EA (2001) Lesions of the human amygdala impair enhanced perception of emotionally salient events. Nature 411:305-309.

Anderson AK, Christoff K, Stappen I, Panitz D, Ghahremani DG, Glover G, Gabrieli JD, Sobel N (2003) Dissociated neural representations of intensity and valence in human olfaction. Nat Neurosci 6:196-202.

Angelini R, Capozzoli F, Lepore P, Grossi D, Orsini A (1994) "Experimental amnesia" induced by emotional items. Percept Mot Skills 78:19-28.

Armony JL, Dolan RJ (2002) Modulation of spatial attention by fear-conditioned stimuli: an event-related fMRI study. Neuropsychologia 40:817-26.

Bechara A, Tranel D, Damasio H, Adolphs R, Rockland C, Damasio AR (1995) Double dissociation of conditioning and declarative knowledge relative to the amygdala and hippocampus in humans. Science. 269:1115-1118.

Bradley MM, Greenwald MK, Petry MC, Lang PJ (1992) Remembering pictures: pleasure and arousal in memory. J Exp Psychol Learn Mem Cogn 18:379-390.

Briere J, Scott C, Weathers F (2005) Peritraumatic and persistent dissociation in the presumed etiology of PTSD. Am J Psychiatry 162:2295-2301.

Brown R, Kulik J (1977) Flashbulb memories. Cognition 5:73-93.

Burnham WH (1903) Retroactive amnesia: illustrative cases and a tentative explanation. Am J Psychol 14:382.

Cahill L, Prins B, Weber M, McGaugh JL (1994) Beta-adrenergic activation and memory for emotional events. Nature 371:702-704.

Cahill L, Babinsky R, Markowitsch HJ, McGaugh JL (1995) The amygdala and emotional memory. Nature 377:295-296.

Christianson SA (1984) The relationship between induced emotional arousal and amnesia. Scand J Psychol 25:147-160

Davis HP (1984) Squire LR, Protein synthesis and memory: a review. Psychol Bull 96:518-59.

Detterman DK, Ellis NR (1972) Determinants of induced amnesia in short-term memory. J Exp Psychol 95:308316.

Dolan RJ (2002) Emotion, cognition, and behavior. Science 298:1191-1194.

Dolan RJ, Heinze HJ, Hurlemann R, Hinrichs H. (2006) Magnetoencephalography (MEG) determined temporal modulation of visual and auditory sensory processing in the context of classical conditioning to faces. Neuroimage 32:778-789. 


\section{R. Hurlemann - The Costs and Benefits of Emotional Memory Formation}

Dolcos F, LaBar KS, Cabeza R (2004) Dissociable effects of arousal and valence on prefrontal activity indexing emotional evaluation and subsequent memory: an event-related fMRI study. Neuroimage 23:64-74.

Donchin E, Coles MG (1988) Is the P300 component a manifestation of context updating? Behavior and Brain Sciences 11:357-427.

Duncan CP (1949) The retroactive effect of electroshock on learning. J Comp Physiol Psychol 42:32.

Eichenbaum HA (2000) Cortical-hippocampal system for declarative memory. Nat Rev Neurosci 1:41-50.

Esteves F, Parra C, Dimberg U, Ohman A (1994) Nonconscious associative learning: Pavlovian conditioning of skin conductance responses to masked fear-relevant facial stimuli. Psychophysiology 31:375-385.

Fertuck EA, Lenzenweger MF, Clarkin JF, Hoermann S, Stanley B (2005) Executive neurocognition, memory systems, and borderline personality disorder. Clin Psychol Rev 3:346-375

Gerard RW (1949) Physiology and psychiatry. Am J Psychiatry 106:161.

Gil S, Caspi Y, Ben-Ari IZ, Koren D, Klein E (2005) Does memory of a traumatic event increase the risk for posttraumatic stress disorder in patients with traumatic brain injury? A prospective study. Am J Psychiatry 162:963-969.

Hamann S (2001) Cognitive and neural mechanisms of emotional memory. Trends Cogn Sci 5:394-400.

Hamann SB, Ely TD, Grafton ST, Kilts CD (1999) Amygdala activity related to enhanced memory for pleasant and aversive stimuli. Nat Neurosci 2:289-293.

Kensinger EA, Corkin S (2004) Two routes to emotional memory: distinct neural processes for valence and arousal. Proc Natl Acad Sci USA 101:3310-3315.

Kirchhoff BA, Wagner AD, Maril A, Stern CE (2000) Prefrontal-temporal circuitry for episodic encoding and subsequent memory. J Neurosci 20:6173-6180.

Kleinsmith LJ, Kaplan S (1963) Paired-associate learning as a function of arousal and interpolated interval. J Exp Psychol 65:190-193.

LaBar KS, Cabeza R (2006) Cognitive neuroscience of emotional memory. Nat Rev Neurosci 7:54-64.

Lang PJ (1995) The emotion probe. Studies of motivation and attention. Am Psychol 50:372-385.

Lang PJ, Bradley MM, Cuthberg BN (1997) International affective picture system, NIMH center for the study of emotion and attention, Gainesville, Florida, USA

Lisman JE, Grace AA (2005) The hippocampal-VTA loop: controlling the entry of information into long-term memory. Neuron 46:703-713.

Loftus EF, Burns TE (1982) Mental shock can produce retrograde amnesia. Mem Cognit 10:318-323.

Markowitsch HJ, Calabrese P, Wurker M, Durwen HF, Kessler J, Babinsky R, Brechtelsbauer D, Heuser L, Gehlen W (1994) The amygdala's contribution to memory-a study on two patients with Urbach-Wiethe disease. Neuroreport 5:1349-1352.

McDougall W (1901) Experimentelle Beitraege zur Lehre vom Gedaechtnis: von G.E. Mueller und A. Pilzecker Mind 10:388-394.

McGaugh JL (2000) Memory - a century of consolidation. Science 287:248-251.

Mogg K, Bradley BP, de Bono J, Painter M (1997) Time course of attentional bias for threat information in nonclinical anxiety. Behav Res Ther 35:297-303.

Morris JS, Ohman A, Dolan RJ (1998) Conscious and unconscious emotional learning in the human amygdala. Nature 393:467-70.

Müller GE, Pilzecker A (1900) Experimentelle Beiträge zur Lehre vom Gedächtnis. Z Psychol 1:1.

Ohman A, Flykt A, Esteves F (2001) Emotion drives attention: detecting the snake in the grass. J Exp Psychol Gen 130:466-478.

Ozer EJ, Best SR, Lipsey TL, Weiss DS (2003) Predictors of posttraumatic stress disorder and symptoms in adults: a meta-analysis. Psychol Bull 129:52-73.

Paller KA, Kutas M, Mayes AR (1987) Neural correlates of encoding in an incidental learning paradigm. Electroencephalogr Clin Neurophysiol 67:360-371.

Phelps EA (2006) Emotion and cognition: Insights from studies of the human amygdala. Annu Rev Psychol $57: 27-53$

Polich J, Kok A (1995) Cognitive and biological determinants of P300: an integrative review. Biol Psychol 41:103-146.

Ranganath C, Rainer G (2003) Neural mechanisms for detecting and remembering novel events. Nat Rey Neurosci 4:193-202.

Richardson MP, Strange BA, Dolan RJ (2004) Encoding of emotional memories depends on amygdala and hippocampus and their interactions. Nal Neurosci 7:278-285.

Russell JA (1980) A circumplex model of affect. J Pers Soc Psychol 39:1161-1178.

Scoville WB, Milner B (1957) Loss of recent memory after bilateral hippocampal lesions. J Neurol Neurosurg Psychiatry 20:11-21.

Simons RF, Graham FK, Miles MA, Chen X (2001) On the relationship of P3a and the Novelty-P3. Biol Psychol 56:207-218.

Small DM, Gregory MD, Mak YE, Gitelman D, Mesulam MM, Parrish T (2003) Dissociation of neural representation of intensity and affective valuation in human gustation. Neuron 39:701-711. 
R. Hurlemann - The Costs and Benefits of Emotional Memory Formation

Strange BA, Henson RNA, Friston KJ, Dolan RJ (2000) Brain mechanisms for detecting perceptual, semantic, and emotional deviance. Neuroimage 12:425-433.

Strange BA, Hurlemann R, Duggins A, Heinze HJ, Dolan RJ (2005) Dissociating intentional learning from relative novelty responses in the medial temporal lobe. Neuroimage 25:51-62.

Teng E, Squire LR (1999) Memory for places learned long ago is intact after hippocampal damage. Nature 400:675-677.

Toga AW, Thompson PM, Mori S, Amunts K, Zilles K. (2006) Towards multimodal atlases of the human brain. Nat Rev Neurosci 7:952-966.

Tulving E (1969) Retrograde amnesia in free recall. Science 164:88-90.

van Stegeren AH, Everaerd W, Cahill L, McGaugh JL, Gooren LJ (1998) Memory for emotional events: differential effects of centrally versus peripherally acting beta-blocking agents. Psychopharmacology 138:305-310.

van Stegeren AH, Wolf OT, Everaerd W, Scheltens P, Barkhof F, Rombouts SA (2007) Endogenous cortisol level interacts with noradrenergic activation in the human amygdala. Neurobiol Learn Mem 87:57-66.

von Restorff H (1933) Ueber die Wirkungen von Bereichsbildung im Spurenfeld. Psychologische Forschung 18:299-342.

Vuilleumier P (2005) How brains beware: neural mechanisms of emotional attention. Trends Cogn Sci 9:585-94. Whalen PJ, Rauch SL, Etcoff NL, McInerney SC, Lee MB, Jenike MA (1998) Masked presentations of emotional facial expressions modulate amygdala activity without explicit knowledge. J Neurosci 18:411418.

Whalen PJ, Kagan J, Cook RG, Davis FC, Kim H, Polis S, McLaren DG, Somerville LH, McLean AA, Maxwell JS, Johnstone T (2004) Human amygdala responsivity to masked fearful eye whites. Science 306:2061.

\section{3.}

Strange BA, Hurlemann R, Duggins A, Heinze HJ, Dolan RJ (2005) Dissociating intentional learning from relative novelty responses in the medial temporal lobe. Neurolmage 25:51-62. (Figure 2 reproduced with permission of the copyright owner. Further reproduction prohibited without permission.)

Dolan RJ, Heinze HJ, Hurlemann R, Hinrichs H (2006) Magnetoencephalography (MEG) determined temporal modulation of visual and auditory sensory processing in the context of classical conditioning to faces. NeuroImage 32:778-789. (Figures 4 and 7 reproduced with permission of the copyright owner. Further reproduction prohibited without permission.) 


\section{CHAPTER 2}

\section{Introduction II: An emotion-induced retrograde amnesia in humans is amygdala- and $\beta$-adrenergic-dependent}

The influence of emotion on human memory is associated with two contradictory effects in the form of either emotion-induced enhancements or decrements in memory. In a series of experiments involving single word presentation, we show that enhanced memory for emotional words is strongly coupled to decrements in memory for items preceding the emotional stimulus, an effect that is more pronounced in women. These memory effects would appear to depend on a common neurobiological substrate, in that enhancements and decrements are reversed by propranolol, a $\beta$-adrenergic antagonist, and abolished by selective bilateral amygdala damage. Thus, our findings suggest that amygdala-dependent beta-adrenergic modulation of episodic encoding has costs as well as benefits.

Substantial evidence indicates that enhanced memory for emotional experience engages a $\beta$-adrenergic system (Cahill and McGaugh, 1998). $\beta$-Adrenergic blockade with the $\beta 1 \beta 2$-antagonist propranolol selectively impairs long-term human episodic memory for emotionally arousing material without affecting memory for a neutral story (Cahill et al., 1994). This modulation of emotional memory by propranolol is centrally mediated, because peripheral $\beta$-adrenergic blockade has no such effect on emotional memory function (van Stegeren et al., 1998). Human amygdala lesions also produce emotional memory impairment (Cahill et al., 1995; Phelps et al., 1998), suggesting that this structure may represent a critical locus for propranolol's influence on emotional memory.

Although emotionality is strongly associated with enhancements in memory, there is evidence for emotion-induced memory decrements (Holmes, 1970; Christianson, 1992). Human behavioral studies demonstrate enhanced memory for central details of an emotional event and memory suppression for peripheral details (Heuer and Reisberg, 1992; Adolphs et al., 2001). Ecological studies show that details of an event are less likely to be remembered if followed by an emotional event (Loftus and Burns, 1982). In experimental contexts a weak, although unreliable, effect on words presented in close proximity to potentially emotional items is reported (Angelini et al., 1994). By contrast to the extensive literature on emotional enhancements in memory, nothing is known regarding the neurobiological processes accounting for emotion-induced impairments in memory.

In a series of related experiments, we present psychological (Exp. 1), psychopharmacological (Exp. 2) and neuropsychological (Exp. 3) data that characterize the 
R. Hurlemann - The Costs and Benefits of Emotional Memory Formation

psychological and neurobiological properties of emotion-induced forgetting. Our first aim was to establish a behavioral index of emotion-evoked memory enhancement and impairment. In an initial behavioral memory experiment (Exp. 1), nouns were presented serially, every $3 \mathrm{~s}$, in semantically related lists, and recall was tested after each list presentation. Each list, in this and subsequent experiments, contained two "oddball" nouns: an emotionally aversive noun ( $E$ noun) and a perceptual oddball noun (P noun), presented in a novel font (Fig. 1a). In line with previous observations (Christianson, 1992; Cahill and McGaugh, 1998), memory for emotional items is enhanced relative to control nouns. Critically, items preceding E nouns (E1 nouns) are recalled less well than controls (see Results).

A previously reported blockade of enhanced memory for emotional stimuli by propranolol (Cahill et al., 1994) indicates central noradrenaline/norepinephrine (NE) release in response to emotional stimuli. In animals, posttraining amygdala stimulation, electrically or with adrenergic agonists, typically leads to enhanced memory for previously learned tasks but can evoke memory impairment (Liang et al., 1990; McGaugh et al., 2002). For example, retrograde amnesia in rodents for visual discrimination learning is produced by postlearning stimulation of the amygdala (Sternberg and Gold, 1981), an effect attenuated by pre-treatment with propranolol. Hence amygdala stimulation-evoked adrenergic release, occurring after learning, may disrupt ongoing consolidation (Sternberg and Gold, 1981). We reasoned that NE release evoked by $E$ nouns may affect consolidation of E-1 encoding. On this basis, we conducted further experiments to examine whether memory impairment for E-1 items, like the memory enhancement for $E$ items, would be attenuated by propranolol. To test this prediction, we conducted a psychopharmacological study (Exp. 2), in which subjects received either propranolol or placebo in a double-blind experimental design. As in Exp. 1, nouns were presented serially in semantically related lists and recall tested after each list presentation. Both enhanced memory for E nouns, and memory impairment for E-I items was abolished by propranolol (see Results).

The adrenergic release that enhances memory for emotional events is thought to be mediated by the amygdala (Cahill et al., 1994, 1995; Phelps et al., 1998), because this memory enhancement is abolished by both $\beta$-adrenergic blockade (Cahill et al., 1994) and amygdala lesions (Cahill et al., 1995; Phelps et al., 1998). Our observation that $\beta$-adrenergic blockade abolishes the emotion-induced impairment of memory for E-1 nouns suggests that the same NE release that enhances memory for the $E$ noun also impairs consolidation of E-1 items. Given that this NE release is thought to be amygdala-dependent (Cahill and McGaugh, 1998), we hypothesized that human amygdala lesions would abolish emotion-induced E-1 memory impairment. We therefore tested a patient with selective bilateral amygdala damage (Exp. 3) on the paradigm used in Exp. 2.

P.

\section{Subjects}

Forty-six healthy right-handed native English-speaking subjects took part in our studies. A further 12 healthy right-handed native German-speaking subjects and a righthanded German patient (A.M.) with bilateral amygdala lesions completed Exp. 3. All subjects gave informed consent and, apart from the patient, were free of neurological or psychiatric history. The study had full ethical approval. 


\section{Experiment 1}

Ten subjects [three male, seven female (age range, 22-32 yr; mean age, 26.3)] viewed nouns presented visually in lower-case at a rate of one every $3 \mathrm{~s}$ (stimulus duration, $1 \mathrm{~s}$ ). During four sessions, subjects were presented with eight lists of 19 nouns, with the words "New List" presented between lists. For each list, 16 nouns were of the same semantic category, were emotionally neutral, and were all presented in the same font. These are referred to as control nouns. To set the context, the first five nouns in each list were always control nouns. A P noun was presented in a novel font but was emotionally neutral and of the same semantic category as control nouns. The emotional oddball was aversive in content but of the same category and perceptually identical to control nouns. A semantic oddball was also included (Strange et al., 2000). Nouns were presented in Times font, except for the P nouns, which were presented in 16 different fonts. Semantically related nouns were constructed by using the Edinburgh associative thesaurus (www.itd.clrc.ac.uk/Activity/Psych).

Subjects engaged in two distinct encoding tasks. During two of the sessions, subjects performed a shallow encoding task (Craik and Lockhard, 1972) by indicating whether the first letter in the noun had an enclosed space. During the other two sessions, subjects indicated whether the noun described a living or nonliving entity (the deep encoding task). The order of encoding instructions was counterbalanced. Memory for presented nouns was assessed by immediate verbal recall after the presentation of each 19-noun list. Recall performance in all three experiments is expressed relative to two randomly selected control nouns (only two controls were chosen to balance numbers in the comparison). The chosen control nouns, like the oddballs, could not occur within the first five nouns of each list.

\section{Experiment 2}

In a double-blind experimental design, 24 subjects [12 male (age range, 21-32 yr; mean age, 24.5) and 12 female (age range, 19-23 yr; mean age, 20.8)] received either a 40-mg oral dose of propranolol hydrochloride or a vitamin $\mathbf{E}$ placebo pill. Drug allocation was balanced for gender, i.e., six males and six females received propranolol. In view of the kinetics of propranolol's peak plasma concentration (1-2 h), the memory task started 90 min after drug administration. Blood pressure was measured immediately before drug administration. A blood sample was taken and blood pressure measured immediately before the memory task (Fig. 2d).

The memory task was identical to Exp. 1 except for the following details. Subjects viewed 38 lists of 14 nouns and engaged in the shallow encoding task for all lists (encoding instructions were provided visually at the start of the experiment). Only emotional oddballs and $\mathrm{P}$ nouns were presented, the latter appearing in 19 different fonts. Thirty-two of the 38 lists were taken from Exp. 1. The presentation of each 14-word list was followed immediately by a 30-s distraction task, during which subjects were instructed to count backwards in threes (out loud). The distractor task was followed immediately by instructions to free-recall the words presented in the preceding list.

The 38 lists had been normed for semantic relatedness and emotional valence by a separate group of 12 native English-speaking subjects [five male (age range 24-37 yrs; mean age 28.2); seven female (age range 23-37 yrs; mean age 27.9)]. For emotional rating, subjects judged the emotional valence of the control nouns, 38 emotionally aversive nouns (E nouns), and 38 emotionally positive nouns (not presented in any of the experiments) from -3 (most aversive) to +3 (most positive). Mean ratings (SE) for $E$ nouns $-1.76(0.08)$ and control nouns 
R. Hurlemann · The Costs and Benefits of Emotional Memory Formation

$0.41(0.02)$ showed a significant difference between $\mathrm{E}$ and control nouns $(P<0.001$ onetailed two-sample $t$ test). Semantic ratings were obtained by randomly mixing words from two lists and subjects successively judging their relatedness to the two categories. Semantic oddballs $(\mathrm{S})$ were rated highly distinctive $(P<0.001$ one-tailed two-sample $t$ tests). The shallow task used is an incidental rather than intentional encoding task. However, subjects may have engaged in intentional encoding, because before the experiment they were instructed that memory would be tested after each list. It is unlikely that subjects' strategy became increasing intentional across the duration of the experiment, because memory performance for control nouns, as well as memory enhancement for $\mathrm{E}$ and perceptual oddball (P) nouns and impairment for E-1 nouns, did not vary over the experiment (i.e., across the 38 lists).

\section{Experiment 3}

Patient A.M. suffers from Urbach-Wiethe disease (lipoid proteinosis), an extremely rare genetic disorder that can cause selective bilateral amygdala damage. A.M. is of normal IQ (107) and within normal limits for a range of cognitive functions, including attention and short-term memory. Patient A.M. completed the same task used in Exp. 2, with the verbal stimuli having been translated from English to German by two bilinguals. A further 12 righthanded native German-speaking subjects [six male (age range, 23-36 yr; mean age, 28.2) and six female (age range, 22-33 yrs; mean age, 27.2)] completed the same German version of our task.

\section{W.}

\section{Experiment 1}

We observed that $E$ nouns are recalled better than neutral nouns after both deep and shallow (Craik and Lockhard, 1972) verbal encoding (Fig. 1b). In this paradigm, there was a striking emotion-related amnesia, with the E-1 noun being recalled less well than neutral nouns (Fig. 1b). Recall of nouns after emotional stimuli did not differ from control stimuli. $\mathrm{P}$ nouns also show enhanced memory, but memory for nouns preceding and after $\mathrm{P}$ items did not differ from controls. Given the greater emotion-induced amnesia effect and more robust memory enhancement for both oddball types (von Restorff effect: von Restorff, 1933) during shallow encoding (Fig. 1b), this task manipulation was used in subsequent psychological, psychopharmacological, and neuropsychological experiments. Note that we have previously demonstrated (Strange et al., 2000) amygdala activation in response to emotional nouns during both shallow and deep encoding.

A memory decrement for items immediately preceding semantic oddballs (S-1) was present at trend level after deep but not shallow encoding, in line with previous observations (1); recall performance relative to control nouns ( $\%$, SE) deep $-5.0(2.9), P=0.06$ one-tailed one-sample $t$ test; shallow -4.4 (5.6). Despite the absence of a significant oddball-1 (E-1, S-1) ' encoding task (deep, shallow) interaction, that the S-1 decrement is greatest after deep encoding and E-1 decrement greatest after shallow encoding supports the suggestion that semantic processing of emotional items cannot explain the memory decrement for E-1 words. Indeed, the shallow task was chosen for Exps. 2 and 3 to minimize any contribution of semantic processing on E-1 memory impairment. 
a

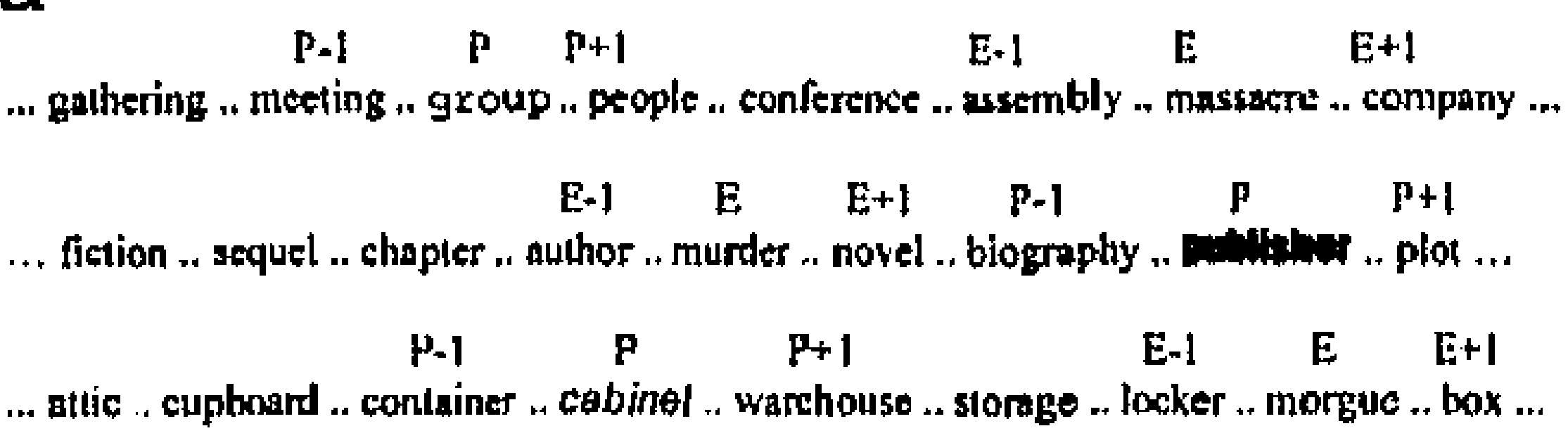

b $\quad \%$ Recall relative to control nouns

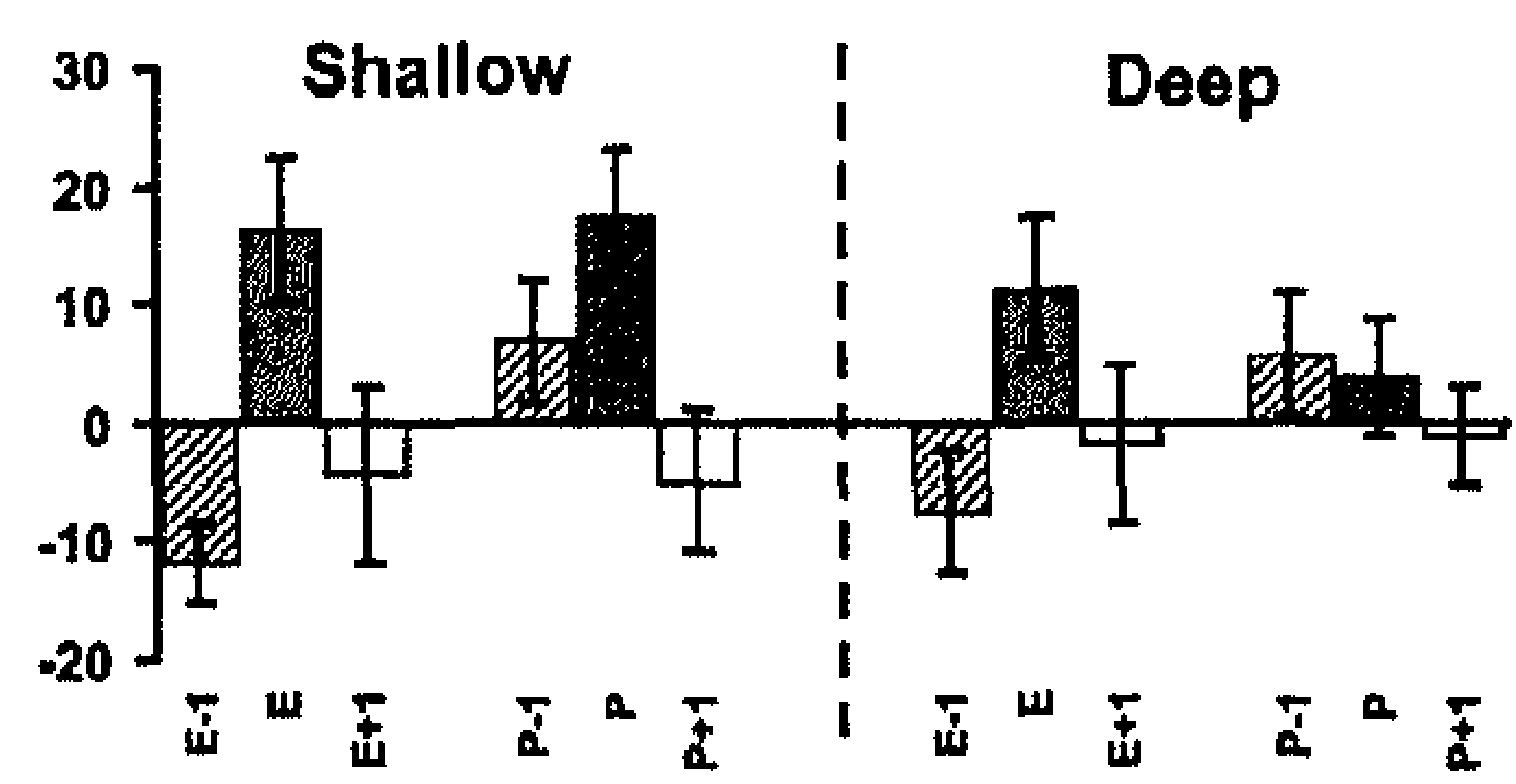

Fig. 1. (a) Examples of presented nouns. (b) Recall performance ( $\pm \mathrm{SE}$ ) relative to control nouns (\%) for deep and shallow encoding in Exp. 1. An encoding task (shallow, deep) $\mathrm{x}$ oddball type (emotional, perceptual) $\mathrm{x}$ position (oddball-1, oddball, oddball +1$) 2 \times 2 \times 3$ ANOVA revealed a significant main effect of position $\left(F_{1.3}\right.$, $11.8=12.7 P<0.005)$ and a significant oddball $\mathrm{x}$ position interaction $\left(F_{1.9,16.9}=3.8 P<0.05\right)$. Mean recall of control nouns (\%; SE) after deep encoding was 58.8 (2.8) and after shallow encoding was 48.1 (3.6). E, emotional oddball; $\mathrm{P}$, perceptual oddball; $\mathrm{E}-1, \mathrm{E}+1, \mathrm{P}-1, \mathrm{P}+1$, nouns presented before and after emotional and perceptual oddballs.

\section{Experiment 2}

This psychopharmacological study demonstrates memory enhancement for emotional nouns and impairment for the E-1 noun in the placebo group (Fig. 2a), replicating our previous behavioral finding. Propranolol reversed both effects, such that memory for emotional nouns equated that for neutral nouns, whereas E-1 nouns were now remembered better than control nouns (Fig. 2a). Propranolol did not influence memory for neutral items; i.e., the improvement was selective for E-1 nouns.

In light of the E-1 memory decrement, we performed a further analysis on memory for the nouns preceding E-1 nouns (E-2). In this analysis, we observed a memory impairment for E-2 nouns in the placebo group that is approximately half the magnitude of E-1 decrement. As for E-1 nouns, this effect on E-2 items was also abolished by propranolol (Fig. 2a). The number of items preceding the emotional noun cannot be dissociated from elapsed time, thus the retrograde effect may be time-dependent (up to $6 \mathrm{~s}$ ) or item-dependent (up to two items). The constraints of our experimental design precluded examination of more enduring retrograde amnesic effects (e.g., E-3).

We next examined, on an item-by-item basis, the dependency of memory for E-1 nouns on successful encoding of the list-related E noun. Fig. $\mathbf{2 b}$ demonstrates that, in the placebo group, the E-1 noun is more likely to be forgotten if the E noun is remembered. This codependency is modulated by propranolol such that far fewer E nouns are remembered, and E-1 nouns are more likely to be remembered if corresponding $E$ nouns are forgotten. Again additional analyses demonstrated an identical pattern for $\mathbf{E}$ and E-2 memory (Fig. 2c). Because previous human behavioral studies demonstrate enhanced memory for central details of an emotional event and suppression for peripheral details (Heuer and Reisberg, 1992; Adolphs et al., 2001), it will be of interest to determine whether central-peripheral effects are modulated by $\beta$-adrenergic blockade (Cahill and van Stegeren, 2003). 
R. Hurlemann · The Costs and Benefits of Emotional Memory Formation

a

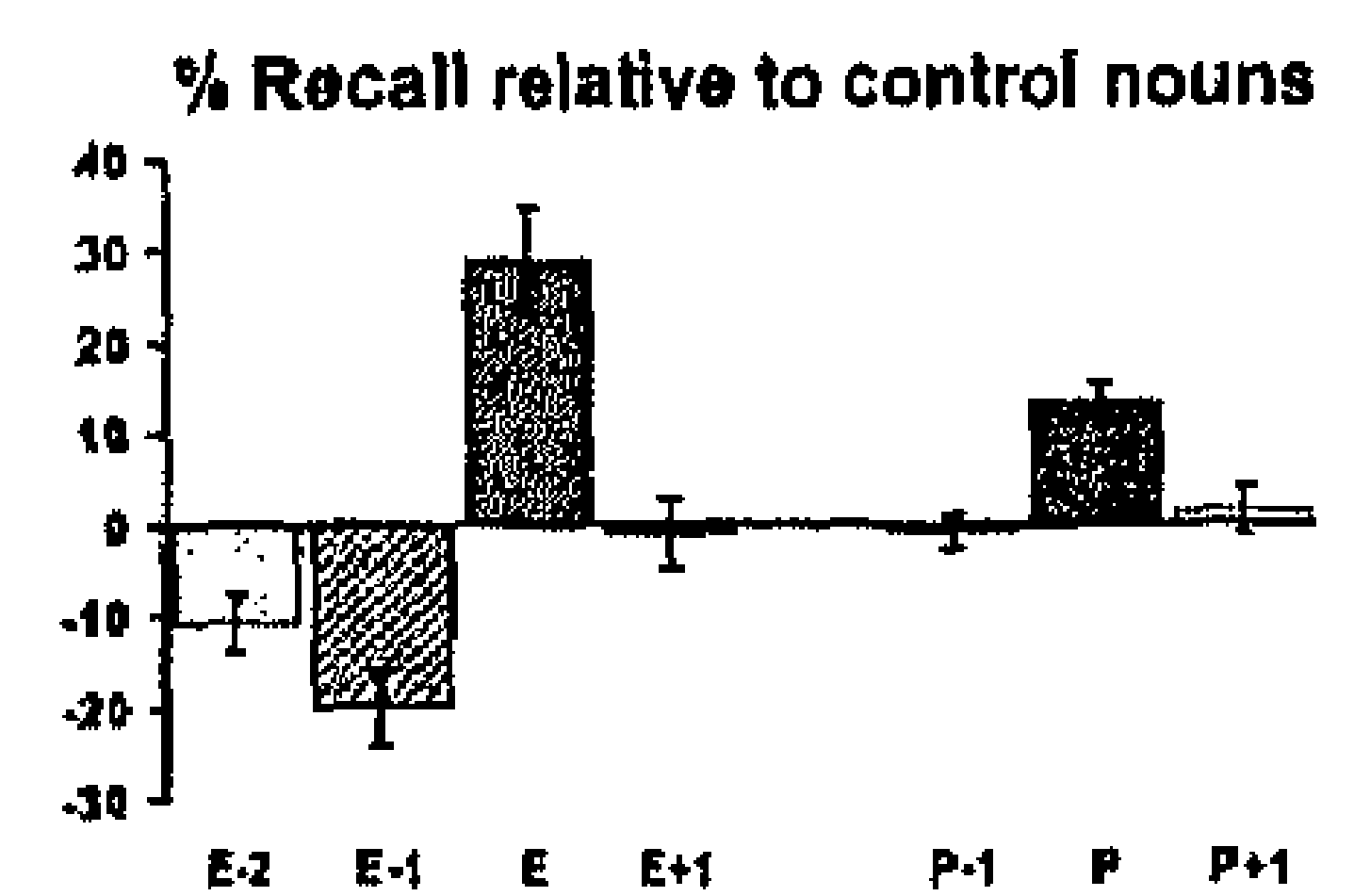

b Mnortar Enam

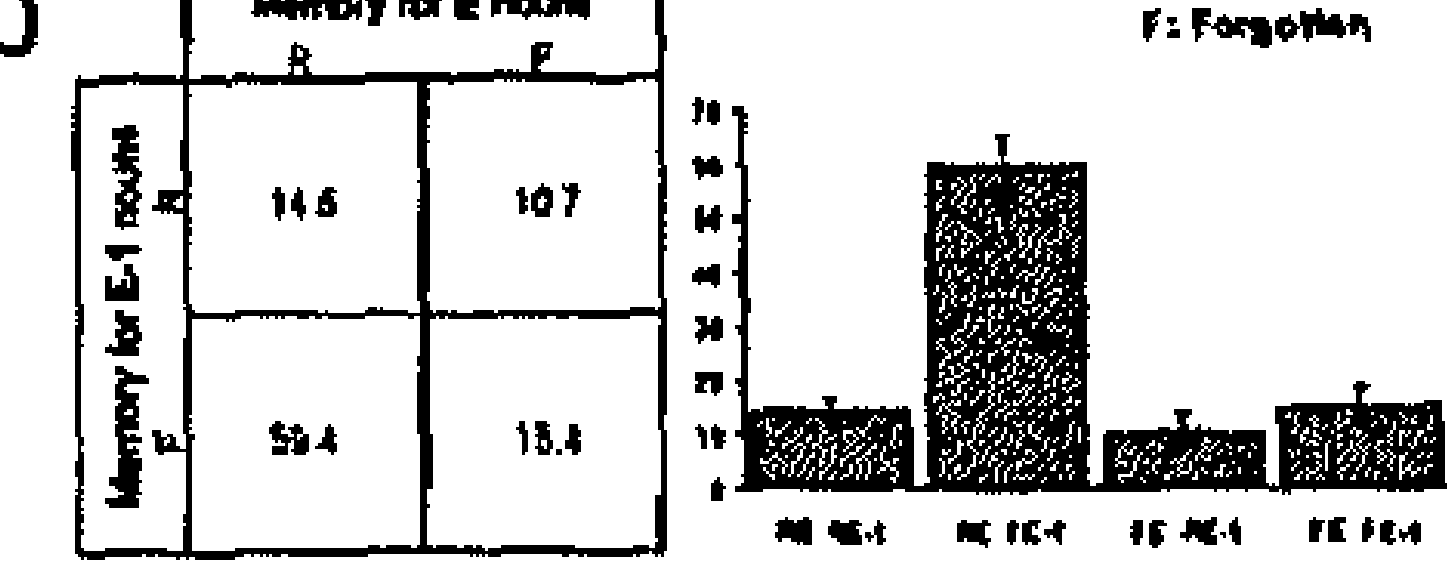

C

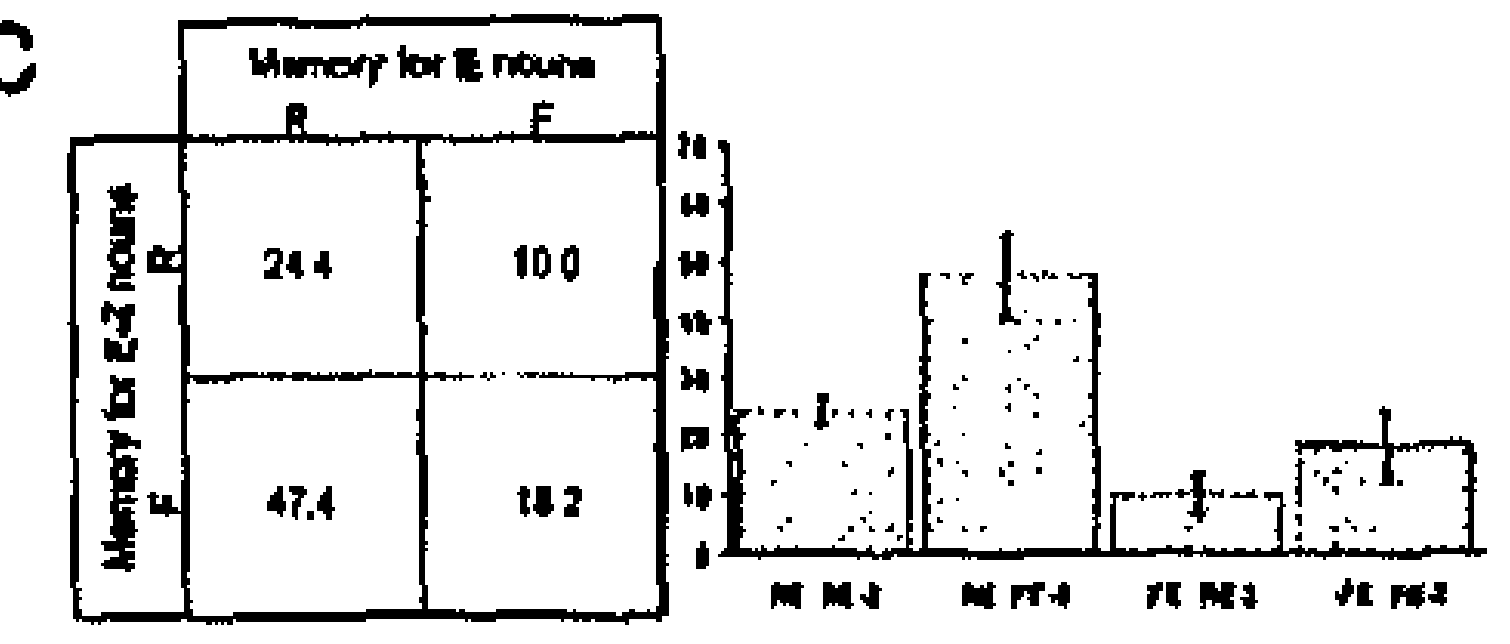

d

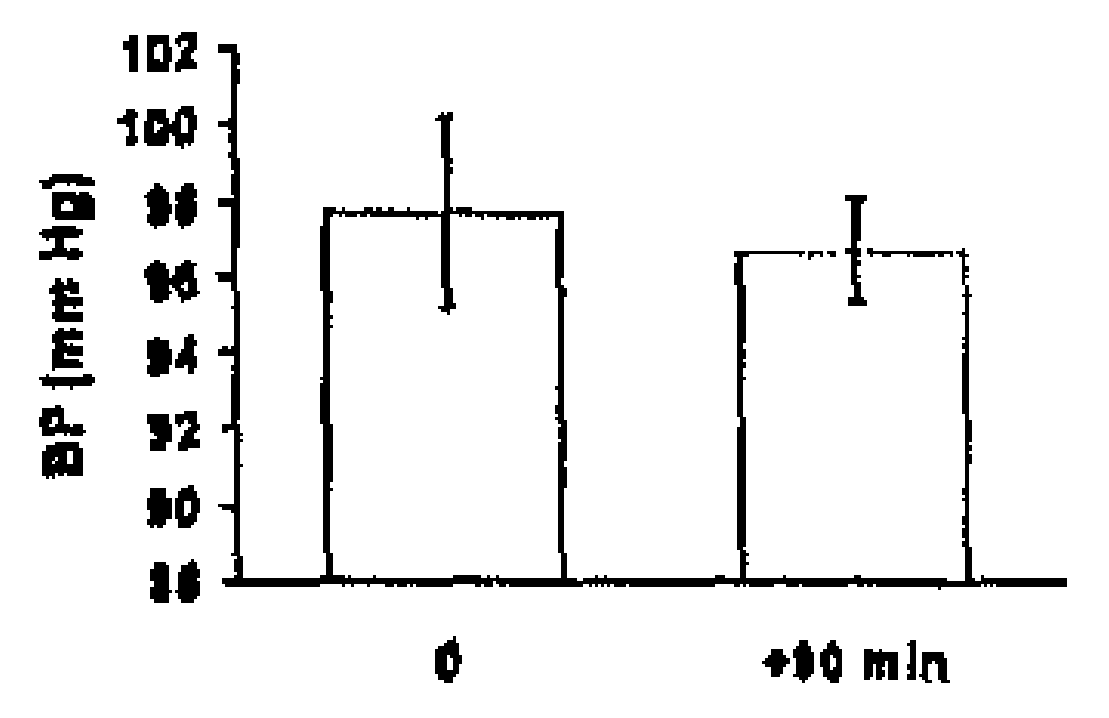

Propranolol

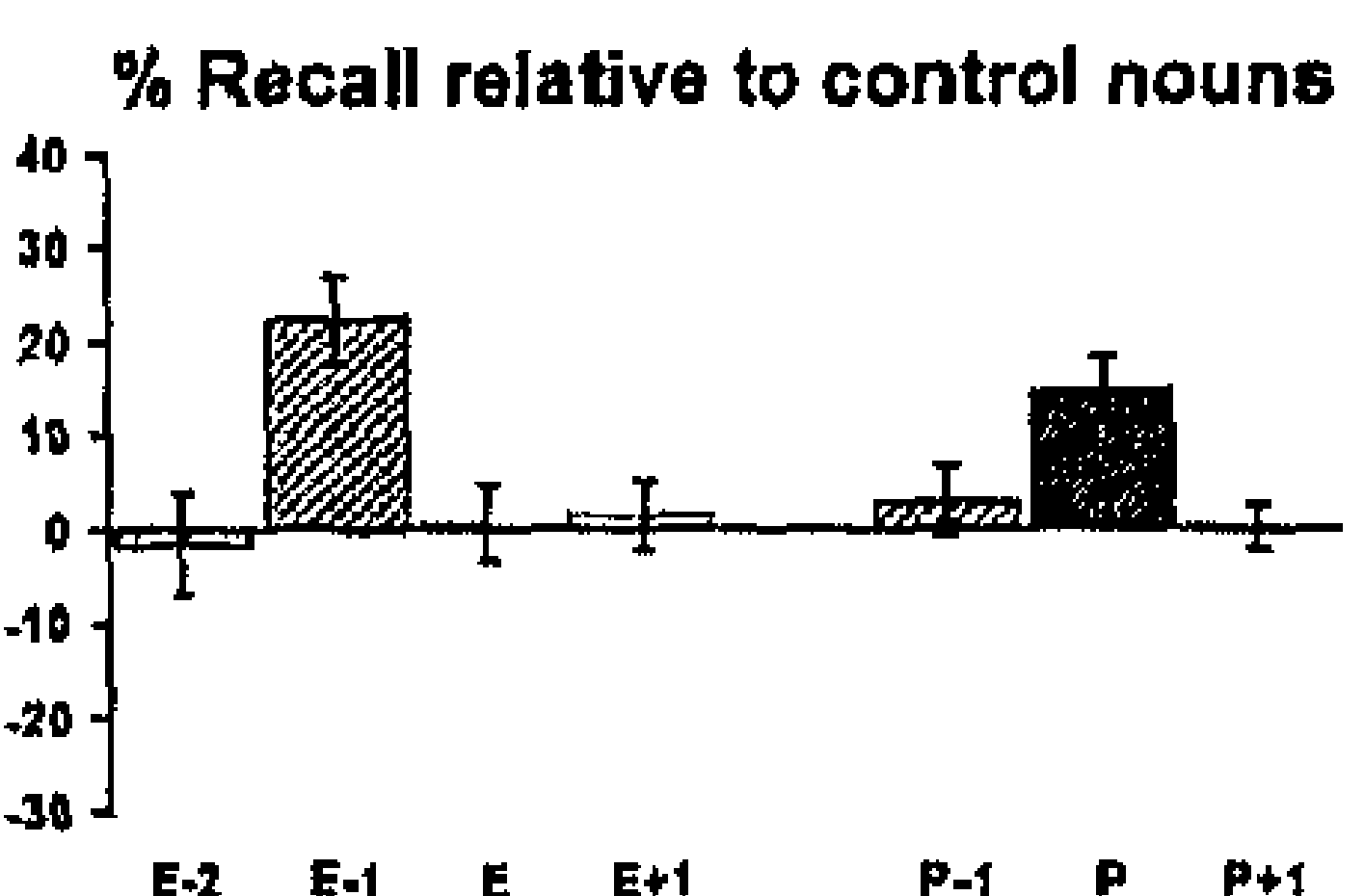

E-2 E-1 E E E
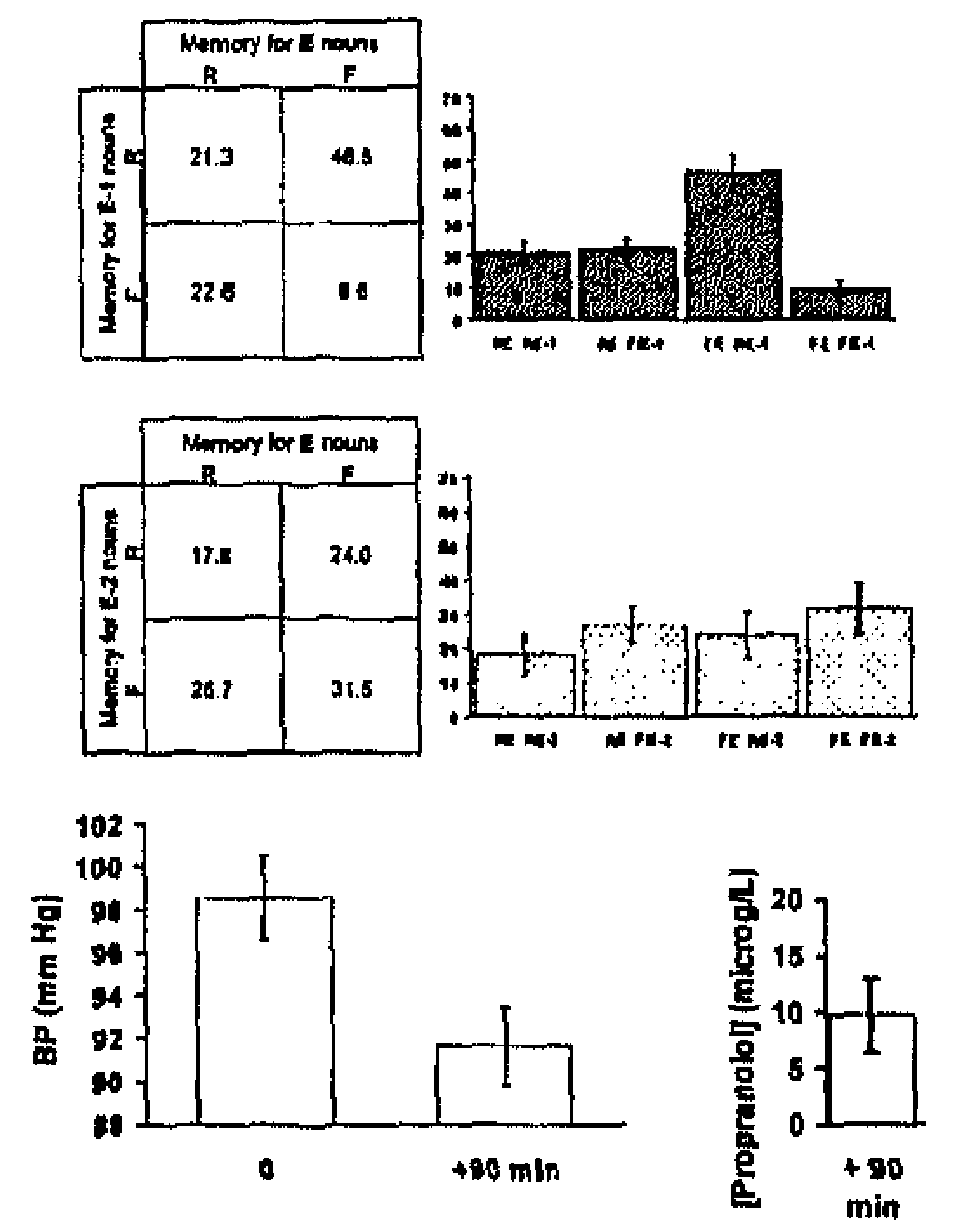

Fig. 2. Emotion-induced memory impairment is $\beta$-adrenergic-dependent. (a) Recall performance relative to control nouns (\%) is plotted after shallow encoding for placebo and propranolol groups in Exp. 2. A group (placebo, drug) $x$ oddball type (emotional, perceptual) $\times$ position (oddball-1, oddball, oddball +1 ) $2 \times 2 \times 3$ ANOVA revealed a significant main effect of position $\left(F_{1.8,19.5}=17.6 P<0.001\right)$, a significant group $\mathrm{x}$ position interaction $\left(F_{1.7,18.6}=34.5 P<0.001\right)$, and a significant group $\mathrm{x}$ oddball type $\mathrm{x}$ position interaction $\left(F_{1.5,16.0}=\right.$ $30.4 P<0.001$ ). A group $\mathrm{x}$ position $2 \times 3$ ANOVA restricted to the emotional factor revealed a significant main effect of group $\left(F_{1,11}=9.3 P<0.05\right)$ and position $\left(F_{1.6,18.1}=5.2 P<0.05\right)$ and a significant group $\mathrm{x}$ position interaction $\left(F_{1,3,14.6}=42.4 P<0.001\right)$. Post hoc $t$ tests demonstrated that $\mathrm{E}-2$ nouns are recalled significantly worse than control nouns in the placebo group $(P<0.001$ one-tailed one-sample $t$ test) and worse at trend level for placebo relative to drug groups $(P=0.08$ one-tailed two-sample $t$ test). The decrement for E-1 nouns was significantly greater than for $\mathrm{E}-2$ nouns in the placebo group $(P<0.05$ one-tailed paired $t$ test). Memory for control nouns was not significantly different between groups; mean recall (\%; SE) for placebo: 45.2 (1.9); drug; 43.5 (2.4). (b) Reciprocal codependency of memory for $\mathrm{E}$ and $\mathrm{E}-1$ nouns demonstrated by contingency tables and plots of the percentage ( $\pm \mathrm{SE}$ ) of remembered $(\mathrm{R})$ and forgotten $(\mathrm{F}) \mathrm{E}$ nouns, split according to memory for the corresponding E-1 nouns. Memory decrement for E-1 and memory enhancement for $E$ nouns show a strong item-by-item codependency in the placebo group $\left(\chi^{2}=4.7 ; P<0.05\right)$. Propranolol modulated this codependency, evident as a significant difference between placebo (expected) and drug (observed) groups $\left(\chi^{2}=93.1 ; P<\right.$ 0.001). (c) Reciprocal codependency of memory for $E$ and $E-2$ nouns as for $b$ except that $E$ nouns are now split according to memory for the corresponding E-2 nouns. The item-by-item codependency for memory decrement for $\mathrm{E}-2$ and memory enhancement for $\mathrm{E}$ nouns in the placebo group is abolished by propranolol $\left(\chi^{2}=32.2 ; P<\right.$ 0.001 ). (d) Mean blood pressure (BP; $\mathrm{mmHg}$ ), at the time of drug/placebo administration (0) and at the start of the experiment ( $+90 \mathrm{~min}$ ), and drug serum concentrations ([propranolol]; $\mu \mathrm{g} / \mathrm{liter}$ ). Propranolol produced the expected decrease in BP $(P<0.001$ in a two-tailed paired $t$ test $)$.

Subsequent ANOVAs demonstrated that emotion-induced memory enhancement and impairment are independent of oddball serial position in each list (2). A group $\mathrm{x}$ oddball $\mathrm{x}$ position $2 \times 2 \times 3$ ANOVA on reaction time (RT) data from encoding indicated that between group memory differences for $\mathrm{E}$ nouns cannot be attributed to different RTs. Despite a significant group $\mathrm{x}$ oddball interaction, there were no other significant interactions or main 
effects, with a posthoc independent $t$ test showing no significant between group difference for $\mathrm{E}$ noun RTs. Despite the absence of a filled delay between study and test in Exp. 1, the identical behavioral profiles obtained in Exps. 1 and 2 indicate that presence or absence of a filled delay does not affect either emotion-induced memory enhancement or suppression.

\section{Experiment 3}

Fig. 3a demonstrates that the recall profile for German controls is identical to that observed for the English-speaking placebo group in Exp. 2 (Fig. 3a). Critically, the emotioninduced memory impairment for E-1 nouns seen in the control group and the codependency of E-1 memory on recall of $E$ nouns (Fig. 3b) are selectively abolished in patient A.M. with bilateral amygdala damage. We again demonstrated impaired memory for E-2 nouns in German controls that was codependent with memory for $E$ nouns. Note that the memory decrement for E-2 nouns seen in patient A.M. (Fig. 3a) is not codependent with memory for $E$ nouns (Fig. 3c).

\section{German Controls}

a
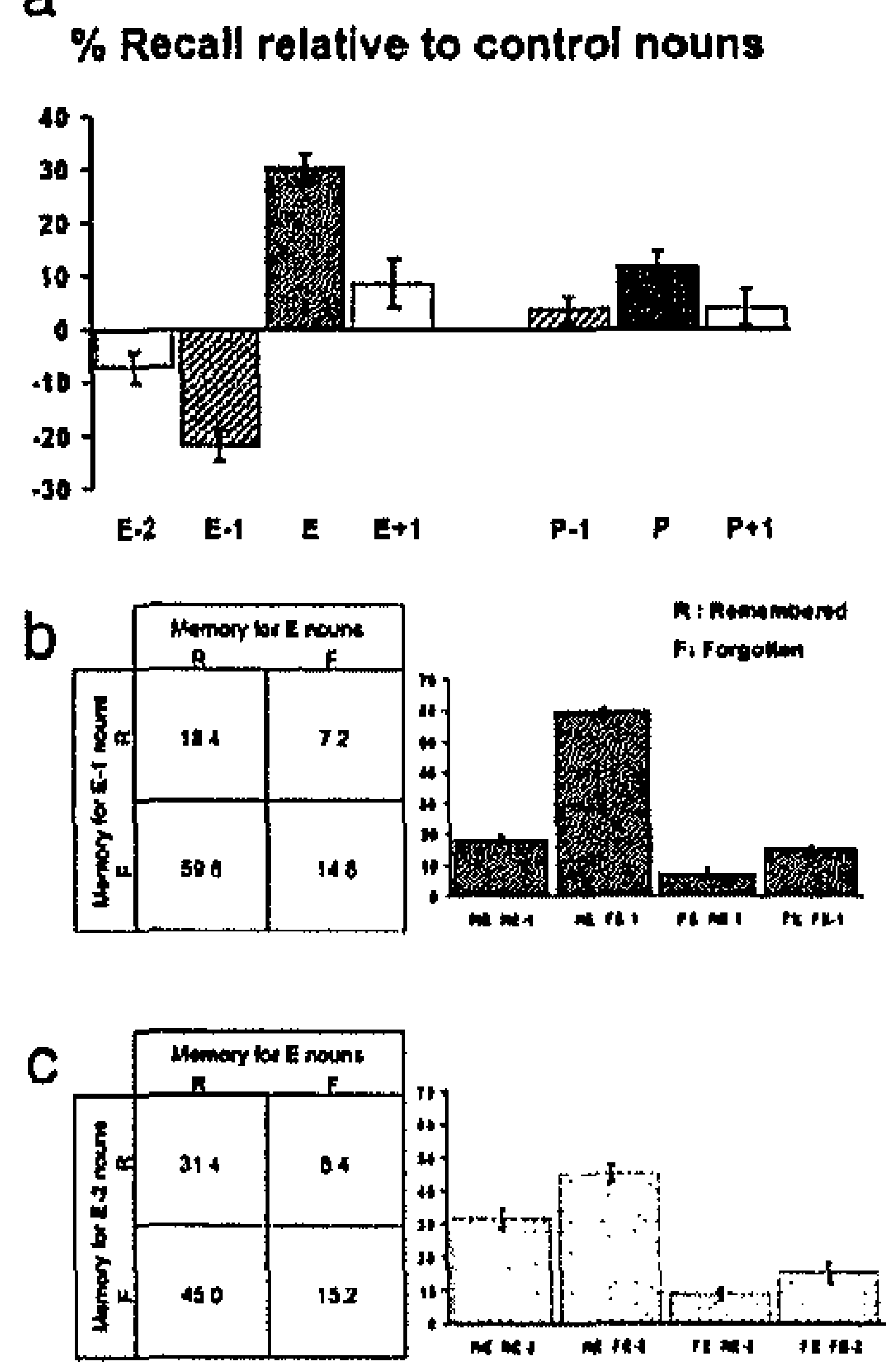

\section{Patient AM}
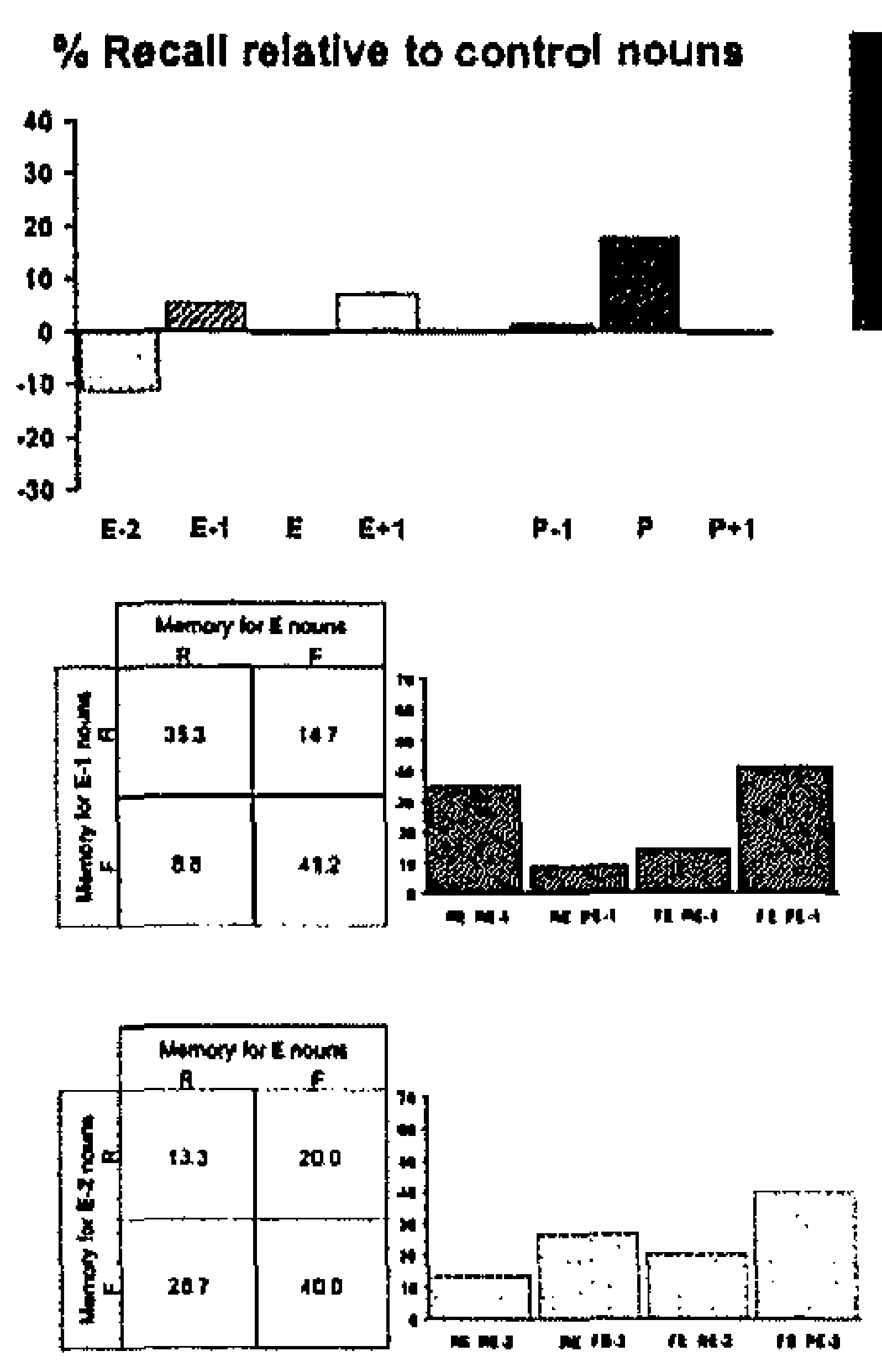

Fig. 3. Emotion-induced memory impairment is amygdala-dependent. (a) Recall performance relative to control nouns (\%) is plotted for the German control group and patient A.M. in Exp. 3. (Right) Coronal and transverse $T_{1}$ MRI images demonstrating patient A.M.'s bilateral amygdala lesion are shown. A group (patient, control) $\mathrm{x}$ oddball type (emotional, perceptual) $x$ position (oddball-1, oddball, oddball +1 ) $2 \times 2 \times 3$ ANOVA (assumes variance in patient population is equal to that in normals) revealed a significant group $\mathrm{x}$ oddball interaction $\left(F_{1,0}\right.$, $1.0=196.6 P<0.05)$ and a trend for the group $\mathrm{x}$ oddball $\mathrm{x}$ position interaction $\left(F_{1.0,1.0}=60.0 P=0.08\right)$. A group $\mathrm{x}$ position $2 \times 3$ ANOVA restricted to the emotional factor revealed a significant group $\mathrm{x}$ position interaction $\left(F_{1,0,1.0}=256.4 P<0.05\right)$. Post hoc independent $t$ tests revealed a significant difference between patient and controls only for recall of E- $1(P<0.01$ two-tailed) and $\mathrm{E}(P<0.005$ two-tailed) nouns. Recall of control nouns was not significantly different between patient and controls; mean recall of control nouns (\%; SE) for patient A.M. 44.7; controls 47.6 (2.1). (b) Reciprocal codependency of memory for E nouns and E-I nouns for controls and patient A.M., as for Fig. $2 b$. The control group demonstrates the same reciprocal effects as the placebo group in Exp. 2 (Fig. $2 b$ ). The presence of bilateral amygdala lesions abolishes this codependency, evident as a significant difference between controls (expected) and patient (observed) $\left(\chi^{2}=113.8 ; P<0.001\right)$. (c) The reciprocal codependency of memory for $\mathrm{E}$ nouns and $\mathrm{E}-2$ nouns present for controls is abolished in patient A.M. $\left(\chi^{2}=74.6 ; P<0.001\right)$. 
As stated in Fig. 4, posthoc independent $t$ tests revealed a significant gender difference only for the E-1 nouns ( $P<0.005$ two tailed). Furthermore, $t$ tests for each experimental group alone revealed a significant E-1 gender difference in the placebo group from Exp. 2 ( $P$ $<0.05$ two-tailed) and a trend for the German control group in Exp. $3(P=0.055$ one-tailed).

\section{Gender differences}

Memory for emotional stimuli and experiences differs between the sexes (Fujita et al., 1991; Seidlitz and Diener, 1998; Cahill et al., 2001; Canli et al., 2002). By balancing for gender in Exps. 2 and 3, we were able to examine gender differences in the memorymodulating effects of emotion. Although an emotion-induced memory decrement for E-1 nouns was present for both genders in both experiments, memory was significantly more impaired in female than male subjects (Fig. 4a), with the impairment in women twice that of men. This could reflect a higher sensitivity in females to the disruptive effect of NE on consolidation of E- 1 items, perhaps reflecting differences in emotional intensity evoked by $\mathrm{E}$ nouns (Seidlitz and Diener, 1998). The latter would predict greater memory enhancement for $\mathrm{E}$ nouns in women compared with men, which we did not observe. We did observe gender differences for E and E-1 memory codependency (Fig. 4b). Furthermore, both genders demonstrated a significant memory decrement for E-2 nouns, with the effect in women nonsignificantly larger than men but with a significant gender difference for $E / E-2$ memory coupling (Fig. 4c).
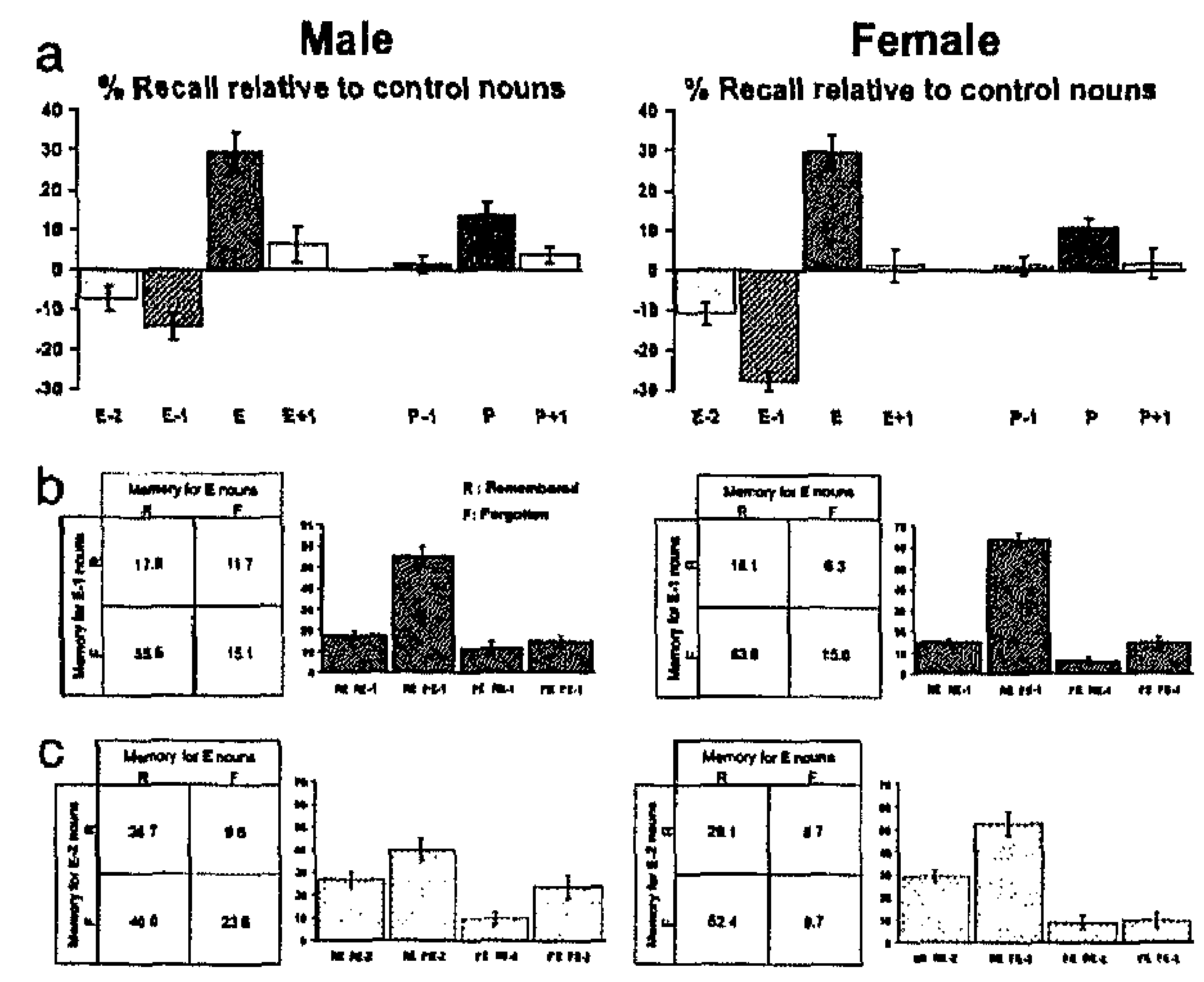

Fig. 4. Women display greater emotion-induced memory impairment than men. (a) Recall performance relative to control nouns (\%) is plotted for male and female subjects collapsing across the placebo group in Exp. 2 and the control group in Exp. 3. A gender (male, female) $x$ oddball type (emotional, perceptual) $x$ position (oddball1, oddball, oddball +1) $2 \times 2 \times 3$ ANOVA across these two groups from Exps. 2 and 3 revealed a significant main effect of position $\left(F_{1.9,21.3}=72.8 P<0.001\right)$, a significant gender x oddball type interaction $\left(F_{1.0,11.0}=9.1\right.$ $P<0.05)$, a significant oddball type $\mathrm{x}$ position interaction $\left(F_{1.4,15.5}=31.6 P<0.001\right)$, and a significant gender $\mathrm{x}$ oddball type $\mathrm{x}$ position interaction $\left(F_{1,4,15,6}=4.7 P<0.05\right)$. A gender $\mathrm{x}$ position $2 \times 3$ ANOVA restricted to the emotional factor revealed a significant main effect of gender $\left(F_{1,11}=6.1 P<0.05\right)$ and position $\left(F_{1.4,15.9}=64.7 P\right.$ $<0.001)$ and a significant gender $\mathrm{x}$ position interaction $\left(F_{16,18.1}=4.4 P<0.05\right)$. Post hoc independent $t$ tests revealed a significant gender difference only for the $\mathrm{E}-1$ nouns ( $P<0.005$ two tailed). ( $b$ and $c$ ) Reciprocal codependency of memory for E nouns and E-1 nouns $(b)$ and E and E-2 nouns $(c)$ for males and females, as for Fig. $2 b$. A significant female vs. male difference for codependency between $\mathrm{E} / \mathrm{E}-1$ memory $\left(\chi^{2}=6.1 ; P<0.05\right)$ and $\mathrm{E} / \mathrm{E}-2$ memory $\left(\chi^{2}=23.0 ; P<0.001\right)$ was observed, with women showing a greater remembered $\mathrm{E}$ and forgotten E-1 (RE FE-1) and RE FE-2 effect. 
We demonstrate that emotional stimuli evoke a graded retrograde amnesia that spans at least $6 \mathrm{~s}$, or two stimuli (E-1 and -2 items), before the occurrence of an emotional item. This retrograde amnesia is amygdala and $\beta$-adrenergic dependent. Impaired memory for $\mathrm{E}-1$ and -2 nouns is tightly coupled on an item-by-item basis to enhanced memory for $E$ items (i.e., if a particular $\mathrm{E}$ nouns is remembered, the corresponding E-1 and -2 nouns are more likely to be forgotten), a coupling abolished by propranolol and amygdala lesions. Our data extend previous observations that amygdala lesions and $B$-adrenergic blockade reverse emotion-induced enhancement of memory (Cahill et al., 1994, 1995). Whereas in these previous studies (Cahill et al., 1994, 1995), the encoded material was a narrated slide show with memory tested weeks later, we demonstrate identical emotional memory effects for verbal material tested after a 30-s delay. That previous studies (Cahill et al., 1994, 1995) fail to report an E-1 retrograde amnesic effect is most likely a reflection of study design. Subjects are shown slides while hearing a narrative in three sequential phases: neutral, emotional, and neutral (Cahill et al., 1994, 1995), with performance averaged across the four stides for each phase. If emotion-induced memory disruption occurred for the last neutral slide before the emotional phase, then averaging over four slides could obscure an effect.

In our experiments, recall of nouns after emotional stimuli ( $E+1$ nouns) does not differ from control stimuli, suggesting that the memory consequences of emotional nouns are restricted to E-1 encoding or consolidation. Encoding refers to the acquisition of a memory representation, whereas consolidation is the stabilization of this representation. E. Tulving (1969) showed a time-limited retrograde amnesia for high-priority events that spanned $1 \mathrm{~s}$ but was not present at $2 \mathrm{~s}$, an effect he conjectured represented either premature termination of encoding or a disruption of consolidation. We favor the latter in view of the enduring nature of the amnesia we observe in the E-2 effect. Note that previously reported retrograde amnesia effects (Tulving, 1969; Angelini et al., 1994) were limited in temporal duration, spanning the order of $1 \mathrm{~s}$. Our data show that an emotional manipulation leads to a robust retrograde effect that spans at least $6 \mathrm{~s}$ or two stimuli.

Animal models demonstrate enhancing and impairing effects of adrenergic stimulation on memory that depend on the degree of adrenergic activation, i.e., an inverted-U function (Liang et al., 1990; McGaugh et al., 2002). Our data suggest that the same level of adrenergic activation can produce memory enhancement and impairment depending on the timing of that activation. Memory is enhanced if adrenergic activation occurs at the time of encoding but impaired if occurring 3-6s after initial encoding. An adrenal hormone response would be too sluggish to mediate the effects we observe. Emotion-induced memory enhancements do not, however, require peripheral adrenergic engagement (van Stegeren et al., 1998), and we would suggest that our emotional memory effects are mediated by rapid arousal-evoked central adrenergic release mediated by the amygdala. An alternative explanation is that postlearning adrenergic hormone activity interacts with arousal associated with initial encoding of $E$ nouns to affect memory storage (Cahill and Alkire, 2003). Why propranolol enhances memory for E-1 nouns has yet to be determined. The effect is phase-dependent, such that under propranolol, consolidation of recently encoded stimuli, but not encoding of the current $\mathrm{E}$ stimulus, is enhanced. The observation that memory for E-2 words is not enhanced by propranolol could imply that propranolol-evoked enhancement depends on the stage of consolidation (i.e., how recently stimuli were encoded). That patient A.M. does not show enhanced memory for E-1 events makes it more suggestive that the E-1 enhancement seen in the propranolol group is an effect specific to blocking $\beta 1$ and -2 adrenergic receptors. 
Because all other nouns in each list in the three experiments were emotionally neutral, the $\mathbf{E}$ nouns constituted emotional oddballs. To control for a nonspecific oddball effect, we included a perceptual oddball control. Memory impairment for the E-1 noun was not due to an oddball-evoked arousal or distinctiveness effect, because memory for nouns preceding a perceptual odd-ball (the P-1 noun; (Fig. 1a) did not differ from control nouns (Figs. 1b, 2a, and 3a). Thus, memory for E-1 nouns was significantly impaired relative to P-1 nouns. Note that distinctiveness of emotional stimuli is a potential confound in previous investigations of emotion-induced memory disruption (Liang et al., 1990; Christianson, 1992; Angelini et al., 1994; Christianson and Nilsson, 1984). Furthermore, the blocking effect of propranolol on the enhancement of memory for $E$ nouns cannot be explained in terms of a blockade of enhanced memory for oddball stimuli (the von Restorff effect; von Restorff, 1933), because propranolol did not abolish enhanced recall for perceptual oddballs (Fig. 2b). Likewise, patient A.M. demonstrates a normal von Restorff effect for perceptual oddballs (Fig. 3a), suggesting that the amygdala does not enhance memory for oddball stimuli. One account of the patient and propranolol data is that amygdala damage impairs attentional orienting to emotional stimuli, as previously demonstrated (Anderson and Phelps, 2001), and that failure of attentional orienting is a component process in the abolition of enhanced emotional memory in the patient and in the propranolol-treated group. It is unlikely that this is the case in the propranolol group, because there is no difference in reaction times to emotional nouns in the placebo vs. drug group. Given that skin conductance responses are preserved in patients with amygdala damage (Tranel and Damasio, 1989), it is unlikely that emotional memory effects in patient A.M. are due to a blunting of arousal to emotional nouns.

In Exp. 2, the effects of propranolol spanned both encoding and free recall. We cannot rule out the possibility that drug effects or the effects of amygdala lesions operate during retrieval rather than encoding or consolidation stages of memory. However, behavioral data indicate that the effects of propranolol on emotional memory are expressed primarily at encoding (Cahill and McGaugh, 1998; Cahill et al., 1994; van Stegeren et al., 2002). Furthermore, functional neuroimaging data demonstrate that amygdala activation at encoding correlates with subsequent memory for emotional stimuli (Cahill et al., 1996; Hamann et al., 1999; Canli et al., 2000), albeit at longer retention intervals. In light of evidence that adrenergic modulation of emotional memory is amygdala dependent (Cahill and McGaugh, 1998), these data support an interpretation that the effects of amygdala lesions and propranolol on emotional memory occur at encoding. Our series of experiments demonstrate that emotion-evoked $\beta$-adrenergic activity disrupts the encoding of items immediately preceding an emotional event. This emotion-induced memory impairment spans at least $6 \mathrm{~s}$, or two stimuli, and is more pronounced in women than men. In line with previous observations (Cahill et al,, 1994, 1995; Phelps et al., 1998), enhanced memory for emotional stimuli is $\beta$ adrenergic-dependent and abolished by bilateral amygdala lesions. We now demonstrate that amygdala lesions also abolish emotion-induced memory decrements. Thus, enhanced recall and enhanced forgetting associated with emotional stimuli are amygdala dependent, with both effects strongly influenced by $\beta$-adrenergic modulation.

Anderson AK, Phelps EA (2001) Lesions of the human amygdala impair enhanced perception of emotionally salient events. Nature 411:305-309.

Angelini R, Capozzoli F, Lepore P, Grossi D, Orsini A (1994) "Experimental amnesia" induced by emotional items. Percept Mot Skills 78:19-28. 
Adolphs R, Denburg NL, Tranel D (2001) The amygdala's role in long-term declarative memory for gist and detail. Behav Neurosci 115:983-992.

Cahill L, McGaugh JL (1998) Mechanisms of emotional arousal and lasting declarative memory. Trends Neurosci 21:294-299.

Cahill L, Alkire MT (2003) Epinephrine enhancement of human memory consolidation: interaction with arousal at encoding. Neurobiol Learn Mem 9:194-198.

Cahill L, van Stegeren A (2003) Sex-related impairment of memory for emotional events with beta-adrenergic blockade. Neurobiol Learn Mem 79:81-88.

Cahill L, Prins B, Weber M, McGaugh JL (1994) Beta-adrenergic activation and memory for emotional events. Nature 371:702-704.

Cahill L, Babinsky R, Markowitsch HJ, McGaugh JL (1995) The amygdala and emotional memory. Nature 377:295-296.

Cahill L, Haier RJ, Fallon J, Alkire MT, Tang C, Keator D, Wu J, McGaugh JL (1996) Amygdala activity at encoding correlated with long-term, free recall of emotional information. Proc Natl Acad Sci USA 93:80168021.

Cahill L, Haier RJ, White NS, Fallon J, Kilpatrick L, Lawrence C, Potkin SG, Alkire MT (2001) Sex-related difference in amygdala activity during emotionally influenced memory storage. Neurobiol Learn Mem 75:19.

Canli T, Zhao Z, Brewer J, Gabrieli JD. Cahill L (2000) Event-Related Activation in the Human Amygdata Associates with Later Memory for Individual Emotional Experience. J Neurosci 20:RC99.

Canli T, Desmond JE, Zhao Z, Gabrieli JD (2002) Sex differences in the neural basis of emotional memories. Proc Natl Acad Sci USA 99:10789-10794.

Craik FIM, Lockhart RS (1972) Levels of porcessing - framework for memory research. J Verbal Leam Verbal Behav 11:671-684.

Christianson S $\AA$ (1992) in The Handbook of Emotion and Memory: Research and Theory, ed. Christianson SA (Erlbaum, Mahwah, NJ) 307-340.

Christianson SA, Nilsson LG (1984) Functional amnesia as induced by a psychological trauma. Mem Cognit $12: 142-155$.

Fujita F, Diener E, Sandvik E (1991) Gender differences in negative affect and well-being: the case for emotional intensity. J Pers Soc Psychol 61:427-434.

Hamann SB, Ely TD, Grafton ST, Kilts CD (1999) Amygdala activity related to enhanced memory for pleasant and aversive stimuli. Nat Neurosci 2:289-293.

Heuer F, Reisberg D (1992) in The Handbook of Emotion and Memory: Research and Theory. ed Christianson SA (Erlbaum, Mahwah, NJ) 151-180.

Holmes DS (1970) Differential change in affective intensity and the forgetting of unpleasant personal experiences. J Pers Soc Psychol 15:234-239.

Liang KC, McGaugh JL, Yao HY (1990) Involvement of amygdala pathways in the influence of post-training intra-amygdala norepinephrine and peripheral epinephrine on memory storage. Brain Res 508:225-233.

Loftus EF, Burns TE (1982) Mental shock can produce retrograde amnesia. Mem Cognit 10:318-323.

McGaugh JL, McIntyre CK, Power AE (2002) Amygdala modulation of memory consolidation: interaction with other brain systems. Neurobiol Leam Mem 78:539-552.

Phelps EA, LaBar KS, Anderson AK, O'Connor KJ, Fulbright RK, Spencer DD (1998) Specifying the contributions of the human amygdala to emotional memory: A case study. Neurocase 4:527-540.

Seidlitz L, Diener E (1998) Sex differences in the recall of affective experiences.J Pers Soc Psychol 74:262-271.

Sternberg DB, Gold PE (1981) Retrograde amnesia produced by electrical stimulation of the amygdala: attenuation with adrenergic antagonists. Brain Res 211:59-65.

Strange BA, Henson RN, Friston KJ, Dolan RJ.(2000) Brain mechanisms for detecting perceptual, semantic, and emotional deviance. NeuroImage 12:425-433.

Tranel D, Damasio H (1989) Intact electrodermal skin conductance responses after bilateral amygdala damage. Neuropsychologia. 27:381-390.

Tulving E (1969) Retrograde Amnesia in Free Recall Science 164:88-90.

van Stegeren AH, Everaerd W, Cahill L, McGaugh JL, Gooren LJ (1998) Memory for emotional events: differential effects of centrally versus peripherally acting beta-blocking agents. Psychopharmacology 138:305-310.

van Stegeren AH, Everaerd W, Gooren LJ (2002) The effect of beta-adrenergic blockade after encoding on memory of an emotional event. Psychopharmacology 163:202-212.

Von Restorff H (1933) Ueber die Wirkungen von Bereichsbildung im Spurenfeld. Psychologische Forschung 18:299-342. 
R. Hurlemann . The Costs and Benefits of Emotional Memory Formation

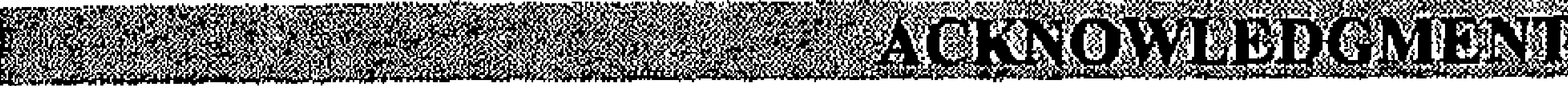

The authors thank P. Patsalos and A. Richardson for storing blood samples, E. Duzel for organizing patient access, U. Wachowius for neuropsychology reporting, and P. Rosthien and U. Noppeney for assistance with Exp. 3. Diagnosis of Urbach-Wiethe disease in A.M. was made by H. Reich. This work was supported by a program grant from the Wellcome Trust (to R.J.D.)

Strange BA, Hurlemann R, Dolan RJ (2003) An emotion-induced retrograde amnesia in humans is amygdala- and beta-adrenergic-dependent. Proceedings of the National Academy of Sciences of the United States of America 100:13626-13631. (Article reproduced with permission of the copyright owner. Further reproduction prohibited without permission.) 


\section{CHAPTER 3}

\section{Noradrenergic modulation of emotion-induced forgetting and remembering}

W.

We used a free recall paradigm to establish a behavioral index of emotion's retrograde and anterograde interference with episodic memory encoding. In two related experiments involving seventy-eight subjects, we show that negatively valenced items elicit retrograde amnesia, while positively valenced items induce retrograde hypermnesia. These data indicate that item valence is critical in determining retrograde amnesia or retrograde hypermnesia. By contrast, we show that item arousal determines the strength of an anterograde amnesic effect, suggesting that arousal-dependent attentional capture compromises episodic encoding. Randomized double-blind administration of the $\beta$-adrenoceptor antagonist propranolol compared to the selective norepinephrine (NE) reuptake-inhibitor reboxetine, and placebo, demonstrated that the magnitude of emotional amnesia and hypermnesia can be up- and down-regulated as a function of emotional arousal and NE signaling. Hence, differential computation of emotional arousal and valence could be part of the design that the brain uses to organize forgetting and remembering.

Emotionality is often characterized along quantitative and qualitative dimensions: arousal (intensity) and valence (negative vs. positive) (Bradley and Lang, 2000). Within the perceptual domains of human gustation (Small et al., 2003) and olfaction (Anderson et al,, 2003), dissociable neural substrates of these dimensions have been identified, with the amygdala coding for intensity and the orbitofrontal cortex responding to valence. Accumulating evidence suggests a similar neural segregation within episodic memory (Dolcos et al., 2004b; Kensinger, 2004; Kensinger and Corkin, 2004).

The initial stage of episodic memory formation is the encoding of novel stimuli (Tulving et al., 1996). Critical effects of emotional arousal on encoding efficiency relate to amygdala's biasing of sensory processing and selective attention (Dolan, 2002), thus prioritizing encoding of emotionally arousing events (Phelps, 2004). Key among the neurochemical factors mediating amygdala's enhancement of episodic encoding during emotional arousal is the NE system (Strange et al,, 2003; Strange and Dolan, 2004; van Stegeren et al., 2005). Pharmacological manipulations that stimulate the NE response to emotional arousal, e.g., by application of reboxetine (Harmer et al., 2003; 2004; but see Papps et al., 2002) or the $\alpha-2$ adrenergic antagonist yohimbine (O'Carroll et al., 1999a; Southwick et al., 2002), support the hypothesis of facilitated episodic memory formation by elevated NE 
signaling (but see Murchison et al., 2004). By contrast, propranolol compromises the memory benefit for emotionally arousing events (Cahill et al., 1994; van Stegeren et al., 2005; but see O'Carroll et al., 1999b) as does amygdala damage (Cahill, 1995). Peripheral $\beta$-adrenergic blockade has no such effect (van Stegeren et al., 1998).

While abundant evidence links emotional arousal to episodic memory enhancement, its retrograde and anterograde amnesic potential (Tulving, 1969; Loftus and Burns, 1982; Angelini et al., 1996) has attracted less attention from neurobiology. Into this void came a report by Strange et al. (2003) who showed that enhanced recall of aversive nouns is coupled to enhanced forgetting of preceding neutral nouns, with both effects eliminated by propranolol. This blockade was equivalent to that observed after bilateral amygdala damage in Urbach-Wiethe disease, implicating the amygdala, and NE input from locus coeruleus (Berridge and Waterhouse, 2003), as critical targets for propranolol's action.

Given that episodic memory formation is fragile and susceptible to disruption by emotion (Strange et al., 2003), the focus of the present study was to elucidate the impact of arousal and valence on emotion's retrograde $\left(E_{x}-\right)$ and anterograde $\left(E_{x}+\right)$ modulation of episodic encoding. The rationale was to devise a free recall paradigm, in which enhanced memory for an oddball stimulus embedded in a homogeneous sequence of neutral standard stimuli (i.e. the von Restorff phenomenon: Von Restorff, 1933; Wallace, 1965) should interfere with encoding of both preceding and following stimuli, particularly if the oddball was emotional. Subjects were instructed to encode 8 stimuli from 36 von Restorff sequences, each followed by an arithmetic distracter task and an episodic memory free recall test. In a purely behavioral experiment (Exp. 1), we first established an index of $E_{x}-$ and $E_{x}+$ effects. In a related psychopharmacological placebo-controlled experiment (Exp. 2), we modulated the NE response by propranolol administration and compared its effects with reboxetine. Our prediction was that emotion's interference with episodic memory formation is regulated by both valence and arousal.

\section{Subjects}

Seventy-eight right-handed volunteers (39 men and 39 women) provided written informed consent to the study, which was approved by the local ethics committee and the Federal Institute for Drugs and Medical Devices (Bonn, Germany). Subjects were determined to be free of either current or past DSM-IV axis I disorder. They had no current physical illness and had not been on medication for $\geq 3$ months. The premenstrual week was avoided for testing female volunteers. Psychological screening prior to study enrollment included the Rey-Osterrieth complex figure test, a vocabulary lexical decision task, and a letter cancellation task which showed normal to above-normal performance (data not shown).

\section{Stimuli}

The paradigm featured 2 categories of stimuli, oddball and standard stimuli, that both consisted of a picture item and a verbal descriptor (semantically identical noun with 3-7 letters; presented in Arial font) to standardize stimulus verbalization at retrieval. Standard stimuli included picture items selected from a set of homogeneous black and white line drawings depicting living and non-living entities (Snodgrass and Vanderwart, 1980; 
Cycowicz et al., 1997). Oddball stimuli included picture items selected from the International Affective Picture System (IAPS; Lang et al., 1997) based on their standard normative scores for emotional arousal and valence as well as additional ratings from 12 independent judges (6 female; age range, $21.7-26.3 \mathrm{yr}$; mean age $23.4 \pm 1.6 \mathrm{yr})$ on a 9-point scale for arousal $(1=$ calm, $9=$ excited $)$, valence $(1=$ negative, $9=$ positive $)$ and semantic congruency of the picture and verbal component $(1=$ lowest, $9=$ highest $)$. To equate the emotional and neutral oddballs for visual complexity and content (e.g., human presence) (Yamasaki et al., 2002), the IAPS pictures were supplemented with neutral pictures from other sources.

Of 36 oddballs presented, 12 were perceptual-neutral $(\mathrm{P})$, and 24 were perceptualemotional $\left(E_{x} P\right)$, including 12 positive $\left(E_{\text {pos }} P\right)$ and 12 negative $\left(E_{n e g} P\right)$ oddballs. The arousal and valence scores (mean $\pm \mathrm{SD}$ ) were as follows: $\mathrm{E}_{\mathrm{pos}} \mathrm{P}$ oddballs $(5.08 \pm 0.52,7.92 \pm 0.79$ ); $\mathrm{E}_{\text {neg }} \mathrm{P}$ oddballs $(5.33 \pm 0.65,2.33 \pm 0.49) ; \mathrm{P}$ oddballs $(2.92 \pm 0.67,5.25 \pm 0.75)$. Only those stimuli were implemented, which yielded high semantic congruency (range, 8-9; mean, 8.44). Thus, $E_{\text {pos }} P$ and $E_{\text {neg }} P$ oddballs differed from each other in terms of valence, but were equally arousing. $E_{x} P$ oddballs differed from $P$ oddballs in terms of valence and arousal. This was confirmed by one-factor within-subjects analyses of variance (ANOVAs), yielding significant effects of arousal $\left(F_{(2,33)}=87.214 ; p<.0001\right)$ and valence $\left(F_{(2,33)}=216.977 ; p<.0001\right)$. Post hoc two-tailed one-sample $t$ tests demonstrated significant differences between (i) the arousal scores for $\mathrm{E}_{\mathrm{x}} \mathrm{P}$ and $\mathrm{P}$ oddballs $(p$ values $<.05)$, but not for $\mathrm{E}_{\mathrm{pos}} \mathrm{P}$ and $\mathrm{E}_{\text {neg }} \mathrm{P}$ oddballs $(p>.05)$, and (ii) the valence scores of the 3 oddball types ( $p$ values $<.05$ ). Hence, arousal-related interference with episodic encoding should be equally induced by $\mathrm{E}_{\mathrm{pos}} \mathrm{P}$ and $\mathrm{E}_{\mathrm{neg}} \mathrm{P}$ oddballs, while differences between them should reflect valence-related interference alone.

To control for interstimulus association (cohesion), the pool of 288 stimuli was divided into 18 semantic categories (e.g., 'traffic') of 16 stimuli each; 36 pseudorandom sequences composed of 8 semantically different stimuli were created, such that each sequence contained 7 standard stimuli and 1 oddball stimulus inserted on list position 3, 4, 5 or 6 to produce the von Restorff effect (von Restorff, 1933; Wallace, 1965). Serial position of oddball stimuli was balanced in order to reduce primacy and recency effects (i.e. the enhanced probability for the first few and the last few stimuli of a sequence to be recalled better) (e.g., Capitani et al., 1992). The restriction to 8 items per input sequence proved effective in balancing out lower recall of $\mathrm{P}$ oddballs and higher recall of $\mathrm{E}_{\mathrm{x}} \mathrm{P}$ oddballs measured in lists of 12 or more items (pilot data, not shown). This equation of von Restorff distinctiveness across oddball types allowed us to isolate, and quantify, the emotional portion of modulatory effects on recall of items neighbouring oddball presentation.

\section{Experiment 1}

Twenty-four subjects (12 female; age range, $21.3-28.2 \mathrm{yr}$; mean age $24.6 \pm 1.9 \mathrm{yr}$ ) viewed stimuli presented sequentially at a rate of 1 every $5 \mathrm{~s}$ (stimulus duration, $2 \mathrm{~s}$; followed by a $3 \mathrm{~s}$ fixation cross) in the center of a 17" flat screen. During each of 3 runs (duration, 20 min; 3 min breaks between runs), volunteers were presented with 12 input sequences (4 sequences per oddball type, randomly assigned), introduced by presentation of the words 'New Sequence', Subjects engaged in a deep encoding task (dichotomous 'natural vs. artificial' judgment for each stimulus, indicated by push-button response). This was immediately followed by an arithmetic distracter task, announced by a triple-digit number (e.g., ' 173 ') presented for $30 \mathrm{~s}$ from which subjects were required to count back serially in sevens. Such interpolation of a filled delay between study and testing has been shown to eliminate recency and rehearsal effects in free recall (e.g., Capitani et al., 1992). Retrieval performance was subsequently tested by free recall. The words 'Please Remember' occurred 
R. Hurlemann - The Costs and Benefits of Emotional Memory Formation

for $30 \mathrm{~s}$, requesting subjects to spontaneously recall as many pictures, using their verbal descriptors, as they could from the just-seen input list before continuing with the next input list. Fig. $1 A$ illustrates the experimental timeline. The recorded free recall profiles were pooled according to the 3 oddball types, consequently yielding a positive $\left(E_{p o s} P\right)$, negative $\left(E_{n e g} P\right)$, and neutral (control) $(P)$ condition. As outcome parameter, memory performance was determined for each condition by calculating the percentage of correct recall (i.e. the output / input ratio) for the following 5 list positions; oddball; oddball \pm 1 ; oddball \pm 2 . Additionally, a sequence index (SI) based on the 7 non-oddball list positions was calculated for each condition (e.g., $\mathrm{Si}_{\mathrm{p}}$ ). Contrasting the emotional conditions with the neutral condition (according to $E_{\mathrm{x}} P-P=E_{\mathrm{x}}$ ) allowed us to extract, and quantify, $\mathrm{E}_{\mathrm{x}}-$ and $\mathrm{E}_{\mathrm{x}}+$ effects produced by positive $\left(E_{\mathrm{pos}}\right)$ and negative $\left(E_{\mathrm{neg}}\right)$ emotion in a maximum time window of 2 adjacent standard events $\left(E_{\mathrm{x}} \pm 1\right.$ and $E_{\mathrm{x}} \pm 2$ ) or \pm 5 and $\pm 10 \mathrm{~s}$ (Fig. $1 B$ ).

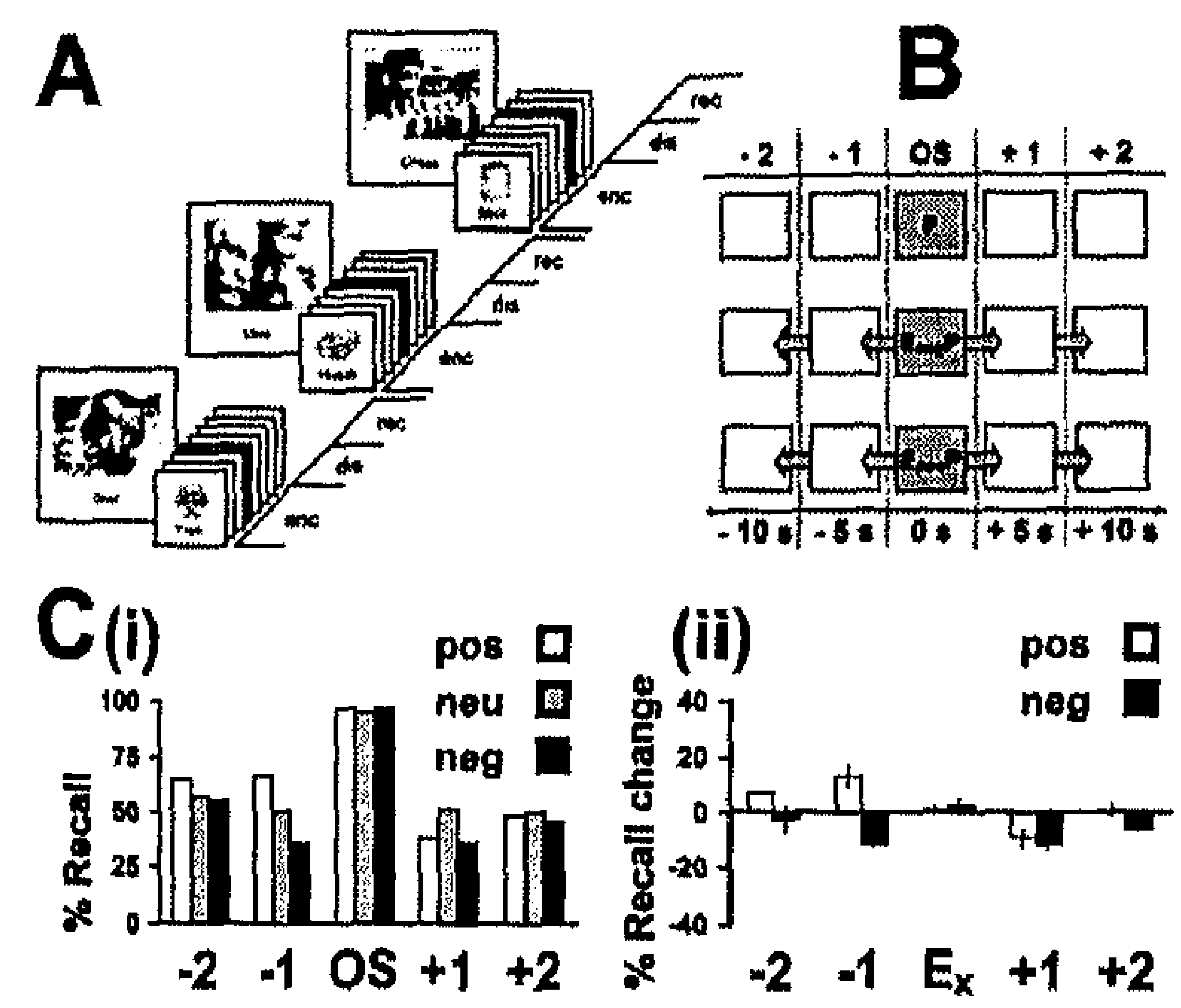

Fig. 1. $A$, Experimental timeline. Subjects were instructed to encode 8 stimuli from 36 input lists (enc, $40 \mathrm{~s}$ ), each followed by a distracter task (dis, $30 \mathrm{~s}$ ) and a free recall test to probe episodic memory (rec, $30 \mathrm{~s}$ ). $B$, Experimental design. In each input list, 1 oddball stimulus (OS), either emotionally salient $\left(\mathrm{E}_{\mathrm{x}} \mathrm{P}\right.$ : positive, $\mathrm{E}_{\mathrm{pos}} \mathrm{P}$; negative, $\mathrm{E}_{\text {neg }} \mathrm{P}$ ) or neutral $(\mathrm{P})$, was interspersed on position $3,4,5$ or 6 , such that it was temporally flanked by $\geq$ 2 standard stimuli. Results from list recall were pooled, thus yielding a positive (pos), negative (neg), and neutral (neu) condition. Contrasting the emotionally loaded conditions with the neutral condition (according to $E_{x} P-P=$ $E_{x}$ ) allowed to extract retrograde $\left(E_{x^{*}}\right)$ and anterograde $\left(E_{x}+\right)$ effects of positive and negative emotion on episodic memory within a time window of $\mathrm{E}_{\mathrm{x}} \pm 2$ stimuli or $\pm 10 \mathrm{~s} . \mathrm{Ci}$, Percentage (\%) recall in Exp. $1(\mathrm{n}=24)$. Equal (near-ceiling) von Restorff effects were obtained for emotional and neutral oddballs (OS). By contrast, memory for preceding $\left(\mathrm{E}_{\mathrm{x}}-1\right)$, but not for following $\left(\mathrm{E}_{\mathrm{x}}+1\right)$ items depended on OS valence. Cii, Recall change $(\%)$ relative to the neutral condition. While negative emotion $\left(\mathrm{E}_{\mathrm{neg}}\right)$ elicited $\mathrm{E}_{\text {neg }}-1$ retrograde amnesia $(-11.46 \%)$, positive emotion ( $\mathrm{E}_{\text {pos }}$ ) evoked $\mathrm{E}_{\text {pos }}-1$ retrograde hypermnesia $(+12.85 \%)$. An $\mathrm{E}_{\mathbf{x}}+1$ amnesic effect followed both $\mathrm{E}_{\text {neg }}(-11.81 \%)$ and $\mathrm{E}_{\text {pos }}(-9.38 \%)$.

\section{Experiment 2}

Fifty-four subjects (27 female; age range, $20.6-29.5 \mathrm{yr}$; mean age $26.2 \pm 2.2 \mathrm{yr}$ ) were randomly allocated to double-blind intervention with one of the 3 following single-dose oral applications: lactose placebo, $40 \mathrm{mg}$ of the $\beta$-adrenoceptor antagonist propranolol hydrochloride, or $4 \mathrm{mg}$ of the selective NE reuptake-inhibitor reboxetine mesilate. Drug allocation was balanced for gender, i.e. 9 males and 9 females were randomly assigned to each group $(n=18)$. In view of the different kinetics (time to peak plasma concentration, propranolol, 1-2 hr; elimination half-life, 3-4 hr; reboxetine, $2 \mathrm{hr}$ and $13 \mathrm{hr}$, respectively), 
the memory task started 90 min (propranolol group and half of the placebo group, sample A) and $120 \mathrm{~min}$ (reboxetine group and the other half of the placebo group, sample B) after drug administration. Blood pressure and pulse frequency were measured immediately before and after application according to the following timelines: Sample A, $-90,-60,-30,0,20,43$, and $66 \mathrm{~min}$; sample B, $-120,-90,-60,-30,0,20,43$, and $66 \mathrm{~min}$. The recall task (identical to Exp. 1) started at $\mathrm{t}=0 \mathrm{~min}$ and finished at $\mathrm{t}=66 \mathrm{~min}$. At $\mathrm{t}=70 \mathrm{~min}$, a venous blood sample was taken to determine drug plasma concentrations. At $t=80 \mathrm{~min}$, subjects performed valence and arousal ratings for each oddball stimulus to assess potential drug effects on emotional experience. Note that the experimenter was blinded for both type and start of pharmacological treatment. Outcome parameters (identical to Exp. 1) were calculated group-wise for statistical analysis. In a first step, data obtained from Exp. 1 were compared to the placebo group data to verify that $\mathrm{E}_{\mathrm{x}}$ - and $\mathrm{E}_{\mathrm{x}}+$ effects were present and not affected by placebo administration or other procedural differences. In a second step, the emotional conditions of the propranolol group and the reboxetine group, respectively, were contrasted with the placebo neutral condition (neutral baseline) in order to qualify drug-related changes of $\mathrm{E}_{\mathrm{x}}$ - and $\mathrm{E}_{\mathrm{x}}+$ effects.

Drug plasma levels were analyzed by high-performance liquid chromatography (HPLC). Propranolol plasma samples were extracted with dichlormethane at ph 9. After evaporation, $100 \mu \mathrm{l}$ mobile phase was added to the residue and injected on a LichroCart 2504, RP-8, $5 \mu \mathrm{m}$ column (Merck, Darmstadt, Germany). The analyte was isocratically eluted with acetonitrile-potassium phosphate buffer $(50 / 50 ; \mathrm{v} / \mathrm{v})$ as mobile phase. Propranolol was detected by ultraviolet (UV) absorption at $210 \mathrm{~nm}$. The absolute extraction recovery was $>$ $85 \%$. Reboxetine plasma samples first underwent solid phase extraction as described by Frahnert et al. (2003). Chromatographic separation of reboxetine was achieved on a Nucleosil 100-Protect 1 column (Macherey-Nagel, Dueren, Germany) with acetonitrile-potassium phosphate buffer $(40 / 60 ; \mathrm{v} / \mathrm{v})$ as mobile phase. Reboxetine was detected by ultraviolet (UV) absorption at $230 \mathrm{~nm}$. The absolute extraction recovery was $>95 \%$.

\section{Statistics}

Recall parameters $\left(E_{x}, E_{x} \pm 1, E_{x} \pm 2, S_{x}\right)$ of the emotional (positive, negative) conditions were analyzed in relation to the corresponding recall parameters $(P, P \pm 1, P \pm 2$, $\mathrm{SI}_{\mathrm{P}}$ ) of the neutral (control) condition. Two-factor within-subjects and three-factor mixed ANOVAs were followed by two-tailed one-sample and two-sample $t$ tests to determine the source of significance. Greenhouse-Geisser correction for inhomogeneity of variance was applied whenever the spericity assumption was violated. To account for an inflation of the type I error rate due to multiple testing, the threshold for significance was Bonferroniadjusted. Data analysis was organized hierarchically, such that a main analysis (restricted to oddball and oddball \pm 1 positions) served to test for $E_{x}$ and $E_{x} \pm 1$ effects; if $E_{x} \pm 1$ retrograde or anterograde effects occured, we extended the analysis to oddball \pm 2 positions. Only significant results of this secondary analysis are reported.

\section{Experiment 1}

The primary goal of Exp. 1 was to determine emotion-induced effects on recall of $E_{x} \pm$ 1 stimuli (Fig. $1 B$ ). The percentage (\%) of mean recall $( \pm \mathrm{SD})$ collapsed across conditions was 95.37 (6.84) for oddball stimuli and 57.59 (10.09) for standard stimuli, demonstrating a 
near-ceiling von Restorff effect (one-sample $t$ test: $t_{(71)}=36.579 ; p<.0001$ ) (Fig. 1Ci). A condition (positive, negative, neutral) $x$ position (oddball, oddball \pm 1 ) $3 \times 3$ ANOVA yielded significant condition $\left(F_{(2,46)}=14.010 ; p<.0001\right)$, position $\left(F_{(1.6,36.2)}=342.070 ; p<.0001\right)$, and condition $\mathrm{x}$ position interaction $\left(F_{(4,92)}=16.150 ; p<.0001\right)$ effects. Post hoc one-sample $t$ tests demonstrated that $E_{n e g}-1$ events were recalled less well $(-11.46 \%)$ than P-1 events $\left(t_{(23)}=\right.$ $-3.058 ; p=.006)$, while $\mathrm{E}_{\mathrm{pos}}-1$ events were recalled better $(+12.85 \%)$ than $\mathrm{P}-1$ events $\left(t_{(23)}=\right.$ $4.270 ; p<.0001)$. In addition, an $\mathrm{E}_{\mathrm{neg}}+1$ decrement of $-11.81 \%\left(t_{(23)}=-3.593 ; p=.002\right)$ and an $\mathrm{E}_{\mathrm{pos}}+1$ decrement of $-9.38 \%\left(t_{(23)}=-3.452 ; p=.002\right)$ were observed (Fig. 1 Cii). There was no influence of condition on oddball recall ( $p$ values $>.05$ ), confirming the presence of equal von Restorff effects across conditions. Thus, positive and negative emotion produced dissociable $E_{x}-1$ effects, implying a differential modulation of $E_{x}-1$ postexposure processing as a function of emotional valence. Fig. $1 C i-i i$ illustrates the results of Exp. 1. An additional gender (male, female) $\times$ emotion (negative, positive) $\times$ position $2 \times 2 \times 3$ ANOVA detected no significant influence of gender $\left(F_{(1,22)}=1.028 ; p>.05\right)$, i.e. the amnesic and hypermnesic effects were equally strong in male and female volunteers. Run $\mathrm{x}$ condition $3 \times 3$ withinsubjects ANOVAs revealed that memory performance for oddballs $\left(F_{(2,142)}=2.298 ; p>.05\right)$ and standard stimuli $\left(F_{(2,142)}=1.062 ; p>.05\right)$ remained unchanged throughout the experiment, i.e. neither practice nor adaptation effects occurred in any condition.

\section{Experiment 2}

\section{II.I Free recall}

The focus of the psychopharmacological experiment was to challenge $E_{x}$ and $E_{x}+$ effects by double-blind placebo-controlled manipulation of emotional arousal using the $\beta$ adrenoceptor antagonist propranolol and the selective norepinephrine (NE) reuptake-inhibitor reboxetine. A procedure (no treatment in Exp. 1, placebo treatment in Exp. 2) $\mathrm{x}$ condition (positive, negative, neutral) $\times$ position (oddball, oddball \pm 1 ) $2 \times 3 \times 3$ ANOVA confirmed that placebo administration per se did not affect recall performance in comparison to Exp. 1 $\left(F_{(1,40)}=0.043 ; p>.05\right)$. A condition $\mathrm{x}$ position $3 \times 3$ ANOVA restricted to the placebo group yielded effects of valence $\left(F_{(2,34)}=14.000 ; p<.0001\right)$ and position $\left(F_{(2,34)}=241.725 ; p<\right.$ $.0001)$, and a significant interaction of these factors $\left(F_{(2.5,41.7)}=12.936 ; p<.0001\right)$. As depicted in Fig. $2 \boldsymbol{A} \boldsymbol{i}$ and $\boldsymbol{B i}$, post hoc one-sample $\boldsymbol{t}$ tests verified the presence of $\mathrm{E}_{\text {neg }}-1$ amnesic $(-14.82 \%)\left(t_{(17)}=-4.531 ; p<.0001\right), \mathrm{E}_{\text {pos }^{-1}}$ hypermnesic $(+15.74 \%)\left(t_{(17)}=3.213 ; p=\right.$ $.005)$ as well as $\mathrm{E}_{\mathrm{neg}}+1(-14.35 \%)\left(t_{(17)}=-3.019 ; p=.008\right)$ and $\mathrm{E}_{\mathrm{pos}}+1(-12.96 \%)\left(t_{(17)}=-\right.$ $3.197 ; p=.005$ ) amnesic effects in the placebo group. Hence, placebo group findings replicated those obtained in Exp. 1 and served as baseline for subsequent comparisons.

A one-way ANOVA with group (placebo, propranolol, reboxetine) as betweensubjects factor showed that SIP scores were unaffected by drug treatment $\left(F_{(2,51)}=0.394 ; p>\right.$ $.05)$, i.e. neither propranolol nor reboxetine administration altered recall performance in the corresponding neutral conditions. Analyzing the influence of propranolol, a group (placebo, propranolol $) \times$ condition $\times$ position $2 \times 3 \times 3$ ANOVA yielded condition $\left(F_{(2,68)}=6.501 ; p=\right.$ $.003)$, position $\left(F_{(2,68)}=428.481 ; p<.0001\right)$, and three-way group $\mathrm{x}$ condition $\mathrm{x}$ position interaction $\left(F_{(2,9,99.6)}=6.288 ; p=.001\right)$ effects. A subsequent $2 \times 2 \times 3$ ANOVA restricted to the emotional factor revealed group $\left(F_{(1,34)}=5.127 ; p=.030\right)$, condition $\left(F_{(1,34)}=10.754 ; p=\right.$ $.002)$, position $\left(F_{(2,68)}=494.071 ; p<.0001\right)$, and three-way interaction $\left(F_{(1.6,52.7)}=7.798 ; p=\right.$ $.002)$ effects. Post hoc two-sample $t$ tests showed that propranolol attenuated the $E_{\text {pos }}-1$ recall increment $\left(t_{(34)}=2.919 ; p=.006\right)$ as it lessened $\mathrm{E}_{\text {neg }}-1\left(t_{(34)}=-3.238 ; p=.003\right), \mathrm{E}_{\text {neg }}+1\left(t_{(34)}=\right.$ $-2.796 ; p=.008)$, and $\mathrm{E}_{\mathrm{pos}}+1\left(t_{(34)}=-2.836 ; p=.008\right)$ recall decrements, such that $\mathrm{E}_{\mathrm{x}} \pm 1$ 
recall equated $\mathrm{P} \pm 1$ recall. No changes in oddball recall were observed ( $p$ values $>.05$ ) (Fig. 2Aii and Bii).

Analyzing the influence of reboxetine, a $2 \times 3 \times 3$ ANOVA yielded group $\left(F_{(1,34)}=\right.$ $4.930 ; p=.033)$, condition $\left(F_{(2,68)}=52.251 ; p<.0001\right)$, position $\left(F_{(2,68)}=481.260 ; p<.0001\right)$, and three-way group $\mathrm{x}$ condition $\mathrm{x}$ position interaction $\left(F_{(3.2,109.3)}=5.226 ; p<.0001\right)$ effects. Post hoc two-sample $t$ tests indicated a significant enhancement of $\mathrm{E}_{\mathrm{x}}$ - and a trend-tosignificant enhancement of $E_{\mathrm{x}}+$ effects relative to the placebo group. The percent (\%) recall changes relative to the placebo emotional baselines (relative to placebo neutral baseline) were as follows: $\mathrm{E}_{\mathrm{neg}}-1,-19.91(-34.72)\left(t_{(34)}=4.690 ; p<.0001\right) ; \mathrm{E}_{\mathrm{pos}}-1,+14.82(+30.56)\left(t_{(34)}=-\right.$ $2.931 ; p=.006) ; \mathrm{E}_{\mathrm{neg}}+1,-12.96(-27.32)\left(t_{(34)}=2.633 ; p=.013\right) ; \mathrm{E}_{\mathrm{pos}}+1,-12.50(-25.46)\left(t_{(34)}\right.$ $=2.715 ; p=.010)$. No changes in oddball recall were present $(p$ values $>.05)$. In light of the robust $E_{x}-1$ effects, further inspection of $E_{x}-2$ recall following a $2 \times 3 \times 5$ ANOVA revealed an $E_{\text {neg }}-2$ recall reduction of $-17.60 \%$ relative to placebo neutral baseline $\left(t_{(34)}=3.269 ; p=\right.$ .002) (Fig. 2Aiii and Biii). This spread of effect is not driven by better memory for $E_{x}-2$ items than for $\mathrm{E}_{\mathrm{x}}-1$ items in the placebo neutral condition (one-sample $t$ test: $t_{(17)}=1.335 ; p>.05$ ). The constraints of our experimental design precluded examination of more enduring $E_{n e g}-$ effects. Comparing $E_{n e g}-1$ recall to $E_{p o s}-1$ recall indicated equal strength of reboxetine-induced elevations of $\mathrm{E}_{\mathrm{x}^{-}}$amnesia and hypermnesia (one-sample $t$ test: $t_{(17)}=.823 ; p>.05$ ). In summary, propranolol administration flattened emotion's retrograde and anterograde effects, whereas NE reuptake-inhibition with reboxetine enhanced retrograde interference more significantly than anterograde interference.

Two ANOVAs with group as between-subjects factor confirmed propranolol effects on systolic $\left(F_{(1,34)}=18.502 ; p<.0001\right)$ and diastolic $\left(F_{(1,30)}=11.368 ; p<.0001\right)$ blood pressure at the start of the cognitive task. Reboxetine had no such effects ( $p$ values $>.05$ ). As illustrated in Fig. $2 \mathrm{Ci}-\mathrm{iii}$, both systolic $\left(t_{(34)}=4.826 ; p<.0001\right)$ and diastolic $\left(t_{(34)}=3.842 ; p\right.$ $=.001$ ) blood pressure were decreased by propranolol (post hoc two-sample $t$ tests). Fig. $2 D$ depicts the plasma concentrations of both propranolol $(20.50 \pm 17.96 \mu \mathrm{g} / \mathrm{l})$ and reboxetine $(75.11 \pm 15.79 \mu \mathrm{g} / \mathrm{l})$ as measured after the recall task.

\section{II.II Oddball ratings}

Fig. 3 illustrates the arousal (Fig. 3A) and valence (Fig. $3 B$ ) scores (mean \pm SD) obtained after memory testing. Placebo treatment: $\mathrm{E}_{\mathrm{pos}} \mathrm{P}$ oddballs $(5.28 \pm 0.67,7.67 \pm 0.77)$; $\mathrm{E}_{\text {neg }} \mathrm{P}$ oddballs $(5.22 \pm 0.73,2.39 \pm 0.50) ; \mathrm{P}$ oddballs $(2.88 \pm 0.68,5.06 \pm 0.73)$. Propranolol treatment: $E_{\text {pos }} P$ oddballs $(4.28 \pm 0.46,7.61 \pm 0.50) ; E_{\text {neg }} P$ oddballs $(4.33 \pm 0.49,2.28 \pm 0.46)$; $\mathrm{P}$ oddballs $(2.78 \pm 0.65,5.00 \pm 0.69)$. Reboxetine treatment: $\mathrm{E}_{\mathrm{pos}} \mathrm{P}$ oddballs $(6.11 \pm 0.58,7.78$ $\pm 0.73) ; E_{\text {neg }} \mathrm{P}$ oddballs $(6.17 \pm 0.52,2.39 \pm 0.61) ; \mathrm{P}$ oddballs $(2.94 \pm 0.87,4.89 \pm 0.68)$. Two separate group $\mathrm{x}$ oddball type $2 \times 3$ ANOVAs were calculated, yielding significant effects of propranolol $\left(F_{(1,34)}=65.964 ; p<.0001\right)$ and reboxetine $\left(F_{(1,34)}=27.508 ; p<.0001\right)$ on arousal scores. In another series of ANOVAs, no group effects on valence scores were found ( $p$ values $>.05$ ). Post hoc two-sample $t$ tests demonstrated significant decreases of arousal scores for emotional oddballs, but not for neutral oddballs, under propranolol: $\mathrm{E}_{\mathrm{pos}} \mathrm{P}$ oddballs $\left(t_{(34)}=5.222 ; p<.0001\right), \mathrm{E}_{\text {neg }} \mathrm{P}$ oddballs $\left(t_{(34)}=4.294 ; p<.0001\right)$, $\mathrm{P}$ oddballs $\left(t_{(34)}=0.504 ; p>\right.$ $0.5)$. By contrast, a significant increase of arousal scores for emotional oddballs, but not for neutral oddballs, was observed under reboxetine: $\mathrm{E}_{\text {pos }} \mathrm{P}$ oddballs $\left(t_{(34)}=-3.984 ; p<.0001\right)$, $\mathrm{E}_{\text {neg }} \mathrm{P}$ oddballs $\left(t_{(34)}=-4.478 ; p<.0001\right)$, $\mathrm{P}$ oddballs $\left(t_{(34)}=-0.213 ; p>0.5\right)$. These results provide substantial evidence for a pharmacological modulation of emotional stimulus evoked arousal, suggesting that propranolol decreased subjects' arousability, whereas reboxetine increased subjects' arousability. 

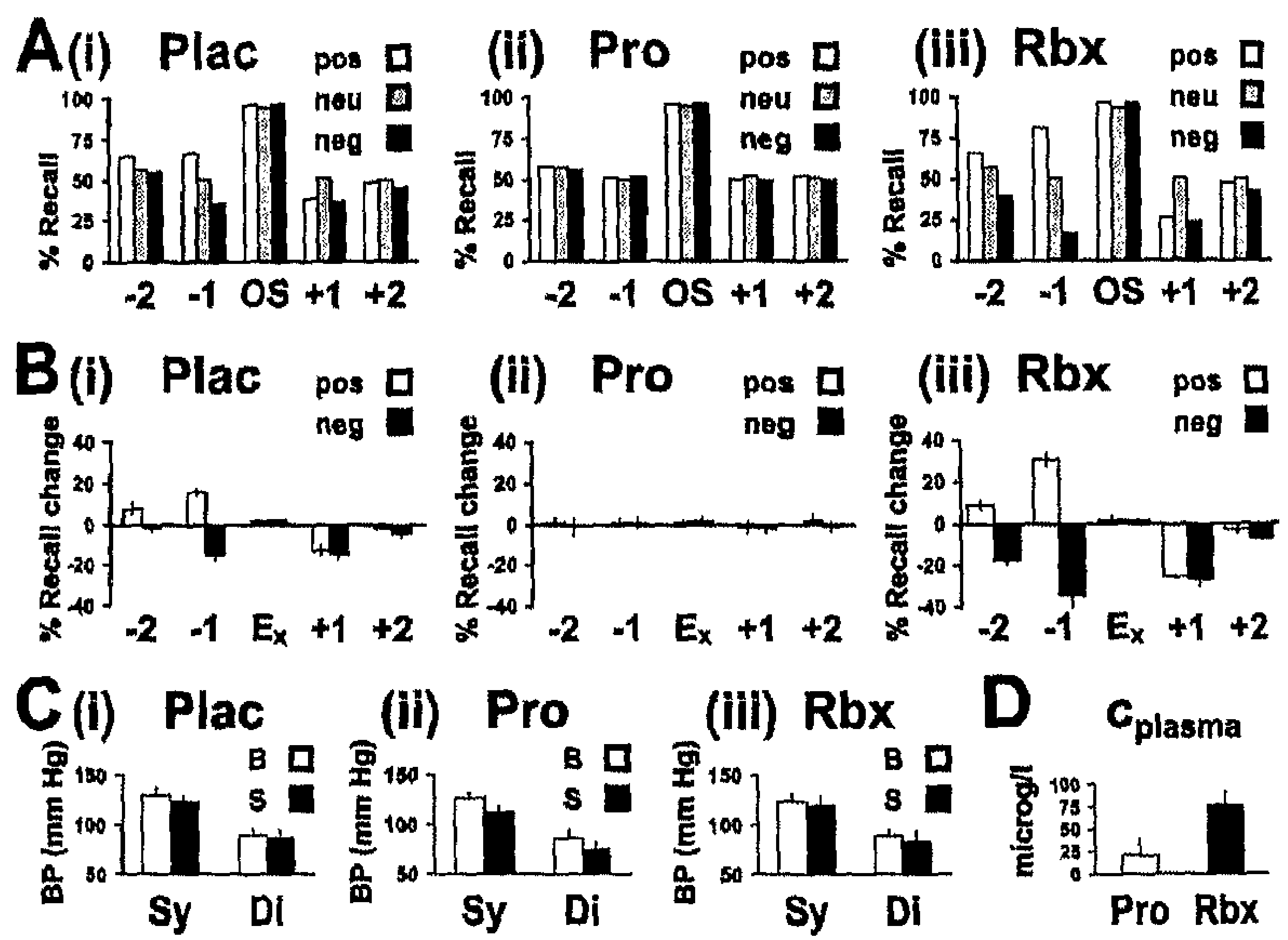

(ii) Pro
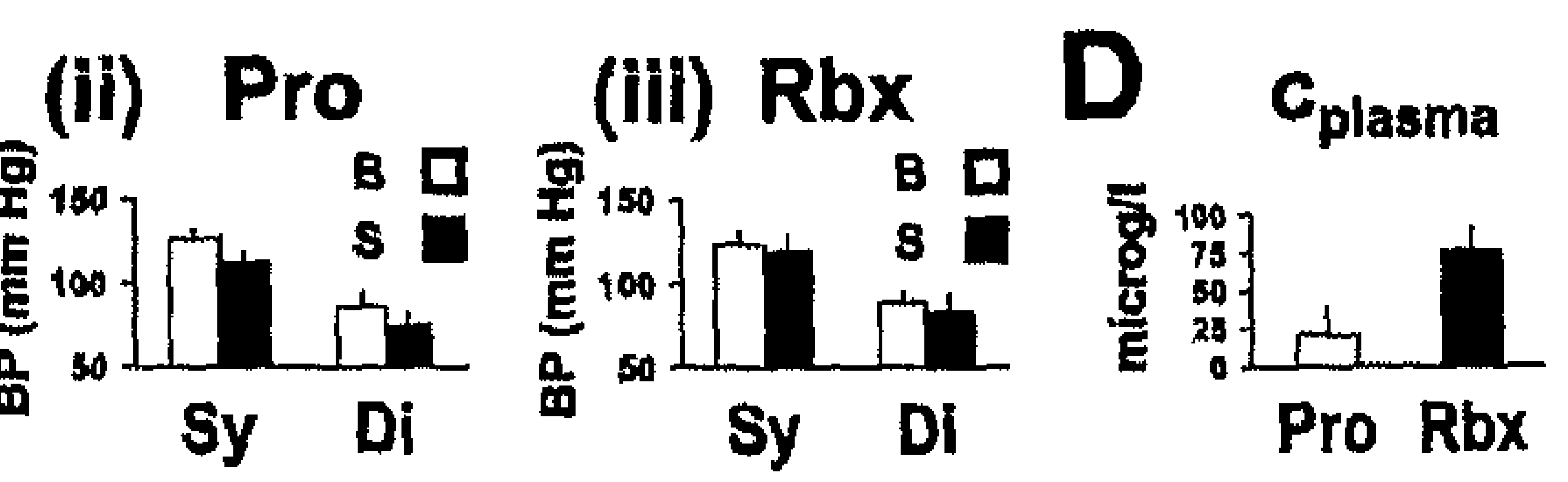

Fig. 2. $A i$, Percentage (\%) recall in Exp. 2, placebo (Plac) group $(\mathrm{n}=18)$. Aii, Percentage (\%) recall in Exp. 2, propranolol $(\mathrm{Pro})$ group $(\mathrm{n}=18)$. Ai, Percentage (\%) recall in Exp. 2, reboxetine $(\mathrm{Rbx})$ group $(\mathrm{n}=18)$. Independent of treatment, equal (near-ceiling) von Restorff effects were present for emotional and neutral oddballs (OS). Note that none of the drugs did affect recall performance in the neutral condition, i.e. drug effects were restricted to the emotional conditions. $B i$, Recall change (\%) relative to placebo neutral baseline. Consistent

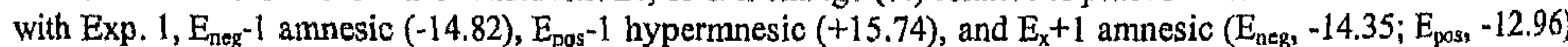
effects were observed. Bii, $\beta$-adrenoceptor blockade with propranolol (Pro; $40 \mathrm{mg}$ oral-dose) eliminated both $\mathrm{E}_{\mathrm{x}}$ and $\mathrm{E}_{\mathrm{x}}+$ effects. Biii, NE-reuptake inhibition with reboxetine (Rbx; $4 \mathrm{mg}$ oral-dose) primarily enhanced $\mathrm{E}_{\mathrm{x}}$ effects, producing a retrograde amnesia of $10 \mathrm{~s}$. The percent (\%) recall changes relative to placebo neutral baseline (relative to corresponding placebo emotional baselines) were: $\mathrm{E}_{\mathrm{neg}}-2,-17.60 ; \mathrm{E}_{\mathrm{neg}}-1,-34.72(-19.91)$; $E_{\text {neg }}+1,-27.32(-12.96) ; E_{\text {pos }}-1,+30.56(+14.82) ; E_{\text {pos }}+1,-25.46(-12.50) . C i-i i i$, Mean systolic (Sy) and diastolic (Di) blood pressure (BP; $\mathrm{mm} \mathrm{Hg}$ ), at the time of drug/placebo administration (B) and at the start of the cognitive task (S). While BP was unaffected by reboxetine, propranolol produced the expected BP decrease. $D$, Propranolol and reboxetine plasma concentrations (microg/l). Abbreviations: $\mathrm{E}_{\mathrm{x}}$, emotion contact; $\mathrm{E}_{\mathrm{x}} \pm 1, \pm 1$ stimulus (or $5 \mathrm{~s}$ ) adjacent to $E_{x} ; E_{x} \pm 2, \pm 2$ stimuli (or 10 s) adjacent to $E_{x}$.

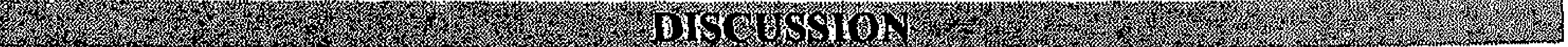

Our data demonstrate distinct functional roles for valence and arousal in emotion's retrograde modulation of episodic memory. The quality of retrograde effects, i.e. $E_{\text {neg }}$-induced extinction vs. $E_{\text {pos }}$-induced facilitation of $E_{x}$ - events, is determined by emotional valence. By contrast, the quantity of retrograde effects, i.e. the magnitude of $E_{x}$ - amnesia and hypermnesia, depends on emotional arousal. By pharmacologically manipulating the NE system, we show that the $\beta$-adrenoceptor antagonist propranolol decreased subjects' arousability and blocked $\mathrm{E}_{\mathrm{x}^{-}}$effects, whereas the selective NE reuptake-inhibitor reboxetine increased subjects' arousability and enhanced $\mathrm{E}_{\mathrm{x}}$ - effects. We did not detect a differential enhancement of memory for oddball stimuli which contrasts with a memory enhancement for emotional oddballs we previously observed (Strange et al., 2003). This lack of enhancement most likely mirrors the use of combined pictorial and verbal stimuli which resulted in near ceiling effects for all three types of oddballs. Additionally, no influence of gender on the size of $E_{x^{-}}$effects was found in this study, possibly reflecting the cost of limiting sensitivity for 
subtle effects by reducing the number of items per input sequence from 15 (Strange et al., 2003) to 8 in the current study.

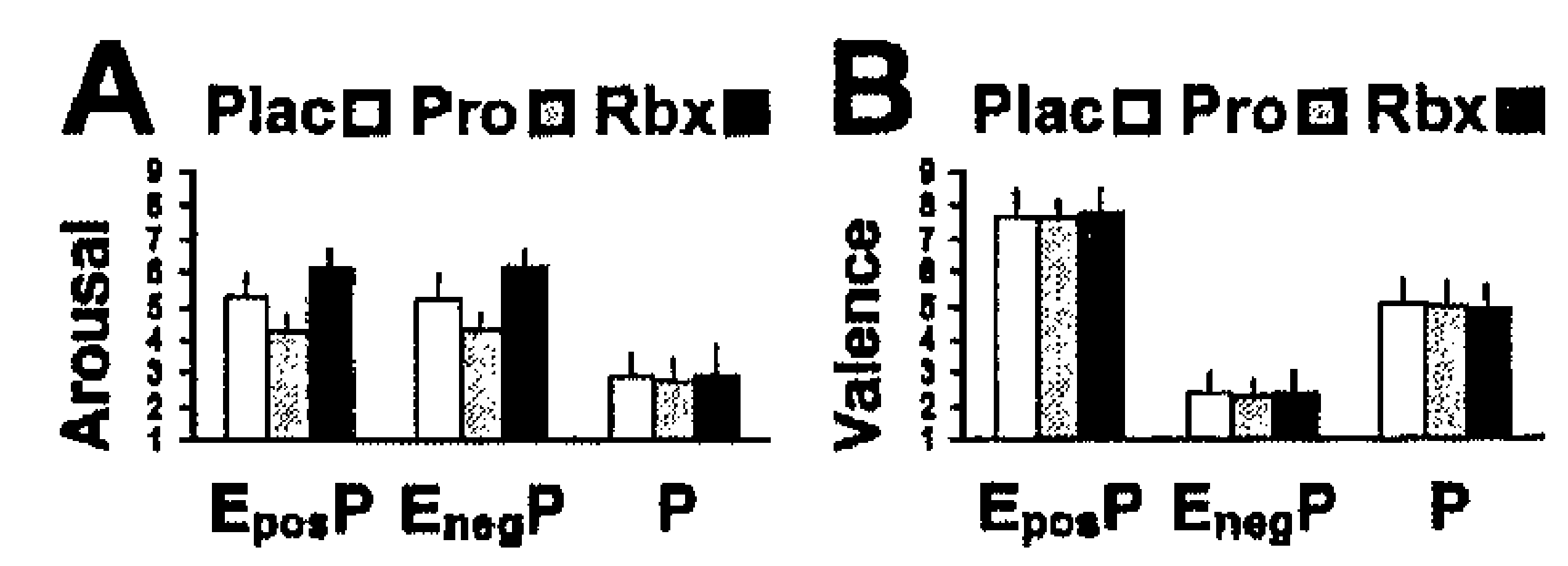

Fig. 3. Drug-related effects on oddball ratings as compared to placebo (Plac). $A$, Arousal judgments. Propranolol (Pro) decreased arousal scores for negative $\left(\mathrm{E}_{\text {neg }} \mathrm{P}\right)$ and positive $\left(\mathrm{E}_{\mathrm{pog}} \mathrm{P}\right)$ oddball stimuli, whereas reboxetine $(\mathrm{Rbx})$ increased $\mathrm{E}_{\mathrm{neg}} \mathrm{P}$ and $\mathrm{E}_{\mathrm{pos}} \mathrm{P}$ arousal scores, thus indicating a noradrenergic modulation of arousability. $B$, Valence judgments. No drug-related effects on valence scores were observed.

In humans, few studies have targeted the hypothesized tole of NE in memory (Gold and van Buskirk, 1978) by challenging the NE system pharmacologically. While yohimbineelicited NE potentiation amplified consolidation and free recall of emotional events (O'Carroll et al., 1999a; Southwick et al., 2002), Papps et al. (2002) detected no effect of prelearning single-dose administrations of $4 \mathrm{mg}$ and $8 \mathrm{mg}$ reboxetine on emotional recall tested after a 7-day interval. By contrast, Harmer et al. (2003) reported that a 4-mg single-dose of reboxetine administered $2 \mathrm{hr}$ before testing enhanced free recall of positive rather than negative stimuli in the absence of changes in non-emotional performance or mood. Reboxetine's bias towards recall of positive stimuli (Harmer et al., 2003; Harmer et al., 2004) conflicts with equal magnitudes of $E_{\text {neg }}$ and $E_{p o s}$-induced retrograde effects in our reboxetine data. This discrepancy is most likely related to differences in test design and stimulus features. We carefully equated positive and negative stimuli for arousal to probe drug performance, accounting for the asymmetrical distribution of arousal between valences (Anderson et al., 2003) and its potential biasing of pharmacological effects. Consistent with Harmer et al. (2003) we observed that single-dose administration of $4 \mathrm{mg}$ reboxetine is effective in modulating free recall of emotional stimuli. We conclude that reboxetine's elevation and propranolol's blockade of retrograde effects observed in this study indicate that

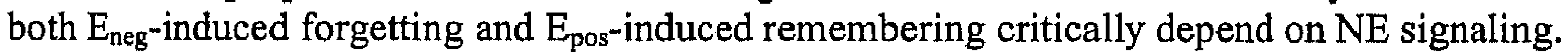

Despite differences in experimental design and stimulus properties, our results are consistent with, and complement our previous findings (Strange et al., 2003). However, amnesia observed in the present study was not restricted to encoding of $E_{x}$ - events, but extended to encoding of $\mathrm{E}_{\mathrm{x}}+$ events, implicating the higher intrinsic arousal of combined pictorial and verbal emotional stimuli compared to verbal items as the principal source of effect. In deed, depending on the arousal level, an $\mathrm{E}_{\mathrm{x}}+1$ anterograde amnesia varied in strength, suggesting that during serial attentive and mnemonic processing, an arousal-induced capture of selective attention irritates attentional re-orienting to and episodic encoding of the following neutral stimulus. This interpretation is motivated by findings using the 'attentional blink' paradigm, referring to a situation where detection of an initial target in a visual stimulus stream induces 'inattentional blindness' for a successive second target (Raymond et al., 1992). While the attentional blink is physiologically attenuated when the second target is emotionally arousing, this attenuation is abolished in patients with amygdala damage (Anderson and Phelps, 2001). Further, patients with amygdala damage do not show the physiological trade-off between memory for emotional gist and non-emotional details of complex visual stimuli (Adolphs et al., 2005). Compatible with Easterbrook's hypothesis 
(1959) and the 'weapon-focus' phenomenon in eyewitness testimony (Loftus, 1979), these patient data highlight amygdala's pivotal role in restricting the attentional and mnemonic focus to an emotionally arousing event, thus leaving less capacity available for processing of competing neutral stimuli.

Intra-amygdalar infusions of NE agonists and antagonists provide compelling evidence that the amygdala is under NE control (McGaugh, 2000). In support of these animal data, amygdala activation at encoding of emotionally arousing stimuli has been reported to depend on amygdala NE (Strange and Dolan, 2004; van Stegeren, 2005). Under placebo conditions, amygdala responses have been shown to increase with emotional stimulus arousal, suggesting that encoding strength varies as a function of amygdala engagement. In view of $\mathrm{NE}$ as a key neurochemical factor in amygdala's modulation of encoding efficiency (Strange et al., 2003; Strange and Dolan, 2004; van Stegeren et al., 2005), reboxetine's (trend-tosignificant) amplification and propranolol's attenuation of $E_{x}+1$ effects supports the idea of a narrowing or broadening of episodic memory access in response to the presence or absence of elevated amygdala NE. Compatible with this interpretation we suggest that anterograde amnesia reflects the cost of devoting attention and encoding resources to preferential processing of emotionally arousing events (Dolan, 2002)

Tulving (1969) conjectured that retrograde amnesia in free recall could arise from premature termination of encoding. An $E_{x}$ - retrograde amnesic effect up to $10 \mathrm{~s}$ duration following NE reuptake inhibition with reboxetine confirms this hypothesis, underpinning the potential of emotional arousal to interfere with episodic encoding. As shown in our previous study (Strange et al., 2003), it is the timing of NE signaling that appears to be critical for triggering retrograde forgetting. Episodic encoding is enhanced for negative stimuli ( $\left.E_{\text {neg }}\right)$ inducing NE release, while it is disrupted if the NE response collides with ongoing encoding of $E_{n e g}-1$ and $E_{n e g}-2$ events. Thus, $E_{n e g}$-induced NE signaling produces opposing effects: Enhanced $\mathrm{E}_{\mathrm{neg}}$ encoding is instantiated at the expense of impaired retrieval of $\mathrm{E}_{\text {neg }}$ - events (for related discussion on glucocorticoids see: de Quervain et al., 1998; Roozendaal et al., 2004), evidencing the vulnerability of episodic encoding to interference with amnesic agents such as negative stressors (for parallel observations in consolidation stages of episodic memory see Diamond et al., 2004). In line with this reasoning, we postulate that $E_{n e g}-$ retrograde amnesia reflects competition of incoming stimuli for rapid access to episodic memory, with emotionally arousing stimuli receiving prioritized processing.

In Exp. 2, the effects of propranolol and reboxetine spanned both encoding and free recall. Thus, we cannot rule out that pharmacological manipulations of the NE system affect retrieval (Murchison et al., 2004) rather than encoding stages of episodic memory. However, substantial evidence links NE release during emotional arousal to amygdala's metacontrol of hippocampal function during encoding. Anatomical studies in rats demonstrate reciprocal amygdalo-hippocampal connections (Pitkanen et al., 2000). Electrical stimulation of the amygdala elicits propranolol sensitive retrograde amnesia (Sternberg and Gold, 1981). Amygdala activation at encoding correlates with subsequent memory for emotionally arousing items (Cahill et al., 1996; Hamann et al., 1999; Canli et al., 2000; Dolcos et al., 2004a; Kensinger and Corkin, 2004). Investigation of patients with amygdalo-hippocampal pathology revealed a reciprocal dependence between amygdala and hippocampus during encoding of emotionally arousing stimuli (Richardson et al., 2004). Such cross-talk at encoding can be blocked by propranolol (Strange and Dolan, 2004), thus abolishing the retrieval advantage of emotional stimuli, despite propranolol being no longer active at retrieval (van Stegeren, 2005). Taken together, these findings are a convincing indicator for amygdala- and NE-dependent modulation of encoding efficiency (McGaugh and Roozendaal, 
2002; Strange et al., 2003), lending credence to the hypothesis that the emotion-induced forgetting and remembering we observed result from variation in encoding-related amygdalohippocampal interactions orchestrated by $\mathrm{NE}$.

Our finding that subjects's arousability varied as a result of drug administration is in contrast to reports of no change of emotional stimulus rating following manipulations of the NE system (e.g., Cahill et al., 1994; van Stegeren et al., 1998, 2005; O'Caroll et al., 1999a, b; Papps et al., 2002). The effects we observed propose a link between the cognitive appraisal of emotional arousal and its physiological response, thus implicating engagement of identical or strongly interconnected brain areas. A logical candidate site is the prefrontal cortex which is reciprocally interconnected with the amygdala (Barbas, 2000) and the locus coeruleus-NE system (Arnsten and Goldman-Rakic, 1984; Arnsten, 1997; Aston-Jones et al., 2000; Berridge and Waterhouse, 2003). Dissociable contributions of arousal and valence to emotion's retrograde effects correspond to a segregation of these dimensions on the neural level (Anderson et al., 2003; Small et al., 2003; Dolcos et al., 2004b; Kensinger, 2004; Kensinger and Corkin, 2004). Compatible with Kensinger and Corkin (2004), we suggest that the quantity of emotion's retrograde effects varies as a function of arousal-driven amygdalohippocampal interplay, while their quality, i.e. the emergence of retrograde amnesia vs. hypermnesia should be related to valence-dependent engagement of prefrontal cortexhippocampal networks (Kensinger and Corkin, 2004). Further support for this interpretation comes from Dolcos et al. (2004b) who identified a valence-specific parcellation of prefrontal cortex. Thus, unlike the evolutionary conserved role of the amygdala in mediating modulatory effects of emotional arousal, it seems that the valence-related malleability, or plasticity, of episodic encoding reflects the more evolved control functions of the prefrontal cortex.

Three conclusions emerge from our observations: First, the neurotransmitter NE modulates episodic encoding independently of emotional valence (for related results on glucocorticoids see: Buchanan and Lovallo, 2001). Consistent with animal data (McGinty and Szymusiak, 1988), arousal-associated NE signaling may thus reflect a change in the intensity rather than valence of emotional events. Second, pre-learning application of drugs selectively interfering with NE neurotransmission allows to up- and down-regulate emotional arousability as well as the magnitude of emotional amnesia and hypermnesia, most likely by modulating encoding-related communication along amygdalo-hippocampal pathways during emotional arousal. Third, compatible with a motivational perspective on emotion (Hamann, 2001; Dolan, 2002; Wise, 2004), emotional valence appears to be critical for retrograde extinction or facilitation of episodic encoding: While enhanced memory for aversive events is coupled to enhanced forgetting of neutral information (Strange et al., 2003) that is no longer relevant for survival and reproductive success, positive emotion promotes retention of information preceding reward contact, enabling 'return to the rewards, and to the cues marking the way to such rewards' (Wise, 2004). Thus, computing the positive and negative value of emotionally arousing information might be part of the design that the brain uses to organize forgetting and remembering.

W.7.6.

Adolphs R, Tranel D, Buchanan TW (2005) Amygdala damage impairs emotional memory for gist but not details of complex stimuli. Nat Neurosci 8:512-518.

Anderson AK, Phelps EA (2001) Lesions of the human amygdala impair enhanced perception of emotionally salient events. Nature 411:305-309. 
Anderson AK, Christoff K, Stappen I, Panitz D, Ghahremani DG, Glover G, Gabrieli JD, Sobel N (2003) Dissociated neural representations of intensity and valence in human olfaction. Nat Neurosci 6:196-202.

Angelini R, Capozzoli F, Lepore P, Grossi D, Orsini A (1994) "Experimental amnesia" induced by emotional items. Percept Mot Skills 78:19-28.

Arnsten AF, Goldman-Rakic P (1984) Selective prefrontal cortical projections to the region of the locus coeruleus and raphe nucleus in the rhesus monkey. Brain Res 306: 9-18.

Arnsten AF (1997) Catecholamine regulation of the prefrontal cortex. J Psychopharmacol 11: 151-162.

Aston-Jones G, Rajkowski J, Cohen J (2000) Locus coeruleus and regulation of behavioral flexibility and attention. Prog Brain Res 126:165-82.

Barbas $\mathrm{H}$ (2000) Connections underlying the synthesis of cognition, memory, and emotion in primate prefrontal cortices. Brain Res Bull 2000 52:319-330.

Berridge CW, Waterhouse BD (2003) The locus coeruleus-noradrenergic system: modulation of behavioral state and state-dependent cognitive processes. Brain Res Brain Res Rev 42:33-84.

Bradley MM, Lang PJ (2000) Measuring emotion: Behavior, feeling, and physiology. In: Cognitive neuroscience of emotion (Lane RD, Nadel L, Eds), pp242-277. New York: Oxford UP.

Buchanan TW, Lovallo WR (2001) Enhanced memory for emotional material following stress-level cortisol treatment in humans. Psychoneuroendoctinology 26:307-317.

Cahill L, Prins B, Weber M, McGaugh JL (1994) Beta-adrenergic activation and memory for emotional events. Nature 371:702-704.

Cahill L, Babinsky R, Markowitsch HJ, McGaugh JL (1995) The amygdala and emotional memory. Nature 377;295-296.

Cahill L, Haier RJ, Fallon J, Alkire MT, Tang C, Keator D, Wu J, McGaugh JL (1996) Amygdala activity at encoding correlated with long-term, free recall of emotional information. Proc Natl Acad Sci USA 93:80168021 .

Canli T, Zhao Z, Brewer J, Gabrieli J, Cahill L (2000) Event-related activation in the human amygdala associates with later memory for individual emotional experience. J Neurosci 20:RC99.

Capitani E, Della Sala S, Logie RH, Spinnler H (1992) Recency, primacy, and memory: reappraising and standardising the serial position curve. Cortex 28:315-342.

Cycowicz YM, Friedman D, Rothstein M, Snodgrass JG (1997) Picture naming by young children: norms for name agreement, familiarity, and visual complexity. J Exp Child Psychol 65:171-237.

de Quervain DJ, Roozendaal B, McGaugh JL (1998) Stress and glucocorticoids impair retrieval of long-term spatial memory. Nature 394:787-790.

Diamond DM, Park CR, Woodson JC (2004) Stress generates emotional memories and retrograde amnesia by inducing an endogenous form of hippocampal LTP. Hippocampus 14:281-291.

Dolan RJ (2002) Emotion, cognition, and behavior. Science 298:1191-1194.

Dolcos F, LaBar KS, Cabeza R (2004a) Interaction between the amygdala and the medial temporal lobe memory system predicts better memory for emotional events. Neuron $42: 855-863$.

Dolcos F, LaBar KS, Cabeza R (2004b) Dissociable effects of arousal and valence on prefrontal activity indexing emotional evaluation and subsequent memory: an event-related fMRI study. Neuroimage 23:64-74.

Easterbrook JA (1959) The effect of emotion on cue utilization and the organization of behavior. Psychol Rev $66: 183-201$.

Frahnert C, Rao ML, Grasmaeder K (2003) Determination of eighteen antidepressants, four antipsychotics and active metabolites in serum by liquid chromatography: a simple tool for therapeutic drug monitoring. $J$ Chromatogr B Biomed Sci Appl 794:35-47.

Gold PE, van Buskirk R (1978) Posttraining brain norepinephrine concentrations: correlation with retention performance of avoidance training and with peripheral epinephrine modulation of memory processing. Behav Biol 23:509-520.

Hamann SB, Ely TD, Grafton ST, Kilts CD (1999) Amygdala activity related to enhanced memory for pleasant and aversive stimuli. Nat Neurosci 2:289-293.

Hamann S (2001) Cognitive and neural mechanisms of emotional memory. Trends Cogn Sci 5:394-400.

Harmer CJ, Hill SA, Taylor MJ, Cowen PJ, Goodwin GM (2003) Toward a neuropsychological theory of antidepressant drug action: increase in positive emotional bias after potentiation of norepinephrine activity. Am J Psychiatry 160:990-992.

Harmer CJ, Shelley NC, Cowen PJ, Goodwin GM (2004) Increased positive versus negative affective perception and memory in healthy volunteers following selective serotonin and norepinephrine reuptake inhibition. Am I Psychiatry 161:1256-1263.

Kensinger EA (2004) Remembering emotional experiences: the contribution of valence and arousal. Rev Neurosci 15:241-251.

Kensinger EA, Corkin S (2004) Two routes to emotional memory: distinct neural processes for valence and arousal. Proc Natl Acad Sci USA 101:3310-3315.

Lang PJ, Bradley MM, Cuthberg BN (1997) International affective picture system, NIMH center for the study of emotion and attention, Gainesville, Florida, USA. 
Loftus EF (1979) The malleability of human memory. Am Sci 67:312-320.

Loftus EF. Burns TE (1982) Mental shock can produce retrograde amnesia. Mem Cognit 10:318-323.

McGaugh JL (2000) Memory - a century of consolidation. Science 287:248-251.

Mcciaugh JL, Roozendaal B (2002) Role of adrenal stress hormones in forming lasting memories in the brain. Curr Opin Neurobiol 12:205-210.

Mc(inty D. Srymusiak R (1988) Neuronal unit activity patterns in behaving animals: brainstem and limbic system. Annu Rev Psychol 39:135-168.

Murchison CF, Zhang XY, Zhang WP. Ouyang M, Lee A, Thomas SA (2004) A distinct role for norepinephrine in memory retrieval. Cell 117:131-143.

O'Carroll RE, Drysdale E, Cahill L, Shajahan P. Ebmeier KP (1999a) Stimulation of the noradrenergic system enhances and blockade reduces memory for emotional material in man. Psychol Med 29:1083-1088.

O'Carroll RF, Drysdale E, Cahill L, Shajahan P. Ebmeier KP (1999b) Memory for emotional material: a comparison of central versus peripheral beta blockade. J Psychopharmacol 13:32-39.

Papps BP, Shajahan PM. Ebmeier KP, O'Carroll RF (2002) The effects of noradrenergic re-uptake inhibition on memory encoding in man. Psychopharmacology 159:311-318.

Phelps EA (2004) Human emotion and memory: interactions of the amygdala and hippocampal complex. Curr Opin Neurobiol 14:198-202.

Pitkanen A. Pikkarainen M. Nurminen N, Ylinen A (2000) Reciprocal connections between the amygdala and the hippocampal formation, perirhinal cortex, and postrhinal cortex in rat. A review. Ann NY Acad Sci 911:369-391.

Raymond JE., Shapiro KL. Arnell KM (1992) Temporary suppression of visual processing in an RSVP task: an attentional blink? J Exp Psychol Hum Percept Perform 18:849-860.

Richardson MP. Strange BA, Dolan RJ (2004) Encoding of emotional memories depends on amygdala and hippocampus and their interactions. Nat Neurosci 7:278-285.

Roozendaal B, Hahn EL, Nathan SV, de Quervain DJ, McGaugh JL (2004) Glucocorticoid effects on memory retrieval require concurrent noradrenergic activity in the hippocampus and basolateral amygdala. J Neurosci $24: 8161-8169$.

Small DM, Gregory MD, Mak YE, Gitelman D, Mesulam MM, Parrish T (2003) Dissociation of neural representation of intensity and affective valuation in human gustation. Neuron 39:701-711.

Snodgrass JG, Vanderwart M (1980) A standardized set of 260 pictures: norms for name agreement, image agreement, familiarity, and visual complexity. J Exp Psychol [Hum Learn] 6:174-215.

Southwick SM, Davis M, Homer B, Cahill L, Morgan CA 3rd, Gold PE, Bremner JD, Chamey DC (2002) Relationship of enhanced norepinephrine activity during memory consolidation to enhanced long-term memory in humans. Am J Psychiatry 159:1420-1422.

Sternberg DB, Gold PE (1981) Retrograde amnesia produced by electrical stimulation of the amygdala: attenuation with adrenergic antagonists. Brain Res 211:59-65.

Strange BA. Hurlemann R, Dolan RJ (2003) An emotion-induced retrograde amnesia in humans is amygdalaand beta-adrenergic-dependent. Proc Natl Acad Sci USA 100:13626-13631.

Strange BA, Dolan RJ (2004) Beta-adrenergic modulation of emotional memory-evoked human amygdala and hippocampal responses. Proc Natl Acad Sci USA 101:11454-11458.

Tulving E (1969) Retrograde amnesia in free recall. Science 164:88-90.

Tulving E, Markowitsch HJ, Craik FE, Habib R, Houle S (1996) Novelty and familiarity activations in PET studies of memory encoding and retrieval, Cereb Cortex 6:71-79.

van Stegeren AH, Everaerd W, Cahill L, McGaugh JL, Gooren LJ (1998) Memory for emotional events: differential effects of centrally versus peripherally acting beta-blocking agents. Psychopharmacology 138:305-310.

van Stegeren AH, Goekoop R, Everaerd W, Scheltens P, Barkhof F, Kuijer JP, Rombouts SA (2005) Noradrenaline mediates amygdala activation in men and women during encoding of emotional material. Neuroimage 24:898-909.

Von Restorff H (1933) Ueber die Wirkungen von Bereichsbildung im Spurenfeld. Psychologische Forschung 18:299-342.

Wallace WP (1965) Review of the historical empirical and theoretical status of the von Restorff phenomenon. Psychol Bull 63:410-424.

Wise RA (2004) Dopamine, learning and motivation. Nat Rev Neurosci 5:483-494.

Yamasaki H, LaBar KS, McCarthy G (2002) Dissociable prefrontal brain systems for attention and emotion. Proc Natl Acad Sci USA 99:11447-11451. 
R. Hurlemann - The Costs and Benefits of Emotional Memory Formation

\section{CROWLEGMEN}

R.H. was supported by BONFOR. The authors thank P. Bangert, R. Fimmers, C. Frahnert, D. Schlich, D. K. Troll, and M. Wagner for significant support.

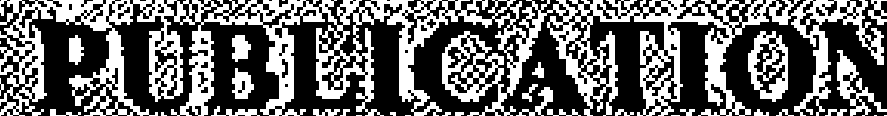

Hurlemann R, Hawellek B, Matusch A, Kolsch H, Wollersen H, Madea B, Vogeley K, Maier W, Dolan RJ (2005) Noradrenergic modulation of emotion-induced forgetting and remembering. The Journal of Neurocience 25:6343-6349. (Article reproduced with permission of the copyright owner. Further reproduction prohibited without permission.) 


\section{CHAPTER 4}

\section{Noradrenergic control of emotion-induced amnesia and hypermnesia: A review}

\section{ABSTR C C 1 -}

Emotional memory encoding is associated with retrograde and anterograde episodic memory changes involving an amnesia and hypermnesia, respectively. These effects are noradrenergic-dependent and reflect an interaction with emotional arousal and valence. Whereas anterograde amnesic effects most likely result from an attentional capture by emotional arousal, retrograde amnesic and hypermnesic effects may reflect a valencedependent filter mechanism that operates during emotional memory encoding, and controls episodic memory access based on behavioral significance. This filter mechanism may originate in amygdala-hippocampal interactions that are modulated by both ascending locus coeruleus and descending prefrontal cortex inputs.

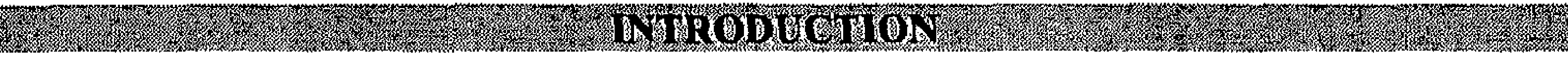

Through evolution, episodic memory formation, a function of the hippocampus (Scoville and Milner, 1957), is biased towards emotion (Dolan, 2002). This bias is evident in that what humans remember most is not the mundane but emotional events, an effect that has been confirmed in numerous psychological studies for a wide range of experimental stimuli (Dolan, 2002). An important neurochemical substrate of emotional memory has been identified in animal experiments that provide evidence of a noradrenergic (norepinephrine, NE) modulation (Cahill and McGaugh, 1996; McGaugh, 2000; 2002; 2004). In a pioneering human study wherein subjects were exposed to an emotional story recall task, Cahill et al. (1994) found that pre-learning administration of the $\beta$-adrenergic antagonist propranolol (40 mg p.o.) abolished the memory benefit for emotional events. This influence of propranolol is centrally mediated, as peripheral $\beta$-adrenoceptor blockade has no such effect (van Stegeren et al., 1998). These results provided an important link to those obtained in animal experiments, by suggesting that an emotion-induced enhancement of episodic memory formation depended on central $\beta$-adrenoceptor activation (Cahill et al., 1994; van Stegeren et al., 2005; but see O'Carroll et al., 1999b; Murchison et al., 2004).

Augmenting a NE response to emotional stimuli with the $\alpha-2$ adrenergic antagonist yohimbine boosted emotional memory (O'Carroll et al., 1999a; Southwick et al., 2002), adding further support to the hypothesis that the influence of emotion on episodic memory formation varies as a function of central $\mathrm{NE}$ signaling. The source of central NE signaling is the locus coeruleus (LC), a collection of noradrenergic neurons $(\sim 16,000$ per hemisphere) located in the dorso-rostral pons (Berridge and Waterhouse, 2003; Aston-Jones and Cohen, 2005a,b). Another striking feature of emotional memory is a dependence on the amygdala. Patients with selective bilateral amygdala calcification lesion due to Urbach-Wiethe disease 
(Fig. 1) do not display an advantage of emotion on episodic memory formation in the emotional story task (Cahill et al., 1995), a finding that closely mimics that observed with propranolol.

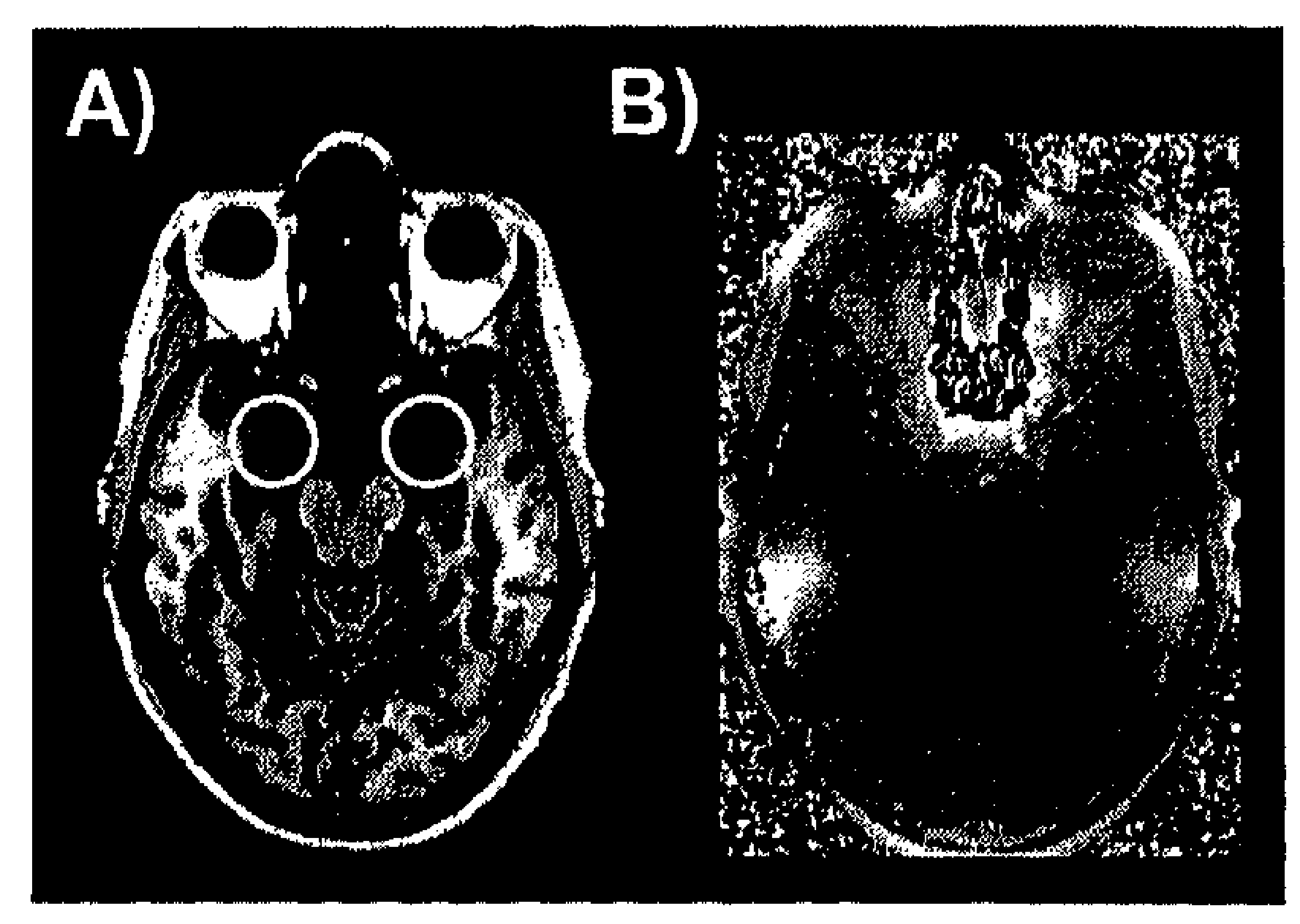

Fig. 1: Horizontal MRI sections of the anterior medial temporal lobe with white circles indexing the selective bilateral amygdala calcification lesions in a patient with Urbach-Wiethe disease (hyalinosis cutis et mucosae, lipoproteinosis) (OMIM 247100). Shown are magnitude (A) and phase (B) images derived from a re-constructed 5 -average MRI data set acquired with $0.8 \mathrm{~mm}$ isotropic resolution.

Encoding operations create initial memory representations, which require postencoding modifications (consolidation) to become more stabile and thereby resistant to disruption. Consolidation has been conceptualized as a re-organization process that transfers memory representations from hippocampal to neocortical circuits (Takashima et al., 2006). The time course of consolidation in humans is unclear. Estimates have extended up to decades, based on retrospective lesion and functional neuroimaging studies (Scoville and Milner, 1957; Haist et al., 2001). When investigated on a shorter time scale, prospective studies in rodents and nonhuman primates have revealed upper-bound estimates of a few weeks (Zola-Morgan and Squire, 1990; Remondes and Schumann, 2004). In humans, the behavioral outcome of declarative memory consolidation can be observed after a night of sleep (Gais and Born, 2004). Current hypotheses of emotional memory formation target consolidation rather than encoding stages (Phelps and LeDoux, 2005). These hypotheses state that emotional stimuli engage LC to release NE in the basolateral amygdala (BLA), an effect critical for potentiating hippocampus-dependent consolidation of these stimuli (McGaugh, $2000 ; 2002 ; 2004)$. However, the proposed timescale of consolidation in this model cannot account for the immediate effects of emotion on episodic memory formation. Instead, there must be rapid mechanisms that operate during emotional memory encoding prior to consolidation (Hamann et al., 1999; Hamann, 2001). One such mechanism is reflected by the amygdala's biasing of selective attention towards emotional stimuli that prioritizes emotional memory encoding (Easterbrook, 1959; Dolan, 2002; Phelps, 2004; 2006; Phelps and LeDoux, 2005). Another mechanism is thought to originate in direct amygdala-hippocampal interplay during emotional memory encoding (Dolcos et al., 2004a; Kensinger and Corkin, 2004; Richardson et al., 2005). 
Several lines of evidence support a critical role of the amygdala in a modulation of hippocampal function during emotional memory encoding. Anatomical studies in rodents demonstrate reciprocal amygdalo-hippocampal connections (Pitkanen et al., 2000). Subseizure electrical stimulation of the rodent amygdala produces retrograde amnesia, which can be prevented by pre-treatment with propranolol (Sternberg and Gold, 1981). Substantial evidence also comes from functional imaging experiments in humans. Positron emission tomography (PET) studies initially established that amygdala engagement during encoding correlates with later emotional memory (Cahill et al., 1996). Crucially, an amplified amygdala activation to both positive and negative stimuli is predicitve of later emotional memory recall (Hamann et al., 1999). Event-related functional magnetic resonance imaging (fMRI) experiments have replicated this correlation using the so-called subsequent memory paradigm (Canli et al., 2000). This paradigm isolates the $\mathrm{Dm}$ (difference due to memory: Paller et al., 1987) effect by contrasting amygdala activation for stimuli that are subsequently remembered versus those that are subsequently forgotten. Enhanced encoding due to emotional influences can then be investigated by comparing the $D m$ effect for emotional versus neutral stimuli (LaBar and Cabeza, 2006).

Emotion-specific $D m$ correlations between amygdala and hippocampus (Dolcos et al., 2004a; Kensinger and Corkin, 2004) suggest a functional coupling of these structures during emotional memory encoding. This is confirmed by a study of temporal lobe epilepsy patients (Richardson et al., 2004) where hippocampal pathology predicted memory for neutral and emotional stimuli alike, while amygdala pathology predicted memory for emotional stimuli alone. This indicates an amygdala-hippocampal interactive response during emotional memory encoding. Such amygdala-hippocampal cross-talk appears to be susceptible to drug challenge with propranolol (Strange and Dolan, 2004), thus neutralizing the retrieval advantage of emotional stimuli, despite propranolol being no longer active during retrieval (van Stegeren et al., 2005). Together with behavioral evidence of facilitated emotional memory encoding by application of the selective NE reuptake inhibitor (SNRI) reboxetine (Harmer et al., 2003; 2004), these data favour a critical role of intra-amygdalar NE release in emotional memory encoding.

W.

Tulving (1969) described an experimental retrograde amnesia in a free-recall task of words lists, produced by inserting items (names of famous people such as 'Freud') having priority in recall. In similar studies, both retrograde and anterograde amnesic effects were demonstrated, particularly in response to negative emotion (Saufley and Winograd, 1970; Detterman, 1975; Christianson, 1984; Loftus and Burns, 1982; Angelini et al., 1996). In contrast to emotional memory encoding per se, emotion's potential to evoke retrograde and anterograde episodic memory changes has attracted less attention from neurobiology. A landmark study in this regard is that of Strange et al. (2003) who combined psychological, pharmacological, and neuropsychological evidence to implicate mechanisms similar to those involved with emotional memory encoding in emotion-induced amnesia. Subjects were exposed to an oddball paradigm composed of word lists, in which enhanced encoding of oddballs (the von Restorff phenomenon: von Restorff, 1933; Wallace, 1965) interfered with the encoding of preceding standard items, if the oddball was emotional (aversive words such 
as 'massacre') (Strange et al. (2003). As a consequence, subjects subsequently recalled the emotional $(E)$ items significantly better than the neutral items, while those items immediately preceding the $E$ items (neutral $E-1$ items) were forgotten, an emotion-induced amnesic effect up to several seconds. Strange et al. (2003) asked whether the $E-1$ amnesic effect in response to $E$ items was triggered by NE- and amygdala-dependent mechanisms. They addressed the first question by administering propranolol $(40 \mathrm{mg} \mathrm{p.o})$ in a double-blind, placebo-controlled, randomized experiment, and addressed the second question by testing a patient with selective bilateral amygdala damage, resulting from Urbach-Wiethe disease (Fig. 1), and matched controls. The findings were similar: NE blockade and bilateral amygdala damage both abolished memory increments for $E$ items and memory decrements for $E-1$ items, demonstrating a significant coupling between the memory-enhancing and amnesic effects of negative emotion: The more likely an aversive $E$ item was remembered, the more likely the preciding neutral item was not. Thus, an emotion-induced amnesia is amygdala- and NEdependent, implicating intra-amygdalar NE release as a critical substrate of emotional memory encoding and the modulatory effects driven by it.

W

The aforementioned findings implicate emotional memory encoding in causing retrograde amnesia. In effect, these authors showed that episodic memory encoding of neutral stimuli temporally contiguous to an emotional stimulus is fragile and susceptible to disruption by encoding of an emotional stimulus. Psychological frameworks propose that emotional stimuli are best characterized along quantitative and qualitative dimensions corresponding to arousal (intensity) and valence (negative vs. positive) (Russel, 1980; Lang, 1995). Increasing evidence indicates a neural organization of emotional memory according to these dimensions (Dolcos et al., 2004b; Kensinger, 2004; Kensinger and Corkin, 2004). This suggests that there could be dissociable contributions of arousal and valence to the retrograde (and anterograde) episodic memory changes associated with emotional memory encoding.

To test the above hypothesis, Hurlemann et al. (2005) established an experimental procedure similar to that used by Strange et al. (2003). However, input lists were shorter and included picture items paired with their verbal descriptors to yield more intense emotionepisodic encoding interactions. Of 36 oddballs implemented in the paradigm, 12 were perceptual-neutral $(P)$, and 24 were perceptual-emotional $\left(E_{x} P\right)$, including 12 positive $\left(E_{p o s} P\right)$ and 12 negative $\left(E_{m e g} P\right)$ oddballs. $E_{\text {pos }} P$ and $E_{n e g} P$ oddballs differed from each other in terms of valence, but were matched for arousal. $E_{x} P$ oddballs, however, differed from $P$ oddballs in terms of valence and arousal. Recall profiles from each list were pooled according to the 3 oddball types, thus yielding a neutral (control), positive, and negative condition. As outcome parameter, episodic memory accuracy was determined condition-wise by calculating the percentage of correct recall (i.e. the output / input ratio) for 'oddball - 1', 'oddball', and 'oddball +1 ' list positions. Contrasting the emotional conditions $\left(E_{x} P\right)$ with the neutral condition $(P)$ (according to $E_{x} P-P=E_{x}$ ) isolated retrograde and anterograde effects in response to positive and negative emotion on 1 adjacent standard item $\left(E_{x} \pm I\right)$ corresponding to a time window of $\pm 5 \mathrm{~s}$ (Fig. 2).

With this subtractive design, Hurlemann et al. (2005) identified an organization of $E_{x}$ 1 retrograde and $E_{x}+1$ anterograde episodic memory changes consistent with a taxonomy of emotion along the dimensions of valence and arousal. Thus, $E_{x-1}-1$ effects are determined by valence, with negative emotion eliciting amnesia and positive emotion eliciting hypermnesia, 
while $E_{x}+1$ effects are determined by arousal, with negative and positive emotion eliciting amnesia (Fig. 3). These distinct types of emotion-episodic encoding interactions can be

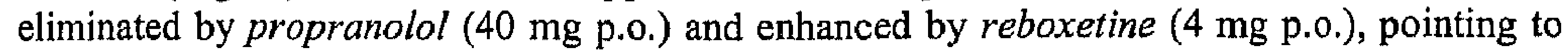
$\mathrm{NE}$ as the control neurochemical substrate.

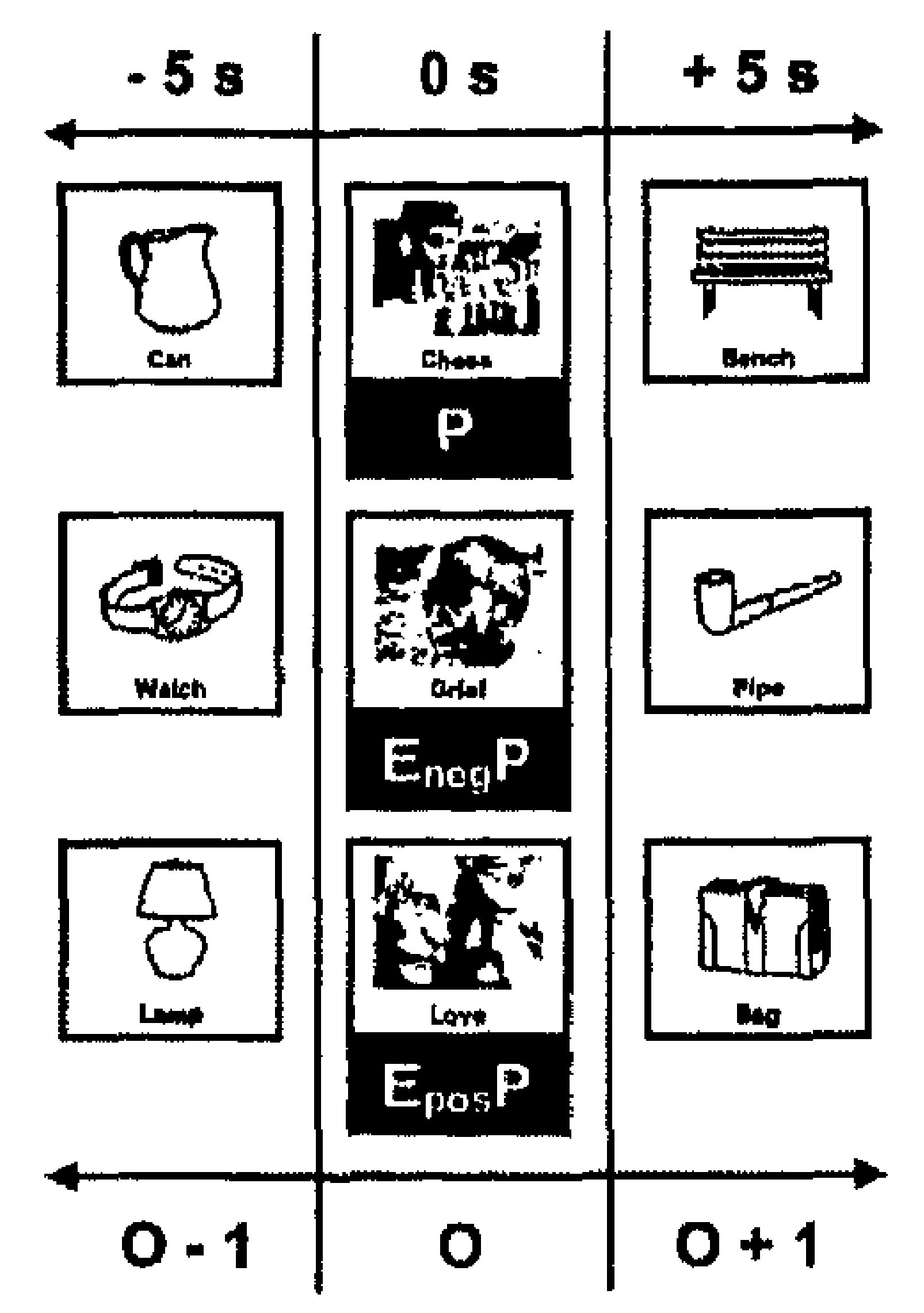

Fig. 2: Experimental design used by Hurlemann et al. (2005): In each input list, 1 oddball (O), either emotionally salient $\left(E_{x}\right.$ : positive, $E_{\text {pas }} P$; negative, $E_{\text {neg }} P$ ) or neutral $(\mathrm{P})$, was temporally flanked by a preceding $(\mathrm{O}-1)$ and following $(O+1)$ standard item. Results from list recall were pooled according to the 3 types of oddballs, thus yielding a positive, negative, and neutral condition. Contrasting the emotional conditions with the neutral condition (according to $E_{x} P-P=E_{x}$ ) allowed to extract retrograde and anterograde effects of positive and negative emotion on episodic memory encoding within a time window of $E_{x} \pm 1$ items or $\pm 5 \mathrm{~s}$.

The amnesic effect observed by Hurlemann et al. (2005) was not restricted to $E_{x-1}$ encoding, but extended to $E_{x}+1$ encoding, implicating a biological mechanism based upon an emotional arousal-dependent capture of selective attention (Angelini et al., 1996). Accoding to Easterbrook's 'cue-utilization' theory (1959), the ability to attend to a to-be-remembered event is a primary factor influencing episodic memory encoding. Encoding rather than retrieval of episodic memories is fragile and vulnerable to attentional manipulation (Craik et al., 1996). Emotional stimuli tend to capture attention (Ohman et al., 2001; Armony and Dolan 2002; Vuilleumier, 2005), thus enhancing the encoding of these stimuli (Phelps, 2004; 2006; Phelps and LeDoux, 2005). Once an emotional stimulus has attracted attention, it is difficult to re-orientate attention to non-emotional stimuli (Fox et al., 2001), illustrating costs and benefits to the emotional bias of attention. Thus, $E_{x}+1$ effects most likely reflect the cost of devoting attentional resources to preferential encoding of $E_{x}$ items and may transiently disnupt an attentional re-orienting that is a prerequisite for encoding a following $E_{x}+1$ item. The above interpretation is in keeping with findings using the 'attentional blink' paradigm, where detection of an initial target in a visual stimulus stream induces inattentional blindness' for a successive second target (Raymond et al., 1992). While the attentional blink is attenuated when the second target is emotional, this attenuation is abolished in amygdala damaged patients (Anderson and Phelps, 2001). Further, these patients do not show a tradeoff between memory for emotional gist and non-emotional details of complex visual stimuli 
(Adolphs et al., 2005). Compatible with Easterbrook's hypothesis (1959) and the 'weaponfocus ${ }^{2}$ phenomenon in eyewitness testimony research (Loftus, 1979) (see Kensinger, 2004 for review), these patient data suggest an amygdala role in narrowing the attentional focus to $\mathrm{E}_{\mathrm{x}}$ items, thus leaving less capacity available for processing competing $E_{x}+1$ items. In view of $\mathrm{NE}$ as a key neurochemical factor in amygdala's modulation of encoding (Strange et al., 2003; Strange and Dolan, 2004; van Stegeren et al., 2005), reboxetine's amplification and propranolol's attenuation of $\mathrm{E}_{\mathrm{x}}+1$ effects indicate a narrowing or broadening of episodic memory access as a function of intra-amygdalar NE levels (Hurlemann et al., 2005).
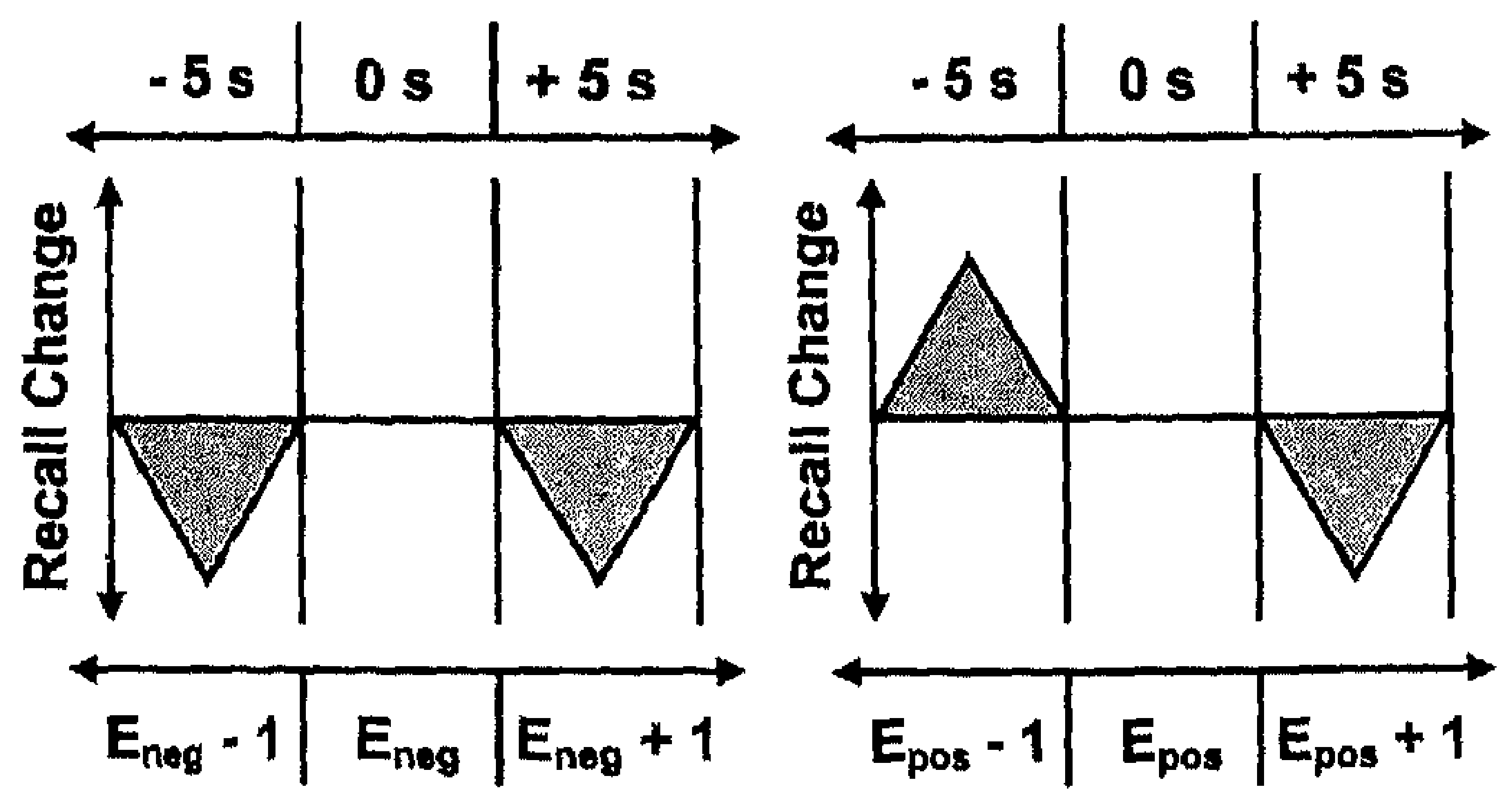

Fig. 3: Schema depicting emotion-induced recall changes (relative to the neutral condition) observed by Hurlemann et al. (2005). Equal (near-ceiling) von Restorff effects were obtained for emotional and neutral oddballs, such that subtraction yielded no difference on the emotion ( $E_{x}$ : positive, $E_{\text {pos }}$; negative, $E_{\text {neg }}$ ) position. In contrast, episodic memory for immediately preceding $\left(E_{x}-1\right)$, but not for following $\left(E_{x}+1\right)$ items depended on emotional valence. While negative emotion elicited retrograde amnesia, positive emotion elicited retrograde hypermnesia. Both positive and negative emotion elicited anterograde amnesia.

\section{3.}

Tulving (1969) conjectured that a retrograde amnesia in free recall could emerge from a premature termination of episodic memory encoding. Retrograde amnesia in response to intense negative emotion, and the enhancement of this effect with reboxetine, is consistent with an emotional arousal cost on ongoing encoding operations in the hippocampus. This premature termination, however, is not expressed when an emotionally arousing stimulus is positive, and indeed there is an opposite effect of hypermnesia in response to intense positive emotion (Hurlemann et al., 2005). This calls for a more complex explanation that invokes an interaction between arousal and valence in the expression of $E_{x}-1$ effects. The amygdala is known to integrate valence and arousal contingencies of emotional stimuli (Winston et al. 2005) rather than codes for arousal per se (Anderson et al., 2003; Small et al., 2003). However, when it comes to emotional memory, a neural segregation of arousal and valence has been reported (Dolcos et al., 2004b; Kensinger and Corkin, 2004), which might underlie dissociable contributions of arousal and valence to $E_{x}-1$ effects.

Compatible with the model proposed by Kensinger and Corkin (2004), the quantity of $E_{x}-1$ effects may vary as a function of emotional arousal perhaps under the control of amygdala-hippocampal connectivity, while their quality (i.e. the occurence of retrograde amnesia vs. hypermnesia) may be related to valence-dependent activation of prefrontal cortex-hippocampal circuits. Thus, differential computation of valence and arousal likely 
determines whether an $E_{x-1}-1$ item is subsequently remembered or forgotten. Substantial support for this interpretation comes from functional imaging findings of a valence- and arousal-specific parcellation within prefrontal cortex (Dolcos et al., 2004b). According to these findings, positively valenced arousing items might engage specific subdivisions of prefrontal cortex to inhibit emotional arousal-related disruption of $E_{x}-1$ encoding in hippocampus, thus augmenting ongoing encoding processes and inducing hypermnesia. This mechanism is evidenced by neurophysiological and modeling studies in nonhuman primates, where descending projections from prefrontal cortex areas represent the major top-down control influence on LC and regulate LC function (Aston-Jones and Cohen, 2005a,b).

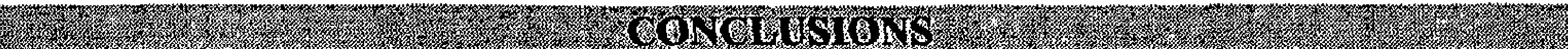

Identification of the psychological indices and biological substrates of emotional memory encoding and the amnesic and hypermnesic effects driven by it extends understanding of the mechanisms that influence episodic memory formation. Accumulating evidence indicates that amygdala- and NE-dependent modulatory influences of emotion on hippocampal function are not restricted to consolidation, but already act during encoding of episodic memories. Amnesic and hypermnesic effects associated with emotional memory encoding suggest that the primary function of episodic memory may be to guide behavior rather than to accurately reproduce the past. Accordingly, up- and downregulation of hippocampal function during encoding in response to the presence or absence of intraamygdalar NE release may represent an important filter mechanism that controls episodic memory access upon criteria of behavioral significance, with behaviorally significant items receiving privileged access to consolidation resources and insignificant items being filtered out. This filter mechanism appears to be a function of amygdala-hippocampal interactions which receive bottom-up modulatory inputs from LC and top-down modulatory inputs from prefrontal cortex. Prefrontal cortex, in turn, controls LC activation and central NE signaling. This functional circuitry may be part of the architecture that has evolved to orchestrate forgetting and remembering (Fig. 4).

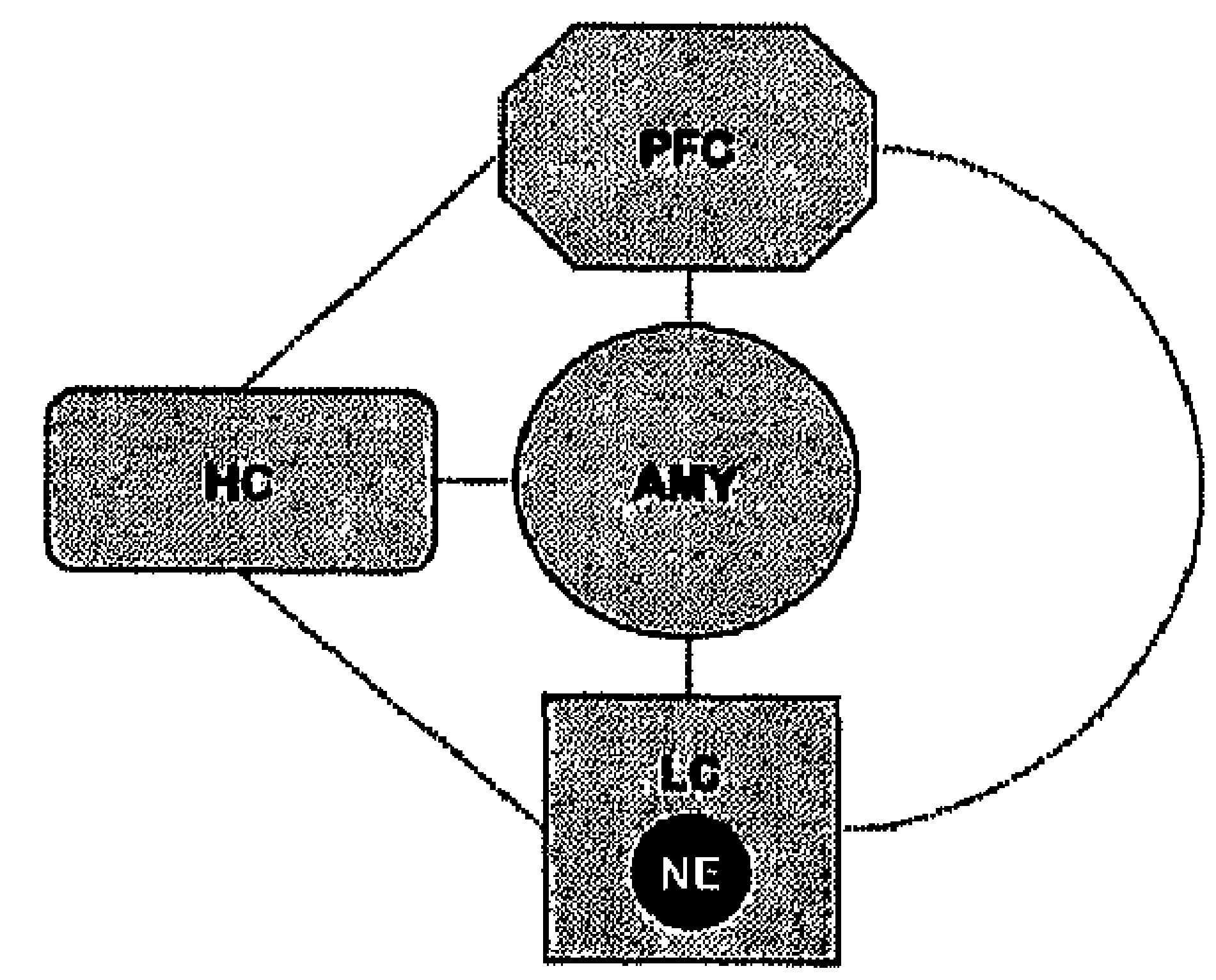

Fig. 4: Schematic outline of the functional circuitry hypothesized to underly emotion-induced amnesia and hypermnesia. While anterograde amnesic effects most likely result from attentional capture by emotional arousal, retrograde amnesic and hypermnesic effects may reflect a filter mechanism that operates during emotional memory encoding and controls episodic memory access upon criteria of behavioral significance. This filter mechanism is based on amygdala-hippocampal interactions which are modulated by ascending locus ceoruleus and descending prefrontal cortex inputs. According to this model, the amygdala (AMY) - activated by noradrenergic (norepinephrine, NE) signaling from locus coeruleus (LC) - communicates emotional arousal to hippocampus (HC), thus rendering HC susceptible to valence transfer from prefrontal cortex (PFC). PFC, in turn, controls LC output. 
Adolphs R, Tranel D, Buchanan TW (2005) Amygdala damage impairs emotional memory for gist but not details of complex stimuli. Nat Neurosci 8:512-518.

Anderson AK, Phelps EA (2001) Lesions of the human amygdala impair enhanced perception of emotionally salient events. Nature 411:305-309.

Anderson AK, Christoff K, Stappen I, Panitz D, Ghahremani DG, Glover G, Gabrieli JD, Sobel N (2003) Dissociated neural representations of intensity and valence in human olfaction. Nat Neurosci 6:196-202.

Angelini R, Capozzoli F, Lepore P, Grossi D, Orsini A (1994) "Experimental amnesia" induced by emotional items. Percept Mot Skills 78:19-28.

Armony JL, Dolan RJ (2002) Modulation of spatial attention by fear-conditioned stimuli: an event-related fMRI study. Neuropsychologia 40:817-826.

Aston-Jones G, Cohen JD (2005a) An integrative theory of locus coenuleus-norepinephrine function: adaptive gain and optimal performance. Annu Rev Neurosci 28:403-450.

Aston-Jones $\mathrm{G}$, Cohen JD (2005b) Adaptive gain and the role of the locus coeruleus-norepinephrine system in optimal performance. J Comp Neurol 493:99-110.

Berridge CW, Waterhouse BD (2003) The locus coeruleus-noradrenergic system: modulation of behavioral state and state-dependent cognitive processes. Brain Res Brain Res Rev 42:33-84.

Cahill L, McGaugh JL (1998) Mechanisms of emotional arousal and lasting declarative memory. Trends Neurosci 21:294-299.

Cahill L, Prins B, Weber M, McGaugh JL (1994) Beta-adrenergic activation and memory for emotional events. Nature 371:702-704.

Cahill L, Babinsky R, Markowitsch HJ, McGaugh JL (1995) The amygdala and emotional memory. Nature 377:295-296.

Cahill L, Haier RJ, Fallon J, Alkire MT, Tang C, Keator D, Wu J, McGaugh JL (1996) Amygdala activity at encoding correlated with long-term, free recall of emotional information. Proc Natl Acad Sci USA 93:80168021.

Canli T, Zhao Z, Brewer J, Gabrieli JD, Cahill L (2000) Event-related activation in the human amygdala associates with later memory for individual emotional experience. J Neurosci 20: RC99.

Christianson SA (1984) The relationship between induced emotional arousal and amnesia. Scand J Psychol 25:147-160.

Craik Fl, Govoni R, Naveh-Benjamin M, Anderson ND (1996) The effects of divided attention on encoding and retrieval processes in human memory. J Exp Psychol Gen 125:159-180.

Detterman DK (1975) The von Restorff effect and induced amnesia: production by manipulation of sound intensity. J Exp Psychol [Hum Learn] 1:614-628.

Dolan RJ (2002) Emotion, cognition, and behavior. Science 298:1191-1194.

Dolcos F, LaBar KS, Cabeza R (2004a)Interaction between the amygdala and the medial temporal lobe memory system predicts better memory for emotional events. Neuron 42:855-863.

Dolcos F, LaBar KS, Cabeza R (2004b) Dissociable effects of arousal and valence on prefrontal activity indexing emotional evaluation and subsequent memory: an event-related fMRI study. Neuroimage 23:64-74.

Easterbrook JA (1959) The effect of emotion on cue utilization and the organization of behavior. Psychol Rev 66:183-201.

Fox E, Russo R, Bowles R, Dutton K. (2001) Do threatening stimuli draw or hold visual attention in subclinical anxiety? J Exp Psychol Gen 130:681-700.

Gais S, Born J (2004) Declarative memory consolidation: mechanisms acting during human sleep. Learn Mem 11:679-685.

Haist F, Bowden Gore J, Mao H (2001) Consolidation of human memory over decades revealed by functional magnetic resonance imaging. Nat Neurosci 4:1139-1145.

Hamann S (2001) Cognitive and neural mechanisms of emotional memory. Trends Cogn Sci 5:394-400.

Hamann SB, Ely TD, Grafton ST, Kilts CD (1999) Amygdala activity related to entanced memory for pleasant and aversive stimuli. Nat Neurosci 2:289-293.

Harmer CJ, Hill SA, Taylor MJ, Cowen PJ, Goodwin GM (2003) Toward a neuropsychological theory of antidepressant drug action: increase in positive emotional bias after potentiation of norepinephrine activity. Am J Psychiatry 160:990-992.

Harmer CJ, Shelley NC, Cowen PJ, Goodwin GM (2004) Increased positive versus negative affective perception and memory in healthy volunteers following selective serolonin and norepinephrine reuptake inhibition. Am J Psychiatry 161:1256-1263.

Hurlemann R, Hawellek B, Matusch A, Kolsch H, Wollersen H, Madea B, Vogeley K, Maier W, Dolan RJ (2005) Noradrenergic modulation of emotion-induced forgetting and remembering. $J$ Neurosci 25:63436349. 
Kensinger EA (2004) Remembering emotional experiences: the contribution of valence and arousal. Rev Neurosci 15:241-251.

Kensinger EA, Corkin S (2004) Two routes to emotional memory: distinct neural processes for valence and arousal. Proc Natl Acad Sci USA 101:3310-3315.

LaBar KS, Cabeza R (2006) Cognitive neuroscience of emotional memory. Nat Rev Neurosci 7:54-64.

Lang PJ (1995) The emotion probe. Studies of motivation and attention. Am Psychol 50:372-385.

Loftus EF (1979) The malleability of human memory. Am Sci 67:312-320.

Loftus EF, Burns TE (1982) Mental shock can produce retrograde amnesia. Mem Cognit 10:318-323.

McGaugh JL (2000) Memory - a century of consolidation. Science 287:248-251.

McGaugh JL (2002) Memory consolidation and the amygdala: a systems perspective. Trends Neurosci. 25:456.

McGaugh JL (2004) The amygdala modulates the consolidation of memories of emotionally arousing experiences. Annu Rev Neurosci 27:1-28.

Murchison CF, Zhang XY, Zhang WP, Ouyang M, Lee A, Thomas SA (2004) A distinct role for norepinephrine in memory retrieval. Cell 117:131-143.

O'Carroll RE, Drysdale E, Cahill L, Shajahan P, Ebmeier KP (1999a) Stimulation of the noradrenergic system enhances and blockade reduces memory for emotional material in man. Psychol Med 29:1083-1088.

O'Carroll RE, Drysdale E, Cahill L, Shajahan P, Ebmeier KP (1999b) Memory for emotional material: a comparison of central versus peripheral beta blockade. J Psychopharmacol 13:32-39.

Ohman A, Flykt A, Esteves F (2001) Emotion drives attention: detecting the snake in the grass. J Exp Psychol Gen 130:466-478.

Paller KA, Kutas M, Shimamura AP, Squire LR (1987) Brain responses to concrete and abstract words reflect processes that correlate with later performance on a test of stem-completion priming. Electroencephalogr Clin Neurophysiol Suppl 40:360-365.

Phelps EA (2004) Human emotion and memory: interactions of the amygdala and hippocampal complex. Curr Opin Neurobiol 14:198-202.

Phelps EA (2006) Emotion and cognition: Insights from studies of the human amygdala. Annu Rev Psychol 57:27-53.

Phelps EA, LeDoux JF (2005) Contributions of the amygdala to emotion processing: from animal models to human behavior. Neuron 48:175-187.

Pitkanen A, Pikkarainen M, Nurminen N, Ylinen A (2000) Reciprocal connections between the amygdala and the hippocampal formation, perirhinal cortex, and postrhinal cortex in rat. A review. Ann NY Acad Sci 911:369-391.

Raymond JE, Shapiro KL, Amell KM (1992) Temporary suppression of visual processing in an RSVP task: an attentional blink? J Exp Psychol Hum Percept Perform 18:849-860.

Remondes M, Schuman EM (2004) Role for a cortical input to hippocampal area CA1 in the consolidation of a long-term memory. Nature 431:699-703.

Richardson MP, Strange BA, Dolan RJ (2004) Encoding of emotional memories depends on amygdala and hippocampus and their interactions. Nat Neurosci 7:278-285.

Russell JA (1980) A circumplex model of affect. J Pers Soc Psychol 39:1161-1178.

Saufley WH Jr, Winograd E (1970) Retrograde amnesia and priority instructions in free recall. J Exp Psychol 85:150-152.

Scoville WB, Milner B (1957) Loss of recent memory after bilateral hippocampal lesions. J Neurol Neurosurg Psychiatry 20:11-21.

Small DM, Gregory MD, Mak YE, Gitelman D, Mesulam MM, Parrish T (2003) Dissociation of neural representation of intensity and affective valuation in human gustation. Neuron 39:701-711.

Southwick SM, Davis M, Horner B, Cahill L, Morgan CA 3rd, Gold PE, Bremner JD, Charney DC (2002) Relationship of enhanced norepinephrine activity during memory consolidation to enhanced long-term memory in humans. Am J Psychiatry 159:1420-1422.

Sternberg DB, Gold PE (1981) Retrograde amnesia produced by electrical stimulation of the amygdala: attenuation with adrenergic antagonists. Brain Res 211:59-65.

Strange BA, Dolan RJ (2004) Beta-adrenergic modulation of emotional memory-evoked human amygdala and hippocampal responses. Proc Natl Acad Sci USA 101:11454-11458.

Strange BA, Hurlemann R, Dolan RJ (2003) An emotion-induced retrograde amnesia in humans is amygdalaand beta-adrenergic-dependent. Proc Natl Acad Sci USA 100:13626-13631.

Takashima A, Petersson KM, Rutters F, Tendolkar I, Jensen O, Zwarts MJ, McNaughton BL, Fernandez G (2006) Declarative memory consolidation in humans: a prospective functional magnetic resonance imaging study. Proc Natl Acad Sci USA 103:756-761.

Tulving E (1969) Retrograde amnesia in free recall. Science 164:88-90.

van Stegeren AH, Everaerd W, Cahill L, McGaugh JL, Gooren LJ (1998) Memory for emotional events: differential effects of centrally versus peripherally acting beta-blocking agents. Psychopharmacology 138:305-310. 
R. Hurlemann - The Casts and Benefits of Emotional Memory Formation

van Stegeren AH, Goekoop R, Everaerd W, Scheltens P, Barkhof F, Kuijer JP, Rombouts SA (2005) Noradrenaline mediates amygdala activation in men and women during encoding of emotional material. Neuroimage 24:898-909.

von Restorff H (1933) Ueber die Wirkungen von Bereichsbildung im Spurenfeld. Psychologische Forschung 18:299-342.

Vuilleurnier P (2005) How brains beware; neural mechanisms of emotional attention. Trends Cogn Sci 9:585594.

Wallace WP (1965) Review of the historical empirical and theoretical status of the von Restorff phenomenon. Psychol Bull 63:410-424.

Winston JS, Gottfried JA, Kilner JM, Dolan RJ (2005) Integrated neural representations of odor intensity and affective valence in human amygdala. J Neurosci 25:8903-8907.

Zola-Morgan SM, Squire LR (1990) The primate hippocampal formation: evidence for a time-limited role in memory storage. Science $250: 288-290$.

3.

The author thanks Professor Raymond J. Dolan (London) and Professor Wolfgang Maier (Bonn) for inspiring discussions and critically reading the manuscript. R.H. was supported by BONFOR.

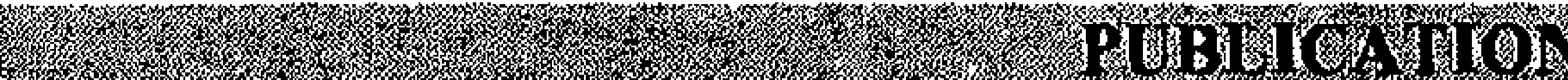

Hurlemann R (2006) Noradrenergic control of emotion-induced amnesia and hypermnesia. Reviews in the Neurosciences 17:525-532. (Article reproduced with permission of the copyright owner. Further reproduction prohibited without permission.) 


\section{CHAPTER 5}

\section{Amygdala control of emotion-induced forgetting and remembering: Evidence from Urbach-Wiethe disease}

When presented in a neutral context, emotional items interfere with episodic encoding of temporally contiguous non-emotional items, resulting in dissociable valence-dependent retrograde and arousal-dependent anterograde modulatory effects. By studying two rare patients with congenital lipoid proteinosis (Urbach-Wiethe) and a focal disease emphasis on the basolateral amygdala (BLA), we demonstrate that this bidirectional modification of episodic encoding by emotion depends on the integrity of the amygdala, as both retrograde and anterograde modulatory effects are absent. Our findings implicate the amygdala in a neural circuitry that orchestrates rapid retrograde and anterograde regulation of episodic memory access upon criteria of behavioral significance.

F

The hippocampus is critical for episodic memory formation (Scoville and Milner, 1957). In contrast, an enhancement of episodic memory formation by emotion is amygdalaand norepinephrine (NE)-dependent, being abolished by both bilateral amygdala lesion (Cahill et al., 1995; Adolphs et al., 1997) and pharmacological blockade of central NE signaling with the $\beta$-adrenergic antagonist propranolol (Cahill et al., 1994; van Stegeren et al., 1998). Current hypotheses of emotional (episodic) memory formation target postencoding (consolidation) rather than encoding stages (Phelps and LeDoux, 2005). These hypotheses state that emotional stimuli evoke, via projections from locus coeruleus (LC) (Aston-Jones and Cohen, 2005), NE release in the basolateral amygdala (BLA), an effect critical for potentiating hippocampal consolidation of these stimuli (McGaugh, 2000; 2004). Consequently, emotional memory formation should increase with time, as the gradual process of consolidation proceeds.

However, this time-dependent mechanism cannot account for the instant effects of emotion on episodic memory formation. Instead, there must be rapid modulatory mechanisms related to emotional memory encoding (Hamann, 2001). Studies of amygdala-lesioned patients demonstrate that one such mechanism depends on the amygdala's modulation of perception and attention (Anderson and Phelps, 2001; Vuilleumier et al., 2004; Adolphs et al., $2005 \mathrm{a}, \mathrm{b})$. Neuroimaging studies demonstrate that another mechanism depends on the amygdala's modulation of hippocampal function during emotional memory encoding (Cahill et al., 1996; Hamann et al., 1999; Canli et al., 2000; Kilpatrick and Cahill, 2003; Dolcos et al, 2004a; Kensinger and Corkin, 2004; Richardson et al., 2004; Kensinger and Schacter, 2006). Pharmacological evidence indicates that this modulation is susceptible to antagonistic 
R. Hurlemann - The Costs and Benefits of Emotional Memory Formation

(Strange et al., 2003; Strange and Dolan, 2004; van Stegeren et al., 2005) and agonistic (Harmer et al., 2003; Harmer et al., 2004) challenges of central NE signaling. Propranolol blocks emotional memory encoding in a manner akin to bilateral amygdala lesion (Strange et al., 2003), implying intra-amygdalar LC-NE release as a potent regulator of amygdalahippocampal interactions during emotional memory encoding.

However, this regulation has costs and benefits. Free recall tests of episodic memory formation demonstrate that enhanced encoding of oddballs (the von Restorff phenomenon: von Restorff, 1933; Wallace, 1965) critically interferes with the encoding of standard stimuli, an effect particularly evident for emotional oddballs (Tulving, 1969; Angelini et al., 1994; Strange et al., 2003). Using an emotional oddball paradigm, we recently showed that emotional memory encoding is associated with retrograde and anterograde episodic memory changes involving an amnesia and hypermnesia, respectively. Consistent with a taxonomy of emotion along the orthogonal dimensions of arousal and valence (Russel, 1980; Lang, 1995), anterograde interference is determined by arousal, with negative and positive emotion eliciting amnesia, whereas retrograde interference is determined by valence, with negative emotion eliciting amnesia and positive emotion eliciting hypermnesia. Both amnesic and hypermnesic effects are propranolol-sensitive, pointing to LC-NE as the control neurochemical substrate (Hurlemann et al., 2005).

Neuropsychological studies of patients with bilateral amygdala lesion provide key mechanistic insights into emotional memory formation (Phelps, 2006; LaBar and Cabeza, 2006 ) - in this case, determining whether the arousal-related anterograde and valence-related retrograde episodic memory changes in response to emotional memory encoding are amygdala-dependent. Given previous findings that an intact amygdala is necessary for emotional memory encoding per se (Hamann et al., 1999) as well as a retrograde amnesic effect in response to it (Strange et al., 2003), we hypothesized that 2 patients with rare lipoid proteinosis (Urbach-Wiethe) and selective bilateral amygdala calcification lesion, but not controls, would be significantly impaired in our behavioral test of emotion-induced amnesia and hypermnesia.

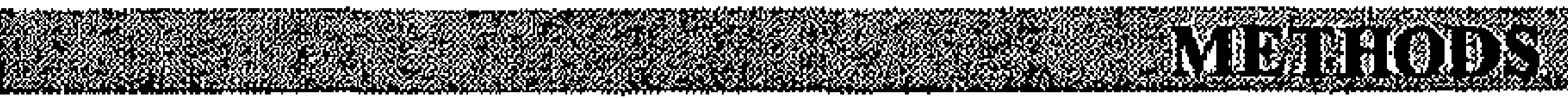

\section{Subjects}

Patients $A M$ and $B G$ are 30-yrs old female monozygotic twins suffering from lipoid proteinosis (LP), also known as Urbach-Wiethe disease or hyalinosis cutis et mucosae (OMIM 247100), a rare autosomal recessive disorder typified by cutaneous, mucosal, and visceral deposits of periodic acid-Schiff (PAS)-positive hyaline (glycoprotein) material. $L P$ is clinically heterogeneous, with classical features including beaded eyelid papules and laryngeal infiltration leading to hoarseness. In $50-75 \%$ of cases, $L P$ causes bilateral calcifications in the medial temporal lobes, which occasionally target the amygdala selectively. Epilepsy, when present, may be related to these calcifications (Appenzeller et al,, 2006). LP maps to chromosome 1q21 and results from mutations of the extracellular matrix protein 1 gene ( $E C M I$ ) (Hamada et al., 2002). In terms of history $B G$ suffered an epileptic grand-mal seizure aged 12, which led to diagnosis of $L P$ and subsequent diagnosis of her twin sister. When tested in our study, $B G$ was on anticonvulsive therapy with a $900-\mathrm{mg}$ daily dose of valproate. $A M$ and $B G$ completed $10 \mathrm{yrs}$ of school education and have been in fulltime employment since. Both are married and have children. Sixteen female control volunteers 
R. Hurlemann - The Costs and Benefits of Emotional Memory Formation

matched for age (age range, 24.3 - 34.2 yrs; mean age $29.1 \pm 2.4$ yrs) and education served as the comparison group. Both controls and $L P$ patients underwent psychiatric exploration to exclude either current or past DSM-IV (Diagnostic and Statistical Manual of Mental Disorders IV) axis I and axis II disorder. Controls had no current physical illness, and had not been on psychoactive medication for $\geq 3$ months. The study was approved by the local ethical committee, and all participants gave written informed consent according to the 1964 Declaration of Helsinki.

\section{Neuropsychological assessment}

Neuropsychologically, $L P$ patients show much less cognitive deviation from controls than initial studies of patients with this rare aetiology had suggested (Siebert et al., 2003). Previous neuropsychological testing showed $A M$ (and $B G$ ) to be of normal verbal IQ (VIQ) and within normal limits for a wide range of cognitive functions, including attention and short-term memory (Strange et al., 2003). Therefore, LP patients and controls underwent restricted neuropsychological screening in the present study. This included the VLMT (Verbaler Lern- und Merkfähigkeitstest) (Helmstaedter et al., 2001), a German version of the RAVLT (Rey Auditory Verbal Learning Test), to assess immediate verbal learning span, new learning, susceptibility to interference, and recognition memory. The ROCF (Rey-Osterrieth Complex Figure Test) (Rey, 1941; Osterrieth, 1944) was used to test incidental visual memory and the visuospatial constructional ability. Motor speed and visual attention were examined with the TMT (Trail Making Test) (Raitan, 1958). VIQ was determined with the HAWIE-R (Hamburg-Wechsler Intelligenztest für Erwachsene) (Tewes, 1991), a German Version of the WAIS-R (Wechsler Adult Intelligence Scale-Revised). A subtest of the RBMT (Rivermead Behavioral Memory Test) (Wilson et al., 1989) was used to investigate recognition of facial identity, whereas facial emotion recognition was assessed with the FEEST (Facial Expressions of Emotions: Stimuli and Test) (Young et al., 2002). As summarized in Table 1, neuropsychological screening showed that $A M$ and $B G$ have an average VIQ (HAWIE-R 100 and 105, respectively) and relatively normal cognitive skills as evident in most tasks, which replicates our previous findings (Strange et al., 2003). Interestingly, $B G$, but not $A M$, was significantly impaired in recognizing fearful facial expressions, with a recognition rate of $50 \%$ relative to $100 \%$ in controls.

\section{Episodic memory test}

Stimulus setup and experimental design have been detailed elsewhere (Hurlemann et al., 2005). The paradigm featured 36 von Restorff lists, each composed of 1 oddball and 7 standard stimuli, presented as picture items paired with their verbal descriptors. Standard stimuli included black and white line drawings of living and non-living entities (Snodgrass and Vanderwart, 1980; Cycowicz et al., 1997), while oddballs included images primarily selected and edited from the International Affective Picture System (IAPS; Lang et al., 2005). Of 36 oddballs implemented in the paradigm, 12 were perceptual-neutral (P), and 24 were perceptual-emotional $\left(\mathrm{E}_{\mathrm{x}} \mathrm{P}\right)$, including 12 positive $\left(\mathrm{E}_{\mathrm{pos}} \mathrm{P}\right)$ and 12 negative $\left(\mathrm{E}_{\text {neg }} \mathrm{P}\right)$ oddballs. $\mathrm{E}_{\mathrm{pos}} \mathrm{P}$ and $\mathrm{E}_{\mathrm{neg}} \mathrm{P}$ oddballs differed from each other in terms of valence, but were matched for arousal, $\mathrm{E}_{\mathrm{x}} \mathrm{P}$ oddballs differed from $\mathrm{P}$ oddballs in terms of valence and arousal.

All participants were presented with 36 study-distraction-test sequences. Episodic memory was tested by free recall. Recall profiles were pooled according to the 3 oddball categories, thus yielding a neutral, positive, and negative condition. As outcome parameter, episodic memory performance was determined condition-wise by calculating the percentage of correct recall (i.e. the output / input ratio) for the following 3 list positions: oddball -1 , 
oddball, and oddball +1 . Additionally, a standard item index (SI) based on the 7 non-oddball list positions was calculated for each condition (e.g., $\mathrm{SI}_{\mathrm{p}}$ ). Contrasting the emotional conditions $\left(E_{x} P\right.$ ) with the neutral condition $(P)$ (according to $E_{x} P-P=E_{x}$ ) allowed us to isolate retrograde and anterograde effects of positive $\left(E_{p o s}\right)$ and negative $\left(E_{\text {neg }}\right)$ emotion on 1 adjacent standard item $\left(E_{x} \pm 1\right)$ corresponding to a time window of $\pm 5 \mathrm{~s}$. While our previous paradigm was designed to demonstrate a coupling between the memory-enhancing ( $E_{\text {neg }}$ items) and memory-impairing ( $\mathrm{E}_{\mathrm{neg}}-1$ items) effects of negative emotion (Strange et al., 2003 ), the present paradigm was optimized to investigate $E_{x}-1$ retrograde and $E_{x}+1$ anterograde effects by using a subtractive design. To assess potential effects of bilateral amygdala damage on the cognitive appraisal of emotion, patients and controls both performed valence and arousal ratings to $E_{x} P$ and $P$ oddballs on a 9-point scale after memory testing.

Table 1

Demographical and neuropsychological characteristics of female Lipoid Proteinosis (Urbach-Wiethe) patients AM and BG and controls $(n=16)$.

\begin{tabular}{|c|c|c|c|c|c|}
\hline 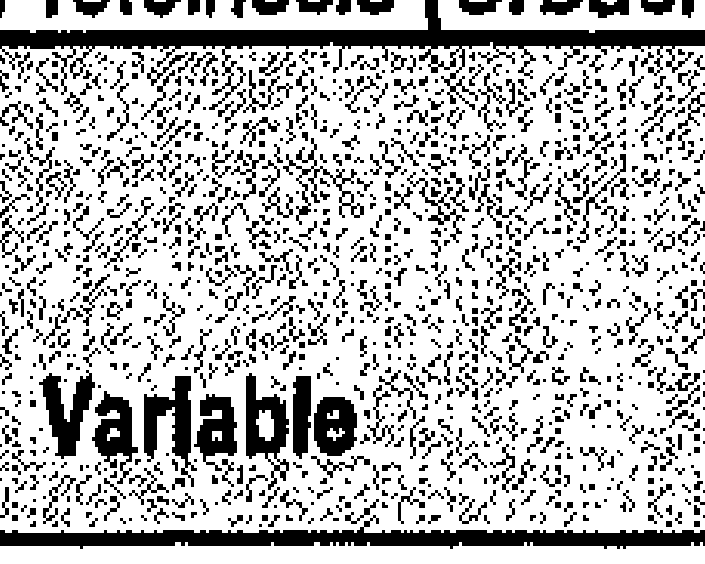 & Wax & oon & $s D^{\prime}$ & $\mathrm{AW}$ & 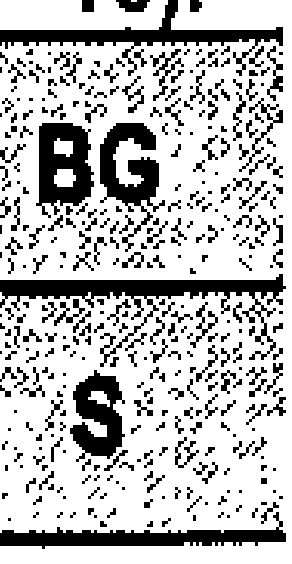 \\
\hline $\begin{array}{l}\text { Age, yrs } \\
\text { Height, } \mathrm{cm} \\
\text { Weight, } \mathrm{kg} \\
\text { Education, yrs }\end{array}$ & & $\begin{array}{c}29.1 \\
163.7 \\
61.3 \\
10.4\end{array}$ & $\begin{array}{l}2.4 \\
6.8 \\
5.5 \\
0.5\end{array}$ & $\begin{array}{c}30 \\
160 \\
60 \\
10\end{array}$ & $\begin{array}{c}30 \\
160 \\
49 \\
10\end{array}$ \\
\hline HAWIE-R VIQ & & 106 & 12.9 & 100 & 105 \\
\hline $\begin{array}{l}\text { VLMT1 } \\
\text { Trial } 1 \\
\text { Trial } 5 \\
\text { Total } \\
\text { Recognition }\end{array}$ & $\begin{array}{l}15 \\
15 \\
75 \\
75\end{array}$ & $\begin{array}{l}7.9 \\
10.9 \\
52.6 \\
13.3\end{array}$ & $\begin{array}{l}1.4 \\
2.1 \\
6.7 \\
1.6\end{array}$ & $\begin{array}{c}9 \\
10 \\
49 \\
12\end{array}$ & $\begin{array}{c}6 \\
12 \\
55 \\
14\end{array}$ \\
\hline $\begin{array}{l}\text { ROCF1 } \\
\text { Copy } \\
\text { 30-min Recall }\end{array}$ & $\begin{array}{l}36 \\
36\end{array}$ & $\begin{array}{l}32.4 \\
19.2\end{array}$ & $\begin{array}{l}3.9 \\
2.3\end{array}$ & $\begin{array}{l}30 \\
18\end{array}$ & $\begin{array}{l}32 \\
19\end{array}$ \\
\hline $\begin{array}{l}\text { TMT1 } \\
\text { Part A, sec } \\
\text { Part B, sec }\end{array}$ & & $\begin{array}{l}26.9 \\
73.3\end{array}$ & $\begin{array}{c}5.7 \\
15.3\end{array}$ & $\begin{array}{l}29 \\
82\end{array}$ & $\begin{array}{l}23 \\
76\end{array}$ \\
\hline $\begin{array}{l}\text { RBMT'1 } \\
\text { Face recognition }\end{array}$ & 5 & 5 & & 5 & 5 \\
\hline $\begin{array}{l}\text { FEEST1 } \\
\text { Happiness } \\
\text { Surprise } \\
\text { Fear } \\
\text { Sadnes } \\
\text { Disgust } \\
\text { Anger } \\
\text { Total }\end{array}$ & $\begin{array}{l}12 \\
12 \\
12 \\
12 \\
12 \\
12 \\
72\end{array}$ & $\begin{array}{l}12 \\
12 \\
12 \\
12 \\
12 \\
12 \\
72\end{array}$ & & $\begin{array}{c}11 \\
9 \\
11 \\
12 \\
10 \\
11 \\
64\end{array}$ & $\begin{array}{c}12 \\
11 \\
6 \\
11 \\
12 \\
12 \\
64\end{array}$ \\
\hline
\end{tabular}

Raw scores. Abbrevlations: Max, maximum possible score; MS, mean score; S, individual score; SD, standard deviation.

\section{MRI scanning}

A Siemens Sonata system (Siemens, Erlangen, Germany), operating at $1.5 \mathrm{~T}$, was used to acquire T1-weighted MRI scans of $A M$ and $B G$. The parameters of the MP-RAGE 
sequence (Mugler and Brookeman, 1991) were optimized to yield the best white matter-gray matter-CSF contrast for in vivo imaging: $\mathrm{TR}=2200 \mathrm{~ms}, \mathrm{TE}=4.38 \mathrm{~ms}, \mathrm{TI}=1240 \mathrm{~ms}$, $=$ $20^{\circ}$. A total of 6 volumes were acquired for each patient. Volume 1 was a standard $3 \mathrm{D}$ anatomical scan with $1.0 \mathrm{~mm}$ isotropic resolution. The whole brain volume was covered by 160 axial slices. The field-of-view (FOV) was $256 \times 256 \mathrm{~mm}$ and the matrix size $256 \times 256$ pixels. Volumes $2-6$ were acquired with the higher isotropic resolution of $0.8 \mathrm{~mm}$, aimed at improving the anatomical characterization of the bilateral amygdala lesions. Whole brain coverage was achieved by measuring 192 slices. The FOV was $205 \times 205 \mathrm{~mm}$ and the matrix size $256 \times 256$ pixels. Due to the proportionality between voxel size and signal-to-noise ratio (SNR) (Hoult and Richards, 1976), the increase in resolution from $1 \times 1 \times 1 \mathrm{~mm}$ to $0.8 \times 0.8 \times$ $0.8 \mathrm{~mm}$ was paralleled by a decrease of the SNR from about 20 to 10 in the single-average image, which is insufficient for accurate anatomical definition. To compensate for the loss of SNR while keeping the resolution, we acquired 5 averages (in form of 5 separate one-average runs, subsequently co-registered and re-sliced) for the final inage. To perform complex averaging, which leads to efficient noise suppression, the product MP-RAGE sequence was modified to output phase images in addition to the usual magnitude images. The real and imaginary parts were calculated for each of the 5 data sets and tehn used to obtain the complex average. The use of real and imaginary values instead of magnitude and phase has the advantage of avoiding phase wraps. Fig. 1 depicts the bilateral amygdala lesion in $A M$ (Fig. 1 Ai-ii) and $B G$ (Fig. 1 Bi-ii).

\section{MRI analysis}

To determine whether or not the BLA is affected in $A M$ and $B G$, we used threedimensional probabilistic maps based on cytoarchitectonic parcellations of the amygdala in histological sections of postmortem brains (Amunts et al., 2005), thus enabling accurate anatomical labeling in the stereotaxic reference space of the Montreal Neurological Institute (MNI) single subject template (Holmes et al., 1998). After segmentation, the MNI single subject template was co-registered with $A M$ 's and $B G$ 's individual MRI, respectively. The coregistration procedure consisted of a linear (affine) and a non-linear step. For the affine coregistration, which adjusts the position, global size, and shape of a given brain within the MRI, the FLIRT tool (Jenkinson and Smith 2001, Jenkinson et al., 2002) implemented in the FSL package (available online at: http://www.fmrib.ox.ac.uk/fsl) was used. In contrast, the non-linear registration served to match the template image and the individual patient's image with each other on a local scale. For this step, an algorithm developed at the Institute of Medicine, Research Center Juelich was applied, mininizing the sum of voxel-wise intensity value differences between both MRIs by computing local deformations of the template image. A regularization tern was added to model the template brain as an elastic body, thus avoiding non-smooth deformations. The non-linear registration resulted in a deformation-field containing local deformations, which was subsequently applied to the BLA probabilistic map to transform it into the patients' image spaces. We used this technique to match the BLA probabilistic map individually with the patients' MRIs. Fig. 2 illustrates the localization of the BLA probabilistic map in relation to the amygdala lesions in $A M$ (Fig. 2 Ai-ii) and $B G$ (Fig. 2 Bi-ii).

\section{Statistics}

To determine whether each of the patients performed within or outside the normal range on the free recall task, we compared $A M$ 's and $B G$ 's individual accuracy scores to the corresponding normative scores derived from the control sample by calculating separate $Z$ scores. On the group level, two-factor within-subjects and three-factor mixed analyses of 
variance (ANOVAs) followed by two-tailed one-sample and two-sample $t$ tests served to determine whether $E_{x}-1$ retrograde and $E_{x}+1$ anterograde memory changes were present or absent in patients as compared to controls. A significance threshold of $p<.05$ was adopted throughout. Effect sizes were quantified by calculating the values of partial Eta squared $\left(\eta_{p}{ }^{2}\right)$ and Cohen's $d$.

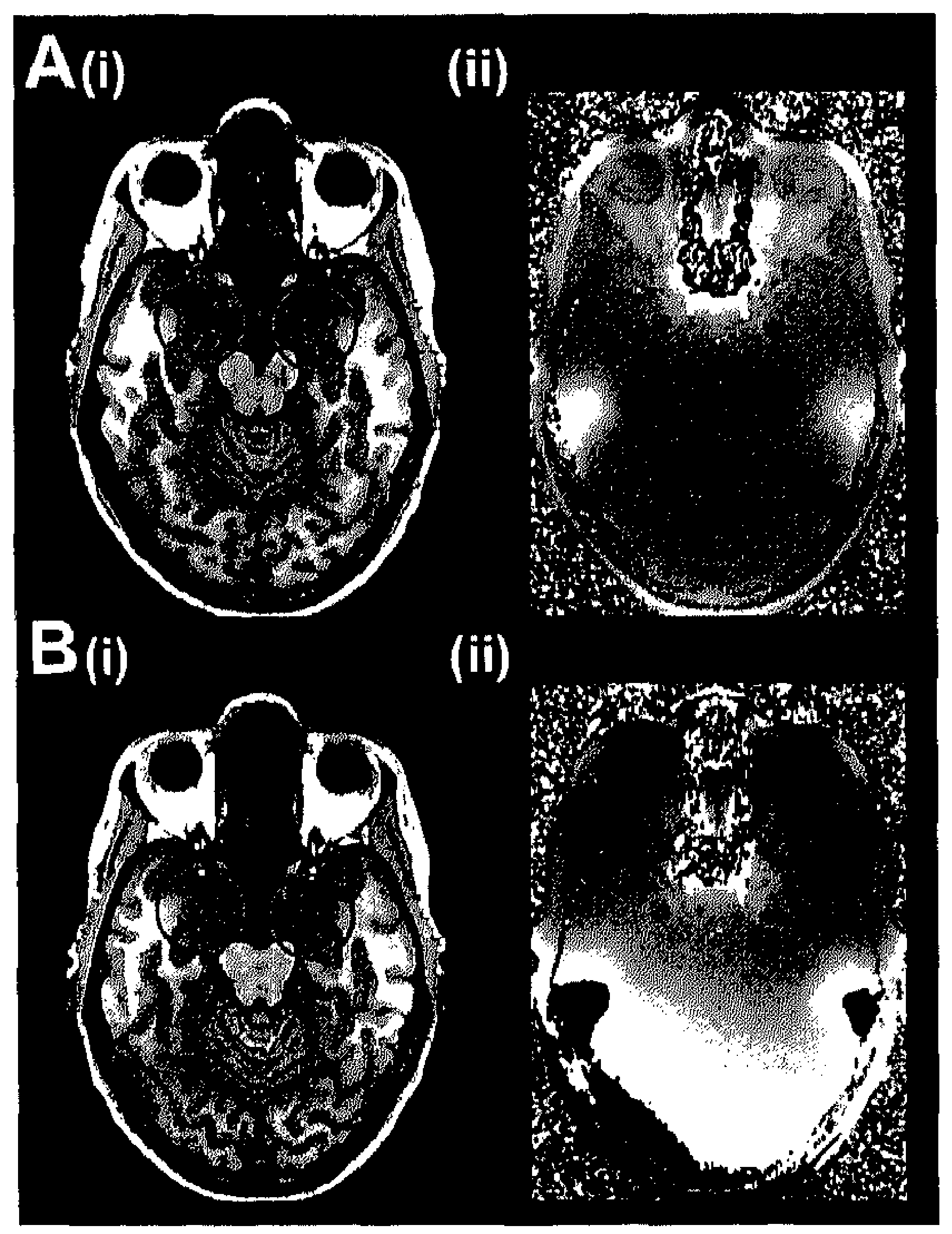

Fig. 1. Horizontal MRI sections of the anterior medial temporal lobe with red circles indexing the bilateral amygdala calcification lesions in Lipoid Proteinosis (Urbach-Wiethe) patients $A M$ and BG. Magnitude (Ai and $\mathrm{Bi}$ ) and phase (Aii and Bii) images are derived from the reconstructed 5 -average data sets acquired with $0.8 \mathrm{~mm}$ isotropic resolution. In the magnitude images, the lesion signal is reduced compared to intact tissue due to the combined effect of enhanced intra-voxel dephasing (susceptibility inhomogeneities) and calcification (reduced water content). Due to differential susceptibility between calcified regions and intact tissue, the amygdala lesions can be delineated more accurately in the phase images. A, magnitude (i) and phase (ii) images of patient $A M$. $\mathbf{B}$, magnitude (i) and phase (ii) images of patient $B G$.

\section{RESULTS}

A condition (positive, negative, neutral) $\mathrm{x}$ position (oddball, oddball \pm 1 ) $3 \times 3$ ANOVA restricted to the control sample yielded effects of condition $\left(F_{(2,30)}=13.527 ; p<\right.$ $\left..0001 ; \eta_{p}{ }^{2}=.474\right)$, position $\left(F_{(2,30)}=317.204 ; p<.0001 ; \eta_{p}{ }^{2}=.955\right)$, and condition $x$ position interaction $\left(F_{(4,60)}=13.698 ; p<.0001 ; \eta_{p}{ }^{2}=.477\right)$ effects. Post hoc one-sample $t$ tests verified the presence of retrograde $\mathrm{E}_{\mathrm{ngg}}-1$ amnesic $(-17.19 \%)\left(t_{(15)}=-3.212 ; p=.006\right)$ and $\mathrm{E}_{\text {pos }}{ }^{-1}$ hypermnesic $(+14.58 \%)\left(t_{(15)}=3.264 ; p=.005\right)$ as well as anterograde $\mathrm{E}_{\text {neg }}+1(-15.10 \%)\left(t_{115)}\right.$ $=-3.498 ; p=.003)$ and $\mathrm{E}_{\text {pos }}+1(-11.46 \%)\left(t_{(15)}=-3.083 ; p=.008\right)$ amnesic effects (Fig. $3 \mathrm{Ai}$ and Bi). Separate session (first, second, third) $x$ condition $3 \times 3$ within-subjects ANOVAs for oddballs $\left(F_{(2,30)}=1.215 ; p>.05\right)$ and standard items $\left(F_{(2,30)}=1.344 ; p>.05\right)$ indicated that 
performance remained unchanged throughout the experiment. Thus, our findings in controls replicated those reported previously (Hurlemann et al., 2005) and served as baseline for the subsequent analyses.

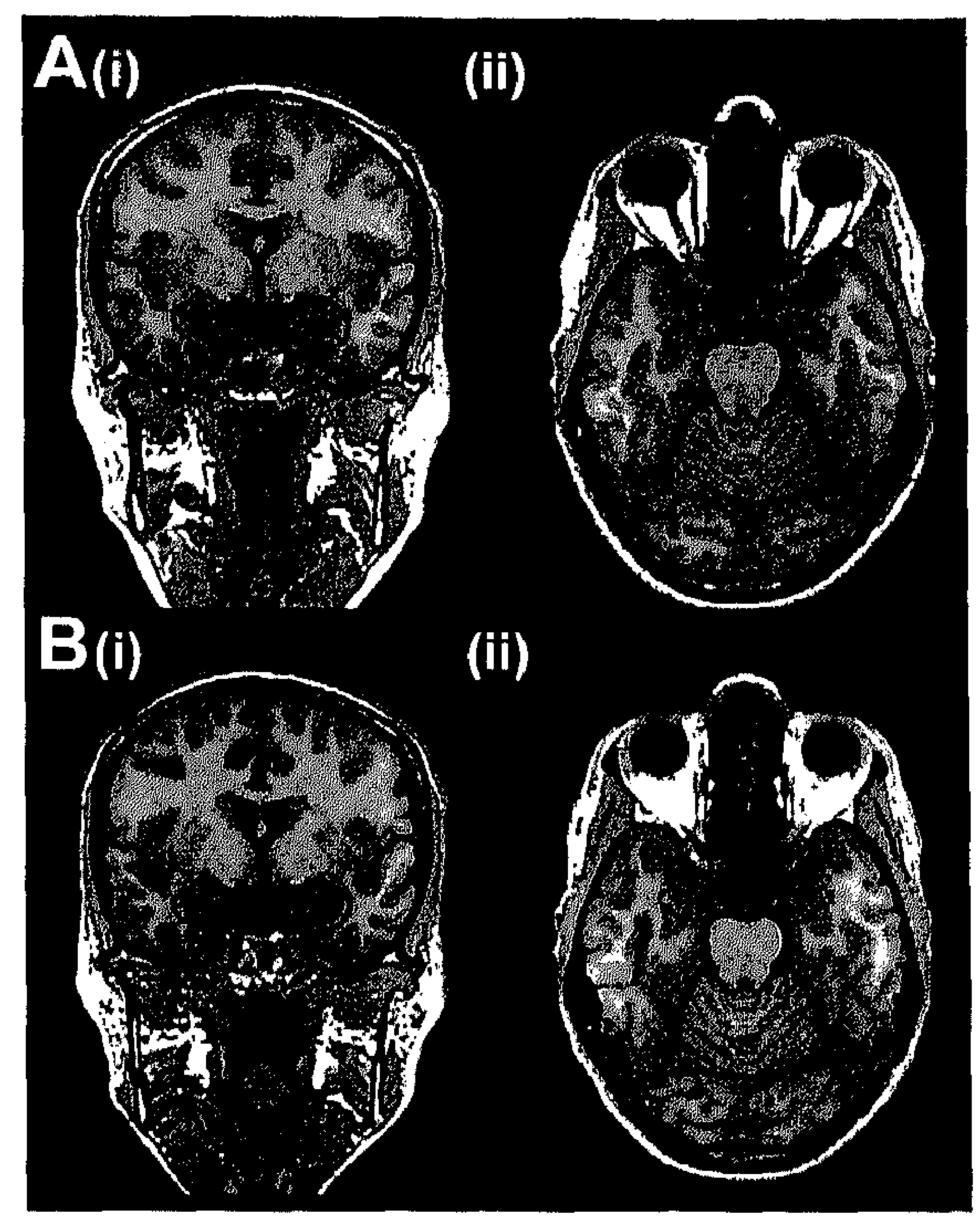

Fig. 2. Superposition of BLA stereotaxic cytoarchitectonic probabilistic maps on the amygdala in Lipoid Proteinosis (Urbach-Wiethe) patients $A M$ and $B G$. Equiprobability contures in blue indicate a $50 \%$ likelihood of a given voxel to be localized within the BLA. A, medial temporal lobe of patient $A M$ in coronal (i) and horizontal view (ii). B, medial temporal lobe of patient $B G$ in coronal (i) and horizontal view (ii). Abbreviations: BLA, basolateral amygdala constituted by the lateral, basolateral, and basomedial nuclei.

$A M^{\prime}$ 's and $B G^{\prime}$ 's individual recall scores were concerted into $\mathrm{Z}$ scores by reference to the mean and standard deviation of scores of the control sample (Table 2). The $\mathrm{Z}$ statistic indicated no performance difference between patients and controls in the neutral condition. Moreover, $A M$ and $B G$ performed similarly to controls on $\mathrm{E}_{\mathrm{x}}$ and $\mathrm{SI}_{\mathrm{x}}$ recall in the emotional conditions. In contrast, each of the patients performed outside the normal range on $E_{\text {neg }} \pm 1$ recall and $E_{\text {pos }}+1$ recall. Since no evidence was found for a differential contribution of the patients' individual performance to these results, $A M$ 's and $B G^{\prime}$ 's data were collapsed to one diagnostic sample. A group (controls, patients) $\mathrm{x}$ condition $\mathrm{x}$ position $2 \times 3 \times 3$ ANOVA yielded group $\left(F_{(1,16)}=12.698 ; p=.003 ; \eta_{p}{ }^{2}=.442\right)$, position $\left(F_{(2,32)}=107.598 ; p<.0001 ; \eta_{p}{ }^{2}\right.$ $=.871)$, and two-way position $\mathrm{x}$ group $\left(F_{(2,32)}=3.765 ; p=.034 ; \eta_{p}{ }^{2}=.190\right)$ interaction effects. Post hoc two-sample $t$ tests revealed between-group differences in $\mathrm{E}_{\text {neg }}-1\left(t_{(16)}=\right.$ $2.995 ; p=.009 ; d=2.38), \mathrm{E}_{\mathrm{ncg}}+1\left(t_{(16)}=-2.648 ; p=.018 ; d=2.11\right)$ and $\mathrm{E}_{\mathrm{pos}}+1\left(t_{(16)}=-\right.$ $2.437 ; p=.027 ; d=1.94)$ recall. The absence of a between-group difference in $\mathrm{E}_{\mathrm{pos}}-1\left(t_{(16)}=\right.$ $0.535 ; p>.05)$ recall is not compatible with preserved $\mathrm{E}_{\text {pos }}-1$ hypermnesic effects in $A M$ and $B G$, as $\mathrm{E}_{\mathrm{pos}}-1$ recall was not better than $\mathrm{P}-1$ recall in either of the patients. Together, these findings indicate no global memory dysfunction in $A M$ and $B G$, but a specific lack of 
emotion-induced memory increments and decrements, such that $E_{x} \pm 1$ recall equated $P \pm 1$ recall (Fig. 3 Aii and Bii).

Table 2

Free recall performance of female Lipoid Proteinosis (UrbachWiethe) patients $A M$ and $B G$ and controls $(n=16)$.

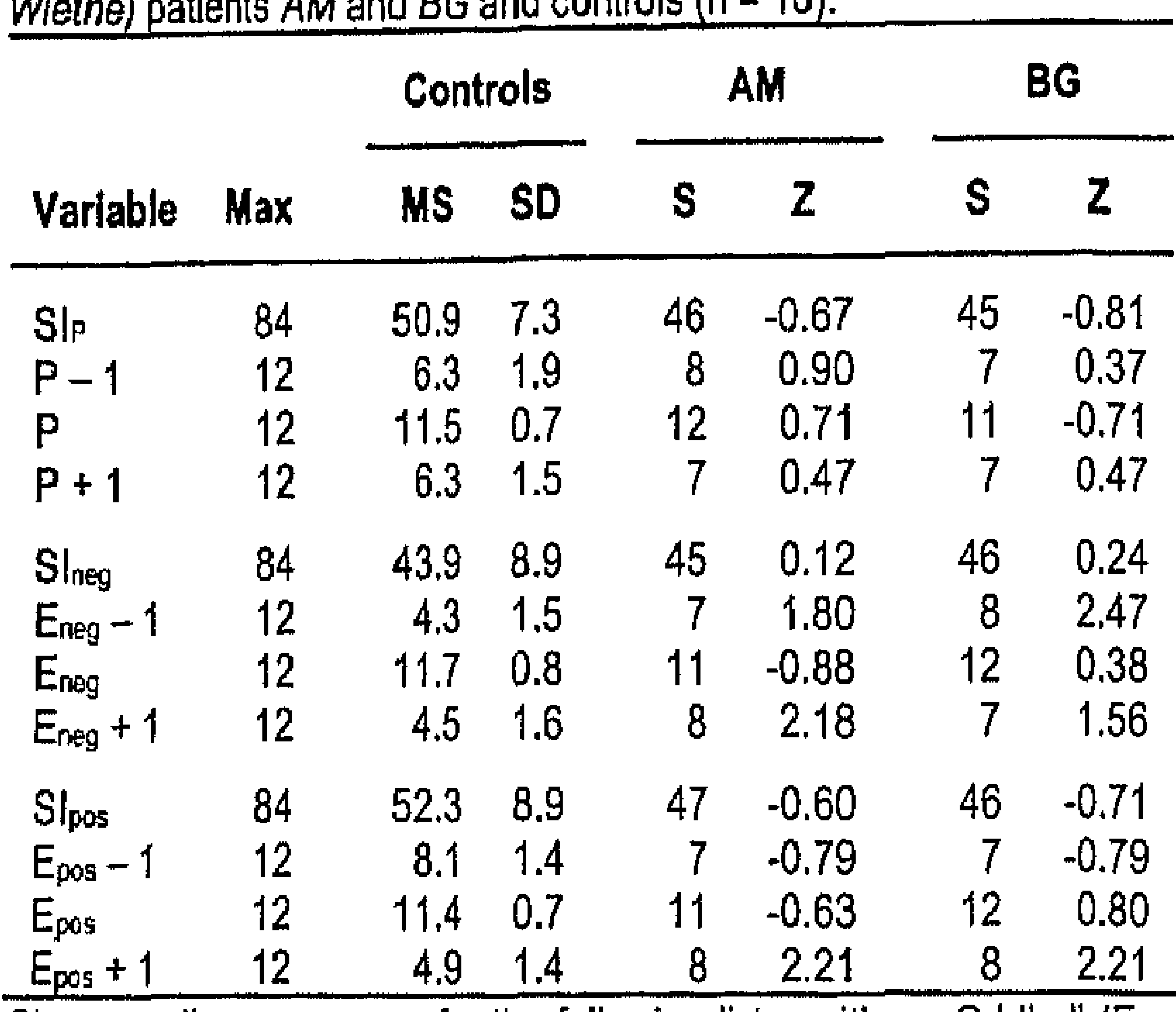

Given are the raw scores for the following list positions: Oddball $\left(E_{x_{1}}\right.$ $P)_{1}$ oddball $\pm 1\left(E_{x} \pm 1, P \pm 1\right)$ and standard items $\left(\left.S\right|_{x}, S \mid p\right)$. Abbreviations: Max, maximum possible score; MS, mean score; $S$, individual score; $S D$, standard deviation.

The oddball arousal and valence scores (mean \pm SD) obtained after memory testing were as follows: Controls: $\mathrm{E}_{\text {pos }} \mathrm{P}$ oddballs $(5.31 \pm 0.60,7.75 \pm 0.78) ; \mathrm{E}_{\text {neg }} \mathrm{P}$ oddballs $(5.25 \pm$ $0.58,2.31 \pm 0.48) ; P$ oddballs $(2.81 \pm 0.66,5.13 \pm 0.72)$. Patients: $(5.44 \pm 0.51,7.69 \pm 0.48)$; $\mathrm{E}_{\mathrm{neg}} \mathrm{P}$ oddballs $(5.19 \pm 0.54,2.44 \pm 0.51) ; \mathrm{P}$ oddballs $(2.94 \pm 0.57,5.25 \pm 0.45)$. Separate group (controls, patients) $\times$ oddball type (positive, negative, neutral) $2 \times 3$ ANOVAs yielded no significant between-group effects on either arousal scores or valence scores ( $p$ values $>$ $.05)$.

\section{DISCUSSION}

Organic syndromes rarely affect the anygdala selectively. If the brain lesion extends to adjacent temporal lobe memory structures, the patient is rendered amnesic, which complicates the study of amygdala-dependent episodic memory changes (LaBar and Cabeza, 2006). In the current neuropsychological experiment, we therefore focused on the $L P$ phenotype in $A M$ and $B G$ as a rare model system of selective amygdala dysfunction to determine the amygdala's role in valence-related $E_{x}-1$ retrograde and arousal-related $E_{x}+1$ anterograde episodic memory changes. The novel finding here is the absence of these specific changes in $A M$ and $B G$, which mimics that observed after anygdala suppression with propranolol in controls (Hurlemann et al., 2005). In our paradigm, perceptual-neutral (P) and perceptual-emotional $\left(\mathrm{E}_{\mathrm{x}} \mathrm{P}\right)$ oddballs were normalized for near-ceiling von Restorff effects to specify the influences of arousal and valence on $E_{x}$-dependent effects by using a subtractive design. While the perceptual component (P) of the von Restorff effect is intact in $A M$ and $B G$, the emotional component $\left(E_{\mathrm{x}}\right)$ is not (Strange et al., 2003), as indicated by the lack of 
retrograde $E_{x}-1$ and anterograde $E_{x}+1$ effects driven by this component (Fig. 3). We thus conclude that an intact amygdala is necessary for generating retrograde and anterograde episodic memory changes in response to positive and negative emotion.

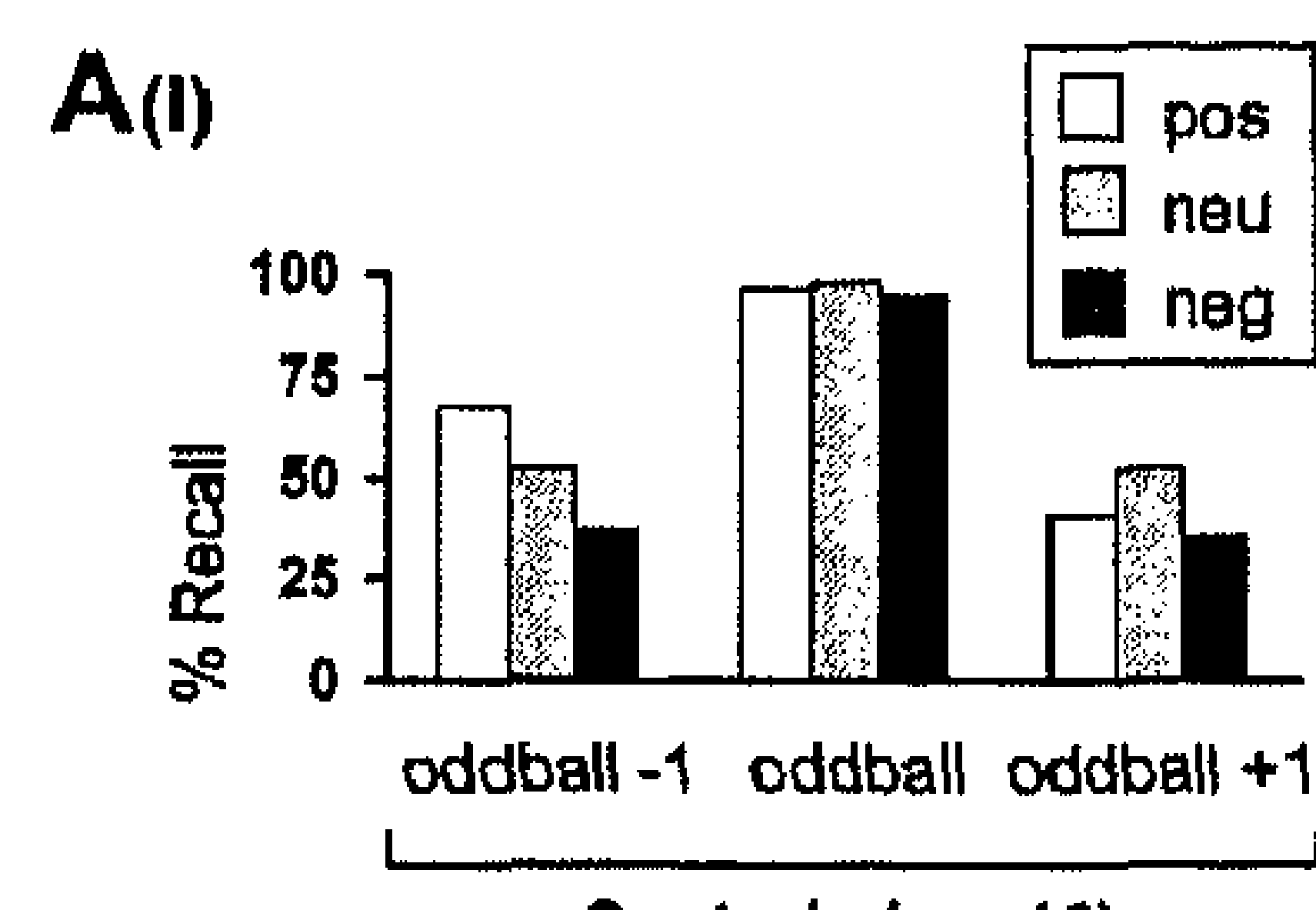

Controls $(\mathbf{n}=16)$

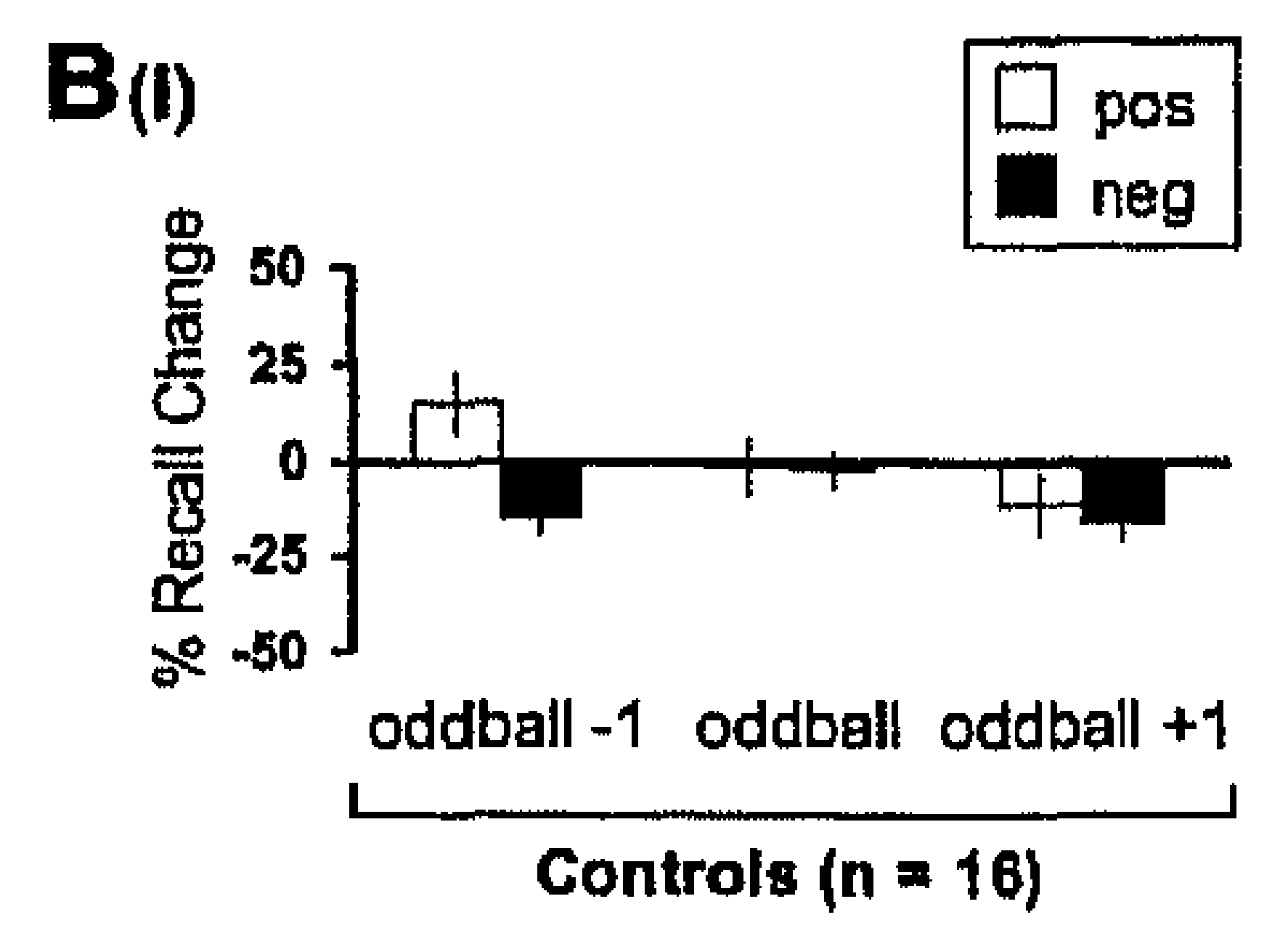

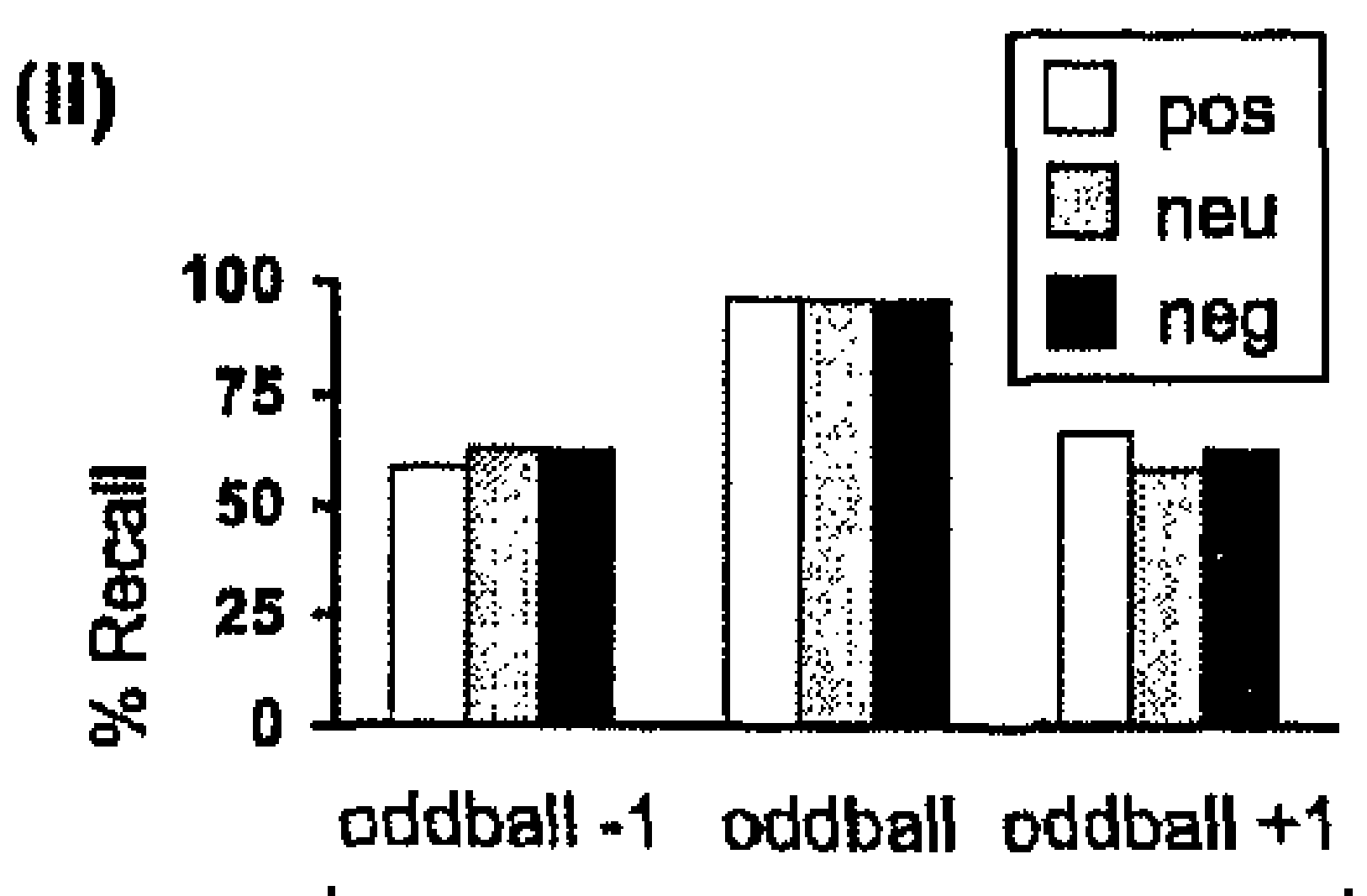

Patients $A M$ and BG

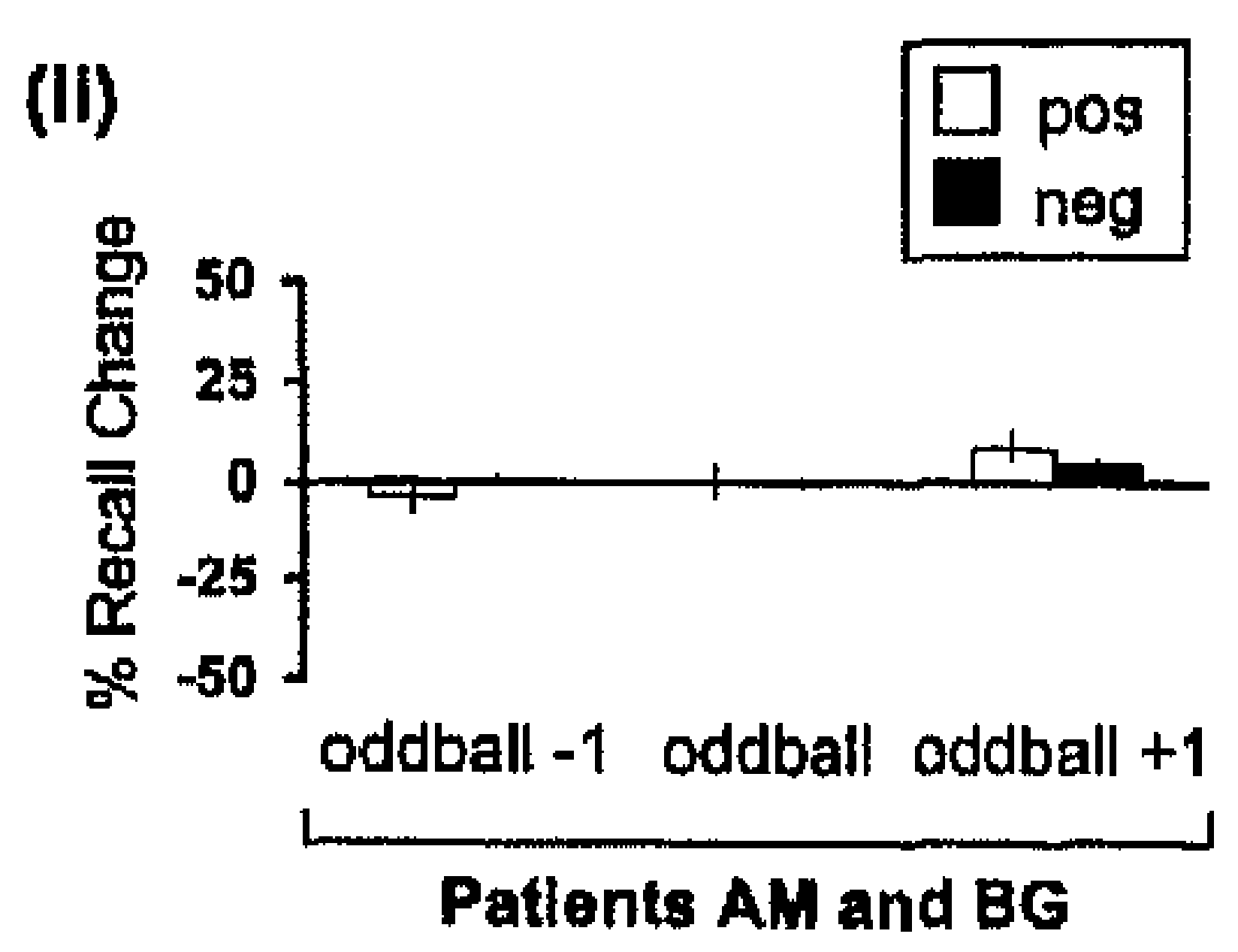

Fig. 3. Recall profile of female Lipoid Proteinosis (Urbach-Wiethe) patients $A M$ and $B G$ as compared to controls $(n=16)$. A, Percentage (\%) correct recall as determined in controls (i) and patients (ii). Global task performance and perceptual von Restorff effects were unaffected by bilateral amygdala lesion. B, Recall changes (\%) in controls (i) and patients (ii). In controls, but not in $A M$ and $B G$, enhanced memory for emotional oddballs was associated with valence-related retrograde and arousal-related anterograde memory changes for the surrounding standard items. Positive emotion elicited retrograde hypermnesia $(+14.58 \%)$ and anterograde amnesia $(-11.46 \%)$, whereas negative emotion elicited both retrograde $(-17.19 \%)$ and anterograde amnesia $(-15.10 \%)$. These emotion-induced memory increments and decrements are amygdala-dependent. Abbreviations: pos, positive; neu, neutral; neg, negative; oddball \pm 1 , standard itern preceding or following the oddball. Error bars indicate 1 SE.

The finding that $A M$ and $B G$ exhibit no arousal-related $\mathrm{E}_{\mathrm{x}}+1$ anterograde amnesic effects is consistent with deficient $E_{x}$ emotional item processing at the amygdala level and parallels the failure of gist memory effects (Adolphs et al., 2005) and an emotional modulation of the attentional-blink effect (Anderson and Phelps, 2001) in amygdala-lesioned patients. Our results emphasize the pivotal role of the amygdala in devoting attention to preferential encoding of $E_{x}$ emotional items. We suggest that this allocation of attentional resources as a function of emotional arousal is adaptive and can provoke a transient refractory period, of at least $5 \mathrm{sec}$ duration, which disrupts attentional re-orienting that is a prerequisite for encoding a following $E_{x}+1$ non-emotional item in the hippocampus.

Whereas arousal-related $E_{x}+1$ anterograde effects appear to reflect the cost of an amygdala-dependent capture of attention, $E_{x}-1$ retrograde effects most likely result from an interference of valence-specific input during emotional memory encoding with ongoing episodic encoding operations in hippocampus (Hurlemann et al., 2005). Our finding that an amygdala dependence of $E_{\text {neg }}-1$ retrograde amnesia (Strange et al., 2003) extends to $E_{\text {pos }}-1$ retrograde hypermnesia, raises the possibility that this input could be generated by the amygdala. However, both lesion and neuroimaging data (Hamann et al., 1999; Kensinger and 
Schacter, 2006) indicate no differential amygdala engagement during encoding of emotionally positive and negative stimuli, which supports the hypothesis of a neural segregation of arousal and valence influences on emotional memory encoding. This hypothesis states that the amygdala communicates arousal to the hippocampus to render it susceptible to valencespecific top-down input from prefrontal cortex (PFC) (Kensinger, 2004; Kensinger and Corkin, 2004; Dolcos et al., 2004b;). Given this background, we suggest that valence-related $\mathrm{E}_{\mathrm{x}}-1$ retrograde effects require arousal-driven amygdala-hippocampal interactions.

In animal models, intra-amygdalar infusions of $\mathrm{NE}$ agonistic and antagonistic drugs demonstrate LC-NE release within the BLA as an important neurochemical factor in the amygdala's control of emotional memory consolidation (McGaugh, 2000; 2004). Similarly, activation of the human amygdala during emotional memory encoding has been revealed to depend on a rise in intra-amygdalar LC-NE (Strange and Dolan, 2004; van Stegeren et al., 2005). Thus, emotional memory encoding and consolidation both appear to depend critically on LC-NE bottom-up activation of the BLA. In this study, we used stereotaxic cytoarchitectonic probabilistic maps to verify that amygdala calcifications in $A M$ and $B G$ encompassed the BLA (Fig. 2). The absence of $\mathrm{E}_{\mathrm{x}}-1$ retrograde effects in $A M$ and $B G$ as well as in controls treated with propranolol indicates that BLA dysfunction, whether due to anatomical lesion or pharmacological inhibition, can abolish an arousal-induced amygdalahippocampal coupling that is a prerequisite for the modification of ongoing episodic encoding operations by valence-specific input from PFC. Our finding that $\mathrm{E}_{\mathrm{x}}$ emotional item valence predicts subsequent memory for $E_{x}-1$ non-emotional items, suggests that amygdala- and LCNE-dependent valence-arousal interactions during emotional memory encoding contribute to a filter mechanism that segregates behaviorally significant items from less significant items, thus restricting the latter from consuming consolidation resources.

Whereas the memory-modulating effects of arousal and valence were absent in $A M$ and $B G$, both patients performed similarly to controls on arousal and valence ratings to emotional oddballs. This result is in keeping with previous reports that bilateral amygdala lesion does not affect the way patients judge arousal and valence attributes of emotional stimuli (Cahill et al., 1995; Adolphs et al., 1997; Anderson and Phelps, 2002). Arousal and valence judgments have indeed been to shown to engage PFC subregions rather than the amygdala (Dolcos and Cabeza, 2002; Dolcos et al., 2004b), which could explain why emotional oddball ratings are normal in $A M$ and $B G$, but significantly changed in controls treated with NE agonistic and antagonistic drugs acting in these subregions (Hurlemann et al., 2005).

Although neuroimaging studies of the amygdala indicate responsiveness to a wide range of facial expressions (Fitzgerald et al,, 2006), the amygdala plays a particular role in fear recognition (Phelps, 2006). Recognizing fear from facial expressions seems to depend primarily on the eye region (Whalen et al., 2004). Defective gaze monitoring has been identified as the critical pathomechanism for impaired fear recognition in patients with bilateral amygdala lesion (Adolphs et al., 2005a, b). However, in a large sample of 9 amygdala-lesioned patients, the ability to recognize fear varied from severely impaired to relatively intact (Adolphs et al., 1999). In the present stuy, $B G$, but not $A M$, was compromised in recognizing fear. The fact that $A M$ and $B G$ are monozygotic twins both suffering from $L P$ argues against a potential influence of dissociable aetiologies. In addition, there is no MRI evidence for significant differences in lesion size. The single clinical factor that distinguishes between the two cases, is that $B G$ 's lesion is epileptogenic. While we cannot exclude that deficient fear recognition in $B G$ could be related to epilepsy or anticonvulsive medication, we consider it more likely that the early onset of the disease during childhood and the slowly 
R. Hurlemann - The Costs and Benefits of Emotional Memory Formation

progressive amygdala degeneration with disease duration (Appenzeller et al., 2006) enables some $L P$ patients, like $A M$, to develop an alternate fear recognition network sparing the amygdala or cognitive strategies compensating their deficit.

The present study of 2 monozygotic twins with bilateral amygdala lesion, although limited by its casuistic nature and the restrictedness of neuropsychological testing, lends credence to the hypothesis that the amygdala has an adaptive role in allocating processing resources during emotional memory encoding, with behaviorally significant items receiving privileged memory access and insignificant items being filtered out. In so doing, the amygdala appears to serve the guidance of behavior rather than an accurate reproduction of the past.

W

Adolphs R, Cahill L, Schul R, Babinsky R (1997) Impaired declarative memory for emotional material following bilateral amygdala damage in humans. Learn Mem 4:291-300.

Adolphs R, Tranel D, Hamann S, Young AW, Calder AJ, Phelps EA, Anderson A, Lee GP, Damasio AR (1999) Recognition of facial expression in nine individuals with bilateral amygdala damage. Neuropsychologia 37:1111-1117.

Adolphs R, Tranel D, Buchanan TW (2005) Amygdala damage impairs emotional memory for gist but not details of complex stimuli. Nat Neurosci 8:512-518.

Adolphs R, Gosselin F, Buchanan TW, Tranel D, Schyns P, Damasio AR (2005) A mechanism for impaired fear recognition after amygdala damage. Nature 6:68-72.

Amunts K, Kedo O, Kindler M, Pieperhoff P, Mohlberg H, Shah NJ, Habel U, Schneider F, Zilles K (2005) Cytoarchitectonic mapping of the human amygdala, hippocampal region and entorhinal cortex: intersubject variability and probability maps. Anat Embryol (Berl) 210:343-352.

Anderson AK, Phelps EA (2001) Lesions of the human amygdala impair enhanced perception of emotionally salient events. Nature 411:305-309.

Anderson AK, Phelps EA (2002) Is the human amygdala critical for the subjective experience of emotion? Evidence of intact dispositional affect in patients with amygdala lesions. J Cogn Neurosci 14:709-720.

Angelini R, Capozzoli F, Lepore P, Grossi D, Orsini A (1994) "Experimental amnesia" induced by emotional items. Percept Mot Skills 78:19-28.

Appenzeller S, Chaloult E, Velho P, Araujo VZ, Cendes F, Li LM (2006) Amygdalae calcifications associated with disease duration in lipoid proteinosis. J Neuroimaging 16:154-156.

Aston-Jones G, Cohen JD (2005) An integrative theory of locus coeruleus-norepinephrine function: adaptive gain and optimal performance. Annu Rev Neurosci 28:403-450.

Cahill L, Prins B, Weber M, McGaugh JL (1994) Beta-adrenergic activation and memory for emotional events. Nature 371:702-704.

Cahill L, Babinsky R, Markowitsch HJ, McGaugh JL (1995) The amygdala and emotional memory. Nature 377:295-296.

Cahill L, Haier RJ, Fallon J, Alkire MT, Tang C, Keator D,Wu J, McGaugh JL (1996) Amygdala activity at encoding correlated with long-term, free recall of emotional information. Proc Nal Acad Sci USA 93:80168021 .

Canli T, Zhao Z, Brewer J, Gabrieli JD, Cahill L (2000) Event-related activation in the human amygdala associates with later memory for individual emotional experience. J Neurosci 20:RC99.

Craik FI, Govoni R, Naveh-Benjamin M, Anderson ND (1996) The effects of divided attention on encoding and retrieval processes in human memory. J Exp Psychol Gen 125:159-180.

Cycowicz YM, Friedman D, Rothstein M, Snodgrass JG (1997) Picture naming by young children: norms for name agreement, familiarity, and visual complexity. J Exp Child Psychol 65:171-237.

Dolcos F, Cabeza R (2002) Event-related potentials of emotional memory: encoding pleasant, unpleasant, and neutral pictures. Cogn Affective Behav Neurosci 2:252-263.

Dolcos F, LaBar KS, Cabeza R (2004a) Interaction between the amygdala and the medial temporal lobe memory system predicts better memory for emotional events. Neuron 42:855-863.

Dolcos F, LaBar KS, Cabeza R (2004b) Dissociable effects of arousal and valence on prefrontal activity indexing emotional evaluation and subsequent memory: an event-related fMRI study. Neuroimage 23:64 74.

Fitzgerald DA, Angstadt M, Jelsone LM, Nathan PJ, Phan KL (2006) Beyond threat: amygdala reactivity across multiple expressions of facial affect. Neuroimage 30:1441-1448. 
Hamada T, McLean WH, Ramsay M, Ashton GH, Nanda A, Jenkins T, et al. (2002) Lipoid proteinosis maps to Iq 21 and is caused by mutations in the extracellular matrix protein 1 gene (ECM1). Hum Mol Genet 11:33840.

Hamann SB, Lee GP, Adolphs R (1999) Imapired declarative emotional memory but intact emotional responses following human bilateral amygdalotomy. Society for Neuroscience Abstracts, 25, 99

Hamann SB, Ely TD, Grafton ST, Kilts CD (1999) Amygdala activity related to enhanced memory for pleasant and aversive stimuli. Nat Neuroscience 2:289-293.

Hamann S (2001) Cognitive and neural mechanisms of emotional memory. Trends Cogn Sci 5:394-400.

Harmer CJ, Hill SA, Taylor MJ, Cowen PJ, Goodwin GM (2003) Toward a neuropsychological theory of antidepressant drug action: increase in positive emotional bias after potentiation of norepinephrine activity. Am J Psychiatry 160:990-992.

Harmer CJ, Shelley NC, Cowen PJ, Goodwin GM (2004) Increased positive versus negative affective perception and memory in healthy volunteers following selective serotonin and norepinephrine reuptake inhibition. Am J Psychiatry 61:256-1263.

Helmstaedter C, Lendt M, Lux S (2001) Verbaler Lern- und Merkfähigkeitstest (VLMT), Göttingen: Hogrefe.

Holmes CJ, Hoge R, Collins L, Woods R, Toga AW, Evans AC (1998) Enhancement of MR Images Using Registration for Signal Averaging. J Comput Assist Tomogr 22: 324-333.

Hoult DI, Richards RE (1976) The signal-to-noise ratio of the nuclear magnetic resonance experiment. J Magn Reson Imaging 24:71-84.

Hurlemann R, Hawellek B, Matusch A, Kolsch H, Wollersen H, Madea B, et al. (2005) Noradrenergic modulation of emotion-induced forgetting and remembering.

J Neurosci 25:6343-6349.

Jenkinson M, Smith SM (2001) A global optimisation method for robust affine registration of brain images. Med Image Anal 5:143-156.

Jenkinson M, Bannister PR, Brady JM, Smith SM (2002) Improved optimisation for the robust and accurate linear registration and motion correction of brain images. Neuroimage 17:825-841,

Kensinger EA (2004) Remembering emotional experiences: the contribution of valence and arousal. Rev Neurosci 15:241-251.

Kensinger EA, Corkin S (2004) Two routes to emotional memory: distinct neural processes for valence and arousal. Proc Natl Acad Sci USA 101:3310-3315.

Kensinger EA, Schacter DL (2006) Amygdala activity is associated with the successful encoding of item, but not source, information for positive and negative stimuli. J Neurosci 26:2564-2570.

Kilpatrick L, Cahill L (2003) Amygdala modulation of parahippocampal and frontal regions during emotionally influenced memory storage. Neuroimage 20:2091-2099.

LaBar KS, Cabeza R (2006) Cognitive neuroscience of emotional memory. Nat Rev Neurosci 7:54-64.

Lang PJ (1995) The emotion probe. Studies of motivation and attention. Am Psychol 50:372-385.

Lang PJ, Bradley MM, Cuthberg BN (2005) International affective picture system (IAPS): Digitized photographs, instruction manual and affective ratings. Technical Report A-6. University of Florida, Gainesville, FL.

McGaugh JL (2000) Memory - a century of consolidation. Science 287: 248-251.

McGaugh JL (2004) The amygdala modulates the consolidation of memories of emotionally arousing experiences. Annu Rev Neurosci 27:1-28.

Mugler JP $3^{\text {td }}$, Brookeman JR (1991) Rapid three-dimensional Tl-weighted MR imaging with the MP-RAGE sequence. J Magn Reson Imaging 1:561-567.

Osterrieth PA (1944) Le test de copie d'une figure complexe. Arch Psychol 30 :206-356.

Phelps EA, LeDoux JF (2005) Contributions of the amygdala to emotion processing: from animal models to human behavior. Neuron 48:175-187.

Phelps EA (2006) Emotion and cognition: Insights from studies of the human amygdala. Annu Rev Psychol $57: 27-53$. Raitan RM (1958). Validity of the trail making test as an indication of organic brain damage. Percept Mot Skills
$8: 271-276$.

Rey A (1941) L'examen psychologique dans les cas d'encéphalopathie traumatique. Arch Psychol 30:286-340. Richardson MP, Strange BA, Dolan RJ (2004) Encoding of emotional memories depends on amygdala and
hippocampus and their interactions. Nat Neurosci 7:278-285.

Russell JA (1980) A circumplex model of affect. J Pers Soc Psychol 39:1 161-1178. Scoville WB, Milner B (1957) Loss of recent memory after bilateral hippocampal lesions. J Neurol Neurosurg
Psychiatry 20:11-21.

Siebert M, Markowitsch HJ, Bartel P (2003) Amygdala, affect and cognition: evidence from 10 patients with . Wiethe disease. Brain 126:2627-2637.

Snodgrass JG, Vanderwart M (1980) A standardized set of 260 pictures: norms for name agreement, image agreement, familiarity, and visual complexity. J Exp Psychol (Hum Learn) 6:174-215. 


\title{
R. Hurlemann - The Costs and Benefits of Emotional Memory Formation
}

\begin{abstract}
A, Hurlemann R, Dolan RJ (2003) An emotion-induced retrograde amnesia in humans is amygdalaeta-adrenergic-dependent. Proceedings of the National Acadamy of Sciences of the USA, 100, 136261.

B. A., \& Dolan, R. J. (2004). Betanadrenergic modulation of emotional memory-evoked human da I a and hippocampal responses. Proc Natl Acad Sci USA 101:11454-11458.

1991) Hamburg-Wechsler-Intelligenztest für Erwachsene - Revision 1991. Hogrefe: Göttingen.

(1969) Retrograde amnesia in free recall. Science 164:88-90.

sren AH, Everaerd W, Cahill L, McGaugh JL, Gooren LJ (1998) Memory for emotional events: ential effects of centrally versus peripherally acting beta-blocking agents. Psychopharmacology $05-310$.

эren AH, Goekoop R, Everaerd W, Scheltens P, Barkhof F, Kuijer JP, Rombouts SA (2005) Irenaline mediates amygdala activation in men and women during encoding of emotional material. jimage 24:898-909.

irff H (1933). Ueber die Wirkungen von Bereichsbildung im Spurenfeld. Psychologische Forschung 9-342.

er P, Richardson MP, Armony JL, Driver J, Dolan RJ (2004) Distant influences of amygdala lesion on I cortical activation during emotional face processing. Nat Neurosci 7:1271-1278.

NP (1965) Review of the historical empirical and theoretical status of the von Restorff phenomenon. 101 Bull 63:410-424.

J, Kagan J, Cook RG, Davis FC, Kim H, Polis S, et al. (2004) Human amygdala responsivity to ad fear ful eye whites. Science 306:2061.

, Cockburn J, Baddeley A, Hiorns R (1989). The development and validation of a test battery for ing and monitoring everyday memory problems. J Clin Exp Neuropsychol 11:855-870.

$\mathrm{S}$, Gottfried JA, Kilner JM, Dolan RJ (2005) Integrated neural representations of odor intensity and ive val ence in human amygdala. J Neurosci 25:8903-8907.

W, Perrett D, Calder A, Sprengelmeyer R, Ekman P (2002) Facial expressions of emotions: stimuli and 'EEST). Thurstone (UK): Thames Valley Test Company.
\end{abstract}

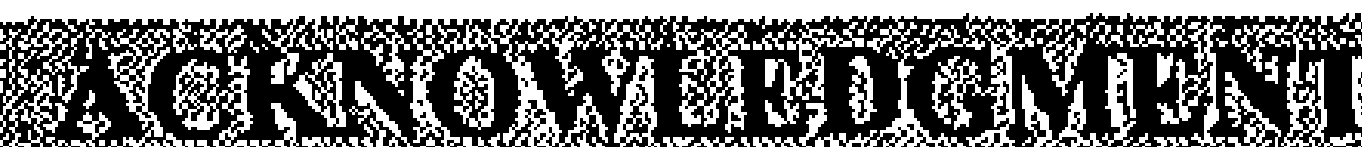

iors thank F. Buhtz for neuropsychology reporting, I. Frommann for statistical advice, ${ }^{r}$ ogeley for organizing MRI scanning. R. Hurlemann was supported by BONFOR and 1an Federal Ministry of Education and Research (BMBF).

an n $\mathbf{R}$, Wagner M, Hawellek B, Reich $\mathrm{H}$, Pieperhoff $\mathrm{P}$, Amunts $\mathrm{K}$, Oros-Peusquens ah NJ, Maier W, Dolan RJ (2007) Amygdala control of emotion-induced forgetting embering: Evidence from Urbach-Wiethe disease. Neuropsychologia 45:877-884. reproduced with permission of the copyright owner. Further reproduction prohibited ’ermission.) 


\section{CHAPTER 6}

\section{A methodological digression: \\ Analysis of neuroreceptor PET data based on cytoarchitectonic maximum probability maps}

-

Three-dimensional maximum probability maps of cytoarchitectonically defined cortical regions based on post-mortem histological studies have recently been made available in the stereotaxic reference space of the Montreal Neurological Institute (MNI) single subject template. This permits the use of cytoarchitectonic maps for the analysis of functional in vivo data sets, including receptor positron emission tomography (PET) studies. In this feasibility study, we used PET of 5-hydroxytryptamine $2 \mathrm{~A}\left(5-\mathrm{HT}_{2 \mathrm{~A}}\right)$ receptors to test the applicability of maximum cytoarchitectonic probability maps for quantitative analysis. As the outcome parameter, we extracted local distribution volume ratios (DVRs) from 19 cytoarchitectonically defined volumes of interest (VOIs) per hemisphere from five healthy subjects. The experimental design included a forward ('PET to atlas' normalization) and a backward ('atlas to PET' normalization) procedure to double-check the stability of transformation and overlay. Resulting DVRs were compared to receptor densities (RDs) obtained from post-mortem [ ${ }^{3} \mathrm{H} \mid$ ketanserin autoradiography of multiple Brodman areas (BAs). Correlations between the bidirectional normalization procedures $(r=0.89 ; 38$ VOIs) as well as between in vivo and in vitro data ( 9 VOIs; $r=0.64$ and $r=0.47$ for forward and backward procedure, respectively) suggest that the implementation of cytoarchitectonical maximum probabillity maps is a promising method for an accurate and observer-independent analysis of neuroreceptor PET data.

9.2 3 -

Accurate identification of cortical regions based on macroscopical topography is limited by the fact that macroscopical structures neither reflect the microscopical parcellation of the cerebral cortex nor its functional organization (Zilles et al., 2002). Therefore, a cytoarchitectonic probabalistic atlas of the human cerebral cortex based on post-mortem histological studies has been developed. Probabilistic maps of the motor (Geyer et al., 1996), somatosensory (Geyer et al., 1999, Grefkes et al., 2001), auditory (Morosan et al., 2001), and visual cortex (Amunts et al., 2000) as well as of Broca's region (Amunts et al., 1999), opercular regions (Eickhoff et al., 2002), and intraparietal areas (Choi et al., 2002) have been created. The underlying data rely on an observer-independent analysis of the cortical architecture of 10 post-mortem brains, which were sectioned into $20 \mu \mathrm{m}$ slices. Borders between cortical areas were identified on the basis of the laminar pattern using the gray-level index (GLI) as a measure of the volume fraction occupied by cell bodies (Schleicher et al., 1999). Resulting cytoarchitectonic data were 3D-reconstructed and warped onto the Montreal Neurological Institute (MNI) single subject reference brain (Evans et al., 1993; Collins et al., 
1994; Holmes et al., 1998) to enable anatomical labeling in stereotaxic space (Mohlberg et al., 2002 ) Equiprobability contures indicate the likelihood (e.g., $10 \%, 20 \%, \ldots 100 \%$ ) of a given voxel being localized in a cytoarchitectonically defined area.

Such cytoarchitectonic probability maps are typcially characterized by an overlap across areas. Based on these maps, maxinum probability maps (MPMs) have been calculated which assign to every voxel the maximum probability that it is localized in a particular anatomical area. Therefore, MPMs are more suitable for application in PET data analysis. In cases of overlap, isoprobability lines distinguish separate areas. In the remaining voxels, MPMs are based on $40 \%$ probability contures (Eickhoff et al., 2004). Note that in the set of regions thus far available, a minimum overlap and sparing of voxels between neighbouring regions occurrs with a $40 \%$ probability. MPMs permit the definition of continuous, nonoverlapping volumes of interest (VOIs), which can be used in the analysis of PET data sets. The MPMs used in this study were as follows: Brodman area (BA)1, BA2, BA3a, BA3b, $\mathrm{BA} 4 \mathrm{a}, \mathrm{BA} 4 \mathrm{p}, \mathrm{BA6}, \mathrm{V} 1$ (homologue to BA17), V2 (homologue to BA18), TE1.0 (part of BA41), TE1.1 (part of BA41), TE3 (partial homology with BA42 and with the putative Wernicke area), BA44 (part of Broca's area), BA45 (part of Broca's area), OP1, OP2, OP3, OP4 (OP1-OP4 are nearly homologous to the functionally defined secondary somatosensory cortex), AIP (anterior intraparietal), and VIP (ventral intraparietal).

The focus of the present study was to test the feasibility of MPMs for the regional analysis of neuroreceptor $\mathrm{PET}$ data. The cerebral $5-\mathrm{HT}_{2 \mathrm{~A}}$ receptor $\left(5-\mathrm{HT}_{2 \mathrm{~A}} \mathrm{R}\right)$ was investigated using $\left[{ }^{18} \mathrm{~F}\right] \mathrm{altanserin}$ for PET and its keto-analogue $\left[{ }^{3} \mathrm{H}\right]$ ketanserin for in vitro studies, respectively. Specifically, we investigated (a) the stability of the applied image analysis, as determined by double checking a forward procedure ('PET to atlas' normalization) to a backward procedure ('atlas to PET' normalization), (b) the selection of those MPMs that permit a stable PET analysis, and (c) an in vivo - in vitro comparison of PET and autoradiography data.

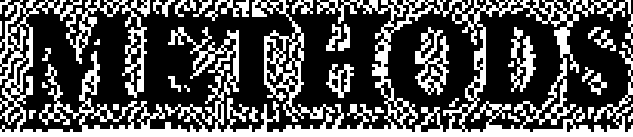

\section{Subjects}

Study protocols were approved by the Ethics Committee of the Medical Faculty of the University of Bonn, Germany, and the German Federal Office for Radiation Protection. Five healthy volunteers ( 2 female, 3 male; mean age $23 \pm 1.8$ yrs; range $21-25$ yrs) participated after giving written informed consent. Subjects were free of any medical, neurological or psychiatric conditions, including head injury, alcohol or substance abuse. Individual highresolution magnetic resonance imaging (MRI) was performed on a $1.5 \mathrm{~T}$ VISION scanner (Siemens, Erlangen, Germany) using a 3D T1-weighted magnetization-prepared rapidacquisition gradient-echo sequence (MP-RAGE) (voxel size 1 x $1 \times 1 \mathrm{~m}^{3}$ ). Human postmortem brains were obtained from the body donor program of the Anatomical Institute, Heinrich-Heine-University Düsseldorf, Germany. Brains from three donors (1 female, 77 years; 2 male, 54 and 77 years) without a history of neurological or psychiatric diseases were selected for in vitro receptor autoradiography. A detailed survey of experimental procedures has been given by Zilles et al. (2002). A total of 16 post-mortem brains was embedded in paraffin, cut, stained for cell bodies and analyzed with respect to cytoarchitecture at different cortical areas. For each area a subset of 10 brains was available to create cytoarchitectonic, probabilistic maps (Zilles et al,, 2002). 


\section{PET Imaging}

Radiosynthesis of $\left[{ }^{18} \mathrm{~F}\right]$ altanserin was performed at the Institute of Nuclear Chemistry, Research Center Jülich, according to Lemaire et al. (1990), followed by high performance liquid chromatography (HPLC) purification (Hamacher et al., 1995) with a radiochemical yield of $30 \%$ and a radiochemical purity of $>99 \%$. At the time of injection the mean specific radioactivity was $85 \mathrm{GBq} / \mu \mathrm{mol}$ (range: $27-138 \mathrm{GBq} / \mu \mathrm{mol}$ ). PET measurements were performed in 3D mode on a Siemens ECAT EXACT HR+ scanner (Siemens-CTI, Knoxville, TN, USA). Scatter from outside the field of view was reduced by inserting a lead ring into the scanner gantry. A 10 -min transmission scan $\left({ }^{68} \mathrm{Ge} /{ }^{68} \mathrm{Ga}\right)$ was obtained for attenuation correction. A bolus $(20 \mathrm{~s}$ ) with a mean radioactivity of $241 \mathrm{MBq}$ (range: $214-260 \mathrm{MBq}$ ) of $\left[{ }^{18} \mathrm{~F}\right]$ altanserin in $10 \mathrm{ml}$ saline was injected intravenously. Dynamic data were collected in 24 frames over a $60-\mathrm{min}$ period starting at time of injection. PET data were corrected for randoms, scatters, and attenuation, Fourier-rebinned into 2D sinograms, reconstructed by filtered backprojection (Shepp filter, $2.5 \mathrm{~mm}$ width) with a voxel size of $2 \times 2 \times 2.43 \mathrm{~mm}^{3}$ (63 slices), and decay-corrected.

\section{Image analysis}

Individual MRI data sets were oriented to the anterior commissure - posterior commissure line using a 3D image registration software (MPITool, ATV Co., Germany). Subsequently, a summed PET image (5-60 min) was co-registered to the realigned MRI, and co-registration parameters were applied to each PET frame. Image analysis was based on a set of $2 \times 19$ volumes of interest (VOIs) defined by 3D MPMs implemented in a supplementary toolbox (Eickhoff et al. 2004) for Statistical Parametric Mapping (SPM2, Wellcome Trust Functional Imaging Laboratory, London, UK).

Normalization was performed bidirectionally using SPM2. In a forward procedure, individual dynamic PET images were spatially normalized to the MNI single subject template. Normalization parameters were obtained from co-registered individual MRI volumes (voxel size $2 \times 2 \times 2 \mathrm{~mm}^{3}$ ). The MPM-VOI set was imported into a PET-analysis specific software (PMOD, V2.5, PMOD Group, Switzerland) and superimposed onto each normalized dynamic PET frame to generate time-activity curves (TACs). In a backward procedure, the single subject template, and thus the MPM-VOI set, was spatially normalized to individual MRI volumes. TACs were generated from each individual's native dynamical PET series. In both the forward and the backward procedure the cerebellum served as a reference region assuming that cerebellar $\left[{ }^{18} \mathrm{~F}\right]$ altanserin uptake mostly reflects free and non-specifically bound ligand (Pazos et al., 1987). For kinetic analyses, Logan's non-invasive graphical analysis (GA) (Logan et al., 1996) was applied. The relative distribution volume ratio (DVR) of $\left[{ }^{18} \mathrm{~F}\right]$ altanserin given by the slope of the linear part of the GA plot (start of linearization at 15 min) was used as an outcome parameter. DVR is directly related to the maximum number of receptors available for ligand binding $(B \max )$ : $D V R=1+f_{2} \times B \max / K D\left(f_{2}\right.$, tissue fraction of free ligand; $\mathrm{KD}$, dissociation constant of the receptor-ligand complex) (Abi-Dargham et al., 1994; Laruelle et al., 1994).

To enable comparison with autoradiography data, volume-weighted averages of corresponding left and right hemispheric VOIs were calculated. $5-\mathrm{HT}_{2 \mathrm{~A}} \mathrm{R}$ densities $\left(\mathrm{R}_{\mathrm{T}}\right.$, total receptor binding) obtained from post-mortem [ $\left.{ }^{3} \mathrm{H}\right]$ ketanserin autoradiography of 3 subjects were measured in 11 cytoarchitectonicaly identified regions based on adjacent Nissl stained sections (Zilles et al., 2002). Autoradiography data were not available for all regions of every 
R. Hurlemann - The Costs and Benefits of Emotional Memory Formation

subject. $R_{T}$ values differed between individuals in range and offset, but not in the rank-order of regions. Individual autoradiography data were therefore linearly normalized to the mean $R_{T}$ values available for 6 regions in each subject. Spearman's rank correlation coefficient was calculated between in vivo DVR values obtained from $\left[{ }^{18} \mathrm{~F}\right]$ altanserin $P E T$ and normalized $R_{T}$ values obtained from in vitro $\left[{ }^{3} \mathrm{H}\right]$ ketanserin autoradiography.

\section{RESULTS}

\section{PET analysis}

Visual inspection confirmed accurate fit of the MPMs to the functional PET data for both normalization procedures (Fig. 1), except for BA3a, which was excluded from further analysis because of its artificial white matter position. DVRs obtained from both forward and backward procedures are given in Table 1. Areas BA1, BA4, and BA6 showed the lowest DVRs, while the temporal subarea TE1.0, the opercular areas OP1, OP4, the anterior intraparietal area (AIP), and BA44 and 45 had high values. There was no evidence for a systematic difference of DVRs between left and right hemispheres.

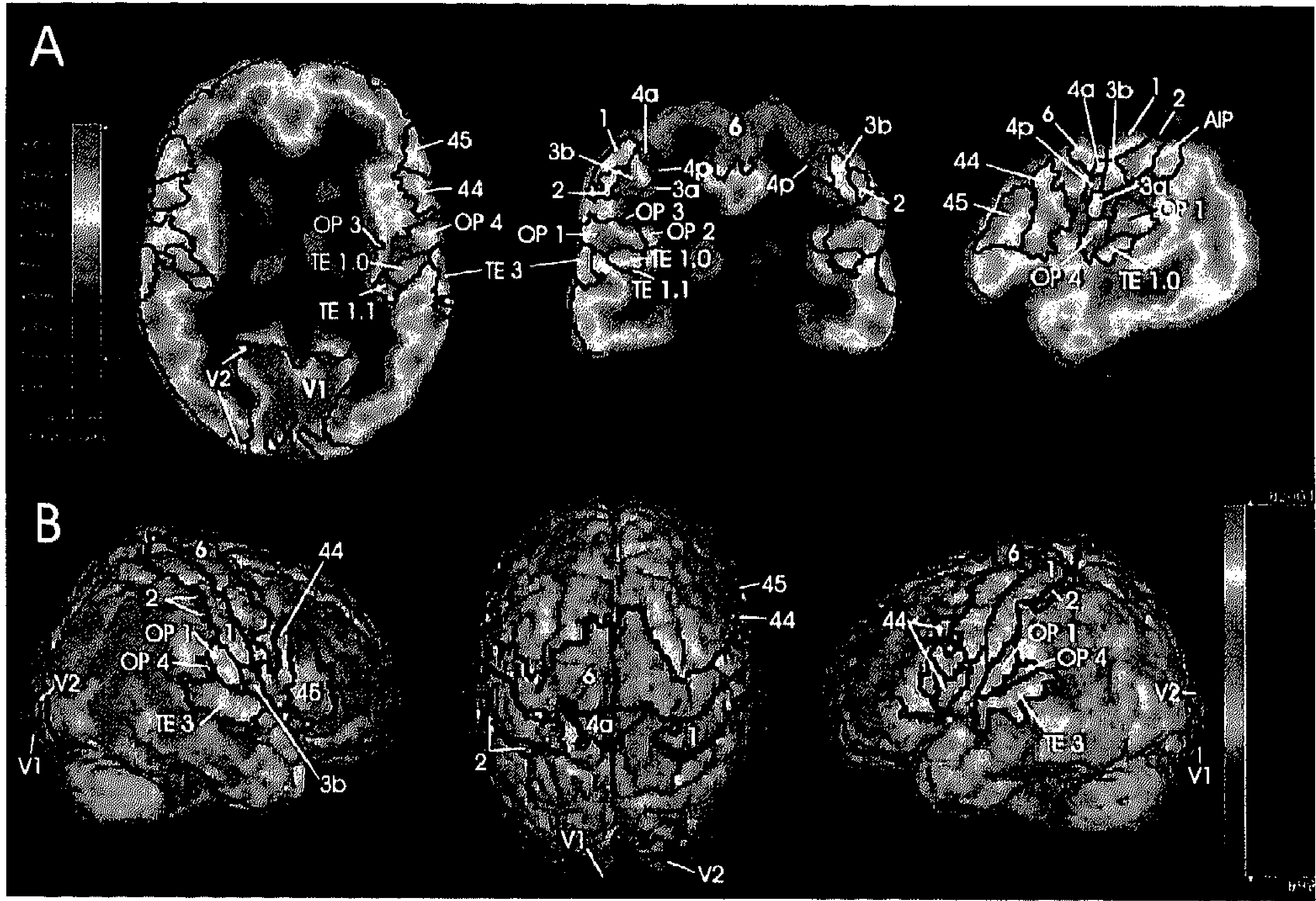

Fig. 1. Superposition of the cytoarchitectonic maximum probability atlas to functional PET data as exemplified in subject 2 (sum of 11 frames, 5-60 min, rainbow-scaled). Numbers of Brodman areas are indicated. A. Three orthogonal cross-sectional planes. B. Projection of PET data (maximum intensity across $6 \mathrm{~mm}$ ) onto the threedimensionally rendered MNI single subject brain. 


\section{Comparison of the procedures for bimodal overlay}

The relative DVR difference between the forward and backward procedures was low as given in Table 1 , exceeding $5 \%$ only in BA1, BA4p, VIP, OP 2 bilaterally, and in the left BA2 and OP3. DVRs were highly correlated between the forward and backward procedures ( $r$ $=0.89$ ). Iterative removal of the smallest region (Table 1) resulted in a correlation coefficient exceeding 0.95 for regions larger than $3.5 \mathrm{ml}$ and 0.975 for regions larger than $8 \mathrm{ml}$ (Fig. 2).

Table 1

\begin{tabular}{|c|c|c|c|c|c|c|c|c|c|c|}
\hline \multirow[b]{3}{*}{ area } & \multicolumn{7}{|c|}{ PET DVR ( $n=5 ; 2$ female; masn $=23,2$ yrs) } & \multirow{2}{*}{\multicolumn{3}{|c|}{$\begin{array}{l}\text { Automolography } \\
\text { friol } / g\end{array}$}} \\
\hline & \multicolumn{3}{|c|}{ lonward procedure } & \multicolumn{3}{|c|}{ backward procedure } & \multirow{2}{*}{$\begin{array}{l}\text { differenco } \\
\text { fonward } \\
\text { bactivard } \\
\%\end{array}$} & & & \\
\hline & $\begin{array}{c}\text { volume } \\
r / 1\end{array}$ & $\begin{array}{c}\text { mean } \\
r / 1\end{array}$ & $\begin{array}{l}\text { SD } \\
I / I\end{array}$ & $\begin{array}{c}\text { volume } \\
\text { [II }\end{array}$ & $\begin{array}{c}\text { maan } \\
r / I\end{array}$ & $\begin{array}{l}\text { SD } \\
111\end{array}$ & & $n ")$ & mean & SD \\
\hline BA1 & $5,7 / 7,3$ & $2,1 / 1,8$ & $0,28 / 0,24$ & $4,5 / 6,4$ & $1,8 / 1_{x} 7$ & $0,20 / 0,08$ & $9,3 / 7,3$ & $3 / 4$ & 384 & 136 \\
\hline BA2 & $8,0 / 8,4$ & $2,2 / 2,3$ & $0,18 / 0,18$ & $6,5 / 7,0$ & $2,3 / 2,3$ & $0,2110,20$ & $5,8 /-1,7$ & $3 / 4$ & 428 & 155 \\
\hline BA3b & $6,8 / 4,7$ & $2,1 / 2,2$ & $0,19 / 0,20$ & $5,8 / 4,8$ & $2,2 / 2,2$ & $0,2710,21$ & $-3,4 / 0,3$ & $3 / 4$ & 440 & 173 \\
\hline BA4a & $9,8 / 10,2$ & $1,8 / 1,8$ & $0,29 / 0,28$ & $8,6 / 777$ & $1,8 / 1,8$ & $0,18 / 0,22$ & $1,1 / 0,7$ & & & \\
\hline BA4p & $3,3 / 3,9$ & $1,711,8$ & $0,28 / 0,12$ & $2,4 / 3,1$ & $2,0 / 1,8$ & $0,1810,15$ & $-14,9 / 7,7,6$ & & & \\
\hline BA4 & & 1,8 & 0.28 & & 1,9 & 0,19 & $-2,2$ & $3 / 4$ & 289 & 83 \\
\hline BA6 & $34,1 / 32,4$ & $2,0 / 2,0$ & $0,23 / 0.25$ & $27,8 / 26,3$ & $1,8 / 1,9$ & $0,2410,21$ & $4,9 / 3,0$ & 23 & 327 & 216 \\
\hline V1 & $19,8120,8$ & $2,3 / 2,3$ & $0,10 / 0,11$ & $15,9 / 16,4$ & $2,3 / 2,3$ & $0,15 / 0,18$ & $1,3 / 2,1$ & 23 & 451 & 204 \\
\hline & $13,0 / 11,1$ & $2,3 / 2,2$ & $0,10 / 0,11$ & $11,5 / 10,1$ & $2,2 / 2,2$ & $0,13 / 0,15$ & $4,4 / 2,3$ & 23 & 414 & 151 \\
\hline TE 1.0.") & $1,8 / 1,6$ & $2,6 / 2,6$ & $0,28 / 0,28$ & $1.711,3$ & $2,7 / 2,7$ & $0,30 / 0,42$ & $-1,41 \cdot 4,4$ & & & \\
\hline TE $\left.1.1^{\circ}\right)$ & $1,3 / 1,2$ & $2,2 / 2,3$ & $0,14 / 0,27$ & $1,1 / 1,0$ & $2,2 / 2,2$ & $0,22 / 0,42$ & $-0,1 / 4,7$ & & & \\
\hline BA41 & & 2,4 & 0,25 & & 2,5 & 0,34 & 0,7 & $3 / 4$ & 432 & 216 \\
\hline TE3 & $6,0 / 6,5$ & $2,3 / 2,3$ & $0,19 / 0,16$ & $5,2 / 5,7$ & $2,3 / 2,4$ & $0,2410,15$ & $-0,3 i-3,6$ & $3 / 4$ & 417 & 135 \\
\hline BA44 & $6,618,4$ & $2,6 / 2,4$ & $0,2010,23$ & $5.6 / 8,0$ & $2,8 / 2,4$ & $0.2510,23$ & $-0,91-2,8$ & 112 & 178 & 13 \\
\hline BA45 & $8,1 / 6,6$ & $2,5 / 2,3$ & $0,18 / 0,22$ & $7,0 / 6,1$ & $2,5 / 2,4$ & $0,2210,22$ & $-1,0 /-2,1$ & $1 / 2$ & 145 & 52 \\
\hline AlP ? & $0,8 / 2,4$ & $2,8 / 2,3$ & $0,2810,23$ & $0,5 / 2.1$ & $2,8 / 2,4$ & $0,3310,18$ & $1,1 / 2,4$ & & & \\
\hline VIP " & $0,9 / 2,7$ & $1,8 / 2,1$ & $0,38 / 0.36$ & $0.812,2$ & $2,3 / 2,4$ & $0,3710,35$ & $-23,01-10,9$ & & & \\
\hline OP1" & $4,8 / 5,6$ & $2,5 / 2,4$ & $0,11 / 0,13$ & $3,8 / 5,0$ & $2,5 / 2,5$ & $0,1310,15$ & $-0,31 \cdot 0,8$ & & & \\
\hline OP2. & $1,2 / 1,7$ & $2,0 / 2,1$ & 0.1710 .28 & $1,010,8$ & $1,811,9$ & $0,1810,38$ & $7,4 / 10,7$ & & & \\
\hline OP3 & $1,7 / 1,8$ & $1,8 / 1,9$ & $0,27 / 0,13$ & $1,8 / 1,8$ & $1,911,9$ & $0,2110,17$ & $-5,1 / 2,4$ & & & \\
\hline OP4 ${ }^{\circ}$ & $3,8 / 4,7$ & $2,4 / 2,2$ & $0,26 / 0,22$ & $3,2 / 4,0$ & $2,4 / 2,3$ & $0,2310,18$ & $-2,5 /-3,1$ & & & \\
\hline Group & 282,6 & 2,150 & 0,197 & 234,8 & 2.142 & 0.199 & 0,4 & & & \\
\hline
\end{tabular}

") TE 1.0 and TE 1.1 are subareas of BA41, TE3 partially overlaps with BA42; AIP and VIP: anterior and ventrat intraparietal area; OP1-4 are nearly homologue to the functionally defined secondary somatosensory cortex, V1 and V2 are homologous to BA17 and BA18, respectively; $\left.{ }^{*}\right)$ number of subjects/number of hemispheres $n=4$ : all hemispheres; $n=3, B A 6$ from hemispheres $1,31,3 r ; B A 17$ and BA18 from hemispheres $2,3 r, 31, n=2$ : hemispheres $3 r$ and 31 .

\section{In vivo - in vitro correlation}

An overview of correlation coefficients is given in Table 2. In vivo - in vitro rank correlations exceeded 0.46 in all subjects with one exception (subject 4), which was also the outlier of the interprocedure correlation, suggesting a suboptimal overlay of PET and atlas in this particular individual. Fig. 3 depicts the relation of mean DVRs and autoradiography values. Autoradiographic data of areas 44 and 45 of broca's region were available only from one subject and, therefore, excluded. In vivo - in vitro correlation analysis based on the remaining 9regions yielded $r=0.64$ (forward procedure) and $r=0.47$ (backward procedure), respectively.

\section{Table 2}

\begin{tabular}{|c|c|c|c|}
\hline \multirow{2}{*}{$\begin{array}{c}\text { Correlation } \\
\text { coefficients } \\
\text { subject }\end{array}$} & \multirow{2}{*}{$\begin{array}{c}\text { PET to PET1 } \\
\text { (all } 38 \text { regions) } \\
\text { forward to } \\
\text { backward }\end{array}$} & \multicolumn{2}{|c|}{$\begin{array}{l}\text { PET to mean } \\
\text { autoradiography } 2 \\
\text { (9 of } 11 \text { reglons) }\end{array}$} \\
\hline & & $\begin{array}{l}\text { forward } \\
\text { procedure }\end{array}$ & $\begin{array}{l}\text { backward } \\
\text { procedure }\end{array}$ \\
\hline 1 & 0.85 & 0.52 & 0.47 \\
\hline 2 & 0.95 & 0.65 & 0.48 \\
\hline 3 & 0.96 & 0.55 & 0.55 \\
\hline 4 & 0.55 & 0.38 & 0.37 \\
\hline 5 & 0.70 & $0.80^{*}$ & $0.65^{\star}$ \\
\hline mean & 0.89 & 0.64 & 0.47 \\
\hline
\end{tabular}

1) Pearson's linear correlation coefficient; ${ }^{2}$ ) Spearman's rank

correlation coefficient; *) $p<0.05$ 
In the present study, we tested the applicability of cytoarchitectonic MPMs to generate TACs for VOI-based neuroreceptor PET analysis. The experimental design comprised a forward and a backward procedure to control for possible confounding factors (e.g., recalculation of pixel values in the forward procedure, non-reversible operations, observerdependent confounds) resulting from spatial normalization. In general, different procedures exist to extract TACs from VOIs. If mean activities across each VOI are to be measured, a normalization should be chosen that preserves pixel-wise mean activity. Conversely, if the focus is on summed activity within a VOI, a normalization should be chosen that preserves total activity. In our analysis, normalization was done the first way, and $2 \times 19$ VOIs were compared to each other and to in vitro autoradiography. We found almost identical DVRs following both the forward and backward procedure. For spatial transformation into stereotaxic space, we applied the nonaffine spatial normalization routine implemented in SPM2, which allows the use of unsegmented native structural MRIs. Alternative normalization routines (e.g., Mohlberg et al., 2003) require elaborate pre-processing including segmentation and/or skull stripping of the structural MRI datasets.

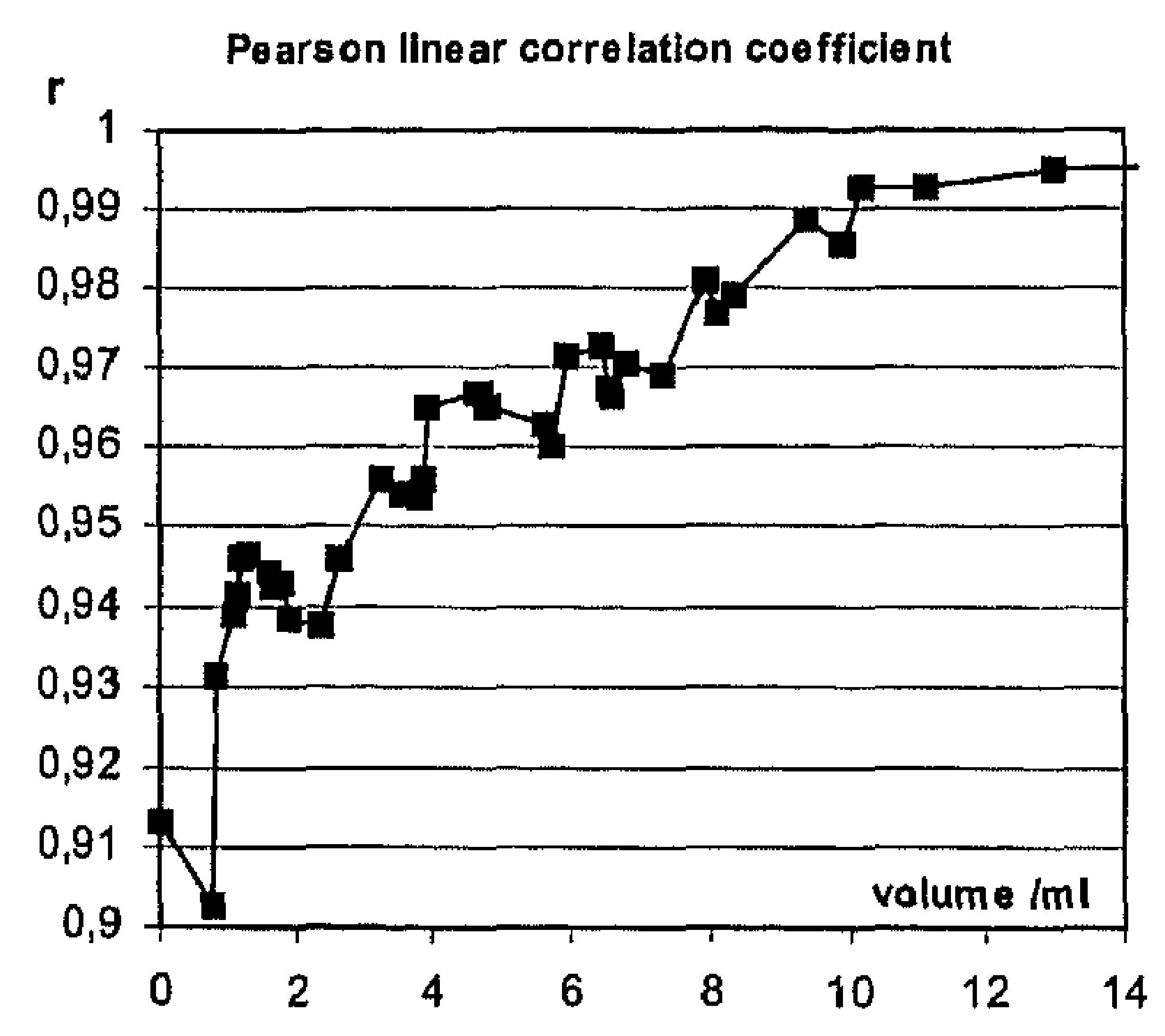

Fig. 2. Correlation between distribution volume ratios (DVRs) obtained from the forward and backward normalization procedures in dependency of the volume of the smallest region. Iterative removal of the smallest region results in a correlation coefficient exceeding 0.95 for regions larger than $3.5 \mathrm{ml}$ and 0.975 for regions larger than $8 \mathrm{ml}$.

The gross uptake of radioactivity in $\left[{ }^{18} \mathrm{~F}\right]$ altanserin PET and the derived DVRs do not directly reflect $5-\mathrm{HT}_{2 \mathrm{~A}} \mathrm{R}$ density, as they are confounded by (a) the uptake of the blood brain barrier-penetrating labeled metabolites $\left[{ }^{18} \mathrm{~F}\right]$ altanserinol and $\left[{ }^{18} \mathrm{~F}\right](4$-fluorophenyl)-pyridine and (b) non-specific binding of $\left[{ }^{18} \mathrm{~F}\right]$ altanserin itself (Tan et al., 1999; Price et al., 2001a, b). As these effects also occur in the reference region (cerebellum), 5-HT $\mathrm{T}_{\mathrm{A}} \mathrm{R}$ density tends to be underestimated by DVR measurements. Furthermore, the PET signal is dispersed due to partial volume effects.

Since spatial resolution of PET is limited, attempts have been made to determine the minimum ROI size critical for PET analysis. In a methodological study on cylindrical objects, 
Hoffman et al. (1979) found an object size of $1.5 \times$ FWHM (full width of half maximum) in each direction $(x, y, z)$ to permit a recovery of object radioactivity with recovery coefficiants (RC) higher than $95 \%$. In our settings this would correspond to a volume of $0,5 \mathrm{ml}$. Because cortical areas are not cylindrical, the relation of volume to VOI surface may represent an adequate parameter to characterize a VOI's shape. However, VOI surface is not easy to assess by means of standard software. In order to identify those MPMs from the atlas which are large enough to enable stable PET analysis, we arranged MPMs by volume and calculated interprocedure correlation coefficients by iteratively removing the smallest MPMs. At a volume of $\geq 3.5 \mathrm{ml}$, the interprocedure correlation coefficient exceeded 0.95 . As there was some interindividual variation of the interprocedure correlation, it appears useful to check forward and backward results to control for suboptimal outcome due to atypical brain morphology. Note that the outcome of normalization, and resulting DVR differences, may be biased due to the localization of some regions in a sulcus (e.g., BA3a, OP2, VIP). This is particularly the case for $\mathrm{BA} 3 \mathrm{a}$, thus explaining its artificial white matter position after normalization to the single-subject template. Suboptimal overlay of PET and atlas in subject 4 may result from an atypical distribution of cytoarchitectonic regions across gyri and sulci in this particular subject.

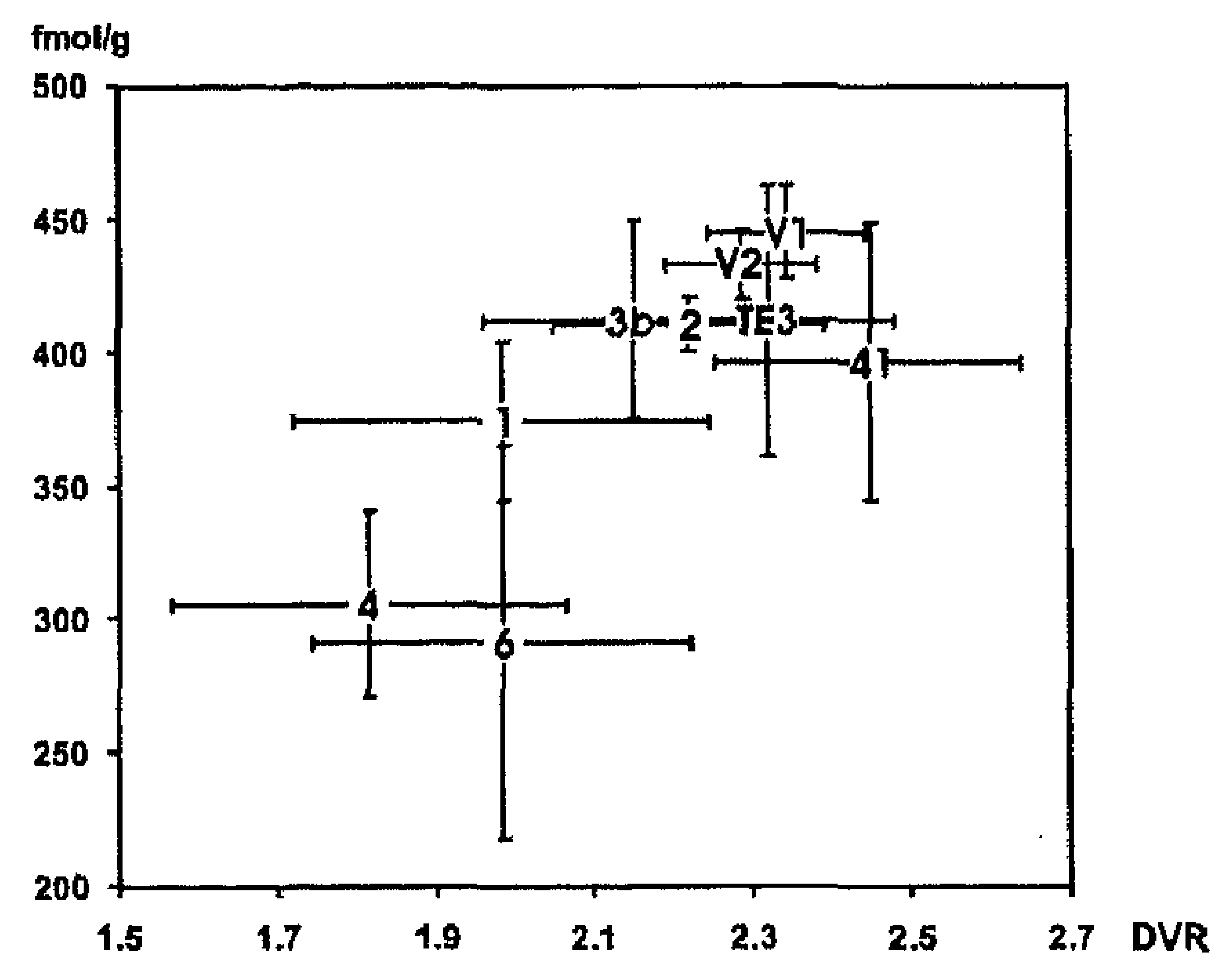

Fig. 3. Scatter plot of the relation of PET data obtained from the forward procedure to linearly normalized receptor densities (fmol/g) obtained from post-mortem autoradiography for 9 corresponding cytoarchitectonic regions: BA1, 2, 3b, 4, 6, V1, V2, BA41, and TE3. Standard deviations are indicated by vertical and horizontal bars.

Consistent with the literature (e.g., Pazos, 1987; Adams et al., 2004), in both PET and autoradiography radioligand binding was highest in BA17 and BA18 and lowest in BA4 and BA6. The low correlation between PET and autoradiography data seems to question the validity of our approach; however, one should note that sample sizes were small, and the number of regions entered into statistical comparison was further reduced by a lack of autoradiographic data. $A$ priori exclusion of areas BA44 and 45 from in vivo - in vitro comparison was necessary, because in vitro data were available from one subject only. Furthermore, regional differences of relative decline of $\left[{ }^{18} \mathrm{~F}\right]$ altanserin binding with age (Adams et al., 2004: similar decline for ventrolateral frontal, superior temporal and sensorimotor areas, but low decline for occipital areas) could account for a non-linear distortion of the regional pattern of $\left[{ }^{18} \mathrm{~F}\right]$ altanserin binding. $A$ higher correlation of 
autoradiography and PET data could be achieved by applying partial volume correction (Koepp et al., 1989), age-mached comparison groups, and larger VOIs. In conclusion, the application of cytoarchitectonic MPMs for the a priori definition of VOIs in neuroreceptor PET analysis is feasible. By accounting for the cytoarchitectonic organization of the cerebral cortex and by avoiding observer-dependent bias, the suggested atlas approach is superior to a manual definition of VOIs. This advantage is of particular interest in studies of clinical populations that show normal morphological indices, but focal neurochemical abnormalities.

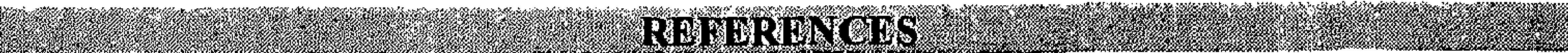

Abi-Dargham A, Laruelle M, Seibl J, Rattner Z, Baldwin RM, Zoghbi SS, Zea-Ponce Y, Bremmer JD, Hyde TM, Charney DS, Hoffer PB, Innis RB (1994) SPECT Measurement of Benzodiazepine receptors in Human Brain with Iodine-123-lomazenil: Kinetic and equilibrium Paradigms. J Nucl Med 35:228-238.

Adams KH, Pinborg LH, Svarer C, Hasselbalch SG, Holm S, Haugbol S, Madsen K, Frokjaer V, Martiny L, Paulson OB, Knudsen GM (2004) A database of [(18)F]-altanserin binding to 5-HT(2A) receptors in normal volunteers: normative data and relationship to physiological and demographic variables. Neuroimage 21:1105-1113.

Amunts K, Schleicher A, Zilles K (2002) Architectonic mapping of human cerebral cortex. In: Cortical areas: unity and diversity. Schütz A, Miller R (eds.) Herwood academic publishers 29-52.

Amunts K, Schleicher A, Buergel U, Mohlberg H Uylings HBM, Zilles K (1999) Broca's region revisited: Cytoarchitecture and intersubject variability. J Comp Neurol 412:319-341.

Amunts K, Malikovic A, Mohiberg H, Schormann T, Zilles, K (2000) Brodmann's areas 17 and 18 brought into stereotaxic space - where and how variable? Neuroimage 11:66-84.

Choi HJ, Amunts K, Mohlberg H, Fink GR, Schleicher A, Zilles K (2002) Cytoarchitectonic Mapping of the Anterior Ventral Bank of the Intraparietal Sulcus in Humans. Human Brain Mapping 2002 Meeting Neuroimage 16:\$591.

Collins DL, Neelin P, Peters TM, Evans AC (1994) Automatic 3D intersubject registration of MR volumetric data in standardized Talairach space. J Comp Assisted Tomography 18:192-205.

Eickhoff S, Geyer S, Amunts K, Mohlberg H, Zilles K (2002) Cytoarchitectonic analysis and stereotaxic map of the Human Secondary Somatosensory Cortex Region. Human Brain Mapping 2002 Meeting Neuroimage 16: $S 792$

Eickhoff S, Mohlerg H, Stephan KE, Fink GR, Zilles K, Amunts K (2004) A new SPM toolbox for the combined analysis of AMRI data and probabilistic cytoarchitectonic maps. Human Brain Mapping 2004 Meeting Poster No. WE 167

Eickhoff S, Walters NB, Schleicher A, Krill J, Egan GF, Zilles K, Watson JDG, Amunts K (2004) Highresolution MRI reflects myeloarchitecture and cytoarchitecture of human cerebral cortex. Human Brain Mapping 24:206-215.

Evans AC, Collins DL, Mills SR, Brown ED, Kelly RL, Peters TM (1993) 3D statistical neuroanatomical models from 305 MRI volumes. Nuclear Science Symposium and Medical Imaging Conference, 1993 IEEE Conference Record 3:1813-1817.

Geyer S, Ledberg A, Schleicher A, Kinomura S, Schormann T, Buergel U, Klingberg T, Larsson J, Zilles K, Roland PE (1996) Two different areas within the primary motor cortex of man. Nature 382:805-807.

Geyer S, Schleicher A, Zilles K (1999) Area 3a, 3b, and 1 of human primary somatosensory cortex: 1 . Microstructural organization and interindividual variability, Neuroimage 10:63-83.

Geyer S, Schormann T, Mohlberg H, Zilles K (2000) Areas 3a, 3b, and 1 of human primary somatosensory cortex: 2. Spatial normalization to standard anatomical space. Neuroimage 11:684-696.

Geyer S, Schleicher A, Schormann T, Mohlberg H, Bodegard A, Roland PE, Zilles K (2001) Integration of microstructural and functional aspects of human somatosensory areas $3 \mathrm{a}, 3 \mathrm{~b}$, and 1 on the basis of a computerized brain atlas. Anat Embryol (Berl) 204:351-366.

Grefkes C, Geyer S, Schormann T, Roland P, Zilles K (2001) Human somatosensory area 2: observerindependent cytoarchitectonic mapping, interindividual variability, and population map. Neuroimage. $14: 617-631$

Hamacher K, Hamkens W. (1995) Remote controlled one step production of ${ }^{18} \mathrm{~F}$ labeled butyrophenone neuroleptics exemplified by the synthesis of n.c.a. [18F]N-methyl-spiperone. Appl Radiat Isot 46:911-916.

Hoffman EJ, Huang SC, Phelps ME (1979) Quantitation in positron emission computed tomography: 1. Effects of object size. J Comput Assist Tomogr 3:299-308. 
R. Hurlemann - The Costs and Benefits of Emotional Memory Formation

Holmes CJ, Hoge R, Collins L, Woods R, Toga AW, Evans AC (1998) Enhancement of MR images using registration for signal averaging. J Comput Assist Tomogr 22:324-333.

Koepp MJ, Hand KS, Labbe C, Richardson MP, Van Paesschen W, Baird VH, Cunningham VJ, Bowery NG, Brooks DJ, Duncan JS (1998) In vivo [11C]flumazenil-PET correlates with ex vivo [3H]flumazenil autoradiography in hippocampal sclerosis. Ann Neurol 43:618-626.

Laruelle M, Baldwin RM, Rattner Z, Al-Tikriti MS, Zea-Ponce Y, Zoghbi SS, Charney DS, Price JC, Frost JJ, Hoffer PB, Innis RB (1994) J Cereb Blood Flow Metab 14:439-452.

Lemaire C, Cantineau R, Guillaume M, Pleneveaux A, Christiaens L (1991) Fluorine-18-Altanserin: A Radioligand for the Study of Serotonin Receptors with PET: Radiolabeling and In Vivo Biologic Behavior in Rats. J Nucl Med 32:2266-2272.

Logan J, Fowler JS, Volkow ND, Wang GJ, Ding YS, Alexoff DL (1996) Distribution volume ratios without blood sampling from graphical analysis of PET data. J Cereb Blood Flow Metab 16:834-840.

Mohlberg H, Evans AC, Lerch J, Amunts K, Zilles K (2003) Probabilistic cytoarchitectonic maps transformed into MNI space. Human Brain Mapping 2003 Meeting Neurolmage 19:S905.

Morosan P, Rademacher J, Schleicher A, Amunts K, Schormann T, Zilles K (2001) Human primary auditory cortex: Cytoarchitectonic subdivisions and mapping into a spatial reference system. Neuroimage 13:684701.

Pazos A, Probst A, Palacios JM. (1987) Serotonin receptors in the human brain--IV. Autoradiographic mapping of serotonin-2 receptors. Neuroscience 21:123-139.

Price JC, Lopresti BJ, Mason NS, Holt DP, Huang Y, Mathis CA (2001a) Analyses of [(18)F] altanserin bolus injection PET data. I: consideration of radiolabeled metabolites in baboons. Synapse 41:1-10.

Price JC, Lopresti BJ, Meltzer CC, Smith GS, Mason NS, Huang Y, Holt DP, Gunn RN, Mathis CA (2001b) Analyses of [(18)F]altanserin bolus injection PET data. II: consideration of radiolabeled metabolites in humans. Synapse 41:11-21.

Schleicher A, Amunts K, Geyer S, Morosan P, Zilles K (1999) Observer-independent method for microstructural parcellation of cerebral cortex: a quantitative approach to cytoarchitectonics. Neuroimage 9:165-177.

Tan PZ, Baldwin RM, VanDyck CH, Al-Tikriti M, Roth B, Khan N, Charney DS,Innis RB (1999) Characterization of Radioactive Metabolites of 5-HT2A-Receptor PET Ligand $\left[{ }^{18} \mathrm{~F}\right]$ Altanserin in Human and Rodent. Nuclear Med Biol 26:601-608.

Zilles K, Palomero-Gallagher N, Grefkes C, Scheperjans F, Boy C, Amunts K, Schleicher A (2002) Architectonics of the human cerebral cortex and transmitter receptor fingerprints: reconciling functional neuroanatomy and neurochemistry. Eur Neuropsychopharmacol 12:587-599.

Zilles K, Schleicher A, Palomero-Gallagher N, Amunts K (2002) Quantilative analysis of cyto- and receptor architecture of the human brain. In: Brain Mapping: the methods. Mazziotta JC , Toga A (eds.) USA: Elsevier; 573-602.

The present project was supported by the German Research Network on Schizophrenia (GRNS), a program of the German Federal Ministry for Education and Research BMBF (grants 01 G19934) and by the Deutsche Forschungsgemeinschaft (Klinische Forschergruppe 112 to Karl Zilles and Andreas Bauer). The authors thank H. Herzog, L. Tellmann, S. Schaden, E. Theelen (PET group), B. Elghahwagi, G. Oefler and J.N. Shah (MRI group) as well as M. Lang, B. Palm, E. Wabbals, and K. Hamacher (Cyclotron and Radiosynthesis Group, Institute of Nuclear Chemistry, Research Center Jülich) for excellent technical support.

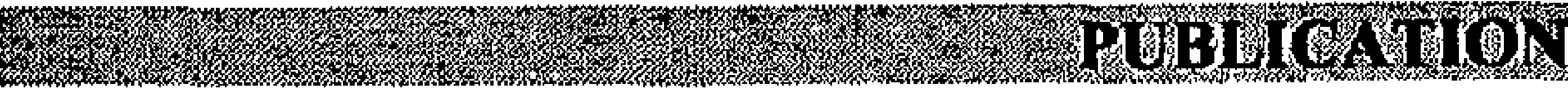

Hurlemann R, Matusch A, Eickhoff SB, Palomero-Gallagher N, Meyer PT, Boy C, Maier W, Zilles K, Amunts K, Bauer A (2005) Analysis of neuroreceptor PET-data based on cytoarchitectonic maximum probability maps: a feasibility study. Anatomy and Embryology 
R. Hurlemann - The Costs and Benefits of Emotional Memory Formation

(Berlin) 210:447-453. (Article reproduced with permission of the copyright owner. Further reproduction prohibited without permission.) 


\section{CHAPTER 7}

\section{Enhanced emotion-induced amnesia in borderline personality disorder}

Current biological concepts of borderline personality disorder (BPD) emphasize the interference of emotional hyperarousal and cognitive functions. A prototypical example is episodic memory. Pre-clinical investigations of emotion-episodic memory interactions have shown specific retrograde and anterograde episodic memory changes in response to emotional stimuli. These changes are amygdala-dependent and vary as a function of emotional arousal and valence. To determine whether there is amygdala hyperresponsiveness to emotional stimuli as the underlying pathological substrate of cognitive dysfunction in BPD, 16 unmedicated female patients with BPD were tested on the behavioral indices of emotion-induced amnesia and hypermnesia established in 16 healthy controls. BPD patients displayed enhanced retrograde and anterograde amnesia in response to presentation of negative stimuli, while positive stimuli elicited no episodic memory-modulating effects. These findings suggest that an amygdala hyperresponsiveness to negative stimuli may serve as a critical etiological contributor to emotion-induced cognitive dysfunction in BPD.

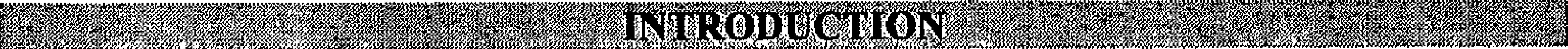

More than any other species, humans are beneficiaries and victims of emotion. A lack of emotional equilibrium is a common denominator across psychiatric conditions, with particular significance in borderline personality disorder (BPD) (Skodol et al., 2002a, b). The BPD clinical phenotype is characterized by an emotionally unstable and impulsive cognitive and behavioral style (Domes et al., 2006), which has led to suggestions that the core pathology of BPD is a hyperarousal-dyscontrol syndrome (Lieb et al., 2004).

To date, no specific cognitive dysfunction in BPD has been identified (Kunert et al., 2003; Ruocco et al., 2005). However, current theories of BPD emphasize the disruptive potential of negative emotion on cognition (Fertuck et al., 2005). One cognitive domain where the interference with emotion can be characterized is episodic (autobiographical) memory (Dolan, 2002; McGaugh, 2004; LaBar and Cabeza, 2006; Phelps, 2006). Functional imaging studies of the associated neural circuitry have revealed amygdala-hippocampal interactions during emotional memory encoding, with hippocampal circuits being modulated by amygdala input (Kilpatrick and Cahill, 2003; Dolcos et al,, 2004a; Kensinger and Corkin, 2004; Richardson et al., 2004). One classic experimental design to study amygdala-hippocampal connectivity is the subsequent memory paradigm, which demonstrates variations in recall of emotional items as a function of amygdala activation at encoding of these items (Cahill et al.,1996; Hamann et al., 1999; Canli et al., 2000; Kilpatrick and Cahill, 2003; Dolcos et al., 
2004a; Kensinger and Corkin, 2004). A key neurochemical mediator of this effect is norepinephrine (NE), which has its major source in locus coeruleus (LC) (Berridge and Waterhouse, 2002; Aston-Jones and Cohen, 2005). Notably, the amplification of emotional memory encoding by endogenous LC-NE release can be further augmented by NE agonists like reboxetine (Harmer et al., 2003, 2004) and blocked by NE antagonists like propranolol (Strange et al., 2003; Strange and Dolan, 2004; van Stegeren et al., 2005).

Amygdala lesion eliminates the episodic memory advantage of emotional stimuli as does amygdala suppression with propranolol, indicating a key intra-amygdalar role for LCNE in enhancing emotional memory encoding (Strange et al,, 2003; Strange and Dolan, 2004; van Stegeren et al., 2005). The psychological 'costs and benefits' of such enhancement have been modelled with free recall tests of episodic memory, in which facilitated encoding of a heterogeneous item (oddball) presented within a train of homogeneous standard items (the von Restorff effect) (Von Restorff, 1933; Wallace, 1965) interferes with the encoding of preceding and following standard items, particularly if the oddball is emotional (Tulving, 1969; Angelini et al., 1994; Hurlemann et al., 2005). In keeping with a taxonomy of emotion along orthogonal dimensions of valence and arousal (Lang, 1995; Russel, 1980), retrograde interference is valence-dependent in that emotionally negative items elicit amnesia and emotionally positive items elicit hypermnesia. In contrast, anterograde interference is arousaldependent, with emotionally negative and positive items eliciting amnesia. As the emotional oddball effect per se, both the retrograde and anterograde episodic memory changes driven by this effect are under amygdala- and LC-NE control (Hurlemann et al., 2005, 2007).

In BPD patients, episodic memory formation is biased towards enhanced encoding of emotionally negative items, possibly resulting from LC-NE (Skodol et al., 2002b) and amygdala hyper-responsiveness to negative emotion (Herpertz et al., 2001; Donegan et al, 2003). Moreover, emotional instability and impulsivity increase under treatment with the NE agonist reboxetine (Anghelescu et al, 2005) and decrease under treatment with the NE antagonist clonidine (Philipsen et al., 2004). Furthermore, challenge studies with the NE agonist yohimbine in controls have linked elevated noradrenergic tone to increased impulsivity (Swann et al., 2005). These observations provide the basis for our experimental hypothesis that BPD patients would display greater retrograde and anterograde amnesia in response to negative emotion as compared to controls. Such a finding would indicate LC-NE hyperactivation of the amygdala as etiological contributor to emotion-induced cognitive dysfunction in BPD. Thus, we tested 16 unmedicated female patients with BPD on a robust laboratory index of emotion-induced amnesia and hypermnesia established in healthy controls.

\section{Subjects}

Informed written consent was obtained from all patients and controls after complete and extensive description of the study, which was approved by the Ethics Committee of the University of Bonn in accordance with the principles of the Declaration of Helsinki (Rickham, 1964). The study included 16 self-harming female outpatients (age range, 19.5 $34.5 \mathrm{yrs}$; mean age $25.2 \pm 4.6 \mathrm{yrs}$ ) treated at the Department of Psychiatry, University of Bonn. In clinical populations, BPD occurs predominantly in females (Lieb et al., 2004). Patients fulfilled both DSM-IV diagnostic criteria for BPD as well as BPD criteria from the 
R. Hurlemann - The Costs and Benefits of Emotional Mernory Formation

DIP-R (Revised Diagnostic Interview for BPD) (Gunderson and Zanarini, 1983). SCID I and II (Structured Clinical Interviews for DSM-IV Diagnoses) (Wittchen et al,, 1997) were performed to exclude lifetime diagnosis of axis I and II co-occuring disorders as a potential confounding factor in the assessment of emotion-episodic memory interactions. The GAF (Global Assessment of Functioning) Scale as part of the $D S M-I V$ axis $\mathrm{V}$ assessment served to evaluate patients' overall level of psychological, social, and occupational functioning (American Psychiatric Association 1994). Cutting was the most common form of self-harm, which provided an objective index of impulsive behavior (Herpertz et al., 1997) and allowed to recruit a homogeneous patient sample (Berlin et al., 2005; Domes et al., 2006). BPD patients were drug-naïve $(n=6)$ or free of psychotropic medication for $\geq 4$ weeks $(n=10)$. Sixteen female control subjects (age range, 20.3 - 34.2 yr; mean age 25.6 $\pm 4.3 \mathrm{yr}$ ), matched for age and educational status and determined to be free of personal as well as first-degree family history of $D S M-I V$ axis I and II disorder, were enrolled in the study. Neither patients nor controls were included if they had current substance or alcohol abuse or a history of neurological or severe somatic disorder. Controls had not been on psychotropic medication for $\geq 12$ weeks. To ensure that potential abnormalities in our test of emotion-episodic memory interactions could not be attributed to deficits in visual, verbal, and cognitive functions, patients and controls both underwent brief neuropsychological screening. This included the VLMT (Verbaler Lern- und Merkfähigkeitstest), a German version of the Rey Auditory Verbal Learning Test, to assess immediate verbal leaming span, new learning, susceptibility to interference, and recognition memory (Helmstaedter et al. 2001). The CFT (Rey-Osterrieth Complex Figure Test) was used to test incidental visual memory and the visuospatial constructional ability (Rey, 1941; Osterrieth, 1944). Motor speed and visual attention were examined with the TMT-A (Trail Making Test, Part A) (Raitan, 1958). The WST (Wortschatz-Test), a vocabulary test implemented in the HAWIE-R (Hamburg-Wechsler Intelligenztest fiir Erwachsene), a German adaptation of the Wechsler Adult Intelligence scale, provided an estimate for intelligence (IQ) (Tewes, 1991). The demographical and neuropsychological data of the patient and control groups are reported in Table 1.

\section{Diagnostic instruments and questionnaires}

BPD patients were characterized utilizing a battery of clinician and self-rating tools. State euthymia was confirmed by a score $<10$ on the HAM-D21 (Hamilton Depression Scale) (Hamilton, 1960). The FAF (Questionnaire for Measuring Factors of Aggression, Fragebogen zur Erfassung von Aggressivitätsfaktoren) (Hampel and Selg 1975), the BIS-11 (Barrat Impulsiveness Scale) (Patton, 1995), and the BDHI (Buss-Durkee Hostility Inventory) (Buss and Durkee, 1957) were administered to assess aggressive and impulsive behaviors. The FDS (Fragebogen für Dissoziative Symptome), a German adaptation of the American Dissociative Experiences Scale served to determine the frequency of dissociative symptoms (Freyberger et al., 1998). The CTQ (Childhood Trauma Questionnaire) was used to investigate prevalence of childhood trauma and relations between childhood trauma and dissociation in adult life (Bernstein et al., 1994). The diagnostic data of the patient group are reported in Table 1.

\section{Episodic memory test}

Experimental design and stimulus setup have been detailed elsewhere (Hurlemann et al., 2005) and are described in abbreviated form here. Subjects were exposed to 36 studydistraction-test sequences. During each 40-s study phase, a von Restorff list composed of 1 oddball and 7 standard stimuli in form of picture items paired with their verbal descriptors, was presented. Standard stimuli included black and white line drawings of living and non- 
living entities (Snodgrass and Vanderwart, 1980; Cycowitz et al., 1997), while oddballs included images primarily selected and edited from the IAPS (International Affective Picture System) (Lang et al., 2005). Of 36 oddballs implemented in the paradigm, 12 were perceptual-neutral $(P)$, and 24 were perceptual-emotional $\left(E_{x} P\right)$, including 12 positive $\left(E_{p o s} P\right)$ and 12 negative $\left(\mathrm{E}_{\text {neg }} \mathrm{P}\right)$ oddballs. $\mathrm{E}_{\mathrm{pos}} \mathrm{P}$ and $\mathrm{E}_{\mathrm{neg}} \mathrm{P}$ oddballs differed from each other in terms of valence, but were matched for arousal. $E_{x} P$ oddballs differed from $P$ oddballs in terms of valence and arousal. Each von Restorff list was followed by a 30-s arithmetic distraction task, before episodic memory was tested by free recall.

Table 1. Demographics, Neuropsychological, and Diagnostic Data of the Sample*

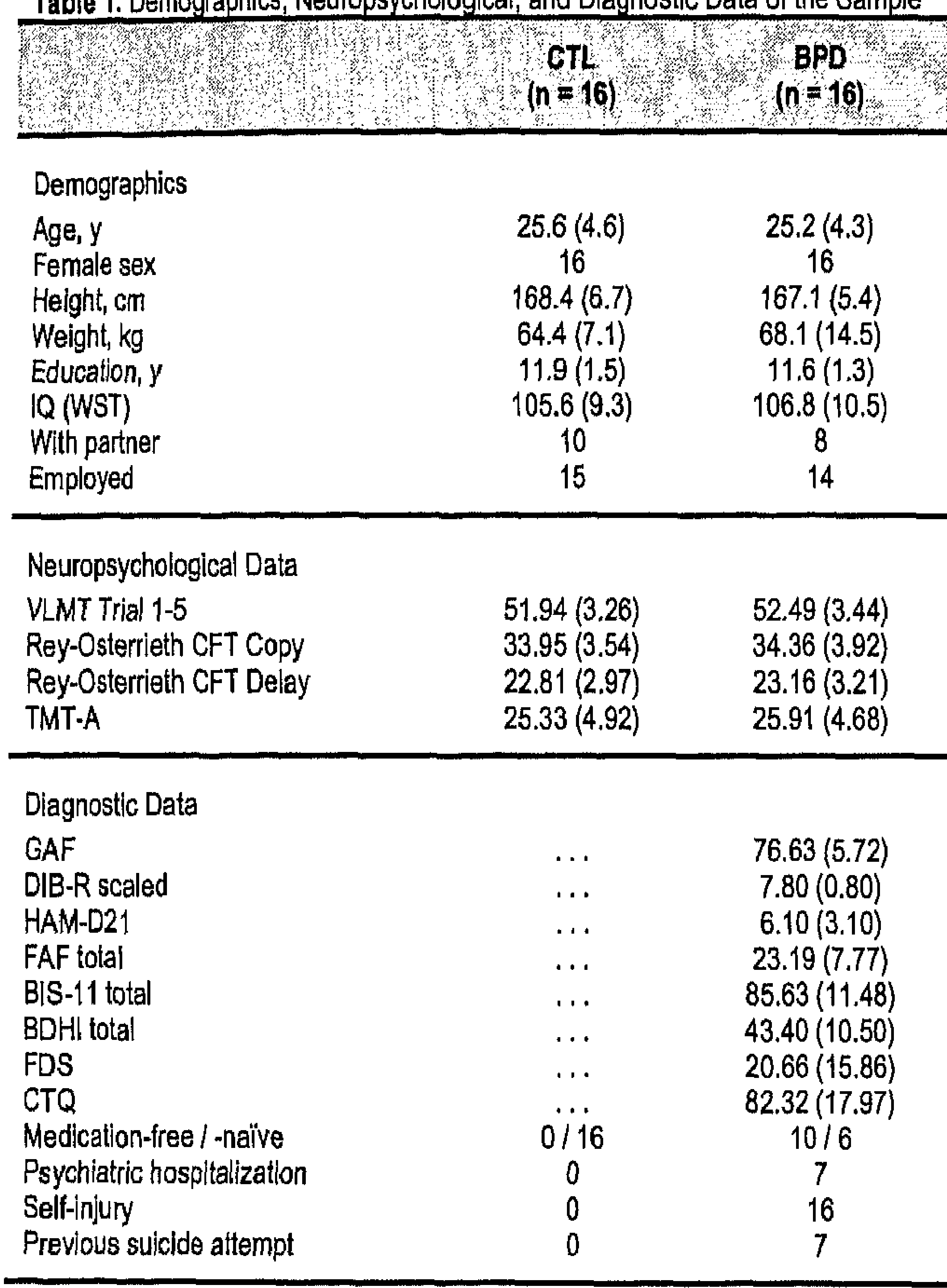

Data are glven as mean (SD) unless otherwise specified.

CTL, Controls. BPD, Borderfine Personality Disorder; IQ (WST), Wortschatztest, a vocabulary test implemented in the HAWIE-R (German adaptation of the Wechsler Adult Intelligence Scale); VLMT, Verbaler Lern- und Merkfähigkeitstest (German version of the Rey Auditory Verbal Learning Test); CFT, Rey-Osterrieth Complex Figure Test; TMT-A, Trall Making Test (part A); GAF, Global Assessment of Functloning; DIB-R, Revised Dlagnostic interview for Borderline personality disorder; HAM-D21, Hamilton Depression Scale; FAF, Questionnaire for Measuring Factors of Aggression; BIS-11, Barrat Impulsiveness Scale; BDHI, Buss-Durkee Hostility Inventory; CTQ, Childhood Trauma Questionnaire; FDS, Fragebogen für Dissoziative Symptome (German version of the American Dissociative Experiences Scale). 
Recall profiles were pooled according to the 3 oddball types, thus yielding a neutral, positive, and negative condition. As outcome parameter, memory performance was determined condition-wise by calculating the percentage of correct recall (i.e. the output / input ratio) for the following 3 list positions: oddball - 1, oddball, and oddball +1 . Additionally, a list index (LI) based on the 7 non-oddball list positions was calculated for each condition (e.g., $\left.\mathrm{LI}_{\mathrm{p}}\right)$. Contrasting the emotional conditions $\left(\mathrm{E}_{\mathrm{x}} \mathrm{P}\right)$ with the neutral condition $(\mathrm{P})$ (according to $\mathrm{E}_{\mathrm{x}} \mathrm{P}-\mathrm{P}=\mathrm{E}_{\mathrm{x}}$ ) allowed us to isolate retrograde and anterograde effects generated by positive $\left(E_{\text {pos }}\right)$ and negative $\left(E_{\text {neg }}\right)$ emotion on the adjacent standard item $\left(E_{x} \pm 1\right)$ corresponding to a time window of $\pm 5 \mathrm{sec}$. Design and timeline of the episodic memory test are illustrated in Figure $1 \mathbf{A}$ and $\mathbf{B}$.
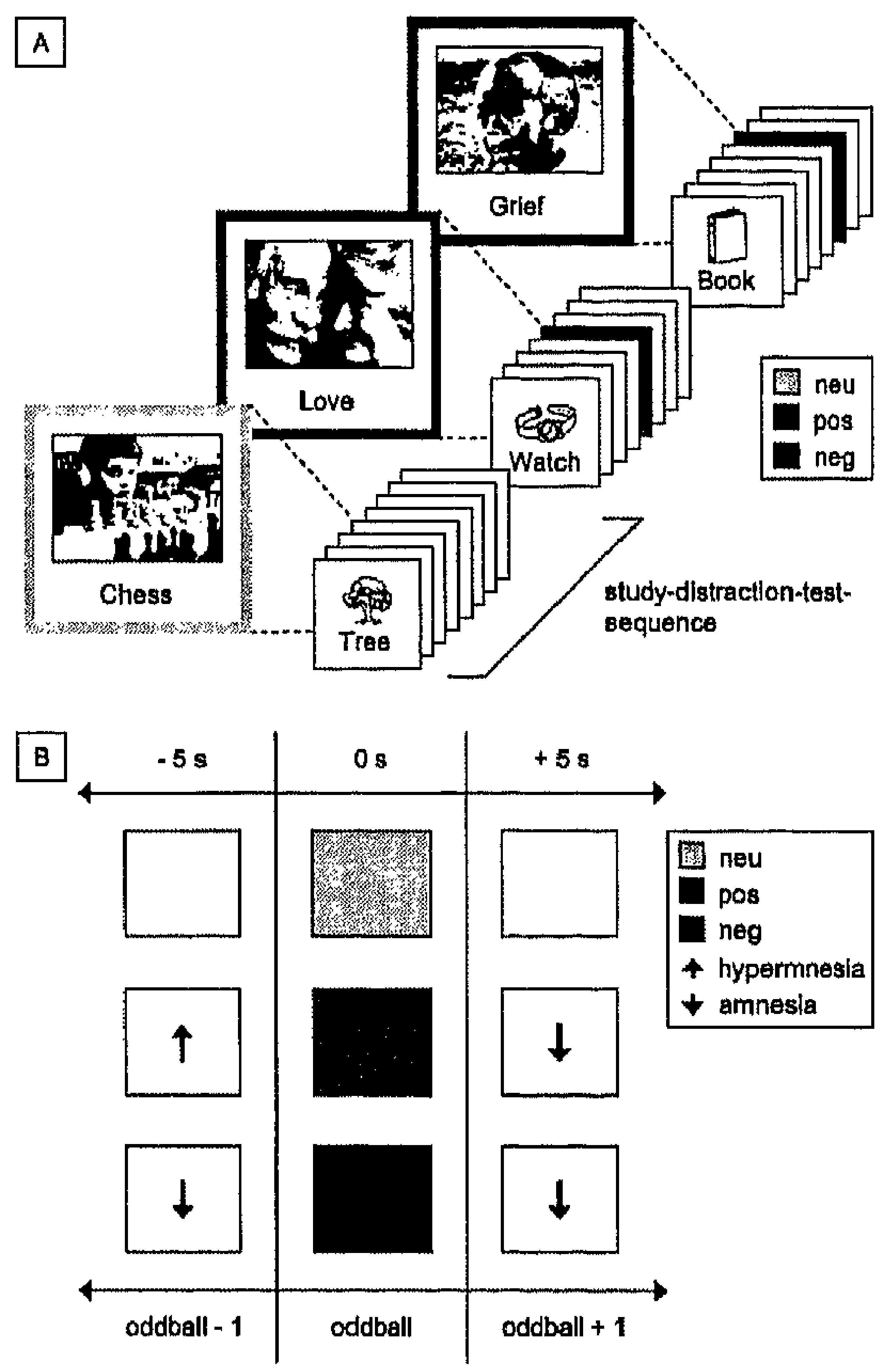

Figure 1. Episodic memory test. A, Timeline. Participants were exposed to 36 study-distraction-test sequences. During each 40-s study phase, they were presented with a list of 8 items, including 7 standard items and 1 oddball inserted on list position 3, 4, 5 or 6 . After a 30-s arithmetic distraction task, encoding strength for the 8 list items was tested by free recall. B, Analysis. In each list, 1 oddball, either emotional ( $E_{x}$ : positive, $E_{p o s} P$; negative, $E_{n e g} P$ ) or neutral $(\mathrm{P})$, was temporally flanked by a preceding (oddball -1 ) and following (oddball +1 ) standard item. Results from list recall were pooled according to the 3 oddball types, yielding a positive, negative, and neutral condition. Contrasting the positive and negative conditions with the neutral condition (according to $E_{x} P-P=E_{x}$ ) allowed to quantify retrograde and anterograde episodic memory-modulating effects of positive and negative emotion within a time window of $E_{x} \pm 1$ items or $\pm 5 \mathrm{~s}$. Positive oddballs $\left(E_{\text {pos }} P\right)$ interfere with $E_{x} \pm$ $I$ encoding in form of retrograde memory increments (hypermnesia) and anterograde memory decrements (amnesia), while negative oddballs $\left(E_{\text {neg }} P\right)$ provoke both retrograde and anterograde memory decrements (amnesia). Abbreviations: neg, negative; neu, neutral; pos, positive. 
While our previous paradigm was devised to investigate $E_{\text {neg }}-1$ retrograde effects as a function of emotional oddball effects (Strange et al., 2003), the present paradigm was optimized to dissociate the contributions of emotional valence and arousal to $E_{x}-1$ retrograde and $E_{x}+1$ anterograde effects by using a subtractive design (Hurlemann et al., 2005). Since BPD might be associated with potential changes in the cognitive appraisal of emotion, patients and controls both performed paper-pencil valence and arousal ratings to $E_{x} P$ and $P$ oddballs on a 9-point scale after the episodic memory test.

\section{Statistics}

Demographical and neuropsychological data obtained from the patient and control groups were compared on the basis of two-sample $t$ tests. The episodic memory test resulted in different recall scores $\left(E_{x}, E_{x} \pm 1, L_{X}\right)$ for the emotional (positive, negative) conditions, which were analyzed in relation to the corresponding recall scores $\left(P, P \pm 1, L_{P}\right)$ for the neutral condition. Two-factor within-subjects and three-factor mixed analyses of variance (ANOVAs) were followed by two-tailed one-sample and two-sample $t$ tests to determine the source of significance. Greenhouse-Geisser correction for inhomogeneity of variance was applied whenever a sphericity assumption was violated. To account for an inflation of the type I error attributable to multiple post hoc testing, the threshold for significance was Bonferroniadjusted.

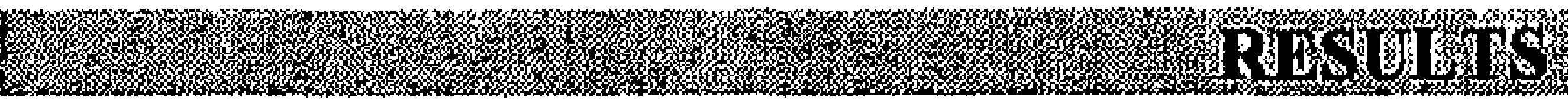

As summarized in Table 1, patients $(B P D, \mathrm{n}=16)$ were euthymic, medication-naïve $(n=6)$ or medication-free for $\geq 4$ weeks $(n=10)$, and demonstrated a high level of psychological, social and occupational functioning, when tested on the behavioral measures of $E_{x} \pm 1$ modulatory effects established in controls $(C T L, \mathrm{n}=16)$. No between-group differences with respect to demographical nor neuropsychological variables (two-sample $t$ tests, $p>.05$ ) confirmed careful matching of patients and controls.

\section{Analysis of the episodic memory test}

The percentages $(\%)$ of mean recall $( \pm$ SD) for oddballs and standard items (collapsed across the positive, negative, and neutral conditions) were as follows: CTL, 96.88 (4.15) and $56.47(7.21) ; B P D, 96.70(2.42)$ and $51.27(7.87)$. One-sample $t$ tests confirmed the presence of near-ceiling von Restorff effects within each group: $C T L, t_{(15)}=24.372 ; p<.0001 ; B P D$, $t_{(15)}=19.455 ; p<.0001$. A one-way ANOVA with group $(C T L, B P D)$ as between-subjects factor showed no difference of $\operatorname{SI}_{P}$ scores between groups $\left(F_{(1,31)}=0.819 ; p>.05\right)$, i.e. $B P D$ did not compromise an ability to recall standard items in the neutral condition.

An exploratory condition (positive, negative, neutral) $\mathrm{x}$ position (oddball, oddball \pm 1 ) $3 \times 3$ ANOVA restricted to the CTL group yielded effects of valence $\left(F_{(2,30)}=13.408 ; p<\right.$ $.0001)$, position $\left(F_{(2,30)}=369.463 ; p<.0001\right)$, and condition $\mathrm{x}$ position interaction $\left(F_{(4,60)}=\right.$ 14.235; $p<.0001$ ) effects. As depicted in Figure $2 \mathbf{A}$ and $\mathbf{B}$ on the left panels, post hoc onesample $t$ tests confirmed the presence of retrograde $\mathrm{E}_{\text {neg }}-1$ amnesic $(-16.67 \%)\left(t_{(15)}=-3.130 ; p\right.$ $=.007)$ and $\mathrm{E}_{\text {pos }}-1$ hypermnesic $(+15.62 \%)\left(t_{(15)}=3.101 ; p=.007\right)$ as well as anterograde $\mathrm{E}_{\text {neg }}+1(-16.15 \%)\left(t_{(15)}=-3.725 ; p=.002\right)$ and $\mathrm{E}_{\mathrm{pos}}+1(-11.97 \%)\left(t_{(15)}=-3.360 ; p=.004\right)$ amnesic effects. Additional session (first, second, third) $\mathrm{x}$ condition $3 \times 3$ within-subjects ANOVAs showed that recall performance for both oddballs $\left(F_{(2,30)}=1.328 ; p>.05\right)$ and 
standard items $\left(F_{(2,30)}=1.542 ; p>.05\right)$ remained stabile throughout the experiment. The pattern of memory increments and decrements measured in the CTL group paralleled those of previous investigations and served as baseline for subsequent comparisons.

Analyzing the influence of $B P D$ diagnosis, a group $(C T L, B P D) \mathrm{x}$ condition $\mathrm{x}$ position $2 \times 3 \times 3$ ANOVA yielded group $\left(F_{(1,30)}=11.972 ; p=.002\right)$, condition $\left(F_{(2,60)}=60.160 ; p<\right.$ $.0001)$, position $\left(F_{(2,60)}=793.660 ; p<.0001\right)$, two-way condition $x$ group $\left(F_{(2,60)}=6.405 ; p=\right.$ $.003)$, position $\times$ group $\left(F_{(2,60)}=6.433 ; p=.003\right)$, condition $\times$ position $\left(F_{(4,120)}=31.617 ; p<\right.$ $.0001)$, and three-way condition $\mathrm{x}$ position $\mathrm{x}$ group $\left(F_{(4,120)}=4.090 ; p=.004\right)$ interaction effects. Post hoc two-sample $t$ tests demonstrated that $\mathrm{E}_{\mathrm{neg}}-1 \quad\left(t_{(30)}=4.945 ; p<.0001\right), \mathrm{E}_{\mathrm{neg}}+1$ $\left(t_{(30)}=-3.196 ; p=.003\right)$, and $\mathrm{E}_{\mathrm{pos}}-1\left(t_{(30)}=3.250 ; p=.003\right)$ recall was different between $B P D$ and $C T L$ groups. A condition $\times$ position $3 \times 3$ ANOVA restricted to the $B P D$ group yielded effects of valence $\left(F_{(2,30)}=53.553 ; p<.0001\right)$, position $\left(F_{(2,30)}=545.084 ; p<.0001\right)$, and a condition $\mathrm{x}$ position interaction $\left(F_{(4,60)}=21.769 ; p<.0001\right)$ effects. Post hoc one-sample $t$ tests revealed enhanced retrograde $\mathrm{E}_{\mathrm{neg}}-1(-41.15 \%)\left(t_{(15)}=-8.399 ; p<.0001\right)$ and anterograde $\mathrm{E}_{\text {neg }}+1(-27.08 \%)\left(t_{(15)}=-6.343 ; p<.0001\right)$ amnesic effects in the $B P D$ group. In contrast, neither retrograde nor anterograde episodic memory changes in response to positive oddballs were present. The percent $(\%)$ recall differences relative to the CTL group negative condition (relative to the CTL group neutral condition) were as follows: $\mathrm{E}_{\mathrm{neg}}-1,-21.35(-38.02) ; \mathrm{E}_{\mathrm{neg}}+1$, $-12.50(-28.65)$ (Figure $2 \mathbf{A}$ and $\mathbf{B}$, right panels).

\section{Analysis of emotion ratings}

The paper-pencil oddball arousal and valence ratings (mean \pm SD) obtained after memory testing resulted in the following scores: CTL group: $\mathrm{E}_{\text {pos }} \mathrm{P}$ oddballs $(5.35 \pm 0.76,7.81$ $\pm 0.75) ; \mathrm{E}_{\text {neg }} \mathrm{P}$ oddballs $(5.56 \pm 0.73,2.06 \pm 0.77) ; \mathrm{P}$ oddballs $(3.15 \pm 0.69,5.13 \pm 0.72) . B P D$ patients: $(4.31 \pm 0.79,7.21 \pm 0.80) ; \mathrm{E}_{\text {neg }} \mathrm{P}$ oddballs $(7.15 \pm 0.75,1.94 \pm 0.77) ; \mathrm{P}$ oddballs $(2.94$ $\pm 0.77,4.96 \pm 0.65$ ) (Figure $2 \mathrm{C}$ ). Separate group $(C T L, B P D) \mathrm{x}$ oddball type (positive, negative, neutral) $2 \times 3$ ANOVAs were calculated, yielding significant between-group effects on arousal scores $\left(F_{(1,31)}=14.222 ; p=.001\right)$ and valence scores $\left(F_{(1,31)}=4.879 ; p=.035\right)$. Post hoc two-sample $t$ tests demonstrated increased arousal scores for $\mathrm{E}_{\text {neg }} \mathrm{P}$ oddballs $\left(t_{(30)}=-6.112\right.$; $p<.0001)$ as well as decreased arousal $\left(t_{(30)}=3.771 ; p=.001\right)$ and valence $\left(t_{(30)}=2.209 ; p=\right.$ $.035)$ scores for $\mathrm{E}_{\mathrm{pos}} \mathrm{P}$ oddballs in patients with $B P D$. This constellation of changes provides evidence for a robust negativity bias in the cognitive appraisal of emotional oddballs.

[7.

In the absence of uniquely defined and identifiable biological markers in BPD (Herpertz et al., 1999; Posner et al., 2002; Berlin et al., 2005), the current experiment focused on emotion-induced amnesia and hypermnesia as a potential cognitive index of a hyperarousal-dyscontrol syndrome in BPD. Our findings indicate enhanced $E_{\text {neg }}-1$ retrograde and $E_{\text {neg }}+1$ anterograde amnesia, relative to controls, in response to items that elicit negative emotion. This profile contrasts with a lack of predicted $\mathrm{E}_{\mathrm{pos}}-1$ retrograde hypermnesic and $E_{\text {pos }}+1$ anterograde amnesic effects in response to items that elicit positive emotion. This constellation of hyper-responsiveness to negative emotion and hypo-responsiveness to positive emotion provides biological evidence that BPD is indeed characterized by enhanced processing of emotionally negative stimuli and relative lack of processing of emotionally positive stimuli. As the effects we observed were unrelated to task demands per se they suggest that this aberrant processing is an obligatory feature in BPD. 


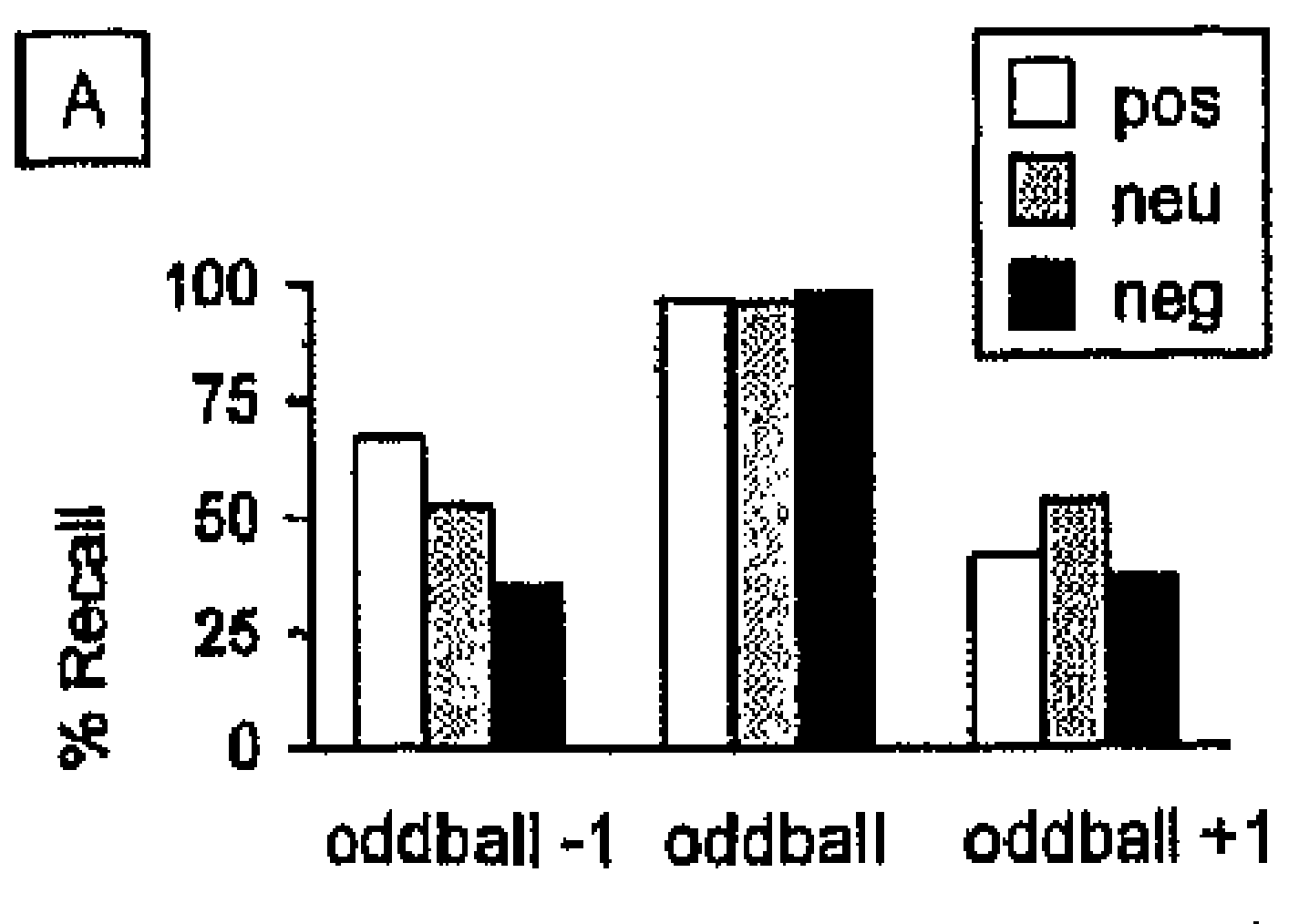

CTL

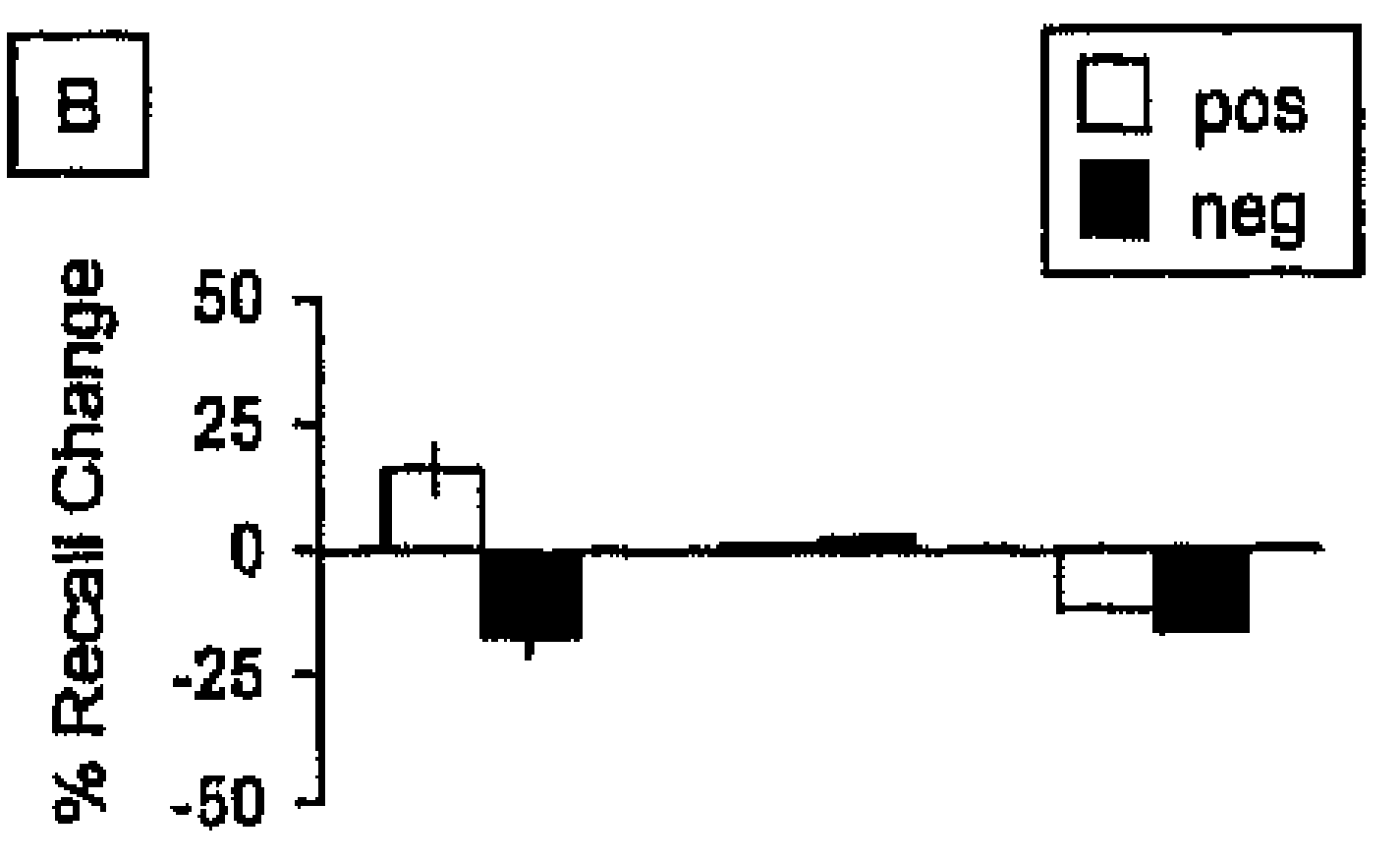

oddball -1 oddball oddball +1

CTL

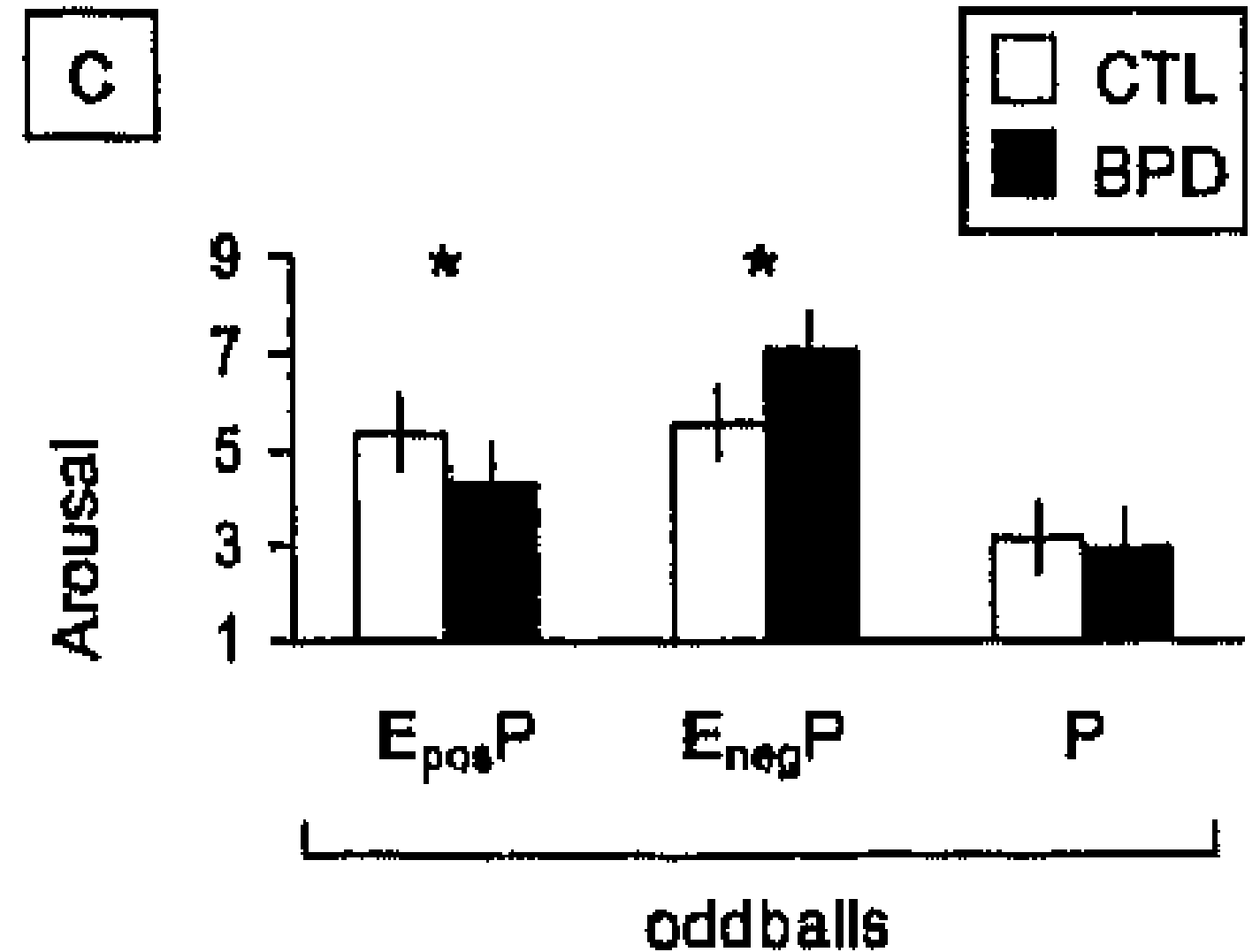

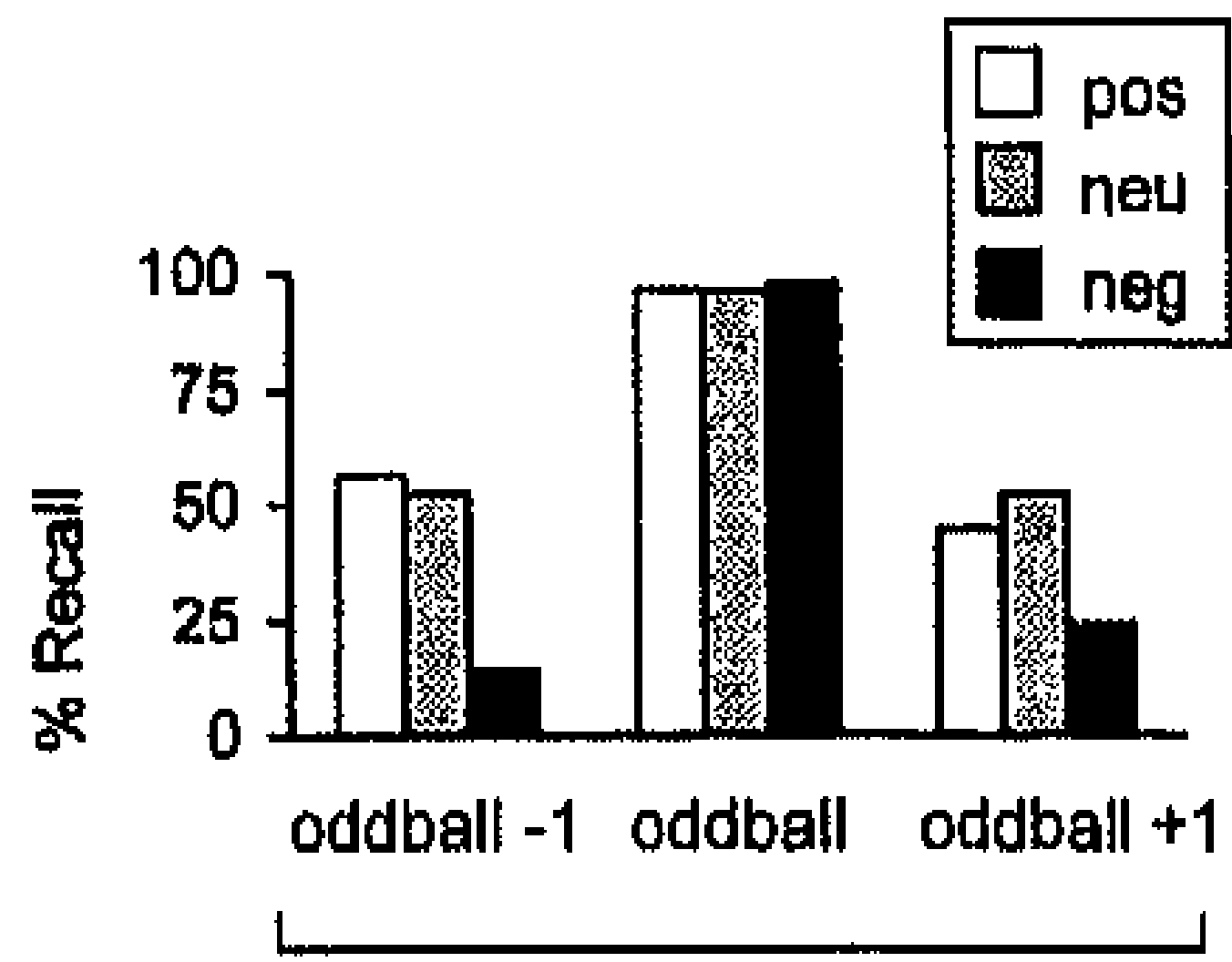

BPD

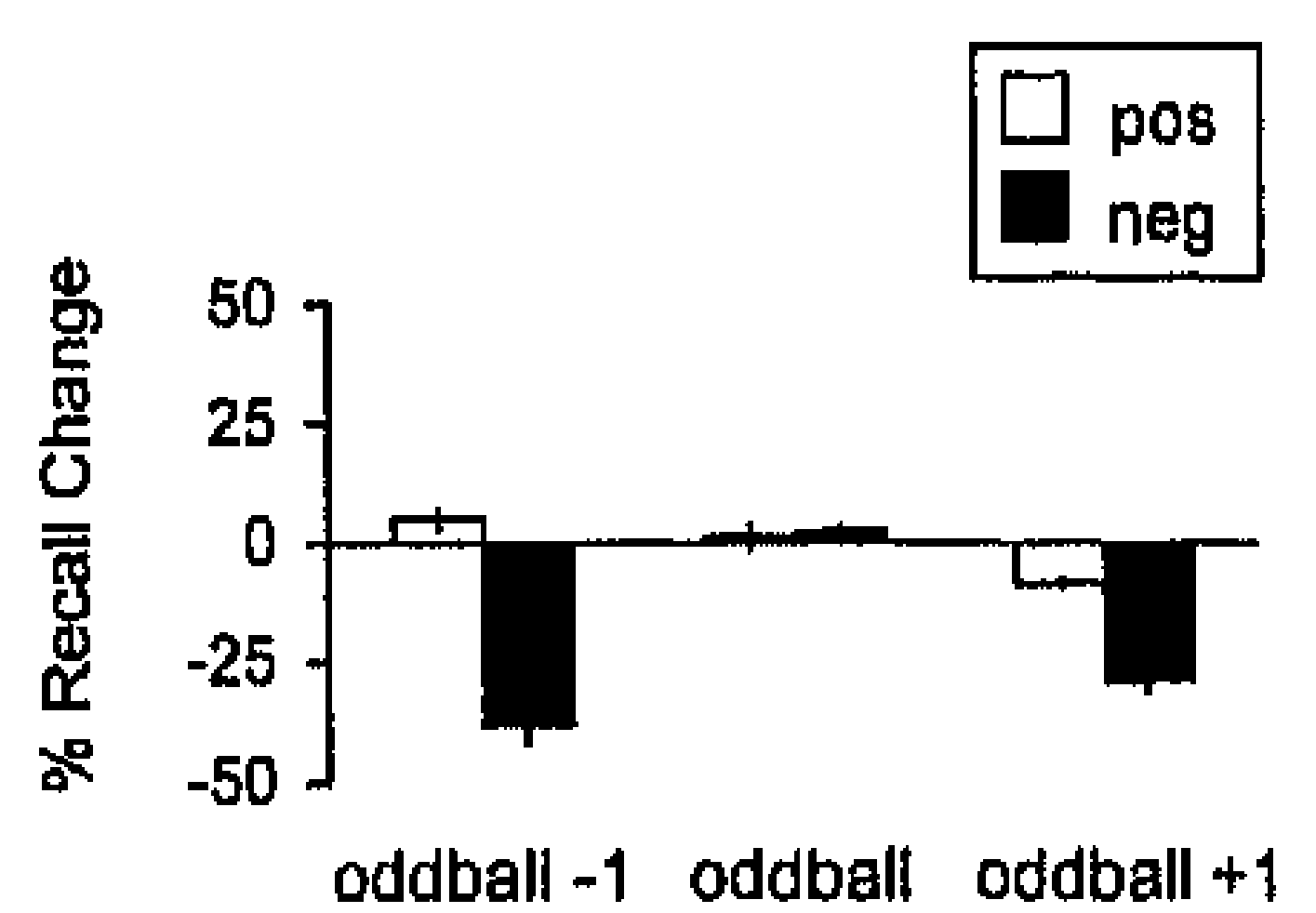

$\mathrm{BPD}$

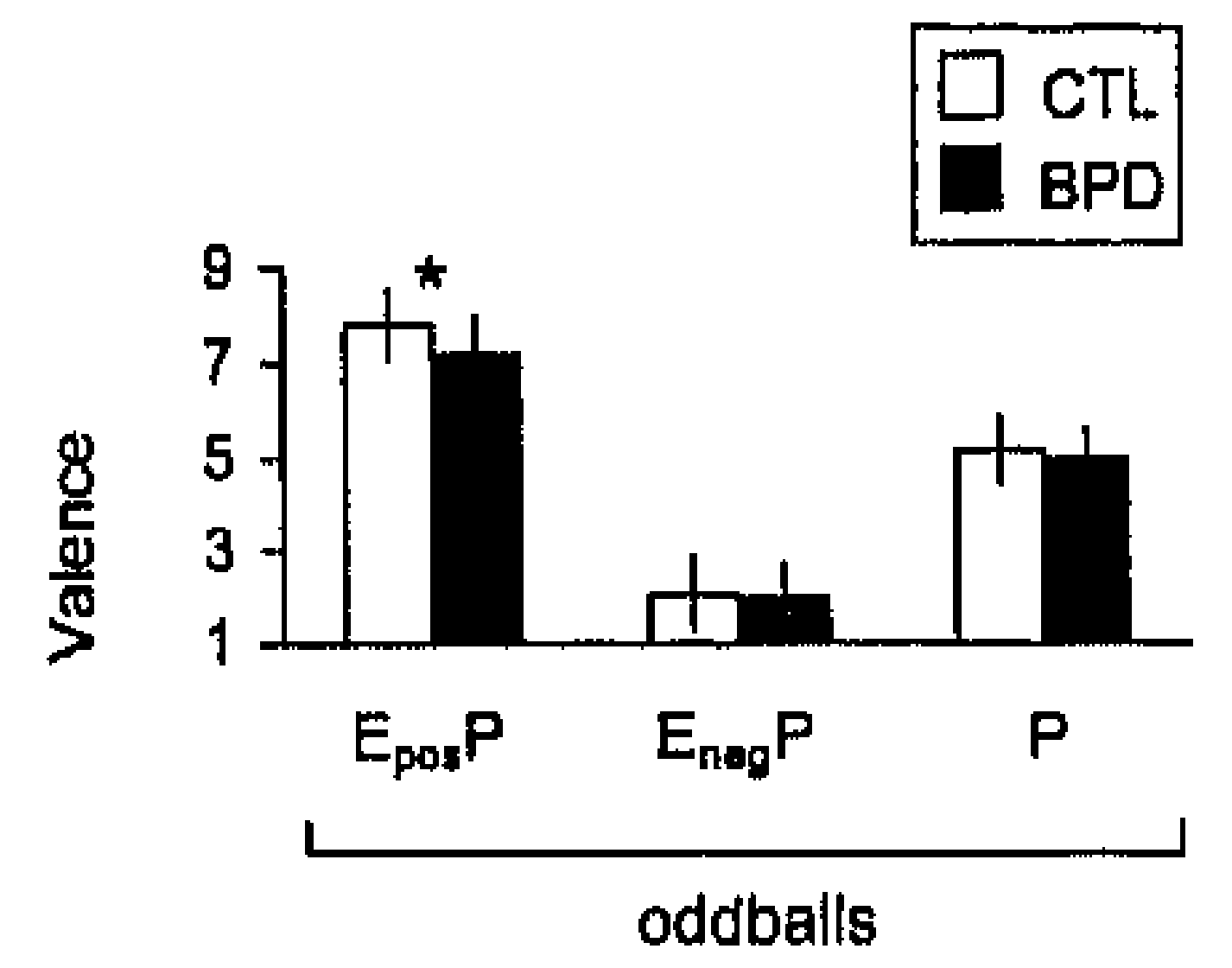

Figure 2. Results of the episodic memory test and oddball ratings. A, Percentage (\%) correct recall as determined in controls (CTL) and patients $(B P D)$. Equal (near-ceiling) von Restorff effects were obtained in both the emotional and the neutral conditions. B, Percentage (\%) of recall change in the emotional conditions relative to the neutral condition. Controls $(C T L)$ displayed a characteristic pattern of emotion-induced memory increments and decrements: Negative emotion elicited retrograde $(-16.67 \%)$ and anterograde $(-16.15 \%)$ amnesia, whereas positive emotion elicited retrograde $(+15.62 \%)$ hypermnesia and anterograde $(-11.97 \%)$ amnesia. In patients $(B P D)$, no episodic memory-modulating effects of positive emotion were present, whereas enlarged retrograde $(-41.15 \%)$ and anterograde $(-27.08 \%)$ amnesic effects of negative emotion were measured, $\mathrm{C}$, Oddball arousal and valence ratings. Increased arousal scores for negative oddballs $\left(E_{\text {neg }} P\right)$ in combination with decreased arousal and valence scores for positive oddballs $\left(E_{p o s} P\right)$ in patients $(B P D)$ relative to controls $(C T L)$ are consistent with a substantial negativity bias in the cognitive appraisal of emotion in $B P D$. Asterixes indicale significant rating differences between controls $(C T L)$ and patients $(B P D)$. Abbreviations: neg, negative; neu, neutral; pos, positive; oddball \pm 1 , standard items preceding or following the oddball; $E_{p o s} P$, positive oddball; $P$, neutral oddball; $E_{n e s} P$, negative oddball. Error bars indicate $1 \mathrm{SE}$.

In previous studies, $E_{x}+1$ anterograde effects have been interpreted as reflecting the psychological 'cost' of devoting attentional resources to preferential encoding of $E_{\mathrm{x}}$ emotional items (Hurlemann et al., 2005, 2007). Specifically, it has been suggested that during serial attentive and mnemonic processing as required in the present paradigm, an amygdaladependent $E_{\mathrm{x}}$ emotional item-induced capture of attention evokes a transient refractory period, of at least 5-s duration, which disrupts attentional re-orienting and causes an inertia in encoding a following $E_{x}+1$ non-emotional item. Enhanced $E_{n e g}+1$ anterograde amnesia in BPD may reflect such a process and would be in keeping with a role for the amygdala in focussing attention on $E_{\text {neg }}$ emotional items. Enhanced attention to emotionally negative events thus may provide a basis for less processing capacity for encoding a competing nonemotional event. In contrast, BPD patients exhibit no $\mathrm{E}_{\mathrm{pos}}+1$ anterograde amnesic effect (as seen in controls), a finding that may reflect a bias away from processing emotionally positive 
events. We note that near-ceiling von Restorff effects are preserved across valences in BPD patients, indicating no global deficit in directing attention to the perceptual 'pop-out' features of oddballs. This is consistent with reports of intact attentional faculties in non-depressed BPD patients under emotionally neutral experimental conditions (Posner et al., 2002; Lenzenweger et al., 2004).

While $E_{x}+1$ anterograde effects are thought to reflect an amygdala-driven attentional model, PFC input is critical for a differential expression of $E_{n e g}-1$ retrograde amnesic vs. $E_{\text {pos }}{ }^{-}$ 1 retrograde hypermnesic effects, whereas the magnitude of these effects is amygdaladependent. The enhancement of $E_{n e g} \pm 1$ modulatory effects in the present study is compatible with abnormal low-threshold and high-amplitude anygdala responses to aversive facial expressions (Donegan et al., 2003) and IAPS items (Herpertz et al., 2001) in BPD. This negative emotion response bias in BPD we suggest is compatible with diminished reactivity of the PFC circuits involved in producing positive emotion and / or regulating negative emotion. Evidence for this view comes from neuroimaging studies in BPD patients indicating PFC alterations at baseline (Goyer et al., 1994; De La Fuente et al., 1997; Lyoo et al., 1998; Juengling et al., 2003) as well as in response to negative emotion (Herpertz et al., 2001; Donegan et al., 2003) and serotonergic (5-HT) challenges (Soloff et al., 2000; Leyton et al., 2001). Further evidence links BPD to functional and structural abnormalities in PFC subareas such as the orbital prefrontal cortex (OFC) (Berlin et al., 2005), specifically hypometabolism (Goyer et al., 1994; De La Fuente et al., 1997; Soloff et al., 2003) and decreased volume (Lyoo et al., 1998; Tebartz van Elst et al., 2003). OFC dysfunction in BPD would be compatible with deficient computation of positive emotion in this subregion (Dolcos et al., $2004 \mathrm{~b}$ ). Together, these lines of evidence provide support for the hypothesis of dual amygdala and $\mathrm{PFC}$ pathology as etiological contributor to a hyperarousal-dyscontrol syndrome in BPD (Lieb et al., 2004).

The degree of inhibitory control over negative emotion is a potent modulator of its psychological impact. To date, research on controllability has largely focused on the monoamine brainstem nuclei such as the 5-HT dorsal raphé nucleus (DRN) and the LC (Amat et al., 2005). As LC-NE signaling is under PFC top-down inhibitory control (Arnsten and Goldman-Rakic, 1984; Weiss and Simson, 1986; Jodo et al., 1998; Berridge and Waterhouse, 2002; Aston-Jones and Cohen, 2005) and determines the magnitude of $E_{x} \pm 1$ effects (Strange et al., 2003; Hurlemann et al., 2005), enhanced $E_{\text {neg }}-1$ retrograde amnesic effects in the present study may reflect deficient regulation of LC-NE bottom-up input to the amygdala. Such hyperactivation of the amygdala we suggest is critical for emotion-induced cognitive dysfunction in BPD. On the basis of our results we speculate that interventions aimed at normalizing negativity bias and increasing PFC top-down inhibitory control provide an effective treatment strategy to influence amygdala hyper-responsiveness to negative emotion in BPD. We note that NE antagonists like clonidine (Philipsen et al., 2004) are reported as exerting beneficial effects on emotional instability and impulsivity in BPD, underscoring the link between these symptoms and increased noradrenergic tone (Arnsten et al., 1999; Swann et al., 2005). In contrast, further exogenous elevation of $\mathrm{NE}$ levels with $\mathrm{NE}$ agonists like reboxetine may provoke an exacerbation of emotional instability and impulsivity in BPD (Anghelescu et al., 2005). Deficient PFC capacity to down-regulate negative emotion in BPD is also susceptible to psychotherapeutical strategies aimed at controlling attention to, and changing the subjective interpretation of, aversive events (Lieb et al., 2004). Such improved cognitive control in BPD may significantly decrease LC-NE hyperactivation of the amygdala in response to negative emotion and neutralize its disruptive effects on cognition (Jackson et al., 2000; Ochsner et al., 2005). 
Amat J, Baratta MV, Paul E, Bland ST, Watkins LR, Maier SF (2005) Medial prefrontal cortex determines how stressor controllability affects behavior and dorsal raphe nucleus. Nat Neurosci 8:365-371.

American Psychiatric Association (1994): Diagnostic and Statistical Manual of Mental Disorders, 4th ed. Washington, DC: American Psychiatric Press.

Angelini R, Capozzoli F, Lepore P, Grossi D, Orsini A (1994) Experimental amnesia induced by emotional items. Percept Mot Skills 78:19-28.

Anghelescu I, Janen B, Schindler F, Lammers CH (2005) Worsening of borderline symptoms under reboxetine treatment. J Neuropsychiatry and Clin Neurosci 17:9-560.

Arnsten AF, Goldman-Rakic P (1984) Selective prefrontal cortical projections to the region of the locus coeruleus and raphe nucleus in the rhesus monkey. Brain 306:9-18.

Amsten AF, Mathew R, Ubriani R, Taylor JR, Li, BM (1999) Alpha-1 noradrenergic receptor stimulation impairs prefrontal cortical cognitive function. Biol Psychiatry 45:26-31

Aston-Jones G, Cohen JD (2005) An integrative theory of locus coeruleus-norepinephrine function: adaptive gain and optimal performance. Annu Rev Neurosci 28:403-450.

Bernstein,DP, Fink L, Handelsman L, Foote J, Lovejoy M, Wenzel K, Sapareto E, Ruggiero J (1994) Initia reliability and validity of a new retrospective measure of child abuse and neglect. Am J Psychiatry 151:1132-1136.

Berlin HA, Rolls ET, Iversen SD (2005) Borderline personality disorder, impulsivity, and the orbitofrontal cortex. Am J Psychiatry 162:2360-2373.

Berridge CW, Waterhouse BD (2003) The locus coeruleus-noradrenergic system: modulation of behavioral state and state-dependent cognitive processes. Brain Res Rev 42:33-84.

Buss AH, Durkee A (1957) An inventory for assessing different kinds of hostility. J Consult Psychol 21:343349.

Cahill L, Prins B, Weber M, McGaugh JL (1994) Beta-adrenergic activation and memory for emotional events. Nature 371:702-704.

Cahill L, Haier RJ, Fallon J, Alkire MT, Tang C, Keator D, Wu J, McGaugh JL (1996) Amygdala activity at encoding correlated with long-term, free recall of emotional information. Proc Natl Acad Sci USA 93:80168021 .

Canli T, Zhao Z, Brewer J, Gabrieli JD, Cahill L (2000) Event-related activation in the human amygdala associates with later memory for individual emotional experience. J Neurosci 20:RC99.

Cycowicz YM, Friedman D, Rothstein M, Snodgrass JG (1997) Picture naming by young children: norms for name agreement, familiarity, and visual complexity. J Exp Child Psychol 65:171-237.

De La Fuente JM, Goldman S, Stanus E, Vizuete C, Morlan I, Bobes J, Mendlewicz J (1997) Brain glucose metabolism in borderline personality disorder. J Psychiatr Res 31:531-541.

Dolan RJ (2002) Emotion, cognition, and behavior. Science 298:1191-1194.

Dolcos F, LaBar KS, Cabeza R (2004a) Interaction between the amygdala and the medial temporal lobe memory system predicts better memory for emotional events. Neuron $42: 855-863$.

Dolcos F, LaBar KS, Cabeza R (2004b) Dissociable effects of arousal and valence on prefrontal activity indexing emotional evaluation and subsequent memory: an event-related fMRI study. Neuroimage 23:6474.

Domes G, Winter B, Schnell K, Vohs K, Fast K, Herpertz SC (2006) The influence of emotions on inhibitory functioning in borderline personality disorder. Psychol Med 36:1163-1172.

Donegan NH, Sanislow CA, Blumberg HP, Fulbright RK, Lacadie C, Skudlarski P, Gore JC, Olson IR, McGlashan TH, Wexler BE (2003) Amygdala hyperreactivity in borderline personality disorder: implications for emotional dysregulation. Biol Psychiatry 54:1284-1293.

Fertuck EA, Lenzenweger MF, Clarkin JF, Hoermann S, Stanley B (2005) Executive neurocognition, memory systems, and borderline personality disorder. Clin Psychol Rev 3:346-375

Freyberger HJ, Spitzer C, Stieglitz RD, Kuhn G, Magdeburg N, Bernstein-Carlson E (1998) Questionnaire on dissociative symptoms. German adaptation, reliability and validity of the american dissociative experience scale (DES). Psychother Psychosom Med Psychol 48:223- 229.

Goyer PF, Andreason PJ, Semple WE, Clayton AH, King AC, Compton-Toth BA, Schulz SC, Cohen RM (1994) Positron-emission tomography and personality disorders. Neuropsychopharmacology 10:21-28.

Gunderson JG, Zanarini MC (1983) The Revised Diagnostic Interview for Borderlines (DIB-R). Belmont, MA: McLean Hospital.

Hamann SB, Ely TD, Grafton ST, Kilts CD (1999) Amygdala activity related to enhanced memory for pleasant and aversive stimuli. Nat Neurosci 2:289-293.

Hamilton M (1960) A rating scale for depression. J Neurol Neurosurg Psychiatry 23:56-62. 
Hampel R, Selg H (1975) FAF-Fragebogen zur Erfassung von Aggressivitätsfaktoren. Hogrefe: Göttingen.

Harmer CJ, Hill SA, Taylor MJ, Cowen PJ, Goodwin GM (2003) Toward a neuropsychological theory of antidepressant drug action: increase in positive emotional bias after potentiation of norepinephrine activity. Am J Psychiatry 160:990-992.

Harmer CJ, Shelley NC, Cowen PJ, Goodwin GM (2004) Increased positive versus negative affective perception and memory in healthy volunteers following selective serotonin and norepinephrine reuptake inhibition. Am J Psychiatry 161:1256-1263.

Helmstaedter C, Lendt M, Lux S (2001) Verbaler Lern- und Merkfähigkeitstest (VLMT). Hogrefe: Göttingen.

Herpertz S, Sass H , Favazza A (1997) Impulsivity in self-mutilative behavior: psychometric and biological findings. J Psychiatr Res 31:451-465.

Herpertz SC, Kunert HJ, Schwenger UB, Sass H (1999) Affective responsiveness in borderline personality disorder: a psychophysiological approach. Am J Psychiatry 156:1550-1556.

Herpertz SC, Dietrich TM, Wenning B, Krings T, Erberich SG, Willmes K, Thron A, Sass H (2001) Evidence of abnormal amygdala functioning in borderline personality disorder: a functional MRI study. Biol Psychiatry 50:292-298.

Hurlemann R, Hawellek B, Matusch A, Kolsch H, Wollersen H, Madea B, Vogeley K, Maier W, Dolan RJ (2005) Noradrenergic modulation of emotion-induced forgetting and remembering. J Neurosci 25:63436349.

Hurlemann R, Hawellek B, Vogeley K, Wagner M, Pieperhoff P, Amunts K, Oros-Peusquens AM, Shah NJ, Maier W, Dolan RJ (2007) Amygdala control of emotion-induced forgetting and remembering: Evidence from Urbach-Wiethe syndrome. Neuropsychologia 45:877-884.

Jackson DC, Malmstadt JR, Larson CL, Davidson RJ (2000) Suppression and enhancement of emotional responses to unpleasant pictures. Psychophysiology 37:515-522.

Jodo E, Chiang C, Aston-Jones G (1998) Potent excitatory influence of prefrontal cortex activity on noradrenergic locus coeruleus neurons. Neuroscience 83:63-79.

Juengling FD, Schmahl C, Hesslinger B, Ebert D, Bremner JD, Gostomzyk J, Bohus M, Lieb K (2003) Positron emission tomography in female patients with borderline personality disorder. J Psychiatr Res 37:109-115.

Kensinger EA (2004) Remembering emotional experiences: the contribution of valence and arousal. Rev Neurosci 15:241-251.

Kensinger EA, Corkin S (2004) Two routes to emotional memory: distinct neural processes for valence and arousal. Proc Natl Acad Sci USA 101:3310-3315.

Kilpatrick L, Cahill L (2003) Amygdala modulation of parahippocampal and frontal regions during emotionally influenced memory storage. Neuroimage 20:2091-2099.

Kunert HJ, Druecke HW, Sass H, Herpertz SC (2003) Frontal lobe dysfunctions in borderline personality disorder? Neuropsychological findings. J Personal Disord 17:497-509.

LaBar KS, Cabeza R (2006) Cognitive neuroscience of emotional memory. Nat Rev Neurosci 7:54-64.

Lang PJ (1995) The emotion probe. Studies of motivation and attention. Am Psychol 50:372-385.

Lang PJ, Bradley MM, Cuthbert BN (2005) International affective picture system (IAPS): Affective ratings of pictures and instruction manual. Technical Report A-6. University of Florida, Gainesville, FL.

Lenzenweger MF, Clarkin JF, Fertuck EA, Kernberg OF (2004) Executive neurocognitive functioning and neurobehavioral systems indicators in borderline personality disorder: a preliminary study. J Personal Disord 18:421-438.

Leyton M, Okazawa H, Diksic M, Paris J, Rosa P, Mzengeza S, Young SN, Blier P, Benkelfat C (2001) Brain regional alpha-[11C]methyl-L-tryptophan trapping in impulsive subjects with borderline personality disorder. Am J Psychiatry 158:775-782.

Lieb K, Zanarini MC, Schmahl C, Linehan MM, Bohus M (2004) Borderline personality disorder. Lancet 364:453-461.

Lyoo IK, Han MH, Cho DY (1998) A brain MRI study in subjects with borderline personality disorder. J Affect Disord 50:235-243.

McGaugh JL (2004) The amygdala modulates the consolidation of memories of emotionally arousing experiences. Annu Rev Neurosci 27:1-28.

Ochsner KN, Gross JJ (2005) The cognitive control of emotion. Trends Cogn Sci 9:242-249.

Osterrieth PA (1944) Le test de copie d'une figure complexe. Arch Psychol 30:206-356.

Patton JH, Stanford MS, Barratt ES (1995) Factor structure of the Barratt impulsiveness scale. J Clin Psychol $51: 768-774$

Phelps EA (2006) Emotion and cognition: Insights from studies of the human amygdala. Annu Rev Psychol $57: 27-53$.

Philipsen A, Richter H, Schmahl C, Peters J, Rusch N, Bohus M, Lieb K (2004) Clonidine in acute aversive inner tension and self-injurious behavior in fermale patients with borderline personality disorder. $\mathrm{J}$ Clin Psychiatry 65:1414-1419.

Posner MI, Rothbart MK, Vizueta N, Levy KN, Evans DE, Thomas KM, Clarkin JF (2002) Attentional mechanisms of borderline personality disorder. Proc Natl Acad Sci USA 99:16366-16370. 
R. Hurlemann - The Costs and Benefits of Emotional Memory Formation

Raitan RM (1958) Validity of the trail making test as an indication of organic brain damage. Percept Mot Skills 8:271-276.

Rey A (1941). L'examen psychologique dans les cas d'encéphalopathie traumatique. Arch Psycho 30:286-340.

Richardson MP, Strange BA, Dolan RJ (2004) Encoding of emotional memories depends on amygdala and hippocampus and their interactions. Nat Neurosci 7:278-285.

Rickham PP (1964) Human experimentation. Code of ethics of the world medical association. Declaration of Helsinki. Br Med J 5402:177-178.

Ruocco AC (2005) The neuropsychology of borderline personality disorder: a meta-analysis and review. Psychiatry Res 137:191-202.

Russell JA (1980) A circumplex model of affect. J Pers Soc Psychol 39:1161-1178.

Skodol AE, Gunderson JG, Pfohl B, Widiger TA, Livesley WJ, Siever LJ (2002a) The borderline diagnosis I: psychopathology, comorbidity, and personality structure. Biol Psychiatry 51:936-950.

Skodol AE, Siever LJ, Livesley WJ, Gunderson JG, Pfohl B, Widiger TA (2002b) The borderline diagnosis II: biology, genetics, and clinical course. Biol Psychiatry 51:951-963.

Snodgrass JG, Vanderwart M (1980) A standardized set of 260 pictures: norms for name agreement, image agreement, familiarity, and visual complexity. J Exp Psychol (Hum Learn) 6:174-215.

Soloff PH, Meltzer CC, Greer PJ, Constantine D, Kelly TM (2000) A fenfluramine-activated FDG-PET study of borderline personality disorder. Biol Psychiatry 47:540-547.

Soloff PH, Meltzer CC, Becker C, Greer PJ, Kelly TM, Constantine D (2003) Impulsivity and prefrontal hypometabolism in borderline personality disorder. Psychiatry Res 123:153-163.

Strange BA, Hurlemann R, Dolan RJ (2003) An emotion-induced retrograde amnesia in humans is amygdalaand beta-adrenergic-dependent. Proc Natl Acad Sci USA 100:13626-13631.

Strange BA, Dolan RJ (2004) Beta-adrenergic modulation of emotional memory-evoked human amygdala and hippocampal responses. Proc Natl Acad Sci USA 101:11454-11458.

Swann AC, Birnbaum D, Jagar AA, Dougherty DM, Moeller FG (2005) Acute yohimbine increases laboratorymeasured impulsivity in normal subjects. Biol Psychiatry 57:1209-1211.

Tebartz van Elst L, Hesslinger B, Thiel T, Geiger E, Haegele K, Lemieux L (2003) Frontolimbic brain abnormalities in patients with borderline personality disorder: A volumetric magnetic resonance imaging study. Biol Psychiatry 54:163-171.

Tewes U (1991) Hamburg-Wechsler-Intelligenztest für Erwachsene - Revision 1991. Hogrefe: Göttingen.

Tulving E (1969). Retrograde amnesia in free recall. Science 164:88-90.

van Stegeren AH, Everaerd W, Cahill L, McGaugh JL, Gooren LJ (1998) Memory for emotional events: differential effects of centrally versus peripherally acting beta-blocking agents. Psychopharmacology 138:305-310.

van Stegeren AH, Goekoop R, Everaerd W, Scheltens P, Barkhof F, Kuijer JP, Rombouts SA (2005) Noradrenaline mediates amygdala activation in men and women during encoding of emotional material. Neuroimage 24:898-909.

von Restorff H (1933) Ueber die Wirkungen von Bereichsbildung im Spurenfeld. Psychol Forsch 18:299-342.

Wallace WP (1965) Review of the historical empirical and theoretical status of the von Restorff phenomenon. Psychol Bull 63:410-424.

Weiss JM, Simson PG (1986) Depression in an animal model: focus on the locus ceruleus. Ciba Found Symp 123:191-215.

Wittchen HU, Zaudig M, Fydrich T (1997) Strukturiertes Klinisches Interview für DSM-IV - (SKID-I und SKID-II). Göttingen; Hogrefe.

62.

The authors thank M. Pankonin for excellent assistance and $\mathrm{K}$. Vogeley for inspiring discussions. R. Hurlemann was supported by BONFOR.

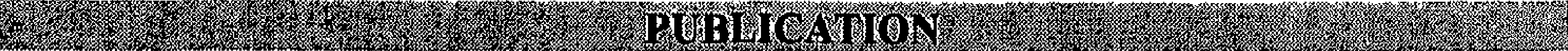

Hurlemann R, Hawellek B, Maier W, Dolan RJ (2007) Enhanced emotion-induced amnesia in borderline personality disorder. Psychological Medicine 37:971-982. (Article reproduced with permission of the copyright owner. Further reproduction prohibited without permission.) 


\section{CHAPTER 8}

\section{Emotion-induced retrograde amnesia varies as a function of noradrenergic-glucocorticoid activity}

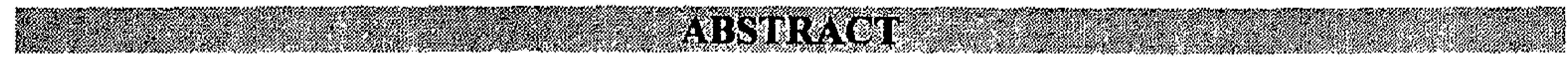

Privileged episodic encoding of an aversive event often comes at a cost of flanking neutral events, resulting in decreased episodic memory for these neutral events. This peri-emotional amnesia is amygdala-dependent and varies as a function of norepinephrine activity. However, less is known about the amnesiogenic potential of cortisol. We used a strategy of pharmacologically potentiating cortisol and norepinephrine activity to probe the putative neurochemical substrates of periemotional amnesia. Fifty-four healthy individuals participated in a randomized doubleblind placebo-controlled study. Within the experimental context of an established periemotional amnesia paradigm, we tested the amnesiogenic potential of hydrocortisone (30 mg p.o.) in the presence or absence of the norepinephrine-reuptake inhibitor reboxetine (4 mg p.o.). Under dual challenge conditions, we observed a linear dose-response relationship in the magnitude and duration of emotion-induced retrograde amnesia. Our results are consistent with a phenotypic expression of retrograde amnesia varying as a function of norepinephrine and cortisol co-activation during episodic encoding of aversive events. Our study demonstrates that the adverse cognitive and behavioral sequelae of aversive emotion can be experimentally modeled by a pharmacological manipulation of its neurochemical substrates.

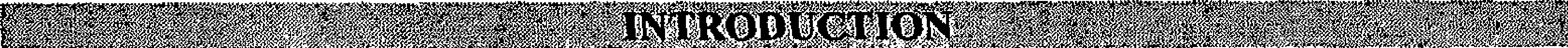

Although abundant scientific evidence confirms anecdotal observations that emotion enhances episodic memory formation (Dolan, 2002), it is also evident that emotion impairs episodic memory formation, and can even induce amnesia (Loftus and Burns, 1982; Christianson 1984). Thus, to advance our understanding of the interaction of emotion and episodic memory formation, it is important to address how emotion corrupts episodic memory formation.

Experimentally, emotion-induced amnesia can be modeled by oddball paradigms where priviliged encoding of an emotional oddball into episodic memory (the emotional von Restorff effect: von Restorff, 1933; Wallace, 1965) disrupts encoding of preceding and following neutral stimuli (Tulving, 1969; Detterman, 1975; Angelini et al., 1994), particularly if the oddball is aversive (Strange et al., 2003; Hurlemann et al,, 2005). One hypothesis is that aversive emotion interferes with episodic encoding by activating an ensemble of neurochemical responses related to acute stress (de Kloet et al., 2005). Support for this hypothesis comes from pharmacological and lesion evidence that the emotional von Restorff 
effect - and the peri-emotional amnesia driven by this effect - both depend on locus coeruleus (LC)-norepinephrine (NE) input to the basolateral amygdala (BLA) (Strange et al., 2003; Hurlemann et al., 2006), which modulates hippocampal function during encoding (Strange and Dolan, 2004; van Stegeren et al., 2005) and consolidation (Cahill et al., 1994, 1995) of emotional episodic memories. Peri-emotional amnesia is amplified by the NE re-uptake inhibitor reboxetine and suppressed by the non-selective $\beta$-adrenergic antagonist propranolol, underscoring its susceptibility to experimental changes in central NE tone (Hurlemann et al., 2005).

In addition, acute stress activates the hypothalamic-pituitary-adrenal (HPA) axis. Central concentrations of adrenal cortisol (CORT) rise to peak stress levels within $15-30$ min and normalize to pre-stress levels 60-90 min later (de Kloet et al., 2005). Stress levels of CORT appear to impair hippocampal function during retrieval (de Quervain et al., 1998, 2000; Roozendaal et al., 2004; Kuhlmann et al., 2005; Cai et al., 2006; Soravia et al., 2006), but to enhance amygdala function during encoding (Cahill et al., 2003) and consolidation (Buchanan and Lavallo, 2001; Roozendaal, 2002; Abercrombie et al., 2003; Okuda et al., 2004) of emotional episodic memories. This profile suggests a synergistic effect of CORT and $\mathrm{NE}$ co-activation in stimulating amygdala-hippocampal interactions expressed during emotional episodic memory formation (Nathan et al., 2004; van Stegeren et al., 2006). Moreover, pharmacological manipulations in rodents indicate that emotional arousal-evoked NE input to the BLA is essential for enabling CORT enhancement of memory formation (Quirarte et al., 1997; Roozendaal et al., 2006).

Given this empirical background, we hypothesized that amnesia in response to aversive emotion would exacerbate under conditions of elevated CORT and NE availability. To prove this hypothesis, we devised a randomized double-blind placebo-controlled trial where healthy volunteers were administered a single oral dose of synthetic CORT (hydrocortisone) on top of either placebo or reboxetine pre-treatment and tested on the established behavioral indices of peri-emotional amnesia (Hurlemann et al., 2005). The rationale of these pharmacological manipulations was to induce stress levels of CORT and determine its amnesiogenic potential in the presence or absence of elevated NE availability.

W.

\section{Subjects}

Fifty-seven right-handed subjects (28 males and 29 females; age range, $20.6-29.3 \mathrm{yr}$; mean age $25.3 \pm 1.8 \mathrm{yr}$ ) provided written informed consent to this study, which was approved by the local ethics committee and the German Federal Institute for Drugs and Medical Devices. Individuals who met any one of the following exclusion criteria were not enrolled in the study: previous exposure to the oddball memory test used in this study, current or past DSM-IV (Diagnostic and Statistical Manual of Mental Disorders IV) axis I or axis II disorder, physical illness, and night shift work, as assessed by an experienced clinician. All subjects were non-smokers and free of any medication apart from contraceptive pills (23 females). Psychological screening prior to study enrollment included the VLMT (Verbaler Lern- und Merkfahigkeitstest) (Helmstaedter et al., 2001), a German version of the RAVLT (Rey Auditory Verbal Learning Test), to assess immediate verbal learning span, new learning, susceptibility to interference, and recognition memory. The ROCF (Rey-Osterrieth Complex Figure Test) (Rey, 1941; Osterrieth, 1944) was used to test incidental visual memory and the 
visuospatial constructional ability. Motor speed and visual attention were examined with the TMT (Trail Making Test) (Raitan, 1958). All volunteers performed within the normal to above-normal range of the psychological screening instruments (data not shown). Mean verbal IQ was $106.88 \pm 9.70(90-122)$ as determined with the HAWIE-R (HamburgWechsler Intelligenztest für Erwachsene), a German Version of the WAIS-R (Wechsler Adult Intelligence Scale-Revised) (Tewes, 1991).

\section{Oddball memory test}

Stimulus setup and experimental task have been detailed elsewhere (Hurlemann et al., 2005). As illustrated in Fig. $1 \mathrm{~A}$, the paradigm was restricted to the presentation of emotionally neutral (P) and negative (E) oddballs. In total, subjects were exposed to 24 study-distractiontest sequences over $45 \mathrm{~min}$. Episodic memory was tested by free recall. Recall profiles were pooled according to the 2 oddball categories, thus yielding a neutral and a negative condition. As outcome parameter, memory performance was determined condition-wise by calculating the percentage of correct recall (i.e. the output / input ratio) for the following 5 list positions: oddball, oddball \pm 1 , and oddball \pm 2 . Additionally, a standard item score (SI) based on the 7 non-oddball list positions was calculated for each condition (e.g., $\mathrm{SI}_{\mathrm{p}}$ ). Contrasting the negative condition with the neutral condition yielded relative recall changes for each list position and thus allowed us to isolate retrograde and anterograde effects of negative emotion on two adjacent standard items $(E \pm 1$ and $E \pm 2$ ) corresponding to a maximum time window of $\pm 10 \mathrm{sec}$. To assess potential pharmacological effects on the cognitive appraisal of emotion, all volunteers performed valence and arousal ratings to $P$ and $E$ oddballs on a 9-point scale after the oddball memory test. Whereas our previous paradigm was designed to demonstrate a causal link between the emotional von Restorff effect and the E-1 retrograde amnesic response (Strange et al., 2003), the present paradigm was optimized to measure pharmacologically induced variation in E-1 retrograde and $\mathrm{E}+1$ anterograde amnesic responses by using a subtractive design (Hurlemann et al., 2005).

\section{Pharmacological dosing.}

Experiments in rodents demonstrate that an inverted U-shaped function characterizes the relation between memory and arousal (Yerkes and Dodson 1908). However, doseresponse studies in humans have yet to replicate these effects. In the present study, a $30-\mathrm{mg}$ single oral dose of hydrocortisone (HCR) was administered to elevate CORT activity to levels ranging between moderate $(20 \mathrm{mg})$ and extreme $(40 \mathrm{mg})$ acute stress (Abercrombie et al. 2004). A 4-mg single oral dose of reboxetine mesilate (RBX) was administered, as it has previously been shown effective in amplifying peri-emotional amnesia (Hurlemann et al. 2005).

\section{Experimental procedure}

Subjects refrained from alcohol, caffeine, and food intake for the $12 \mathrm{~h}$ prior to the experiment. The experiment started at 08:00 h $(t=-150 \mathrm{~min})$ and finished at 11:45 h $(\mathrm{t}=+75$ min). Subjects were administered 2 capsules, the first at $08: 30 \mathrm{~h}(\mathrm{t}=-120 \mathrm{~min})$ and the second at $09: 30 \mathrm{~h}(\mathrm{t}=-60 \mathrm{~min})$, in a double-blind, randomized, parallel-group design. Control group A received lactose placebo (PLC) (capsule 1 and 2), whereas group B received PLC (capsule 1) followed by $30 \mathrm{mg}$ of HCR (capsule 2). Group C received $4 \mathrm{mg}$ of RBX (capsule 1) followed by $30 \mathrm{mg}$ of HCR (capsule 2). Three subjects dropped out of the study due to acute RBX-related side-effects in the form of dizziness and tachycardia. Drug allocation was 
balanced for age, IQ, and sex, i.e. 9 males and 9 females were assigned to each treatment group $(\mathrm{n}=18)$.

To ensure that the start of the oddball memory test coincided with peak plasma concentrations of HCR and RBX, we scheduled the intake of capsule 1 and 2 according to the plasma kinetics ob both agents (HCR, time to peak plasma concentration, $1 \mathrm{hr}$, elimination half-life, $1.5 \mathrm{hr}$; RBX, $2 \mathrm{hr}$ and $13 \mathrm{hr}$, respectively). Blood pressure and pulse frequency were monitored throughout the experiment. The oddball memory test started at $t=0 \mathrm{~min}$ and finished at $t=+45 \mathrm{~min}$. Thereafter, subjects performed paper-pencil emotion ratings. At $t=-$ $135 \min$ and $t=+60$ min, venous blood samples were drawn for prechallenge (baseline) (CORT I) and postchallenge (CORT II, RBX) plasma level analyses. Fig. 1 B illustrates the experimental timeline.

A

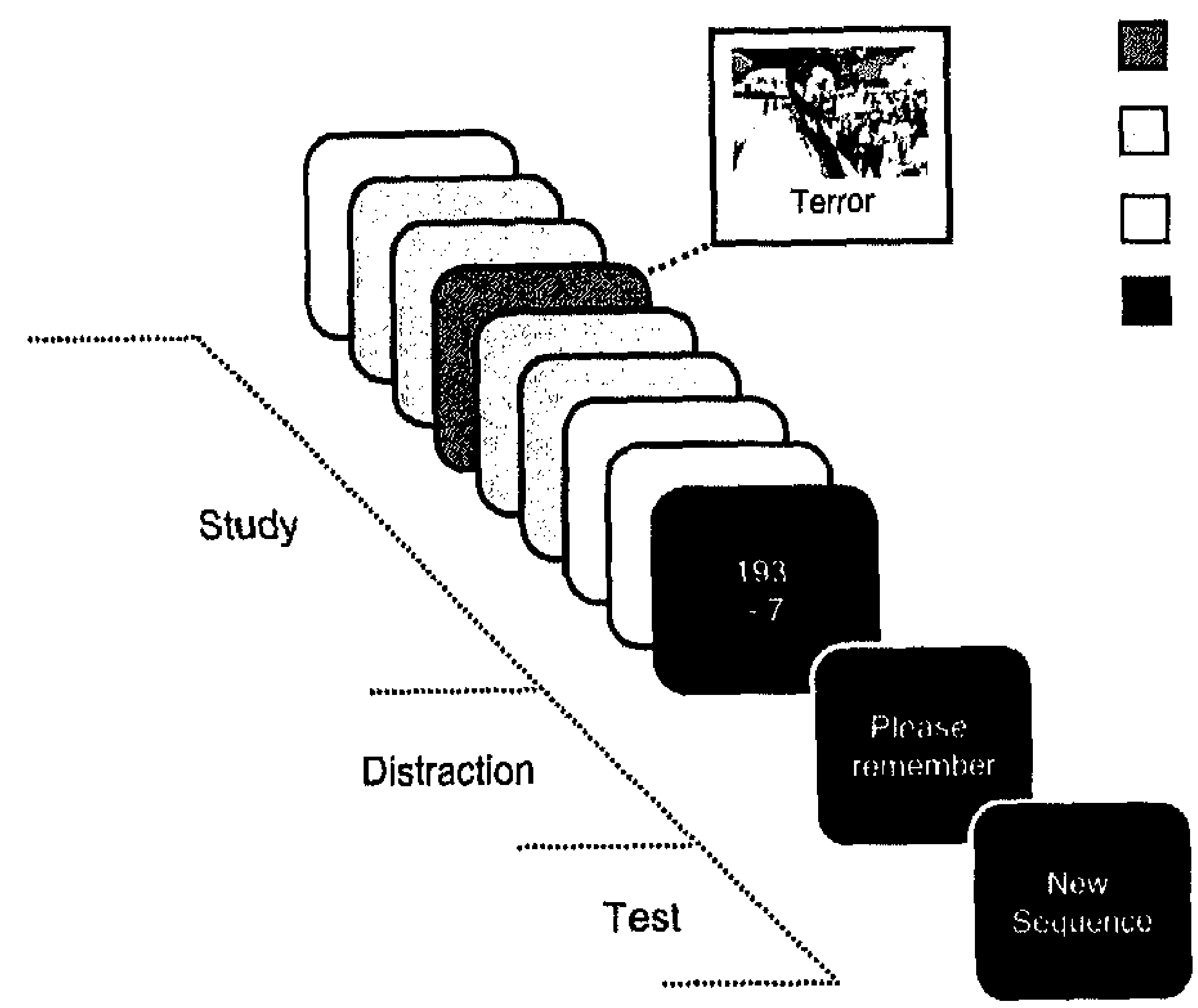

Emotional oddball

Peri-emotional standard items

Other standard items

Instruction

B

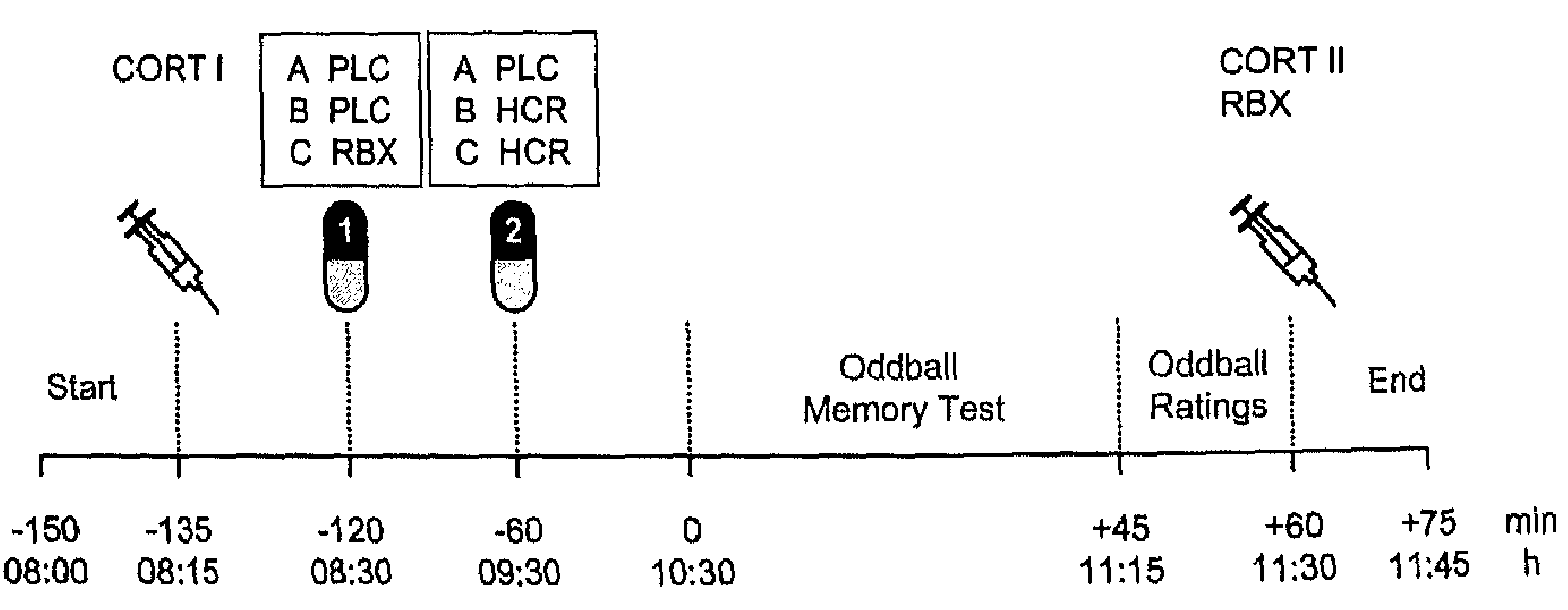

Fig. 1. Experimental design. A, Oddball memory test. Subjects were exposed to 24 study-distraction-test sequences. During each 40-sec study phase, they were presented with a list of 8 items, including 7 standard items and 1 oddball inserted on list position $3,4,5$ or 6 . After a 30 -sec arithmetic distraction task (e.g., count back in sevens), encoding strength for the 8 list items was tested by free recall. In each list, the oddball, either 
emotionally negative or neutral, was temporally flanked by $\geq 2$ surrounding standard items. Results from list recall were pooled according to the 2 oddball types, yielding a negative and neutral condition. Contrasting the negative condition with the neutral condition allowed to quantify retrograde and anterograde amnesic responses to negative emotion within a time window of \pm 2 standard items or $\pm 10 \mathrm{sec}$. B, Experimental timeline. Subjects $(n=54)$ were administered 2 capsules, the first at 08:30 h $(t=-120 \mathrm{~min})$ and the second at $09: 30 \mathrm{~h}(\mathrm{t}=-60 \mathrm{~min})$, in a double-blind, randomized, parallel-group design. Control group A received lactose placebo (PLC) twice (capsule 1 and 2), whereas group B received PLC (capsule 1) followed by $30 \mathrm{mg}$ of hydrocortisone (HCR) (capsule 2). Group $\mathrm{C}$ received $4 \mathrm{mg}$ of reboxetine mesilate (RBX) (capsule 1) followed by $30 \mathrm{mg}$ of HCR (capsule 2). Drug allocation was balanced for age, IQ, and sex, i.e. 9 males and 9 females were assigned to each treatment group $(n=18)$. The oddball memory test started at $t=0$ min and finished at $t=+45$ min. Thereafter, subjects performed paper-pencil emotion ratings. At $t=-135 \mathrm{~min}$ and $t=+60 \mathrm{~min}$, venous blood samples were drawn for prechallenge (baseline) and postchallenge plasma level analyses.

\section{Plasma assays}

The CORT plasma level analyses were performed by an extramural biomedical laboratory (Gaal, 53115 Bonn, Germany) using a fluorescence polarization immunoassay (FPIA) technique. The RBX plasma level analyses were performed in-house by highperformance liquid chromatography (HPLC) and UV detection as previously described (Hurlemann et al., 2005). As expected, RBX plasma levels $(133 \pm 38 \mu \mathrm{g} / \mathrm{L}, 94-231 \mu \mathrm{g} / \mathrm{L})$ exceeded those reported in our previous study $(75 \pm 16 \mu \mathrm{g} / \mathrm{L}, 44-104 \mu \mathrm{g} / \mathrm{L}$ ) (Hurlemann et al., 2005). This discrepancy is explained largely by the fact that subjects had fasted for the 12 $h$ prior to RBX intake in the present study, resulting in increased resorption. Moreover, 2 of 18 subjects assigned to the RBX/HCR group were phenotyped as poor metabolizers (209 and $231 \mu \mathrm{g} / \mathrm{L}$, respectively). Pharmacokinetic interactions between co-administered RBX and HCR also contributed to elevated measures of RBX plasma levels in the present study. CYP3A4 is the predominant cytochrome P450 expressed in human liver (Shimada et al., 1994) and responsible for the catabolism of both RBX and CORT. In view of the plasma kinetics of RBX, competitive inhibition of CYP3A4 by CORT could account for $5-10 \%$ higher RBX plasma levels in the present study. In addition, as demonstrated by a series of in vitro assays, displacement of RBX from plasma protein binding by CORT dose-dependently increased the recovery of the analyte RBX. Based on the resulting calibration curve (Fig. 5), we propose the following correction term for $R B X$ plasma levels: $R_{B X}$ corrected $=R B X_{\text {measured }}$ $0.025 \mathrm{~L} / \mu \mathrm{g} \times$ CORT. Application of this correction term yielded RBX plasma levels of 121 $\pm 37 \mu \mathrm{g} / \mathrm{L}(84-216 \mu \mathrm{g} / \mathrm{L})$, which is consistent with peak plasma levels of $130 \mu \mathrm{g} / \mathrm{L}$ after ingestion of a single 4-mg RBX tablet as reported by the manufacturer (Merz Pharmaceuticals). As illustrated in Fig. 3 A, CORT I plasma levels did not differ between groups (two-sample $t$ tests: $p$ values $>.05$ ). CORT II plasma levels were increased in the $\mathrm{PLC} / \mathrm{HCR}$ and $\mathrm{RBX} / \mathrm{HCR}$ groups as a result of $\mathrm{HCR}$ treatment, but decreased in the PLC/PLC group (one-sample $t$ tests: $p$ values $<.0001$ ), which reflects the physiological circadian flux in endogenous CORT levels (de Kloet et al., 2005). Moreover, CORT II plasma level elevations were greater in the RBX/HCR group than in the PLC/HCR group (twosample $t$ test: $\left.t_{(34)}=3.902 ; p<.0001\right)$. This finding is consistent with a stimulation of HPA axis activity and elevated CORT plasma/saliva levels following intake of a single 4-mg oral dose of RBX (Hill et al., 2003).

\section{Statistics}

Recall parameters $\left(\mathrm{E}, \mathrm{E} \pm 1, \mathrm{E} \pm 2, \mathrm{SI}_{\mathrm{E}}\right)$ of the negative condition were analyzed in relation to the corresponding recall parameters $\left(\mathrm{P}, \mathrm{P} \pm 1, \mathrm{P} \pm 2, \mathrm{SI}_{\mathrm{P}}\right)$ of the neutral condition. Two-factor within-subjects and three-factor mixed ANOVAs were followed by two-tailed one-sample and two-sample $t$ tests to determine the source of significance. Greenhouse- 
Geisser correction for inhomogeneity of variance was applied whenever the sphericity assumption was violated. To account for an inflation of the type I error rate due to multiple post hoc testing, the threshold for significance was Bonferroni-adjusted. Effect sizes were quantified by calculating the values of partial Eta squared $\left(\eta_{p}{ }^{2}\right)$ and Cohen's $d$. Pearson correlation coefficients were computed to investigate a potential relationship between the individual magnitude of emotion-induced amnesia and the body-weight corrected plasma levels of CORT and RBX.

\section{PHSULTS}

In a first analysis, we demonstrated that neither oddball recall nor standard item recall in the neutral condition differed between groups as a function of treatment. The percentages $(\%)$ of mean recall $( \pm \mathrm{SD})$ for oddballs $(\mathrm{P})$ and standard items $\left(\mathrm{SI}_{\mathrm{P}}\right)$ in the neutral (control) condition were as follows: PLC/PLC group, 95.37 (5.87) and 55.62 (6.03); PLC/HCR group, $96.30(6.53)$ and 53.57 (4.64); RBX/HCR group, 95.37 (5.13) and $52.84(6.93)$. A series of one-way ANOVAs with group as between-subjects factor confirmed no changes in P-1, P, $\mathrm{P}+1$, and $\mathrm{SI}_{\mathrm{P}}$ recall as a function of treatment ( $p$ values $>.05$ ). This result is consistent with reports that immediate retrieval of non-emotional items is not compromised by either HCR (Elzinga et al., 2004) or RBX (Harmer et al., 2003) administration.

In a second analysis, we demonstrated the presence of E-1 retrograde and $E+1$ anterograde amnesic effects in the PLC/PLC group. These effects served as baseline for subsequent comparisons with the PLC/HCR group and the RBX/HCR group. A condition (negative, neutral) $x$ position (oddball, oddball \pm 1 ) $2 \times 3$ ANOVA restricted to the PLC/PLC group yielded effects of condition $\left(\mathrm{F}_{(1,17)}=21.640 ; p<.0001 ; \eta_{\mathrm{p}}{ }^{2}=.560\right)$, position $\left(F_{(2,34)}=\right.$ $\left.832.467 ; p<.0001 ; \eta_{p}{ }^{2}=.980\right)$, and condition $\mathrm{x}$ position interaction $\left(F_{(2,34)}=17.116 ; p<\right.$ $\left..0001 ; \eta_{p}{ }^{2}=.502\right)$ effects. Post hoc one-sample $t$ tests confirmed the presence of E-1 retrograde $(-14.35 \%)\left(t_{(17)}=-6.200 ; p<.0001\right)$ and $\mathrm{E}+1$ anterograde $(-11.57 \%)\left(t_{(17)}=-3.828\right.$; $p=.001)$ amnesic effects engendered by the negative items, replicating our previous findings (Hurlemann et al., 2005) (Fig. 2 Ai and Bi).

Analyzing the influence of PLC/HCR treatment, a group (PLC/PLC, PLC/HCR) $\mathrm{x}$ condition $\times$ position $2 \times 2 \times 3$ ANOVA yielded group $\left(F_{(1,34)}=7.076 ; p=.012 ; \eta_{p}{ }^{2}=.172\right)$, condition $\left(F_{(1,34)}=69.627 ; p<.0001 ; \eta_{p}{ }^{2}=.672\right)$, position $\left(F_{(2,68)}=1323.883 ; p<.0001 ; \eta_{p}{ }^{2}=\right.$ $.975)$, two-way group $\mathrm{x}$ position $\left(F_{(2,68)}=4.586 ; p=.014 ; \eta_{p}{ }^{2}=.119\right)$, and condition $\mathrm{x}$ position $\left(F_{(2,68)}=39.710 ; p<.0001 ; \eta_{p}{ }^{2}=.539\right)$ interaction effects. Post hoc two-sample $t$ tests demonstrated a subtle, but significant, enhancement of the E-1 retrograde amnesic effect in the PLC/HCR group relative to the PLC/PLC group. The percent $(\%)$ recall change relative to the E-1 (P-1) scores measured in the PLC/PLC group was $-9.72(-24.07)\left(t_{(34)}=-3.378 ; p=\right.$ $.002 ; d=1.16)$ (Fig. 2 Aii and Bii).

Analyzing the influence of additional RBX pre-treatment, a group (PLC/HCR, $\mathrm{RBX} / \mathrm{HCR}) \times$ condition $\mathrm{x}$ position $2 \times 2 \times 3$ ANOVA yielded group $\left(F_{(1,34)}=20.336 ; p<\right.$ $\left..0001 ; \eta_{p}{ }^{2}=.375\right)$, condition $\left(F_{(1,34)}=234.936 ; p<.0001 ; \eta_{p}{ }^{2}=.878\right)$, position $\left(F_{(2,68)}=\right.$ $\left.856.855 ; p<.0001 ; \eta_{p}{ }^{2}=.962\right)$, two-way group $\mathrm{x}$ condition $\left(F_{(1,34)}=22.664 ; p<.0001 ; \eta_{p}{ }^{2}=\right.$ $.400)$, group $x$ position $\left(F_{(2,68)}=7.656 ; p=.001 ; \eta_{p}{ }^{2}=.184\right)$, condition $\times$ position $\left(F_{(2,68)}=\right.$ $\left.130.681 ; p<.0001 ; \eta_{p}{ }^{2}=.794\right)$, and three-way group $\mathrm{x}$ condition $\mathrm{x}$ position $\left(F_{(2,68)}=12.997 ; p\right.$ $\left.<.0001 ; \eta_{p}{ }^{2}=.277\right)$ interaction effects. Post hoc two-sample $t$ tests demonstrated robust enhancements of both the $E-1$ retrograde and $E+1$ anterograde amnesic effect in the 
RHBX/HCR group relative to the PLC/HCR group. An additional $2 \times 2 \times 5$ ANOVA followed by post hoc two-sample $t$ tests revealed that the retrograde amnesia now extended to span E-2 recall. The percent (\%) recall changes relative to the $\mathrm{E}-2$ and $\mathrm{E} \pm 1$ scores of the PLC/HCR group (P-2 and P \pm 1 scores measured in the PLC/PLC group) were as follows: $\mathrm{E}-$ $2,-16.67(-22.22)\left(t_{(34)}=-7.109 ; p<.0001 ; d=2.44\right) ; \mathrm{E}-1,-18.98(-43.06)\left(t_{(34)}=-7.241 ; p<\right.$ $.0001 ; d=2.48) ; \mathrm{E}+1,-9.72(-24.07)\left(t_{(34)}=-4.220 ; p<.0001 ; d=1.66\right)$. The constraints of our paradigm precluded examination of more enduring retrograde amnesic effects. (Fig. 2 Aiii and Biii).

In a third analysis, we examined a potential variation of $E-1$ retrograde and $E+1$ anterograde amnesic effects as a function of gender or treatment. A series of three-factor mixed ANOVAs with gender as between-subjects factor revealed no influence of gender ( $p$ values $>.05$ ). However, individual drug plasma levels were significantly correlated to task performance in the RBX/HCR group, but not in the PLC/HCR group. Specifically, the magnitude of E-1 retrograde amnesic effects correlated with $\mathrm{RBX}(\mathrm{r}=.670 ; p=.002)$ and CORT II $(\mathrm{r}=.626 ; p=.005)$ plasma levels, whereas the magnitude of $\mathrm{E}+1$ anterograde amnesic effects correlated with the $\operatorname{RBX}(\mathrm{r}=.731 ; p=.001)$ plasma level only (Fig. 3 Bi and Bii). These findings are compatible with a linear dose-response relationship under $\mathrm{RBX} / \mathrm{HCR}$ dual treatment conditions.

$A_{(i)}$

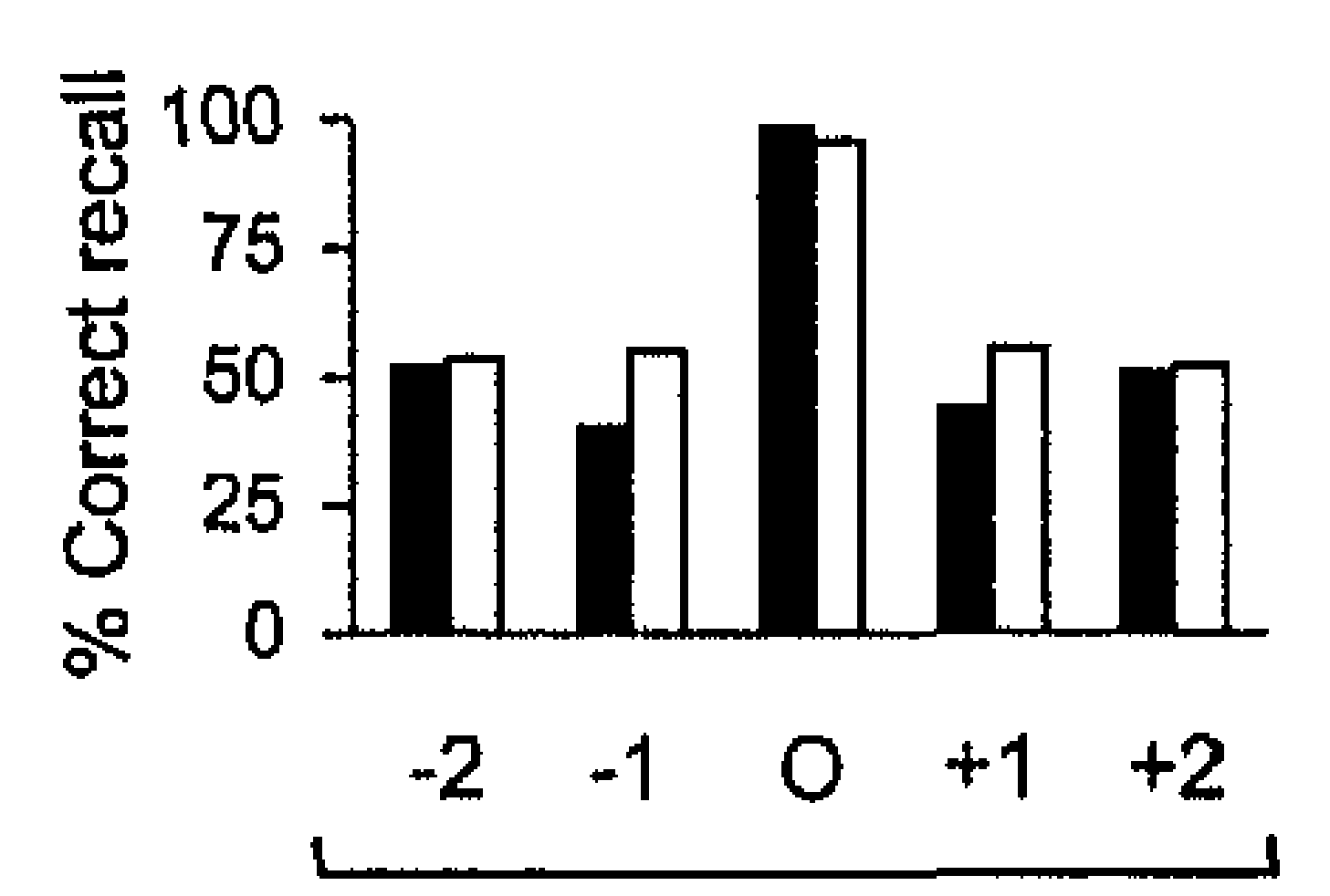

$\mathbf{B}_{\text {(i) }}$

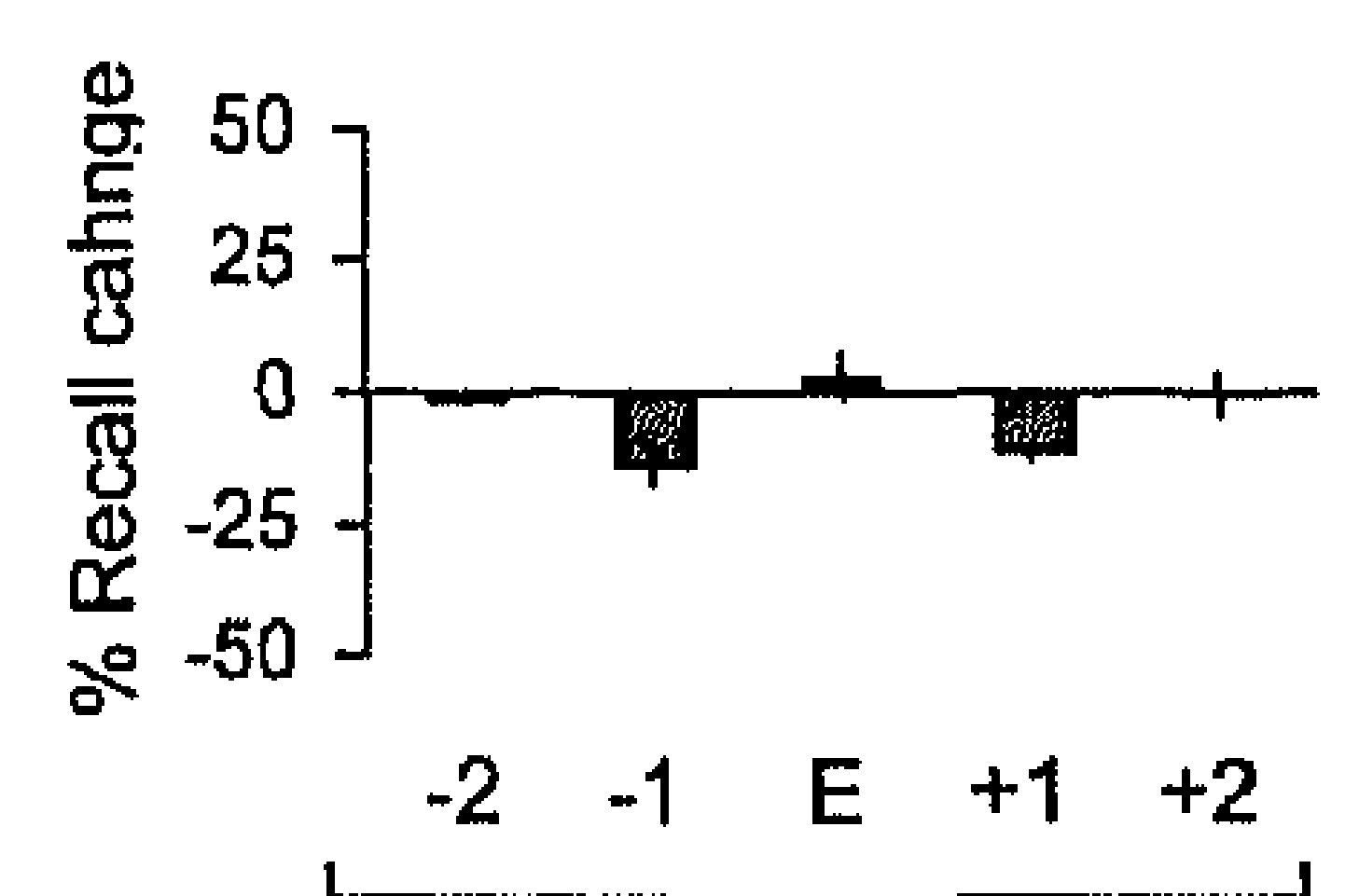

PLC/PLC (ii)

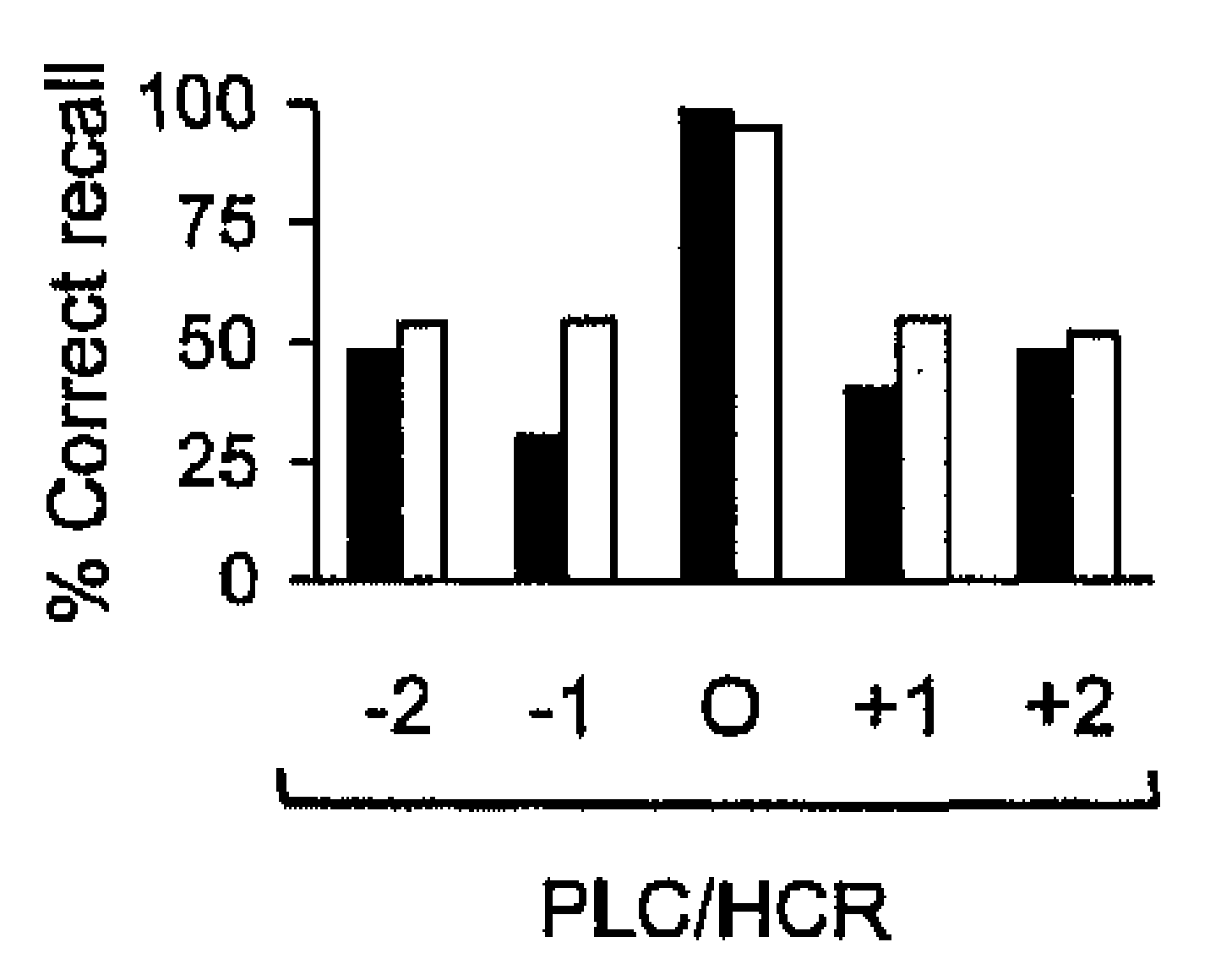

(ii)

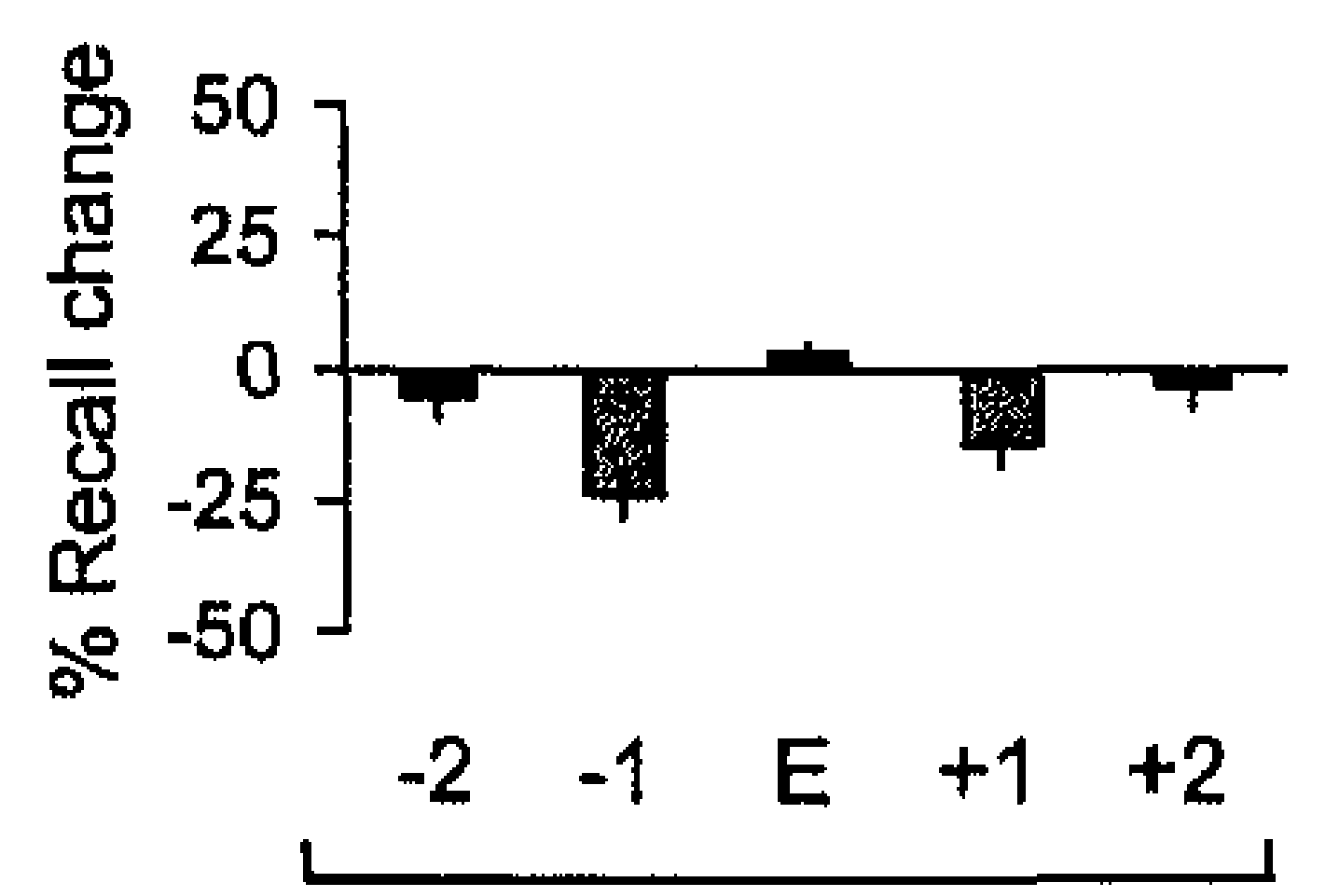

PLC/HCR (iii)

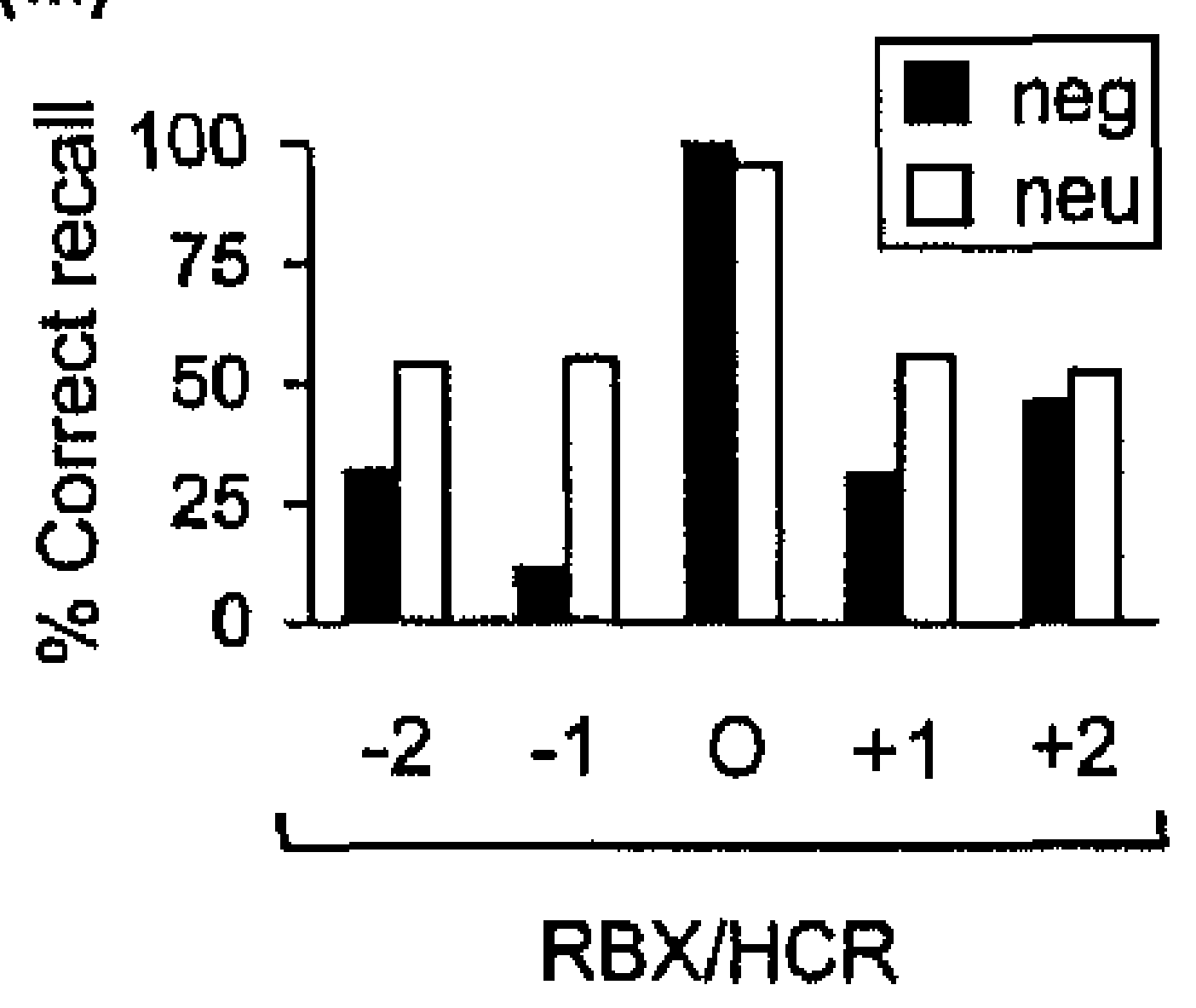

(iii)

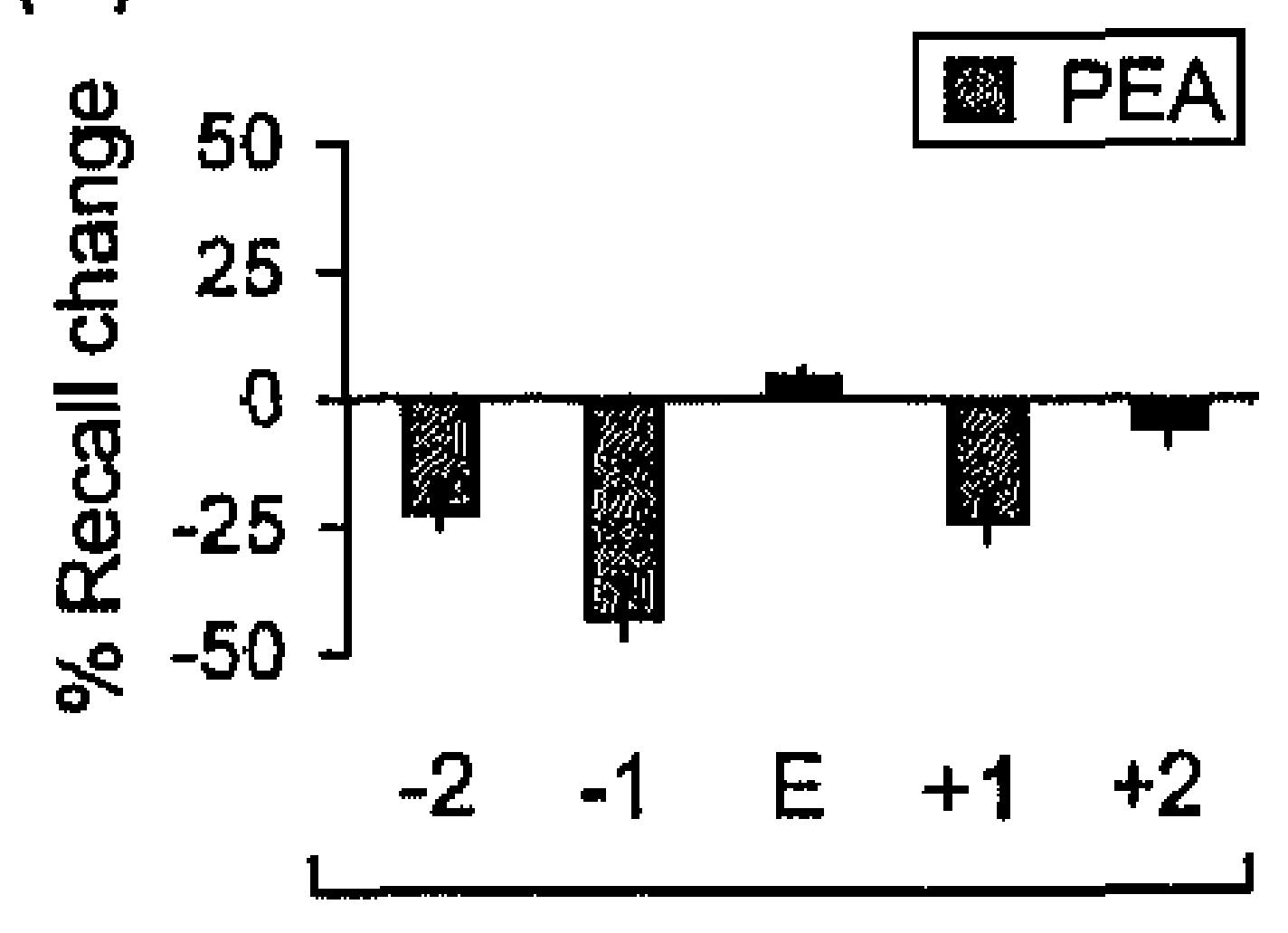

$\mathrm{RBX/HCR}$

Fig. 2. Results of the oddball memory test. A, Percentage (\%) correct recall as determined in the PLC/PLC (i), PLC/HCR (ii), and RBX/HCR (iii) groups ( $n_{\text {group }}=18$ ). Independent of the type of pharmacological treatment, equal (near-ceiling) von Restorff effects were present for emotionally negative and neutral oddballs. None of the applied treatments altered task performance in the neutral condition, i.e. treatment effects were restricted to the emotional condition. B, Percentage (\%) of recall change in the emotional condition contrasted with the neutral condition. (i) The PLC/PLC group displayed a characteristic pattern of E-1 retrograde $(-14.35 \%)$ and $E+1$ anterograde amnesic responses (-11.57\%). (ii) PLC/HCR treatment selectively enlarged the E-1 retrograde ($24.07 \%$ ) amnesic effect. (iii) Under RBX/HCR dual treatment conditions, increases of both E-1 retrograde ($43.06 \%)$ and $E+1$ anterograde $(-24.07 \%)$ amnesic effects were measured. The retrograde amnesic effect extended to E-2 items $(-22.22 \%)$ and thus spanned a period of 10 sec. Error bars indicate SE. Abbreviations: E, emotion contact; HCR, hydrocortisone; neg, negative condition; neu, neutral condition; $\mathrm{O}$, oddball; PEA, periemotional amnesia; PLC, placebo; RBX, reboxetine. 
A

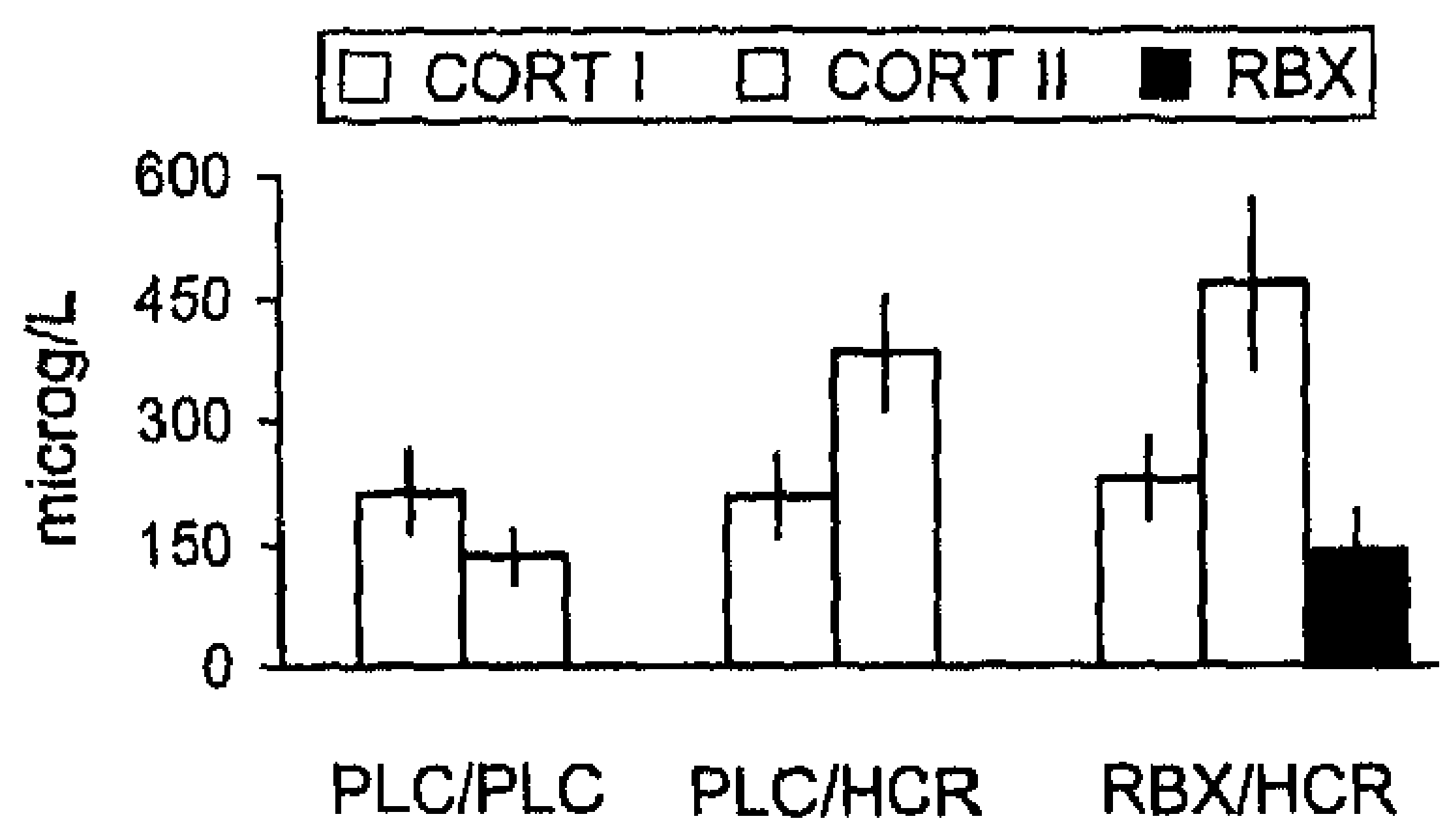

$B_{(i)}$

microg/L

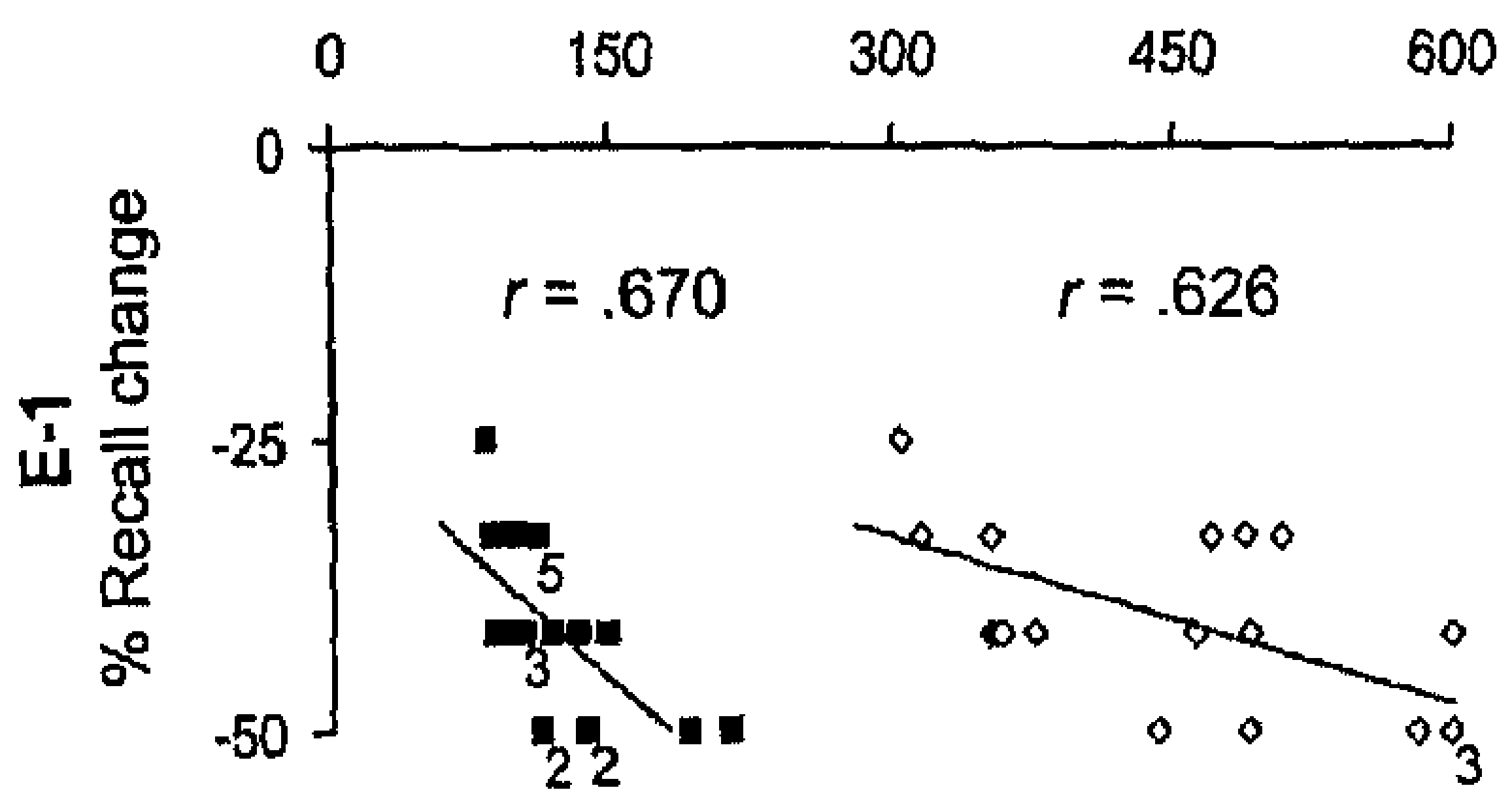

$B_{\text {(ii) }}$

microg/L

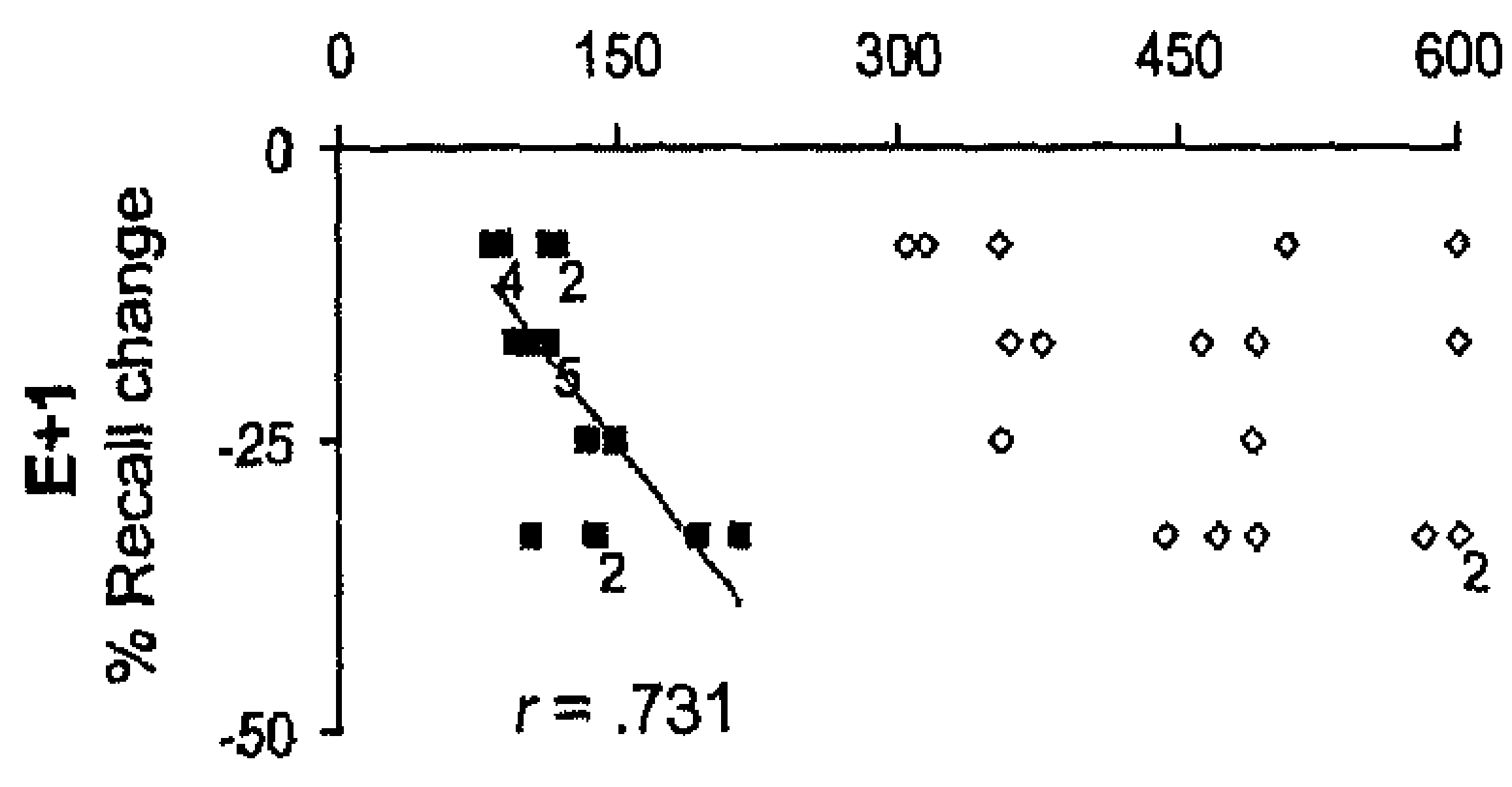

CORTII RBX

Fig. 3. Dose-dependent variation of peri-emotional amnesia. A, Results of the plasma level analyses. Prechallenge (baseline) cortisol (CORT I) plasma levels did not differ between groups. Postchallenge cortisol (CORT II) plasma levels were increased in the PLC/HCR and RBX/HCR groups as a result of HCR treatment, but decreased in the PLC/PLC group, which reflects the physiological diurnal variation in HPA axis activity. CORT II plasma level elevations were greater in the RBX/HCR group than in the PLC/HCR group, consistent with reports of a stimulation of HPA axis activity and elevated CORT plasma/saliva levels following intake of a single 4-mg oral dose of RBX. Error bars indicate SE. B, Dose-response correlations as detected under $\mathrm{RBX} / \mathrm{HCR}$ dual treatment conditions, (i) The magnitude of emotion-induced $\mathrm{E}-1$ retrograde amnesic responses varied as a function of CORT II and RBX plasma levels. (ii) In contrast, $E+1$ anterograde amnesic responses conrelated with the RBX plasma level only. Abbreviations: CORT I, prechallenge (baseline) cortisol plasma level; CORT II, postchallenge cortisol plasma level; E, emotion contact; HCR, hydrocortisone; NE, norepinephrine; PLC, placebo; RBX, reboxetine.

We performed a fourth analysis to assess whether treatment affected the cognitive appraisal of emotion. The oddball arousal and valence judgments (mean \pm SD) obtained after 
the oddball memory test were as follows: PLC/PLC group: $\mathrm{E}$ oddballs $(5.28 \pm 0.46,2.56 \pm$ $0.51)$; $\mathrm{P}$ oddballs $(2.39 \pm 0.50,5.11 \pm 0.58)$; PLC/HCR group: E oddballs $(5.44 \pm 0.51,2.61 \pm$ $0.48) ; \mathrm{P}$ oddballs $(2.67 \pm 0.49,5.22 \pm 0.43) ; \mathrm{RBX} / \mathrm{HCR}$ group: $\mathrm{E}$ oddballs $(7.06 \pm 0.54,2.33 \pm$ $0.49)$; P oddballs (2.56 $\pm 0.51,5.06 \pm 0.54)$. A series of group $\mathrm{x}$ condition ANOVAs followed by post hoc two-sample $t$ tests demonstrated that treatment with PLC/HCR had no influence on either valence or arousal ratings, whereas pre-treatment with RBX increased subjects' emotional arousability $\left(t_{(34)}=-9.198 ; p<.0001 ; d=3.15\right)$, which replicates our previous results (Hurlemann et al., 2005). However, this finding is not compatible with a cognitive bias towards negative emotion, as valence ratings were not affected by RBX/HCR treatment. Additional analyses demonstrated no correlations between the subjective arousal scores and the individual drug plasma levels or the individual $\mathrm{E} \pm 1$ amnesic responses ( $p$ values $>.05$ ).

P.

Within the experimental context of peri-emotional amnesia, we determined the $\mathrm{E} \pm 1$ amnesiogenic potential of HCR ( $30 \mathrm{mg}$ p.o.) in the presence or absence of RBX (4 mg p.o.). As neither pharmacological manipulation affected $P \pm 1$ recall performance in the neutral (control) condition, RBX and/or HCR treatment do not mimic or replace emotional arousal, but interact with it. These interactions likely involve neural circuits engaged in the encoding and/or retrieval of emotional episodic memories. However, evidence from electrophysiological and functional imaging studies points to emotional episodic encoding as the core neural process underlying the emotional von Restorff effect (Fabiani and Donchin 1995; Strange and Dolan 2001; Wiswede et al. 2006) and the peri-emotional amnesia driven by this effect (Hurlemann 2006).

Our results indicate that the HCR single challenge selectively augmented the E-1 retrograde amnesic response. RBX pre-treatment further amplified this E-1 retrograde amnesic response in both magnitude and temporal extent, such that it impaired E-2 recall and spanned a period of $10 \mathrm{sec}$. Given our previous results (Hurlemann et al. 2005), it seems that CORT and NE both act as agonists on the neurochemical pathways underpinning emotioninduced retrograde amnesia. Under $\mathrm{RBX} / \mathrm{HCR}$ dual challenge conditions, we observed a linear dose-response relationship, i.e. the higher the individual plasma levels of both drugs, the greater the magnitude and duration of E-1 retrograde amnesic responses. These results implicate peripheral HCR and RBX plasma levels as a proxy of central CORT and NE activity. While we cannot rule out that the observed correlations are primarily driven by RBX effects alone, the absence of any dose-response relationship under RBX (Hurlemann et al. 2005) and HCR monotreatment suggests a pharmacodynamic interaction of CORT and NE in enhancing E-1 retrograde amnesic responses under RBX/HCR dual challenge conditions. However, the limited dynamic range of amnesic responses obtained with the present oddball paradigm precludes accurate distinction between additive and over-additive (synergistic) effects of CORT and NE.

The finding that HCR monotreatment did not modulate either the magnitude of $E+1$ anterograde amnesic responses or the subjective report of emotional arousal contrasts sharply with the previously observed effects of RBX monotreatment (Hurlemann et al. 2005). E+1 anterograde amnesic responses have been interpreted as resulting from a BLA-dependent capture of attention to enable preferential encoding of emotionally arousing stimuli. In principle, such allocation of attentional resources as a function of emotional arousal might be regarded as adaptive and can provoke a transient refractory period, of at least $5 \mathrm{sec}$ duration. 
This process disrupts attentional re-orienting and is supposed to be a prerequisite for encoding a following $E+1$ non-emotional stimulus in anterior hippocampus (Hurlemann et al. 2006).

While E+1 anterograde amnesia appears to reflect the cost of a BLA-dependent bias of attention to emotionally arousing stimuli, E-1 retrograde amnesia most likely results from an interference of privileged encoding of aversive episodic memories with ongoing (premature) encoding of non-emotional episodic memories in anterior hippocampus (Hurlemann et al. 2005). This view is in line with the prevailing concept that BLA-dependent arousal signals transmitted to anterior hippocampus render it susceptible to valence input from specific prefrontal cortex (PFC) subregions (Dolcos et al. 2004; Kensinger 2004; Kensinger and Corkin 2004). According to this model, negative vs. positive valence assessment in medial PFC (mPFC) is critical for a differential expression of E-1 retrograde amnesic vs. hypermnesic effects, with the magnitude of these effects varying as a function of BLA activation. Specifically, we suggest that positive valence input triggers associative encoding of a rewarding stimulus and non-predictive stimuli preceding this rewarding stimulus, whereas negative valence input eliminates encoding of preceding stimuli in order to prioritize encoding of an aversive stimulus (Hurlemann 2006).

At the timing and dosing regimen applied in the present study, E-1 retrograde, but not $\mathrm{E}+1$ anterograde amnesic responses were amenable to experimental changes in central CORT tone. This discrepancy suggests that stress levels of CORT enhance emotional episodic encoding by amplifying amygdala-hippocampal interactions rather than increasing attentional bias to emotional stimuli. Substantial evidence in support of this view comes from in vitro studies in rodents that document enhanced excitability of BLA neurons treated with stress doses of CORT (Duvarci and Paré 2007). By increasing the susceptibility of BLA neurons to LC-NE input, stress levels of CORT could enhance amygdalar input to anterior hippocampus during emotional episodic memory formation. This interpretation would be in keeping with reports of synergistic CORT and NE effects in the BLA of behaving rodents (Quirarte et al. 1997; Roozendaal et al. 2006). Extending this rodent model to the human, interactions of endogenous CORT plasma levels with increasing amygdala activation under placebo, but not under propranolol administration have been demonstrated (van Stegeren et al, 2007). This finding is consistent with the results of another human study that revealed a positive correlation of endogenous CORT plasma levels with enhanced memory formation only in those individuals who were emotionally aroused (Abercrombie et al. 2003).

The enhancement of $\mathrm{E}-1$ retrograde amnesic responses by CORT in our study could be caused by early genomic effects of CORT (e.g., through enhancement of BLA neuronal activity) (Duvarcy and Paré 2007) and/or instantaneous non-genomic CORT action. The latter has been investigated in rodent experiments that provide evidence of a direct inhibition of the extra-neuronal monoamine transporter (EMT) on glia cells with CORT (Grundemann et al. 1998). The close proximity between synaptic and glia cell processes implicates EMT in rapid inactivation of pre-synaptically released NE. While this rodent model has not been replicated in humans explicitly, CORT-induced blockade of EMT-mediated NE re-uptake would be compatible with an immediate increase of NE synaptic levels in the BLA, thereby enhancing E-1 retrograde amnesic responses under RBX/HCR dual challenge conditions. A potentiation of NE neurotransmission by CORT could thus allow rapid allocation of limited episodic encoding resources in anterior hippocampus based upon criteria of emotional significance (Hurlemann 2006). Such filtering would be rendered ineffective if only the slower genomic responses to CORT occurred. 
Our finding of exacerbated retrograde amnesic responses under RBX/HCR dual challenge conditions is consistent with a phenotypic expression of retrograde amnesia varying as a function of CORT and NE co-activation during acute stress. A model of the underlying neurocircuitry is suggested in Fig. 4. Extrapolating this model to conditions of uncontrollable acute stress (e.g., during emotional trauma) allows to predict the maladaptive effects that an emotional regulation of episodic encoding can have. Under normal circumstances, both HPA axis (Radley et al. 2006) and LC function (Aston-Jones and Cohen 2005) are under top-down inhibitory control by mPFC (Maier et al. 2006). However, when it comes to uncontrollable acute stress, disinhibited CORT and LC-NE signaling due to insufficient mPFC top-down control may result in exaggerated amygdalar input to anterior hippocampus. As a consequence, hyper-encoding of the aversive episodic memory paralleled by peri-emotional amnesia might occur, further augmenting decontextualization of the aversive episodic memory. Thus, what may clinically manifest as a dissociative (or peri-traumatic) amnesia due to a deficit in episodic retrieval, may eventually prove to be a true amnesia driven by a neurobiological mechanism fundamental to priviliged encoding of aversive episodic memories.

In conclusion, our results implicate CORT and NE co-activation during acute stress in mediating clinically relevant forms of emotion-induced retrograde amnesia. In addition, our study demonstrates that the adverse cognitive and behavioral sequelae of aversive emotion can be experimentally modeled by pharmacologically interacting with its neurochemical substrates.

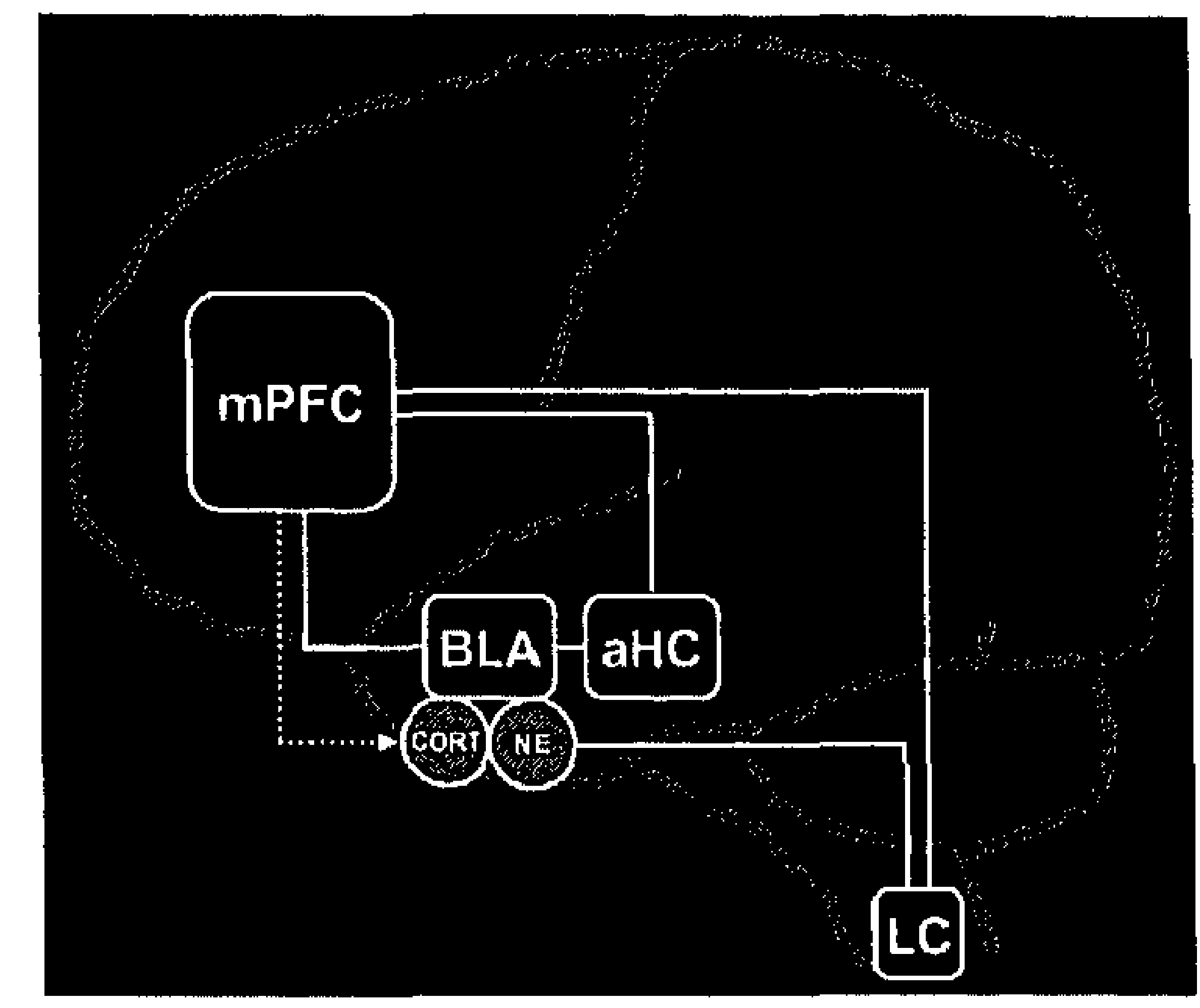

Fig. 4. Neurocircuitry model of peri-emotional amnesia. Whereas anterograde amnesic responses most likely result from a transient failure of attentional re-orienting after emotion contact, retrograde amnesic responses appear to reflect a filter mechanism that controls episodic memory access based upon criteria of behavioral significance indexed by emotion. According to this model, basolateral amygdala (BLA) - when activated by ascending locus coeruleus (LC)-noradrenergic (NE) signaling - communicates emotional arousal to anterior hippocampus (aHC), thus rendering it susceptible to descending emotional valence input from medial prefrontal cortex (mPFC). Circulating cortisol (CORT) interacts with LC-NE in amplifying BLA activation. Both CORT and LC-NE signaling are under MPFC top-down inhibitory control. Prioritized encoding of emotional episodic memories in aHC is realized at the cost of ongoing encoding of non-emotional episodic memories, as indicated by robust retrograde amnesic responses. During uncontrollable stress, MPFC top-down control is insufficent to inhibit CORT and LC-NE signaling, resulting in exaggerated BLA responses to aHC. As a consequence, there is hyper-encoding of the stressor event coupled with exacerbated peri-emotional amnesia. 


\section{Calibration of the determination of reboxetine dependent on cortisol plasma levels}

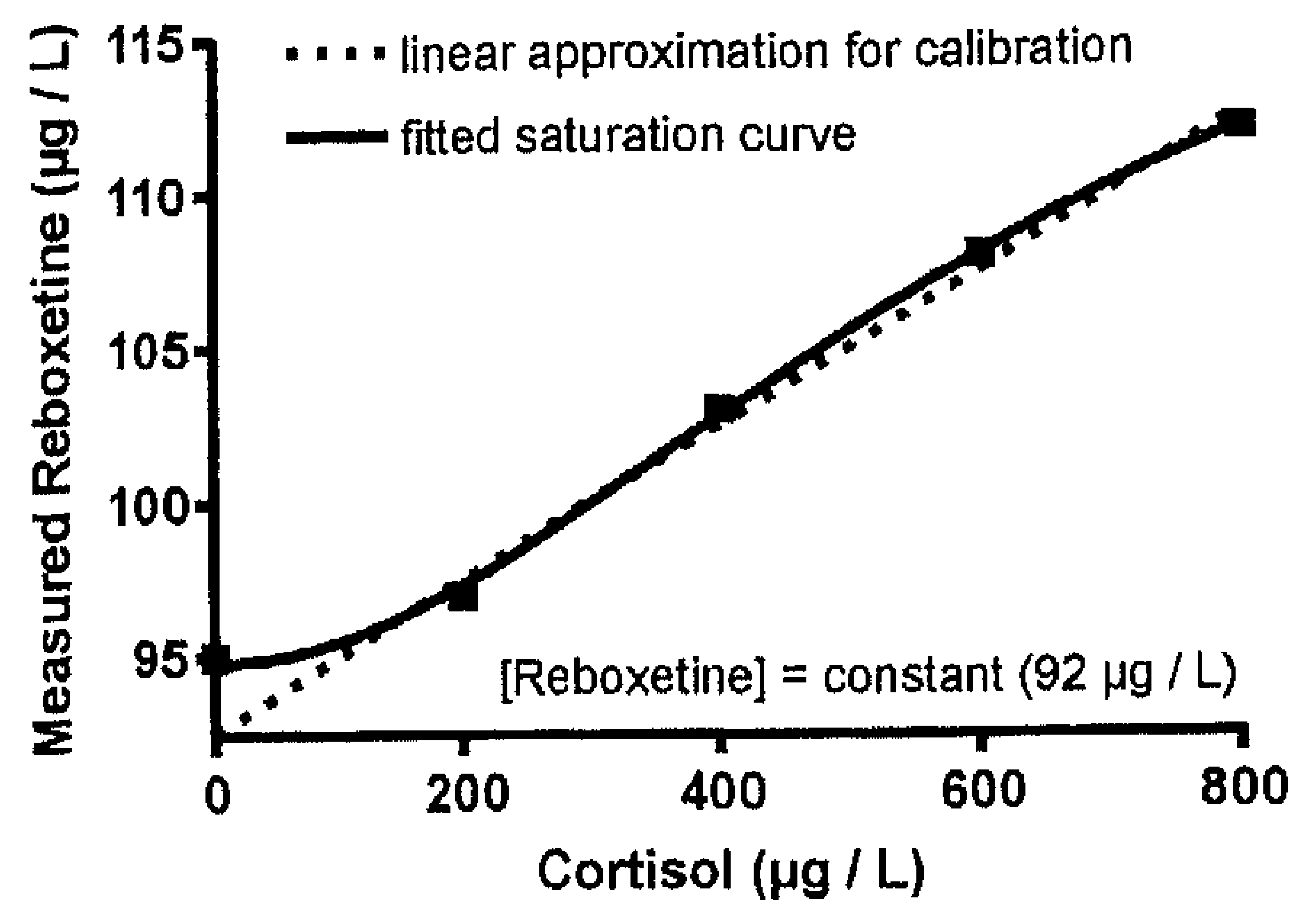

Supplemental Fig. 5. Pharmacokinetic interference of reboxetine and cortisol. To detect potential methodological influences on reboxetine (RBX) plasma levels in the presence or absence of cortisol (CORT), we performed a series of in vitro assays. Initially, one RBX 4-mg tablet was dissolved in $40 \mathrm{~mL}$ of water. Then, 80 $\mu \mathrm{L}$ of different dilutions from this stock solution were added to $1920 \mu \mathrm{L}$ of fresh human plasma yielding concentrations of $0,25,50,75,100,125,150,175$, and $200 \mu \mathrm{g} / \mathrm{L}$, incubated for $180 \mathrm{~min}$ at $37^{\circ} \mathrm{C}$, and subsequently analyzed in the same way as the in vivo samples. The measured RBX plasma concentrations were $0.25,46,72,104,132,165,181$, and $211 \mu \mathrm{g} / \mathrm{L}$, respectively, yielding the relationship: $\mathrm{RBX}_{\text {measured }}=1.09 \times$ $\mathrm{RBX}_{\text {nummal }}-5.3 \mu \mathrm{g} / \mathrm{L}$. In a second series of plasma standards, $40 \mu \mathrm{L}$ of analyte solution were added to several aliquots of $1920 \mu \mathrm{L}$ plasma yielding a concentration of $100 \mu \mathrm{g} / \mathrm{L}$ and incubated for $60 \mathrm{~min}$ at $37^{\circ} \mathrm{C}$. Then, either $40 \mu \mathrm{L}$ of water or CORT solution were added resulting in concentrations of 0 ( 3 vials), 200, 400, $600,800 \mu \mathrm{g} / \mathrm{L}$ CORT, respectively, and incubated for additional $120 \mathrm{~min}$. The measured analyte concentrations were 95,97 , 103,108 , and $112 \mu \mathrm{g} / \mathrm{L}$, respectively, resulting in the depicted calibration curve for RBX as a function of CORT plasma levels. For the purpose of external quality control, 2 of the 3 blank plasma standards containing $100 \mu \mathrm{g} / \mathrm{L}$ RBX alone underwent HPLC-tandem mass spectroscopy (HPLC-MS/MS) after addition of a deuterated calibrator (Medical Laboratory of Bremen, 28357 Bremen, Germany), which yielded RBX concentrations of 90 and $94 \mu \mathrm{g} / \mathrm{L}$ as compared to $95 \mu \mathrm{g} / \mathrm{L}$ determined in our in-house analysis. We conclude that CORT dosedependently increased the recovery of the analyte RBX in the present study.

\section{REFERENCES}

Abercrombie HC, Kalin NH, Thurow ME, Rosenkranz MA, Davidson RJ (2003) Cortisol variation in humans affects memory for emotionally laden and neutral information. Behav Neurosci 117:505-516.

Angelini R, Capozzoli F, Lepore P, Grossi D, Orsini A (1994) "Experimental amnesia" induced by emotional items. Percept Mot Skills 78:19-28.

Aston-Jones $G$ and Cohen JD (2005) An integrative theory of locus coeruleus-norepinephrine function: adaptive gain and optimal performance. Ann Rev Neurosci 28:403-450.

Buchanan TW, Lovallo WR (2001) Enhanced memory for emotional material following stress-level cortisol treatment in humans. Psychoneuroendocrinology 26:307-317.

Calill L, Prins B, Weber M, McGaugh JL (1994) Beta-adrenergic activation and memory for emotional events. Nature 371:702-704.

Cahill L, Babinsky R, Markowitsch HJ, McGaugh JL (1995) The amygdala and emotional memory. Nature 377:295-296.

Cahill L, Gorski L, Le K (2003) Enhanced human memory consolidation with post-learning stress: interaction with the degree of arousal at encoding. Learn Mem. 10:270-274.

Cai WH, Blundell J, Han J, Greene RW, Powell CM (2006) Postreactivation glucocorticoids impair recall of established fear memory. J Neurosci. 26:9560-9566. 
Christianson SA (1984) The relationship between induced emotional arousal and amnesia. Scand J Psychol. 25:147-160.

de Kloet ER, Joels M, Holsboer F (2005) Stress and the brain: from adaptation to disease. Nat Rev Neurosci. 6:463-475.

de Quervain DJ, Roozendaal B, McGaugh JL (1998) Stress and glucocorticoids impair retrieval of long-term spatial memory. Nature 394:787-790.

de Quervain DJ, Roozendaal B, Nitsch RM, McGaugh JL, Hock C (2000) Acute cortisone administration impairs retrieval of long-term declarative memory in humans. Nat Neurosci 3:313-314.

Detterman DK (1975) The von Restorff effect and induced amnesia: production by manipulation of sound intensity. J Exp Psychol [Hum Leam] 1:614-628.

Dolcos F, LaBar KS, Cabeza R (2004) Dissociable effects of arousal and valence on prefrontal activity indexing emotional evaluation and subsequent memory: an event-related IMRI study. Neuroimage 23:64-74.

Duvarci S, Paré D (2007) Glucocorticoids enhance the excitability of principal basolateral amygdala neurons. J Neurosci 27:4482-4491.

Elzinga BM, Bakker A, Bremner JD (2005) Stress-induced cortisol elevations are associated with impaired delayed, but not immediate recall. Psychiatry Res 134:211-223.

Fabiani M, Donchin E (1995) Encoding processes and memory organization: a model of the von Restorff effect. J Exp Psychol Learn Mem Cogn 21:224-240.

Grundemann D, Schechinger B, Rappold GA, Schomig E (1998) Molecular identification of the corticosteronesensitive extraneuronal catecholamine transporter. Nat Neurosci 1:349-351

Harmer CJ, Hill SA, Taylor MJ, Cowen PJ, Goodwin GM (2003) Toward a neuropsychological theory of antidepressant drug action: increase in positive emotional bias after potentiation of norepinephrine activity. Am J Psychiatry 160:990-992.

Helmstaedter C, Lendt M, Lux S (2001) Verbaler Lern- und Merkfähigkeitstest (VLMT). Göttingen: Hogrefe

Hill SA, Taylor MJ, Harmer CJ, Cowen PJ (2003) Acute reboxetine administration increases plasma and salivary cortisol. J Psychopharmacol 17:273-275.

Hurlemann R (2006) Noradrenergic control of emotion-induced amnesia and hypermnesia. Rev Neurosci 17:525-532.

Hurlemann R, Hawellek B, Matusch A, Kolsch H, Wollersen H, Madea B, Vogeley K, Maier W, Dolan RJ (2005) Noradrenergic modulation of emotion-induced forgetting and remembering. J Neuroci 25:6343-6349.

Hurlemann R, Wagner M, Hawellek B, Reich H, Pieperhoff P, Amunts K, Oros-Peusquens AM, Shah NJ, Maier W, Dolan RJ (2006) Amygdala control of emotion-induced forgetting and remembering: Evidence from Urbach-Wiethe disease. Neuropsychologia 45:877-884.

Kensinger EA (2004) Remembering emotional experiences: the contribution of valence and arousal. Rev Neurosci 15:241-251.

Kensinger EA, Corkin S (2004) Two routes to emotional memory: distinct neural processes for valence and arousal. Proc Nat1 Acad Sci USA 101:3310-3315.

Kim JJ, Diamond DM (2002) The stressed hippocampus, synaptic plasticity and lost memories. Nat Rev Neurosci 3:453-462

Kuhlmann S, Piel M, Wolf OT (2005) Impaired memory retrieval after psychosocial stress in healthy young men. J Neurosci 25:2977-2982

Loftus EF, Burns TE (1982) Mental shock can produce retrograde amnesia. Mem Cognit 10:318-323.

Maier SF, Amat J, Baratta MV, Paul E, Watkins LR (2006) Behavioral control, the medial prefrontal cortex, and resilience. Dial Clin Neurosci 8:397-406.

Nathan SV, Griffith QK, McReynolds JR, Hahn EL, Roozendaal B (2004) Basolateral amygdala interacts with other brain regions in regulating glucocorticoid effects on different memory functions. Ann N Y Acad Sci 1032:179-182.

Okuda S, Roozendaal B, McGaugh JL (2004) Glucocorticoid effects on object recognition memory require training-associated emotional arousal. Proc Natl Acad Sci USA 101;853-858.

Osterrieth PA (1944) Le test de copie d'une figure complexe. Arch Psychol 30:206-356.

Quirarte GL, Roozendaal B, McGaugh JL (1997) Glucocorticoid enhancement of memory storage involves noradrenergic activation in the basolateral amygdala. Proc Natl Acad Sci USA 94:14048-14053.

Radley JJ, Arias CM, Sawchenko PE (2006) Regional differentiation of the medial prefrontal cortex in regulating adaptive responses to acute emotional stress. J Neurosci 26:12967-12976.

Raitan RM (1958) Validity of the trail making test as an indication of organic brain damage. Percept Mot Skills 8:271-276.

Rey A (1941) L'examen psychologique dans les cas d'encéphalopathie traumatique. Arch Psychol 30:286-340.

Roozendaal B (2002) Stress and memory: opposing effects of glucocorticoids on memory consolidation and memory retrieval. Neurobiol Learn Mem 78:578-595.

Roozendaal B, Hahn EL, Nathan SV, de Quervain DJ, McGaugh JL (2004) Glucocorticoid effects on memory retrieval require concurrent noradrenergic activity in the hippocampus and basolateral amygdala. J Neurosci 24:8161-8169. 
Roozendaal B, Okuda S, Van der Zee EA, McGaugh JL (2006) Glucocorticoid enhancement of memory requires arousal-induced noradrenergic activation in the basolateral amygdala. Proc Natl Acad Sci USA 103:6741. 6746.

Shimada T, Yamazaki H, Mimura M, Inui Y, Guengerich FP (1994) Interindividual variations in human liver cytochrome P-450 enzymes involved in the oxidation of drugs, carcinogens and toxic chemicals: studies with liver microsomes of 30 Japanese and 30 Caucasians. J Pharmacol Exp Ther 270:414-423.

Soravia LM, Heinrichs M, Aerni A, Maroni C, Schelling G, Ehlert U, Roozendaal B, de Quervain DJ (2006) Glucocorticoids reduce phobic fear in humans. Proc Natl Acad Sci USA 103:5585-5590.

Strange BA, Dolan RJ (2001) Adaptive anterior hippocampal responses to oddball stimuli. Hippocampus 11:690-698.

Strange BA, Hurlemann R, Dolan RJ (2003) An emotion-induced retrograde amnesia in humans is amygdalaand beta-adrenergic-dependent. Proc Natl Acad Sci USA 100:13626-13631.

Strange BA, Dolan RJ (2004) Beta-adrenergic modulation of emotional memory-evoked human amygdala and hippocampal responses. Proc Natl Acad Sci USA 101:11454-11458.

Tewes U (1991) Hamburg-Wechsler-Intelligenztest für Erwachsene - Revision 1991. Göttingen: Hogrefe

Tulving E (1969) Retrograde amnesia in free recall. Science 164:88-90.

van Stegeren AH, Goekoop R, Everaerd W, Scheltens P, Barkhof F, Kuijer JP, Rombouts SA (2005) Noradrenaline mediates amygdala activation in men and women during encoding of emotional material. Neuroimage 24:898-909.

van Stegeren AH, Wolf OT, Everaerd W, Scheltens P, Barkhof F, Rombouts SA (2007) Endogenous cortisol level interacts with noradrenergic activation in the human amygdala. Neurobiol Learn Mem 87:57-66.

Von Restorff H (1933) Ueber die Wirkungen von Bereichsbildung im Spurenfeld. Psychologische Forschung 18:299-342.

Wallace WP (1965) Review of the historical empirical and theoretical status of the von Restorff phenomenon. Psychol Bull 63:410-424.

Wiswede D, Russeler J, Hasselbach S, Munte TF (2006) Memory recall in arousing situations - an emotional von Restorff effect? BMC Neurosci 24;7:57.

Yerkes RM, Dodson JD (1908) The relation of strength of stimulus to rapidity of habit-formation. J Comp Neurol Psychol 18:459-482.

\section{ACROWLEGMEN}

The authors wish to thank R.-E. Berg and C. Santoro for excellent assistance. R. Hurlemann was supported by a German Federal Ministry of Education and Research (BMBF) grant (01GW0671) and a BONFOR fellowship. The authors have no conflicts of interest to report, nor any involvement to disclose, financial or otherwise, that may bias the conduct, interpretation or presentation of this work.

\section{PUBMTCATON}

Hurlemann R, Matusch A, Klingmuller D, Hawellek B, Kolsch H, Maier W, Dolan RJ (2007) Emotion-induced retrograde amnesia varies as a function of noradrenergicglucocorticoid effects. Psychopharmacology (Berlin), in press (Article reproduced with permission of the copyright owner. Further reproduction prohibited without permission.) 


\section{CHAPTER 9}

\section{The costs and benefits of emotional memory formation}

An ability to form emotional memories is highly adaptive, as it confers advantages for survival and reproductive success. As exemplified in Chapter 1, recent research has begun to reveal the neuroanatomical substrates and temporal dynamics by which sensory processing is modulated as a result of emotional memory formation (Dolan et al., 2006). Such emotional memory-driven plastic changes are not restricted to the sensory domain, but also manifest within the cognitive domain, as evident in retrograde amnesic and hypermnesic effects that are associated with emotional memory encoding. In contrast, anterograde amnesic responses most likely reflect the costs of a fixation of attention during emotional memory encoding. Similar forms of anterograde interference have been demonstrated in fMRI studies, where emotional distracters interfere with attentional re-orienting and decrease working memory performance (Dolcos and McCarthy, 2006). Another detrimental consequence is evidenced by the focusing of attention on central gist information at the expense of peripheral details for complex emotional stimuli that require serial processing (e.g., emotional narratives or social encounters), as exemplified by 'weapon focus' in eyewitness testimony research. Witnesses to a crime often remember the weapon from the crime, but not other details such as the perpetrator's clothing. This effect has been replicated in the laboratory. Subjects spend a disproportionate amount of time looking at a weapon in a threatening visual scene. This looking time is inversely related to the likelihood that subjects will subsequently identify the perpetrator of the crime (Loftus et al., 1987).

Easterbrook (1959) originally described this form of cognitive bias in his cueutilization theory by predicting that emotional arousal would narrow the focus of attention to the emotional arousal-evoking stimulus. As a consequence, information central to the source of emotional arousal would be encoded while peripheral details would not. Interestingly, Urbach-Wiethe patients with selective bilateral amygdala calcification lesion do not focus on central gist information when memory is tested for audiovisual narratives of emotionally arousing events (Adolphs et al., 2005). This becomes evident when these patients generate intact skin conductance responses (SCRs) and normal arousal/valence ratings, implying specific deficits in emotional memory formation rather than global impairments in the cognitive interpretation of emotion. However, critical characteristics of emotional memory are preserved following bilateral amygdala damage. Amygdalectomized patients preferentially remember items that are emotionally valent but low in arousal as well as neutral items encoded in emotional contexts (Phelps, 2006). These patients appear to access other cognitive resources that enhance emotional memory formation, most likely by recruiting $\mathrm{PFC}$ hippocampal routes that code emotional valence (Kensinger and Corkin, 2004). These findings suggest a critical role of PFC subregions in emotional memory formation and extend current rodent-based models, which emphasize the role of the amygdala. Future functional imaging studies may use cytoarchitectonic maximum probability maps of PFC subregions to 
specify the individual contribution of these subregions to emotional memory formation. The technical feasibility of this innovative strategy has been demonstrated in Chapter 6.

Pharmacological manipulations in humans have implicated both $\beta$-adrenergic and glucocorticoid mechanisms in emotional memory formation, although with less anatomical specificity than in animals. The memory advantage of emotional items relative to neutral items is eliminated by administration of $\beta$-adrenergic receptor antagonists (e.g., propranolol) (Cahill et al., 1994; van Stegeren et al., 1998) and amplified by administration of $\alpha_{2-}$ adrenergic receptor antagonists (functional NE agonists, e.g., yohimbine) ( $O^{\prime}$ Carroll et al., 1999). These results have been interpreted in support of the memory-modulation hypothesis (Chapter 1 and 4). However, in the majority of these studies, pharmacological manipulation was performed before encoding. When $\beta$-adrenergic blockade was established after encoding, no effect of propranolol on emotional memory was observed (van Stegeren et al., 2002). These findings are compatible with those presented in Chapter 2 and $\mathbf{3}$ by suggesting that NE-dependent mechanisms already operate during emotional memory encoding and significantly modulate episodic memory prior to consolidation. Comparison of $\beta$-adrenergic receptor antagonists that readily cross the blood-brain barrier (e.g., propranolol) versus those that do not (e.g., nadolol) reveals that $\beta$-adrenergic effects on emotional memory encoding are centrally mediated (van Stegeren et al., 1998). The temporal dynamics of peripheral stress hormone activation would be far too sluggish to account for the effects of propranolol presented in Chapter 2 and 3. Instead, impaired locus coeruleus (LC)-NE-dependent $\beta$ adrenergic activation is likely responsible for the observed effects of propranolol in these studies. Apparently, peripheral $\beta$-adrenergic activation, though critical to enhanced memory of highly arousing stimuli as indicated by extensive animal research (Chapter 1 and 4) (McGaugh, 2000), is not critical to memory enhancements for mildly arousing stimuli (van Stegeren at al., 1998). The observation that both emotional memory encoding and the related retroactive plastic changes in hippocampus are abolished in Urbach-Wiethe patients with a focal disease emphasis on the BLA (Chapter 2 and 5), extends current neuropsychological and $\mathrm{FMRI}$ findings that have converged on the amygdala as a likely mediator of $\beta$-adrenergic influences. Strikingly, these influences can be exogenously enhanced by single-dose administration of the NE re-uptake inhibitor reboxetine. Clinically, this compound is used as an energizing antidepressant. However, as discussed in Chapter 7, its application in patients with BPD should be carefully considered, as it might amplify emotion-induced cognitive dysfunction in these patients.

Glucocorticoids such as CORT interact with both emotional and nonemotional forms of human memory. Variation in CORT influences on memory is attributable to several factors, including gender, stress (acute versus chronic forms), dose (typically as an inverted U-shaped function) and time of day relative to the circadian flux in endogenous CORT levels (LaBar and Cabeza, 2006). Stress can be defined as a condition that involves heigthened arousal and aversiveness, with the latter referring to an experience that an individual would avoid or attenuate if given the opportunity (Kim and Diamond, 2002). Exogenous administration of CORT or stress-induced endogenous CORT release during encoding enhances memory, but similar experimental manipulations during retrieval impair recall of earlier memories (Het et al,, 2005). On tests of working memory, stress or high-dose CORT administration impair performance, which is consistent with the animal literature (Lupien et al., 1999). The observation that both the beneficial effects of CORT on emotional memory encoding and the detrimental effects of CORT on working memory are most pronounced when subjects are emotionally aroused (Abercrombie et al., 2003; Elzinga and Roeloefs, 2005), suggests a synergistic effect of CORT and NE co-activation in enhancing amygdalahippocampal interactions during emotional memory encoding (van Stegeren et al., 2007) as 
well as in compromising working-memory-related dorsolateral PFC function. This is of particular relevance when it comes to life events, where an individual is exposed to excessive stress (e.g., during emotional trauma). Work in humans has shown that having control over an aversive event has a profound mitigating influence on how stressful this event feels. Thus, the degree of control is the variable that ultimately determines the magnitude of the stress response and the susceptibility of the individual to develop stress-induced behavioral sequelae ( $\mathrm{Kim}$ and Diamond, 2002). Animal studies indicate that when an aversive event is controllable, activation of (phylogenetically ancient) brainstem nuclei is inhibited by ventromedial PFC (a more recently evolved executive center), and the behavioral sequelae of uncontrollable stress are blocked (Amat et al., 2005). This seminal finding suggests that control processes mediated by ventromedial PFC can buffer the adverse consequences of excessive stress. In those cases, where control is insufficient, there might be disinhibited hormonal stress responses in form of high-amplitude CORT and NE signaling.

As demonstrated in Chapter 8, CORT effects produce robust peri-emotional amnesia only when combined with $\beta$-adrenergic activation. One might speculate about the validity of these findings as a potential neurochemical model for peri-traumatic amnesia and the pathogenesis of post-traumatic stress disorder (PTSD). PTSD emerges after exposure to an inescapable stressor that elicits fear, horror or helplessness and involves bodily injury or threat of death to one's self or another person. Community-based studies in the United States estimate a lifetime prevalence of trauma exposure at $50 \%$, but only $5 \%$ of men and $10 \%$ of women will subsequently develop PTSD (Kessler et al., 1995). Meta-analytic evidence indicates that peri-traumatic amnesia constitutes an important predictor of PTSD (Ozer et al., 2003). However, current neurobiological concepts on PTSD emphasize the pivotal role of implicit emotional memory dysfunction, given the obvious phenomenological parallels between Pavlovian fear conditioning in rodents and the pathogenesis of PTSD in humans (Rauch et al., 2006). Evidence in humans, however, suggests that emotional memory-related diagnostic symptoms (such as intrusive re-experiencing of the traumatic event and avoidance of reminders) transcend the explicit-implicit distinction, thus portraying PTSD as the quintessential emotional memory disorder (Yovell et al., 2003). In fact, the Pavlovian model fails to account for persistent disturbances of episodic memory that are characteristic of PTSD in clinical experience: hypermnesia for the traumatic event and peri-traumatic amnesia for immediately preceding and following events (Layton and Krikorian, 2002). It is this constellation of hypermnesia for the emotional oddball and amnesia for the neutral context that has been modeled in the oddball experiments presented in Chapter 3 and 8 .

Given this empirical background, it is tempting to speculate about the neurobiological underpin-nings of peri-traumatic amnesia and PTSD by emphasizing the role of disinhibited CORT and NE signaling during emotional trauma. Under normal circumstances, both LC (Aston-Jones and Cohen, 2005) and HPA axis (Radley et al., 2006) are under top-down inhibitory control by ventromedial PFC. Disinhibition of NE and CORT signaling may be the result of relatively insufficient top-down inhibitory control under conditions of emotional trauma and responsible for exaggerated amygdalar input to anterior hippocampus. As a consequence, hyper-encoding (and hyper-consolidation) of the core traumatic event paralleled by peri-traumatic amnesia might occur, further augmenting decontextualization and dissociation of the traumatic memory. Cue-related re-activation of the traumatic memory may establish a self-perpetuating vicious cycle of re-consolidation and low-threshold hyperretrieval due to cue generalization, which in turn can cause intrusive re-experiencing in form of daytime recollections, traumatic nightmares, and flashbacks. Support for the validity of this model comes from findings that abnormally high initial epinephrine and CORT urinary levels predict later PTSD in child trauma victims (Delahanty et al., 2005) as do abnormally low $\gamma$ - 
aminobutyric acid (GABA) plasma levels in road traffic accident victims (Vaiva et al., 2004; 2006), thus implicating an imbalance between endogenous agonists and antagonists of emotional memory formation at the very outset of PTSD.

The question raises about the potential therapeutic implications of this neurochemical model. Whereas psychotherapeutic strategies have been established for clinical PTSD, there has been little psychopharmacological research on the secondary prevention of PTSD. This is surprising, given that PTSD is the psychiatric disorder with the most clearly defined cause and onset. In clinical PTSD, substantial evidence points to NE overdrive as an important neurochemical substrate - and thereby obvious therapeutic target - of hyperarousal in PTSD (Southwick et al., 1997, 1998; Pitman et al. 2002; Vaiva et al. 2003; Debiec and LeDoux, 2006). In contrast, the role of CORT is less understood (Cai et al., 2006). Reductions of baseline CORT plasma levels have been reported, and reduced CORT excretion in response to a traumatic event is associated with higher risk for subsequent PTSD (Yehuda, 2002). Moreover, there is preliminary evidence for preventive effects of CORT as prolonged administration of CORT at stress doses during intensive care treatment decreases the risk for subsequent PTSD (Schelling et al., 2001). Low-dose hydrocortisone (10 $\mathrm{mg} / \mathrm{day})$ has been used in clinical trials to attenuate cardinal symptoms of PTSD (Aerni et al., 2004; de Quervain 2006) and phobia (Soravia et al., 2006). These therapeutic effects of CORT seem to involve both inhibition of low-threshold hyper-retrieval and facilitation of fear-memory extinction consolidation (Cai et al., 2006). However, the findings presented in Chapter 8 suggest that the same treatment that may be beneficial in clinical PTSD, might be detrimental in the initial post-trauma period, where further exogenous elevation of CORT signaling could increase susceptibility to peritraumatic amnesia and PTSD. Instead, $\beta$-adrenergic blockade with propranolol administered in the immediate aftermath of emotional trauma appears to be effective in the secondary prevention of PTSD (Pitman et al. 2002; Vaiva et al. 2003). Although amygdala responses to emotional stimuli are susceptible to GABAergic modulation with lorazepam (Paulus et al., 2005), benzodiazepines could be contraproductive at this initial stage by further compromising top-down inhibitory influences by ventromedial PFC. In contrast, current animal models of PTSD underscore the beneficial effects of serotonin (5-HT) re-uptake inhibitors (SSRIs) in the early aftermath of emotional trauma (Matar et al., 2006). Indeed, treatment with SSRIs might strengthen top-down control, since 5-HT receptors such as the postsynaptic $5-\mathrm{HT}_{2 \mathrm{~A}}$ subtype are densely distributed in the ventromedial PFC (Chapter 6) and likely involved in the regulation of top-down control processes. However, the ethics of these pharmacological interventions, as well as their precise empirical and theoretical basis, require further investigation.

Abercrombie HC, Kalin NH, Thurow ME, Rosenkranz MA, Davidson RJ (2003) Cortisol variation in humans affects memory for emotionally laden and neutral information. Behav Neurosci 117:505-516.

Adolphs R , Tranel D, Buchanan TW (2005) Amygdala damage impairs emotional memory for gist but not details of complex stimuli. Nat Neurosci 8:512-518.

Aerni A, Traber R, Hock C, Roozendaal B, Schelling G, Papassotiropoulos A, Nitsch RM, Schnyder U, de Quervain DJ (2004) Low-dose cortisol for symptoms of posttraumatic stress disorder. Am J Psychiatry 161:1488-1490.

Amat J, Baratta MV, Paul E, Bland ST, Watkins LR, Maier SF (2005) Medial prefrontal cortex determines how stressor controllability affects behavior and dorsal raphe nucleus. Nat Neurosci 8:365-371.

Aston-Jones $\mathrm{G}$ and Cohen JD (2005) An integrative theory of locus coeruleus-norepinephrine function; adaptive gain and optimal performance. Ann Rev Neurosci 28:403-450. 
Cai WH, Blundell J, Han J, Greene RW, Powell CM (2006) Postreactivation glucocorticoids impair recall of established fear memory. J Neurosci. 26:9560-9566.

Debiec J, LeDoux JE (2006) Noradrenergic signaling in the amygdala contributes to the reconsolidation of fear memory: treatment implications for PTSD. Ann N Y Acad Sci. 1071:521-524.

Delahanty DL, Nugent NR, Christopher NC, Walsh M (2005) Initial urinary epinephrine and cortisol levels predict acute PTSD symptoms in child trauma victims. Psychoneuroendocrinology 30:121-128.

de Quervain DJ (2006) Glucocorticoid-induced inhibition of memory retrieval: implications for posttraumatic stress disorder. Ann N Y Acad Sci 1071:216-220.

Dolcos F, McCarthy G (2006) Brain systems mediating cognitive interference by emotional distraction. J Neurosci 26:2072-2079.

Easterbrook JA (1959) The effect of emotion on cue utilization and the organization of behavior. Psychol Rev 66:183-201.

Elzinga BM, Roelofs K (2005) Cortisol-induced impairments of working memory require acute sympathetic activation. Behav Neurosci 119:98-103.

Het S, Ramlow G, Wolf OT (2005) A meta-analytic review of the effects of acute cortisol administration on human memory. Psychoneuroendocrinology 30:771-784.

Kensinger EA, Corkin S (2004) Two routes to emotional memory: distinct neural processes for valence and arousal. Proc Natl Acad Sci USA 101:3310-3315.

Kessler RC, Sonnega A, Bromet E, Hughes M, Nelson CB (1995) Posttraumatic stress disorder in the National Comorbidity Survey. Arch Gen Psychiatry 52:1048-1060.

Kim JJ, Diamond DM (2002) The stressed hippocampus, synaptic plasticity and lost memories. Nat Rev Neurosci 3:453-462

LaBar KS, Cabeza R (2006) Cognitive neuroscience of emotional memory. Nat Rev Neurosci 7:54-64.

Layton B, Krikorian R (2002) Memory mechanisms in posttraumatic stress disorder. J Neuropsychiatry Clin Neurosci 14:254-261

Loftus EF, Loftus G, Messo J (1987) Some facts about "weapon focus" Law Hum Behav 11:55-62.

Lupien SJ, Gillin JC, Hauger RL (1999) Working memory is more sensitive than declarative memory to the acute effects of corticosteroids: a dose-response study in humans. Behav Neurosci 113:420-430.

Cahill L, Prins B, Weber M, McGaugh JL (1994) Beta-adrenergic activation and memory for emotional events. Nature 371:702-704.

Matar MA, Cohen H, Kaplan Z, Zohar J (2006) The effect of early poststressor intervention with sertraline on behavioral responses in an animal model of post-traumatic stress disorder. Neuropsychopharmacology $31: 2610-2618$.

McGaugh JL (2000) Memory - a century of consolidation. Science 287:248-251.

O'Carroll RE, Drysdale E, Cahill L, Shajahan P, Ebmeier KP (1999) Stimulation of the noradrenergic system enhances and blockade reduces memory for emotional material in man. Psychol Med 29:1083-1088.

Ozer EJ, Best SR, Lipsey TL, Weiss DS (2003) Predictors of posttraumatic stress disorder and symptoms in adults: a meta-analysis. Psychol Bull 129:52-73.

Paulus MP, Feinstein JS, Castillo G, Simmons AN, Stein MB (2005) Dose-dependent decrease of activation in bilateral amygdala and insula by lorazepam during emotion processing. Arch Gen Psychiatry 62:282-288

Phelps EA (2006) Emotion and cognition: Insights from studies of the human amygdala. Annu Rev Psychol $57: 27-53$.

Pitman RK, Sanders KM, Zusman RM, Healy AR, Cheema F, Lasko NB, Cahill L, Orr SP (2002) Pilot study of secondary prevention of posttraumatic stress disorder with propranolol. Biol Psychiatry 51:189-192.

Pitman RK, Delahanty DL (2005) Conceptually driven pharmacologic approaches to acute trauma. CNS Spectr 10:99-106.

Pitman RK, Sanders KM, Zusman RM, Healy AR, Cheema F, Lasko NB, Cahill L, Orr SP (2002) pilot study of secondary prevention of posttraumatic stress disorder with propranolol. Biol Psychiatry 51:189-192.

Radley JJ, Arias CM, Sawchenko PE (2006) Regional differentiation of the medial prefrontal cortex in regulating adaptive responses to acute emotional stress. J Neurosci 26:12967-12976.

Rauch SL, Shin LM, Phelps EA (2006) Neurocircuitry models of posttraumatic stress disorder and extinction: human neuroimaging research - past, present, and future. Biol Psychiatry 60:376-382.

Schelling G, Briegel J, Roozendaal B, Stoll C, Rothenhausler HB, Kapfhammer HP (2001) The effect of stress doses of hydrocortisone during septic shock on posttraumatic stress disorder in survivors. Biol Psychiatry 50:978-985.

Soravia LM, Heinrichs M, Aerni A, Maroni C, Schelling G, Ehlert U, Roozendaal B, de Quervain DJ (2006) Glucocorticoids reduce phobic fear in humans. Proc Natl Acad Sci U S A. 103:5585-5590.

Southwick SM, Krystal JH, Morgan CA, Johnson D, Nagy LM, Nicolaou A, Heninger GR, Charney DS (1993) Abnormal noradrenergic function in posttraumatic stress disorder. Arch Gen Psychiatry 50:266-274.

Southwick SM, Krystal JH, Bremner JD, Morgan CA 3rd, Nicolaou AL, Nagy LM, Johnson DR, Heninger GR, Charney DS (1997) Noradrenergic and serotonergic function in posttraumatic stress disorder. Arch Gen Psychiatry 54:749-758. 


\section{R. Hurlemann · The Costs and Benefits of Emotional Memory Formation}

Vaiva G, Ducrocq F, Jezequel K, Averland B, Lestavel P, Brunet A, Marmar CR (2003) Immediate treatment with propranolol decreases posttraumatic stress disorder two months after trauma. Biol Psychiatry 54:947949 and 1471.

Vaiva G, Thomas P, Ducrocq F, Fontaine M, Boss V, Devos P, Rascle C, Cottencin O, Brunet A, Laffargue P, Goudemand M (2004) Low posttrauma GABA plasma levels as a predictive factor in the development of acute posttraumatic stress disorder. Biol Psychiatry 55:250-254.

Vaiva G, Boss V. Ducrocq F, Fontaine M, Devos P, Brunet A, Laffargue P, Goudemand M, Thomas P (2006) Relationship between posttrauma GABA plasma levels and PTSD at 1-year follow-up. Am J Psychiatry 163:1446-1448

van Stegeren AH, Everaerd W, Cahill L, McGaugh JL, Gooren LJ (1998) Memory for emotional events: differential effects of centrally versus peripherally acting beta-blocking agents. Psychopharmacology 138:305-310.

van Stegeren AH, Everaerd W, Gooren LJG (2002) The effect of beta-adrenergic blockade after encoding on memory of an emotional event. Psychopharmacology 163:202-212.

van Stegeren AH, Wolf OT, Everaerd W, Scheltens P, Barkhof F, Rombouts SA (2007) Endogenous cortisol level interacts with noradrenergic activation in the human amygdala. Neurobiol Learn Mem 87:57-66.

Yehuda R (2002) Post-traumatic stress disorder. N Engl J Med 346:108-114.

Yovell Y, Bannett Y, Shalev AY (2003) Amnesia for traumatic events among recent survivors: a pilot study. CNS Spectr 8:676-685. 
From an evolutionary perspective, emotion, whether of an appetitive or aversive nature, signals an event that is likely to have both immediate and future relevance to survival and reproductive success. Therefore, emotion should be susceptible to preferential perceptual and cognitive processing. Recent research has begun to reveal the neuroanatomical substrates and temporal dynamics by which perception is modulated in the service of emotion. With respect to the cognitive domain of episodic (autobiographical) memory, however, emotion is a double-edged sword, as it may enhance and impair episodic memory. In a series of behavioral experiments involving an oddball paradigm, enhanced episodic memory for emotional oddballs has been shown to be coupled to episodic memory decrements for standard items preceding the emotional oddball, a phenomenon more pronounced in women. These effects appear to depend on a common neurobiological substrate, in that episodic memory increments and decrements are abolished by single oral-dose administration of the $\beta$-adrenergic receptor antagonist propranolol $(40 \mathrm{mg})$ in a manner similar to selective bilateral amygdala calcification lesion caused by congenital lipoid proteinosis (Urbach-Wiethe). These findings suggest that an amygdala- and $\beta$-adrenergic-dependent modulation of episodic encoding has costs and benefits. Follow-up studies showed that - consistent with a widely accepted psychological taxonomy of emotion along the orthogonal dimensions of valence and arousal there is a dimensional organization of an emotional modulation of episodic encoding. Thus, retrograde interference is determined by valence, with negative emotion eliciting amnesia and positive emotion eliciting hypermnesia, whereas anterograde interference is determined by arousal, with both negative and positive emotion eliciting amnesia. This bidirectional modulation of episodic encoding by emotion appears to depend on the integrity of the basolateral amygdala (BLA), as both retrograde and anterograde modulatory effects are absent in two Urbach-Wiethe patients with a focal disease emphasis on the BLA.

Retrograde and anterograde interference are both eliminated by propranolol $(40 \mathrm{mg})$ and enhanced by the norepinephrine (NE) re-uptake inhibitor reboxetine $(4 \mathrm{mg})$, pointing to $\mathrm{NE}$ as a control neurochemical substrate. These findings suggest that anterograde amnesic responses result from a fixation of attention by emotional arousal, whereas retrograde amnesic and hypermnesic responses reflect a valence-dependent filter mechanism that operates during emotional memory encoding and controls episodic memory access upon criteria of behavioral significance indexed by emotion. This filter mechanism may originate in amygdalahippocampal interactions that are modulated by both ascending inputs from locus coeruleus and descending inputs from prefrontal cortex. This functional circuitry might be disturbed in pathological conditions such as borderline personality disorder (BPD) and post-traumatic stress disorder (PTSD). Indeed, current theories of BPD emphasize the disruptive effects of dysregulated negative emotion on cognitive functioning. To examine the interaction of emotion and episodic encoding in BPD, sixteen unmedicated female BPD patients were tested on the behavioral indices of emotion-induced amnesia and hypermnesia established in healthy controls. BPD patients displayed enhanced retrograde and anterograde amnesia in response to negative oddballs, whereas positive oddballs elicited no memory-modulating effects at all. These findings suggest that an amygdala hyper-responsiveness to negative emotion could serve as a crucial etiological contributor to emotion-induced cognitive dysfunction in BPD.

In an attempt to model the neurochemical mechanisms precipitating retrograde amnesia by traumatic stress, a pharmacological challenge experiment was carried out, wherein the amnesic potential of elevated cortisol (CORT) levels was tested in the presence or absence of elevated NE levels. Under dual challenge conditions, a linear dose-response relationship in 
the magnitude of retrograde amnesia was observed, which is consistent with a phenotypic expression of retrograde amnesia varying as a function of NE and CORT co-activation during emotional oddball encoding. Though derived from a reductionist pharmacological model, these results suggest that the magnitude of acute NE and CORT responses to emotional trauma could provide an early vulnerability marker of peritraumatic amnesia and PTSD. Thus, blocking NE and CORT signaling in the acute aftermath of emotional trauma might constitute a feasible pharmacological approach for the secondary prevention of peritraumatic amnesia and PTSD. 
Vanuit evolutionair oogpunt signaleren emoties, al dan niet appetitief of aversief, een gebeurtenis met een mogelijk belang voor het overleven. Bijgevolg zouden emoties moeten kunnen steunen op een voorkeursbehandeling bij perceptuele en cognitieve processen. Recente studies beginnen net de onderliggende neuroanatomische substraten en de temporele dynamiek te ontrafelen van de manier waarop perceptie gemoduleerd wordt in dienst van emoties. Wat betreft de cognitieve processen in het episodisch (autobiografisch) geheugen zijn emoties een tweesnijdend zwaard: ze kunnen het episodisch geheugen zowel versterken als verzwakken. Gedragsexperimenten gebruikmakend van het oddball paradigma hebben aangetoond dat het versterken van emotionele oddballs in het episodisch geheugen gepaard gaat met verminderd herinneren van standaard stimuli voorafgaand aan de emotionele oddball. Dit fenomeen is meer uitgesproken bij vrouwen. Deze effecten blijken afhankelijk te zijn van eenzelfde onderliggend neurobiologisch substraat: zowel de versterking als de vermindering worden tenietgedaan door een enkele orale toediening van een $\beta$-adrenerge receptor antagonist propranolol. Een vergelijkbaar fenomeen wordt gezien in zogenaamde Urbach-Wiethe patiënten. Deze stoornis wordt gekenmerkt door een selectieve bilaterale laesie van de amygdala veroorzaakt door congenitale lipoid proteinose. Deze bevindingen suggereren dat de modulatie van het episodisch geheugen via de amygdala en $\beta$-adrenerge mechanismen zowel voor- als nadelen (costs and benefits) heeft. In overeenstemming met de wijd verspreide psychologische taxonomie van emoties volgens de orthogonale dimensies van valentie en arousal, hebben vervolgstudies aangetoond dat ook de emotionele modulatie van het episodisch geheugen dimensioneel georganiseerd kan worden. Retrograde interferentie wordt bepaald door de valentie: negatieve emoties veroorzaken amnesie, terwijl positieve hypermnesie teweegbrengen. Anterograde interferentie is echter afhankelijk van de mate van arousal. In dit geval hebben zowel positieve als negatieve emoties amnesie tot gevolg. Deze bidirectionele modulatie blijkt afhankelijk te zijn van de basolaterale amygdala daar twee Urbach-Wiethe patiënten met een calcificatiefocus in dit gebied noch anterograde, noch retrograde interferentie vertoonde.

De retro- en anterograde modulerende invloeden kunnen beiden tenietgedaan worden door propranolol (40mg), en versterkt door de norepinefrine (NE) re-uptake inhibitor reboxetine $(4 \mathrm{mg})$. Het voorgaande wijst in de richting van $\mathrm{NE}$ als een neurochemische controlerende faktor. Bovengenoemde bevindingen betreffende de dimensionale organisatie suggereren dat de anterograde modulatie het resultaat is van aandachtsfixatie door emotionele arousal. De retrograde amnesie en hypermnesie weerspiegelen een valentie-afhankelijke filter. Dit filtermechanisme treedt in werking bij emotionele geheugencodering. Het reguleert eveneens de toegang tot het episodisch geheugen aan de hand van emotionele significantie.

Interacties tussen de amygdala en de hippocampus kunnen aan de basis liggen van zulk een systeem, gemoduleerd door opstijgende input vanuit de locus coeruleus en dalende inbreng van de prefrontale cortex. Mogelijke verstoringen in dit circuit zou men kunnen terugvinden in pathologische aandoeningen zoals een borderline persoonlijkheidsstoornis (BPS) en posttraumatische stressstoornis (PTSS). Huidige BPS-theorieën accentueren inderdaad de verstorende effecten van de ontregelde negatieve emoties op cognitief functioneren. De interactie tussen emotie en de codering in het episodisch geheugen, zoals gevonden met het oddball paradigma in gezonde controlepersonen, werd ook onderzocht in $B P D$. Patiënten met BPS vertonen een versterkte retro- en anterograde amnesie bij negative oddballs. Positive oddballs hebben echter geen geheugenmodulerend effect. Men zou hieruit 
kunnen afleiden dat de hyperresponsiviteit van de amygdala op negatieve emoties een cruciale etiologische bijdrage levert tot de emotie geïnduceerde cognitieve disfunctie in BPS.

Retrograde amnesie ten gevolge van traumatische stress werd gemodelleerd in een farmacologisch experiment waarbij het amnesiepotentieel van cortisol (CORT) onderzocht werd in de aan- en afwezigheid van verhoogde NE-niveaus. De grootte van amnesie vertoonde een lineaire dosis-respons relatie in twee challenge condities. Deze uitkomst doet vermoeden dat de fenotypische expressie van retrograde amnesie varieert in functie van noradrenaline en cortisol tijdens "emotional oddball encoding". Deze bevindingen, alhoewel afkomstig van een reductionistisch farmacologisch model, wijzen er mogelijk op dat de acute CORT- en NE-respons na trauma een vroege marker van kwetsbaarheid voor peritraumatische amnesie en PTSS kan zijn. Het inhiberen van NE en CORT signaaltransductie direct volgend op een trauma zou dan ook een mogelijke aanpak kunnen zijn in de secundaire preventie van peritraumatische amnesie en PTSS. 
I am especially grateful to my mentors, Ray Dolan and Wolfgang Maier, for their constant support, patience, guidance, and encouragement. Ray Dolan's pioneering work in the neuroscience of emotion provided a superb foundation from which many of the ideas included in this thesis were derived from. Wolfgang Maier's tremendous expertise in and enthusiasm for psychiatric neuroscience make it a continuous source of inspiration to work with him. I am deeply indepted to my promotor, and formidable teacher in affective neuroscience, Eric Griez. Without Eric Griez' exceptional support, thorough supervision, and valuable advice this thesis would not be possible.

I also owe a great deal of gratitude to numerous friends and colleagues, both past and present. Those especially deserving of a mention here include Andreas Bauer, Mike Cohen, Andrew Duggins, Lies Goossens, Alexander Hammers, Barbara Hawellek, Hans-Jochen Heinze, Andreas Matusch, Johannes Schultz, Danny Smith, and Bryan Strange. My warmest thanks go to Leni Noteborn and Ilona Treschwig, for their generous help and support. In addition, I would like to thank more than 250 volunteers who participated in my studies. The medical students who assisted me with my research, deserve special mention for their excellence and commitment. Much of this research was funded by a BONFOR fellowship and the Brain Imaging Center West (BICW) supported by the German Federal Ministry for Education and Research (BMBF).

Finally, I wish to thank my family, and Nina, for their love and trust in me. 


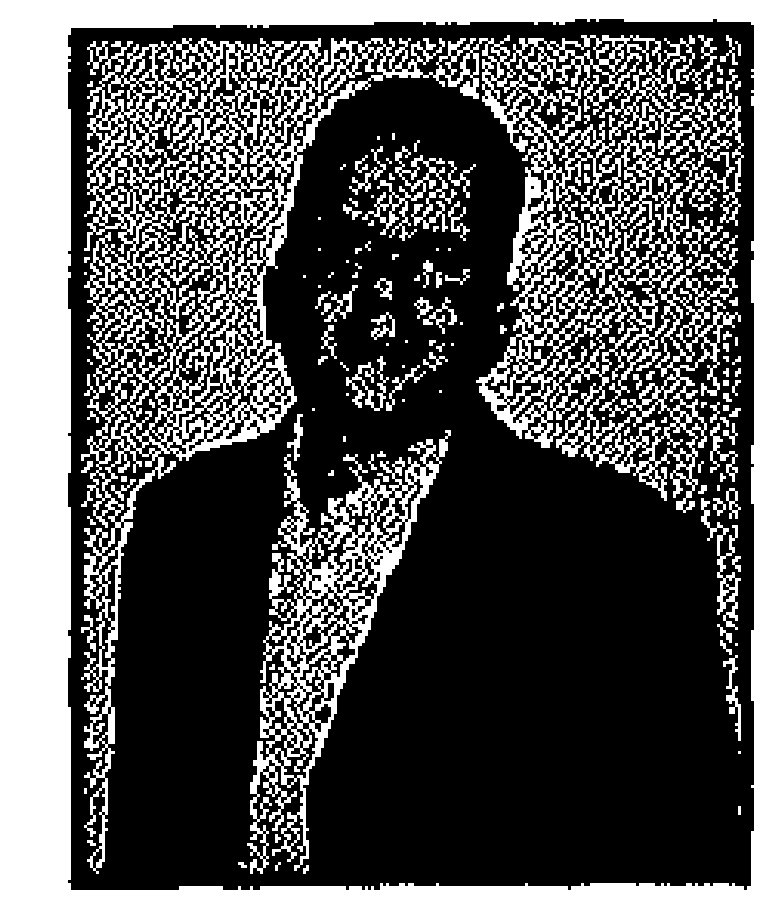

René Hurlemann, M.Sc., M.D., Ph.D.

Department of Psychiatry

University of Bonn

53105 Bonn

Germany

I was born in Cologne, Germany, on September 17, 1973. I went to medical school at University of Bonn and University College London and graduated in 2002. Moreover, I hold an M.Sc. degree in affective neuroscience from Maastricht University. In 2007, I completed my residency in psychiatry and psychotherapy at University of Bonn, where I conducted most of the research presented in this thesis. I was awarded a BONFOR fellowship from University of Bonn to pursue my Ph.D. studies. My current areas of research focus on the pharmacology of emotion and memory and on the molecular pathology of prodromal schizophrenia. I am a member of the Society for Neuroscience (SfN) and act as adhoc referee for international peerreviewed journals in the fields of cognitive neuroscience and experimental psychiatry. 